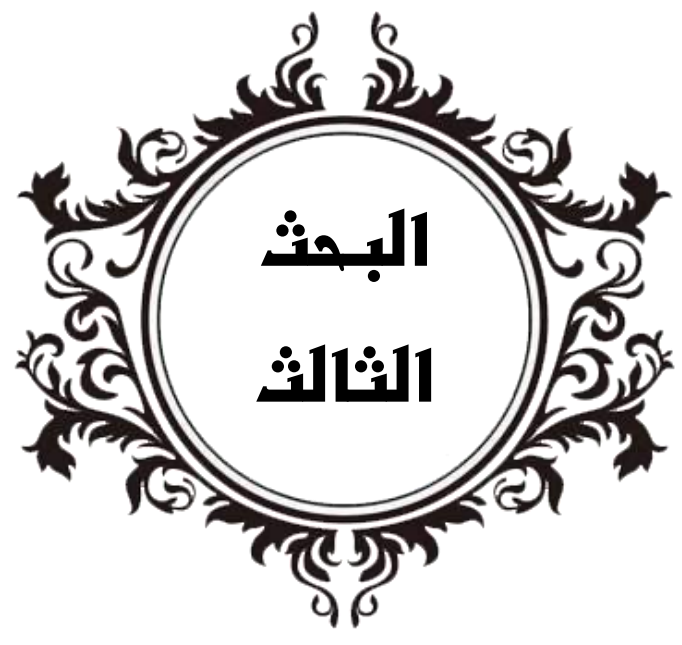

فعالية برنامج قائع عليَّ إستر|نيجية دراسة الدرس

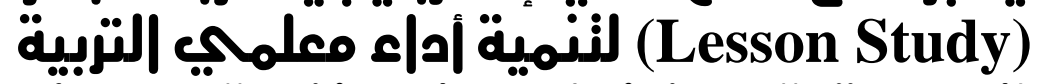

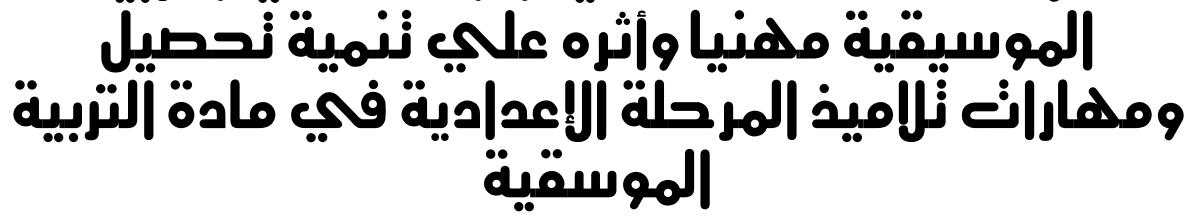

إعــــاد:

د/ مهمود أحمد الوكيل

مدرس مناهـج و طرق تدريس التربيت الموسيقيت

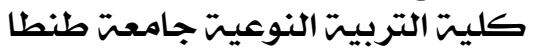





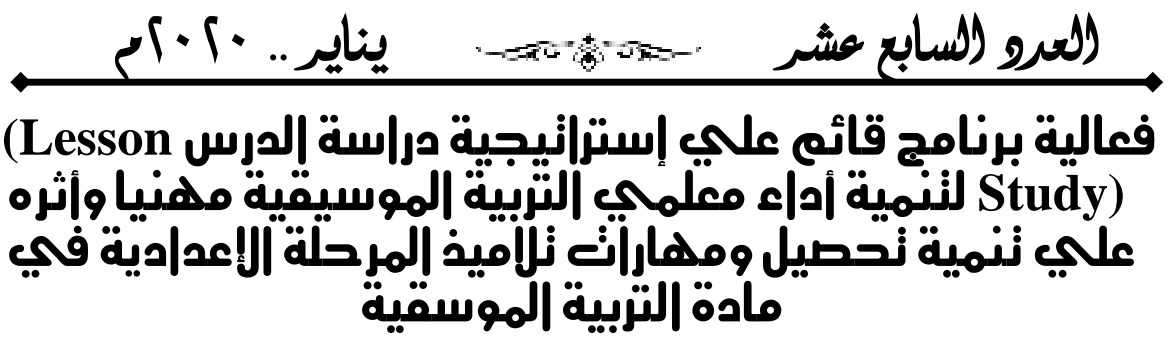

$$
\begin{aligned}
& \text { د/ مصمود أمهد الوكــل } \\
& \text { مدرس مناهـج و طرق تدريس التربيت الموسيقيت }
\end{aligned}
$$

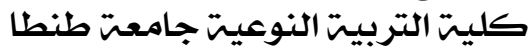

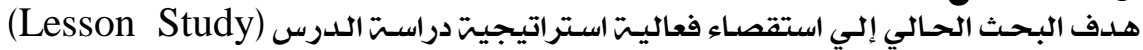

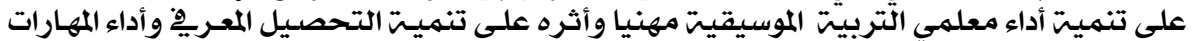

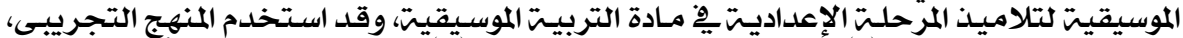

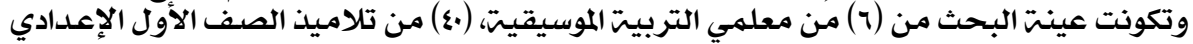

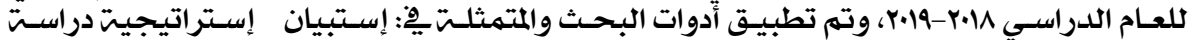

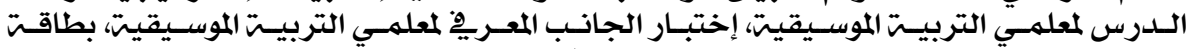

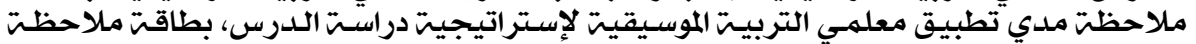

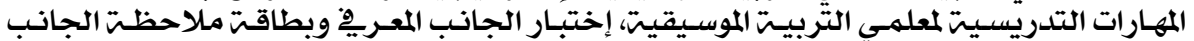

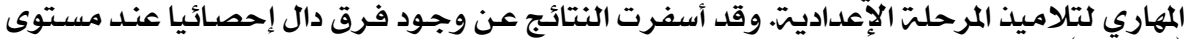

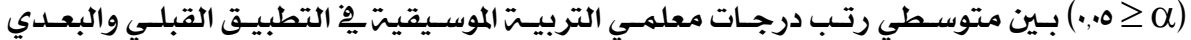

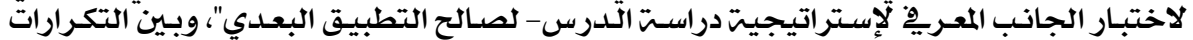

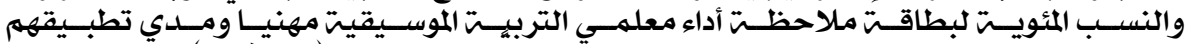

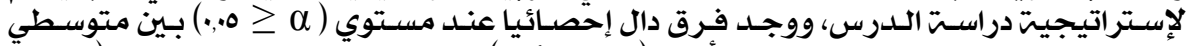

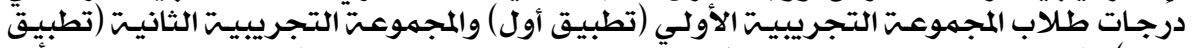

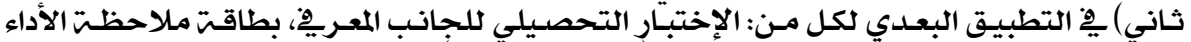

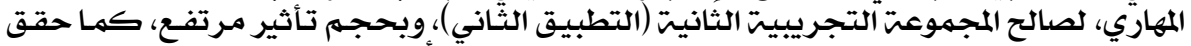

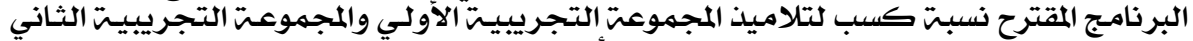

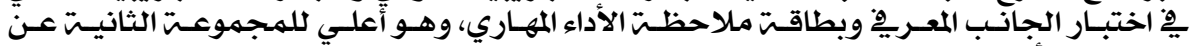

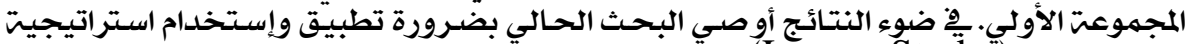

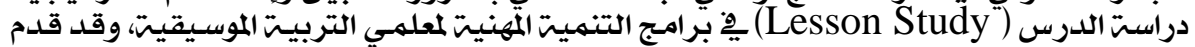

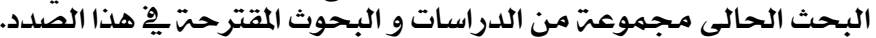

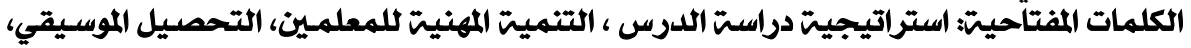

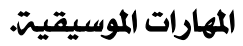

The effectiveness a program based on the Lesson Study strategy on professional development of music teachers, and its' impact on the development of achievement and performance for students of the preparatory stage in music education.

\section{Dr. Mahmoud Elwakeel}

\section{Abstract:}

The purpose of this research is to investigate the effectiveness of the Lesson Study strategy on professional development of music teachers and its' impact on the development of cognitive achievement and performance of musical skills for students of the preparatory stage. The experimental method was used. The

$$
1.0
$$


research sample consisted of (6) music teachers, (40) first grade students for the academic year 2018-2019, research tools has been applied: questionnaire, cognitive test for music teachers, observation form for the application of Lesson Study srategy, observation form for teaching skills for music teachers, cognitive test and observation form for students. The results revealed that there is a statistically significant difference at $(\alpha \leq 0.05)$ between the average grades of music teachers in the pre-and post-test to test the cognitive aspect of the lesson study strategy - in favor of post-application ", and between the iterations and percentages of observation form of the performance of music teachers professionally, and There was a statistically significant difference at the level $(\alpha \leq 0.05)$ between the average scores of students of the first experimental group (first application) and the second experimental group (second application) in the post application of: cognitive test, observation form, in favor of the second experimental group (second application), with high impact size, and the program also achieved gain ratio for the students of the first experimental group and the second experimental group in the cognitive test and observation form, which is higher for the second group than the first group. In light of the results, the current research recommended the necessity of applying and using the Lesson Study strategy in the professional development programs of music education teachers.

Keywords : the Lesson Study strategy - professional development of music teachers - achievement - performance students of the preparatory stage in music education.

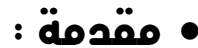

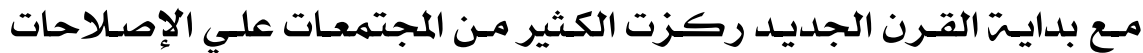

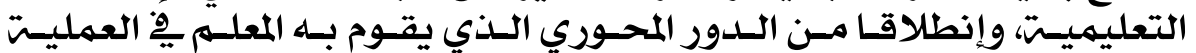

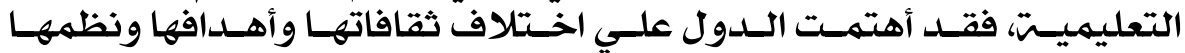

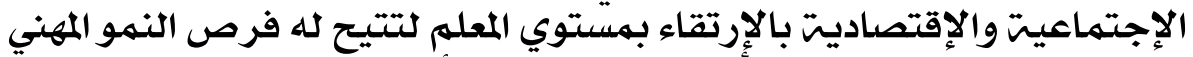

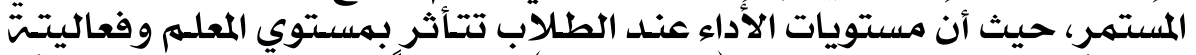

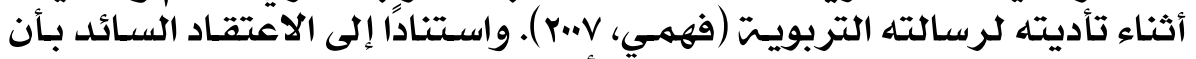

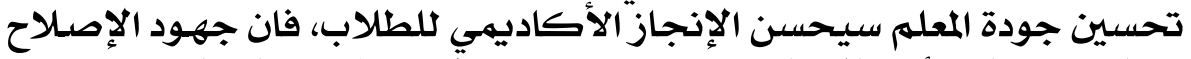

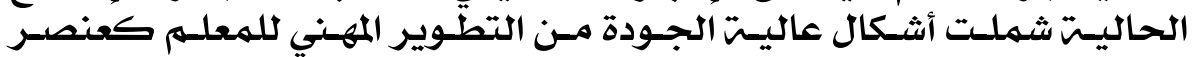
أساسي ِِّ برنامـج تحسين أداء الطلاب. Desimone, Porter, Garet, Yoon, \& Birman, 2000; National Research Council, 2001; Suppovitz \& Turner, 2000; Wenglinsky, 2000).

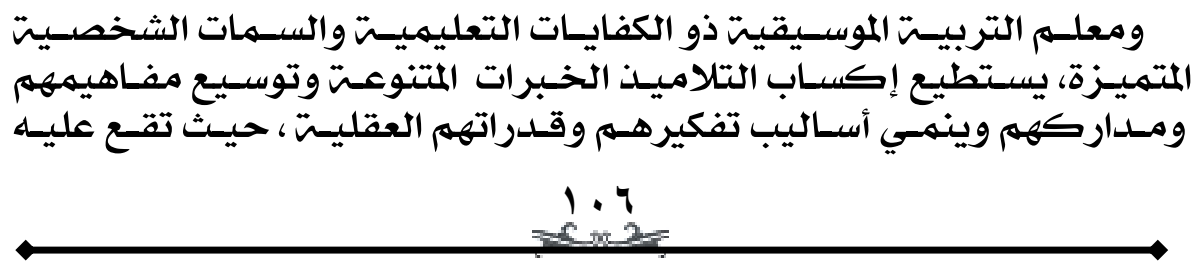




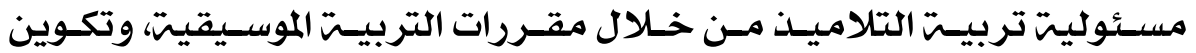

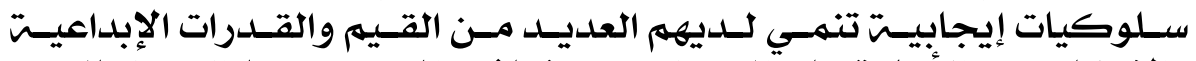

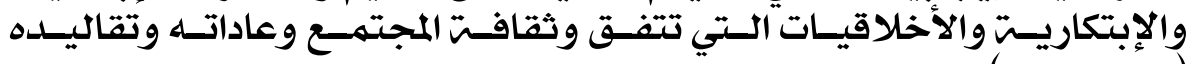

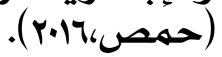

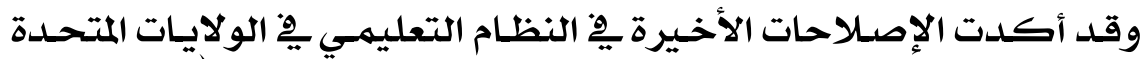

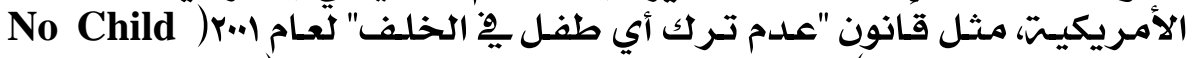
Race to the (Left Behind,2001

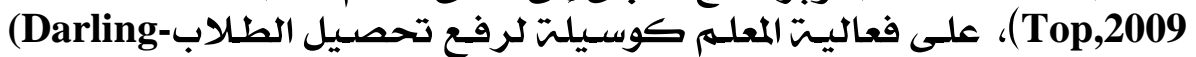

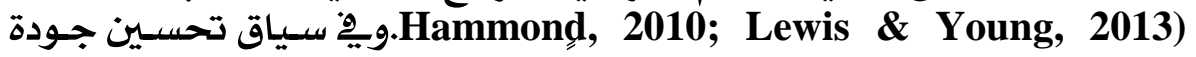
المعله، تعتبر برامج التتميت المهنيت عاملا أساسيا لتعزيز مهارسـات التـدريس. \& Koellner, 2010; Cohen \& Hill, (Barrett, 2006; Borko, Jacobs, Darling- 2000; Conway \& Edgar, 2014; Stanley, 2011; Wei, Hammond, \& Adamson, 2010).

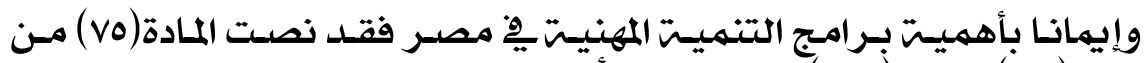

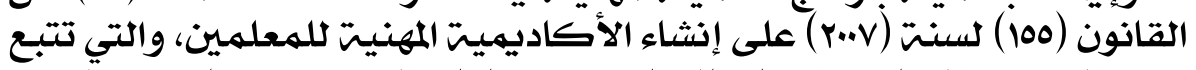

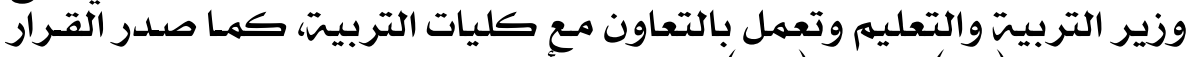

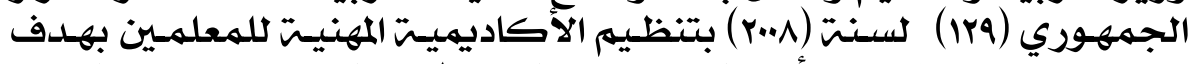

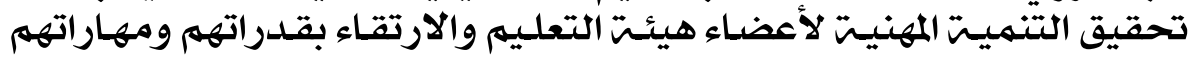

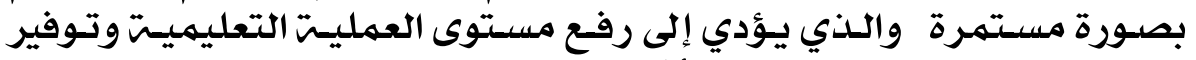

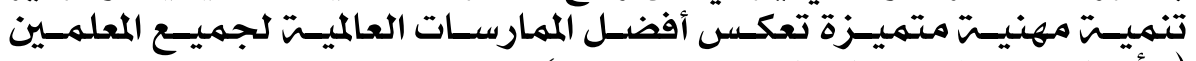

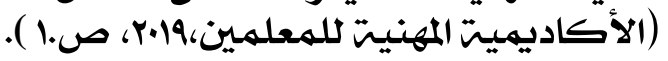

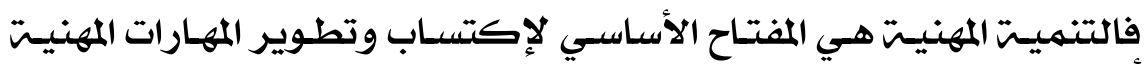

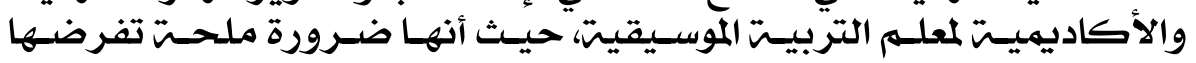

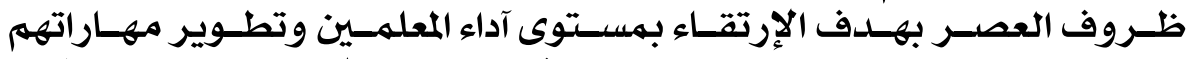

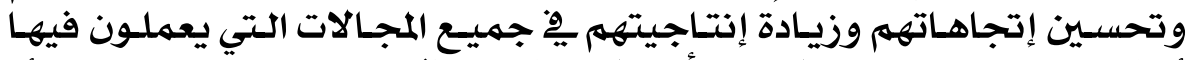

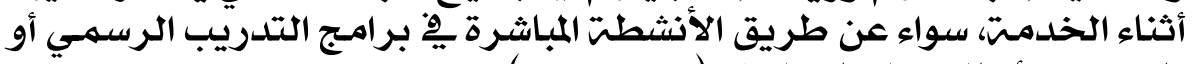

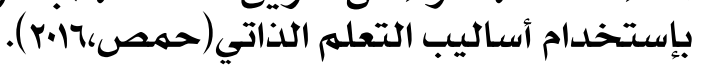

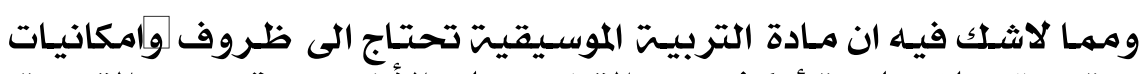

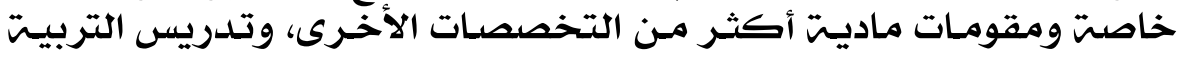

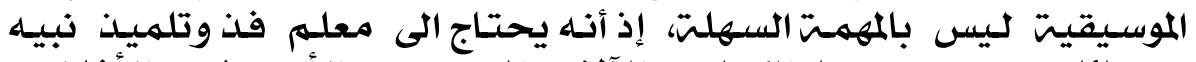

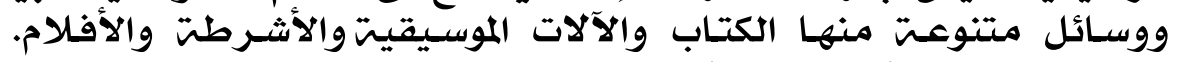

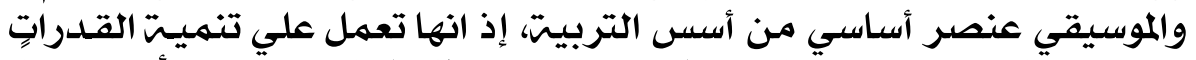

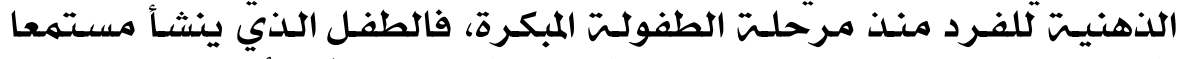

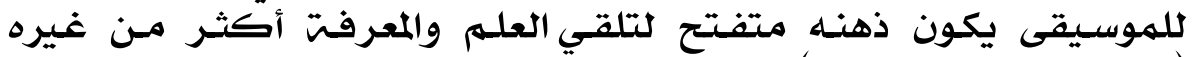

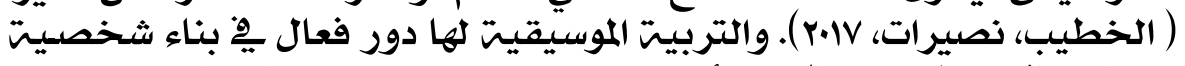

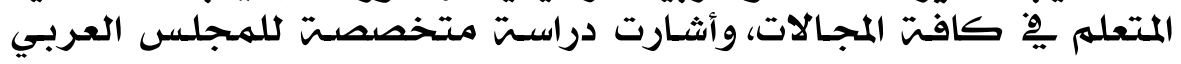


للطفولت والتتميتة، بعنوان (الموسيقي وإحياء عالم الطفل،ب..r) إلى أهميتة

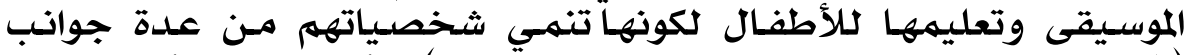

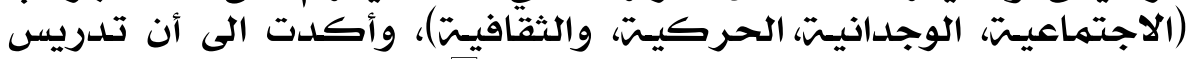

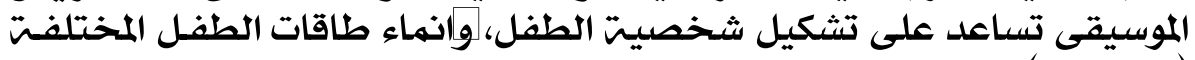

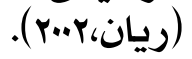

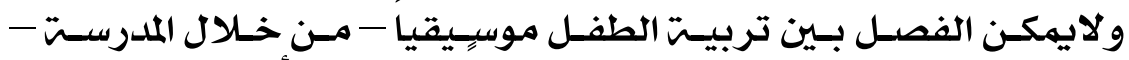

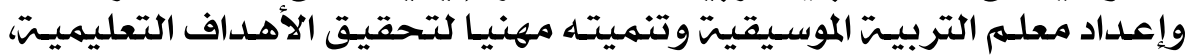

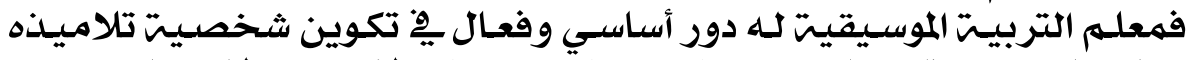

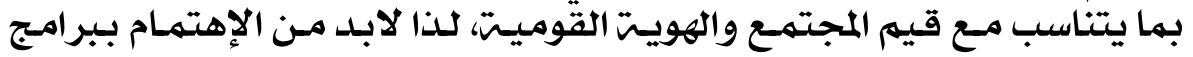

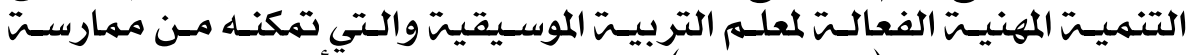

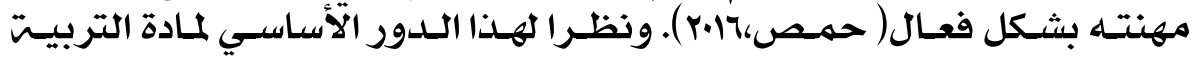

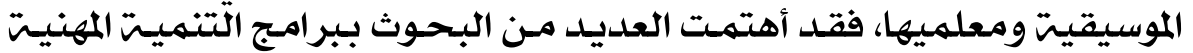

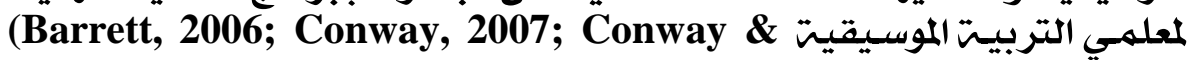
Edgar, 2014; Hookey, 2002; Stanley, Snell, \& Edgar, 2014)

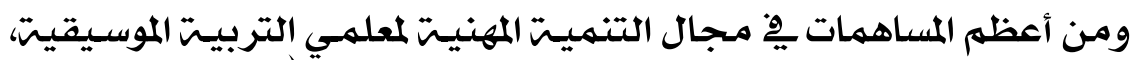

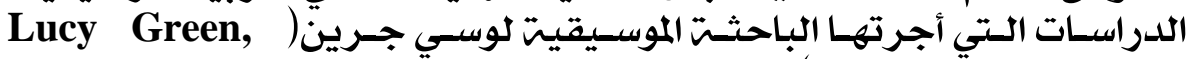

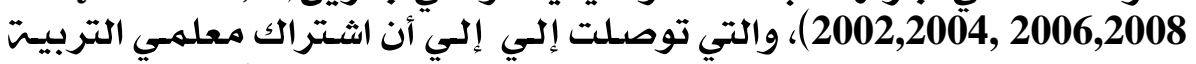

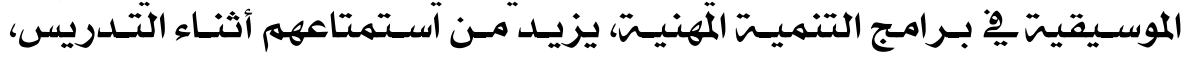

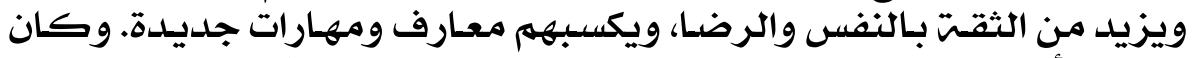

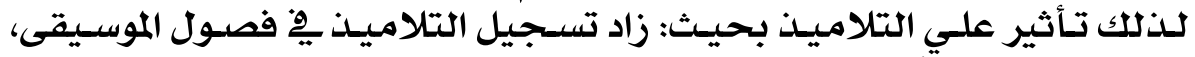

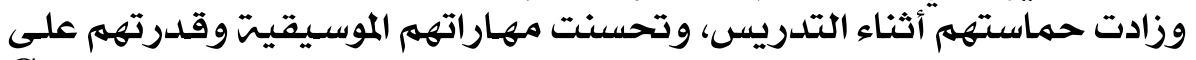

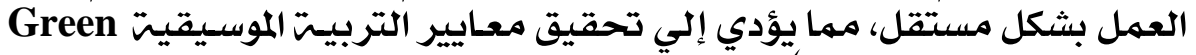
(\& Walmsley, 2006)

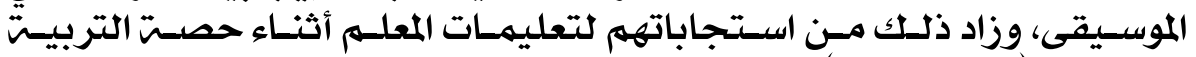
الموسيقيتي (Byo, 2017).

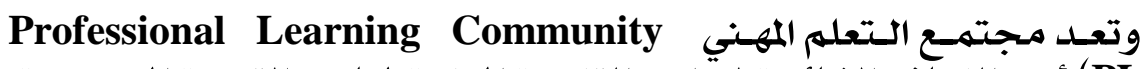

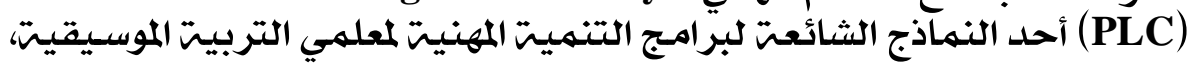

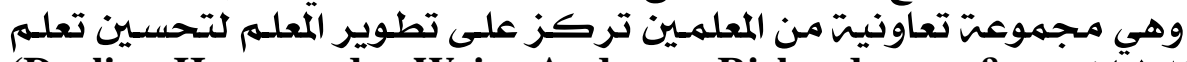
الطتّلاب. DuFour, \& Eaker, 2008; Stanley, 2011; Orphanos, 2009; DuFour, Vescio et al., 2008).

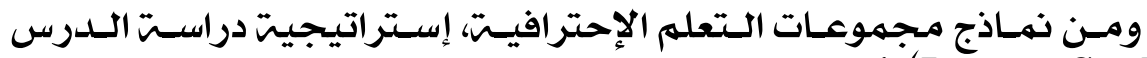

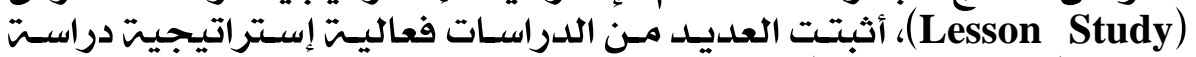

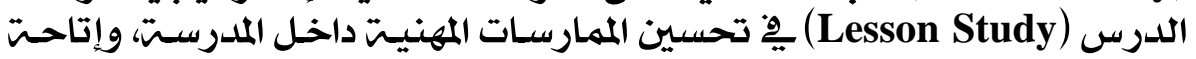

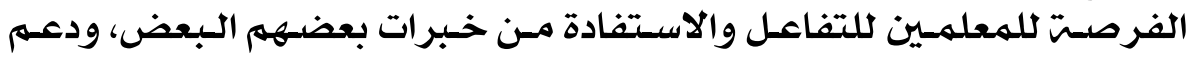

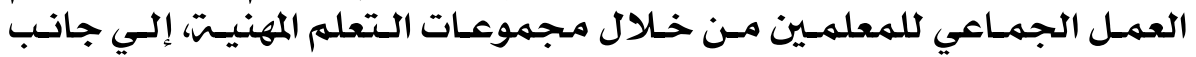




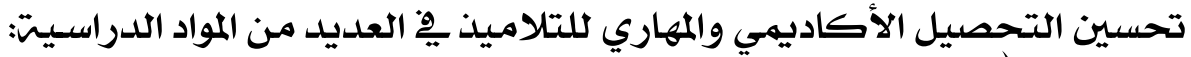
الرياضيات (Shouffler , 2018; Barbar,2016; Mon, Dalï \& Sam, 2016 (حين الاديل ; Rock\&Wilson,2005; Jenne, 2005; Podhorsky, 2005; Puchner\&

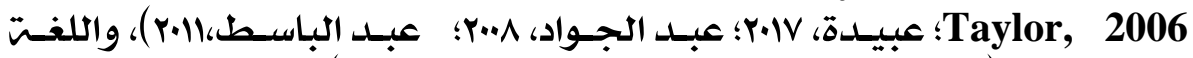

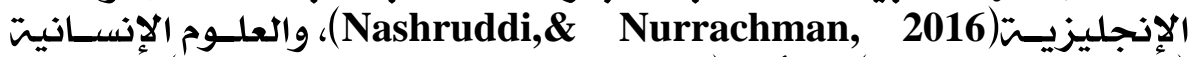

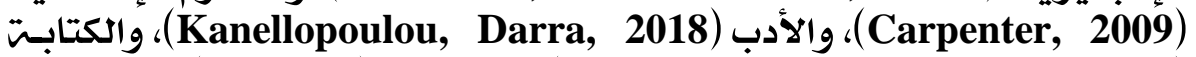

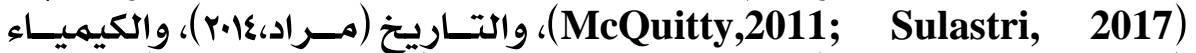
(Espinosa, et al 2018)، والدراسات الإجتماعيت (2005، Hubbard).

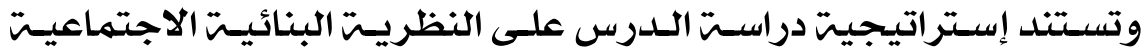

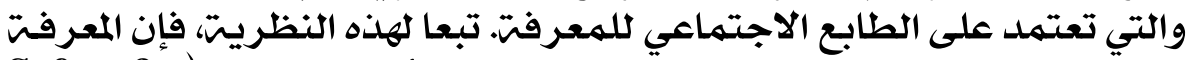

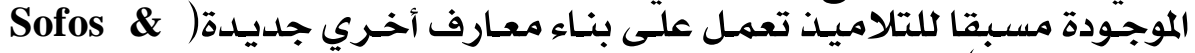

.(Darra, 2015

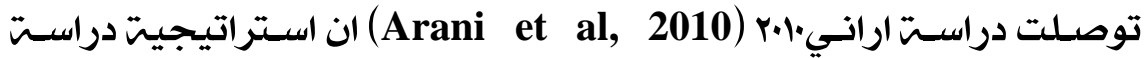

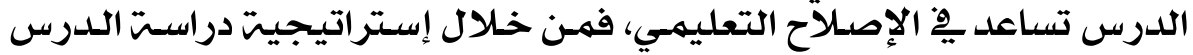

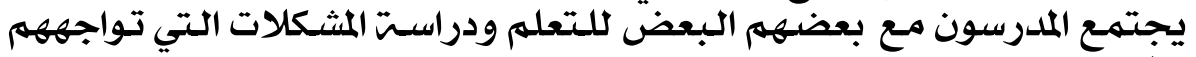

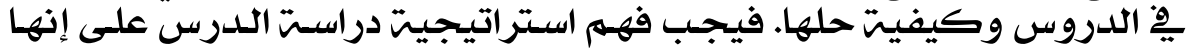

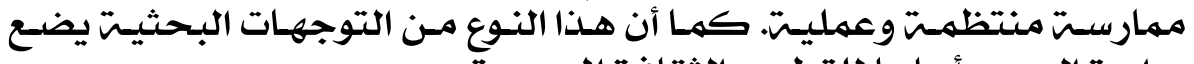

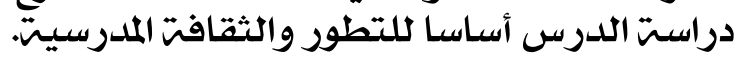

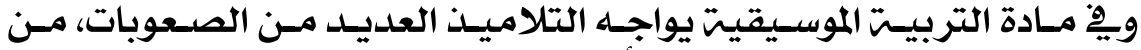

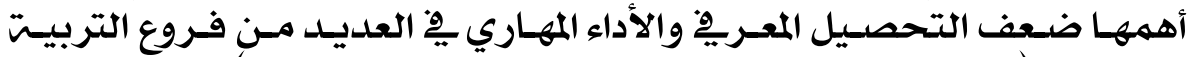

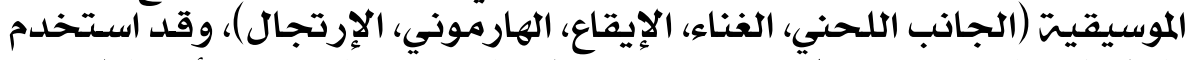

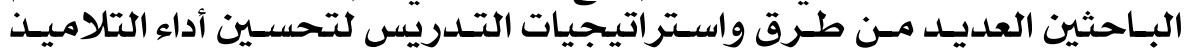

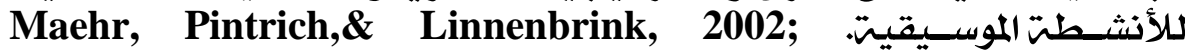
McCombs, \& Whisler,1997; Yoder-White,1993; Freeman, 2011; Johnson, 2011; Bush, 2000; Noor,2014; Levy,2016;

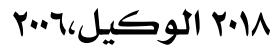

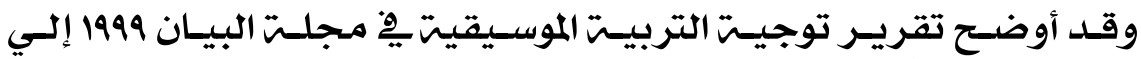

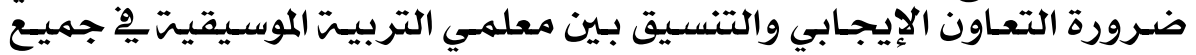

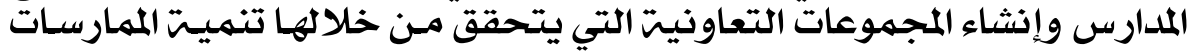

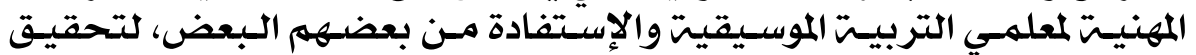

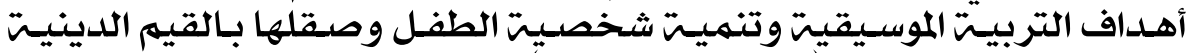

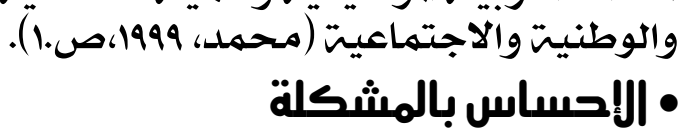

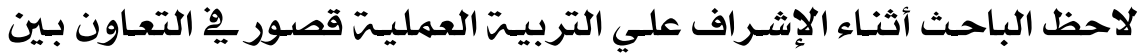

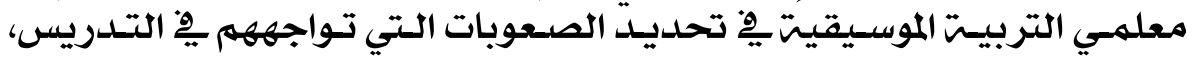

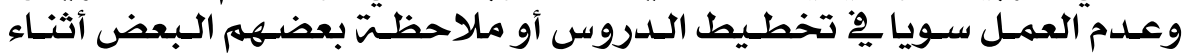




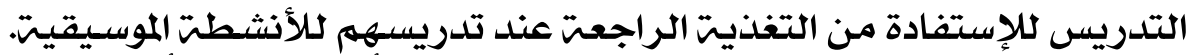

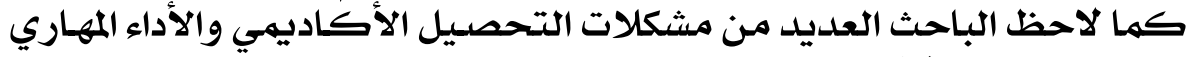

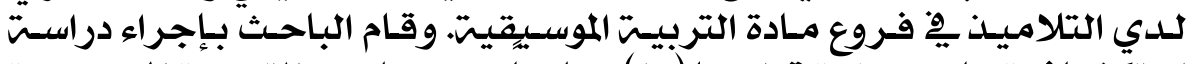

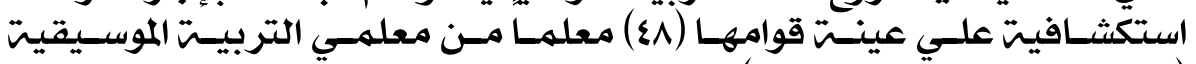

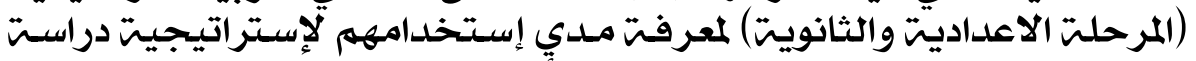

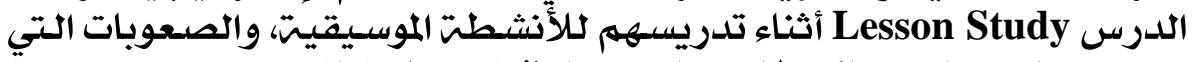

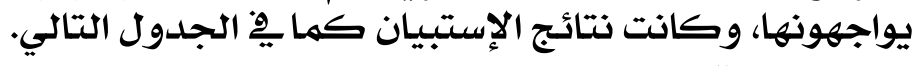

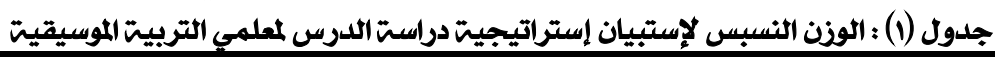

\begin{tabular}{|c|c|c|c|c|c|c|c|c|c|}
\hline \multirow{2}{*}{ 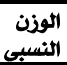 } & \multirow{2}{*}{ المتوسط } & \multirow{2}{*}{ لصالح } & \multicolumn{2}{|c|}{ داثما } & \multicolumn{2}{|c|}{ أحياثا } & \multicolumn{2}{|c|}{ نادرا } & \\
\hline & & & $\%$ & ك & $\%$ & ك & $\%$ & ك & \\
\hline & & & & & & & & & فقرات الإستبانت \\
\hline 00,07 & $1,7 v$ & 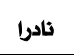 & 17,78 & $\wedge$ & rr,rr & 17 & o. & $Y \varepsilon$ & تستخليت الموسيقيتيّة إستيت دراست الدرس خلال تدريس مقرر \\
\hline 71111 & l,Ar & 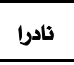 & rr,rr & 17 & $17,7 \mathrm{~V}$ & $\wedge$ & o. & $\mathbf{Y \varepsilon}$ & 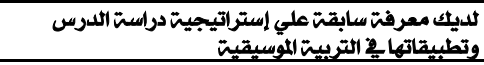 \\
\hline$\Delta 0,07$ & $1,7 V$ & ن ادرا & 17,78 & $\wedge$ & מr,rr & 17 & o. & $Y \varepsilon$ & 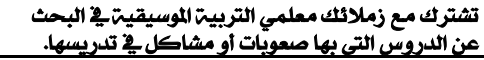 \\
\hline 䄱 & Y,* & 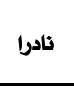 & $17,7 V$ & $\wedge$ & TT,T & rr & $17,7 V$ & $\wedge$ & 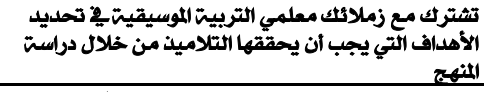 \\
\hline 00,04 & $1,7 v$ & ثادرا & 17,78 & $\wedge$ & rr,rr & 17 & o. & $Y \varepsilon$ & 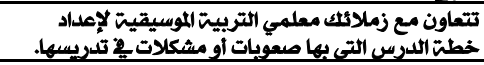 \\
\hline 00,04 & $1,7 \mathrm{~V}$ & 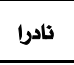 & $17,7 \mathrm{~V}$ & $\wedge$ & rr.rr & 17 & o. & $Y \varepsilon$ & 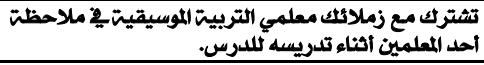 \\
\hline 00,07 & $1,7 \mathrm{~V}$ & 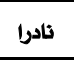 & 17,78 & $\wedge$ & rr,rr & 17 & o. & $Y \varepsilon$ & تدون الملاحل التخ يوإجهونها. كيفيت تفاعل التلاميذ مع الدرس \\
\hline$\Delta 0,07$ & $1,7 \mathrm{~V}$ & 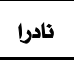 & 17,78 & $\wedge$ & rr.rr & 17 & o. & Y & 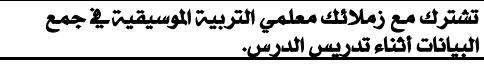 \\
\hline $07,9 \varepsilon$ & $1, \mathrm{~V}$ & نادرا & $r \cdot \wedge r$ & 1. & $\mathrm{YQ}, \mathrm{IV}$ & $1 \varepsilon$ & 0. & $Y \varepsilon$ & تسجل مع زملاثك اجابات التلاميذ الشفهيت \\
\hline $0, \cdots$ & 1,0. & ن ادرا & $17,7 \mathrm{~V}$ & $\wedge$ & 17,48 & $\wedge$ & TT,T & rr & 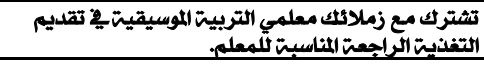 \\
\hline $0,, \cdots$ & 1,0. & ن ادرا & $17,7 \mathrm{~V}$ & $\wedge$ & $17,7 \mathrm{~V}$ & $\wedge$ & $77, \mathrm{TV}$ & rr & 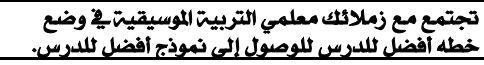 \\
\hline 00,07 & $1,7 \mathrm{~V}$ & 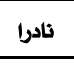 & $17,7 \mathrm{~V}$ & $\wedge$ & 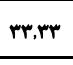 & 17 & o. & Y & 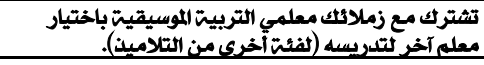 \\
\hline จT,१६ & $\mid, V$ & ن ادرا & $r \cdot \wedge r$ & 1. & ra,IV & $1 \varepsilon$ & ه. & Yq & 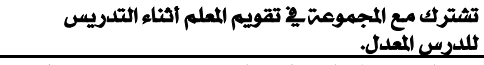 \\
\hline $0, \cdots$ & 1,0* & 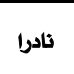 & 17,78 & $\wedge$ & 17,78 & $\wedge$ & עד,דר & $r Y$ & 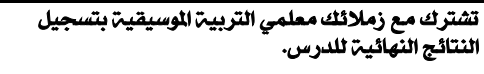 \\
\hline
\end{tabular}

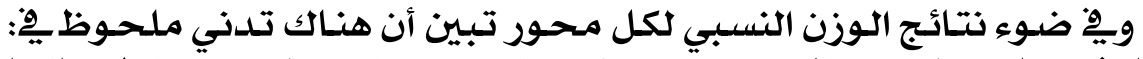

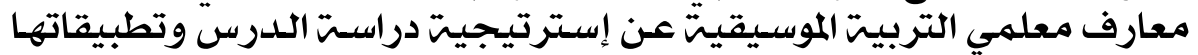

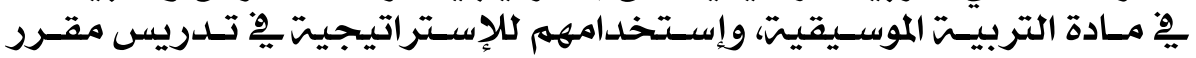

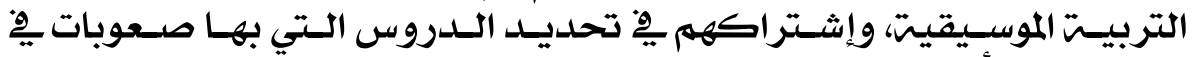

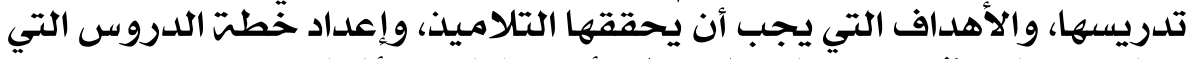

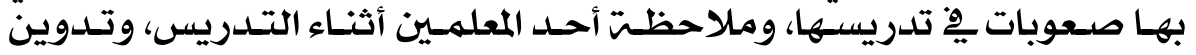

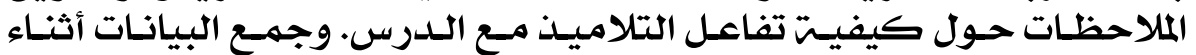

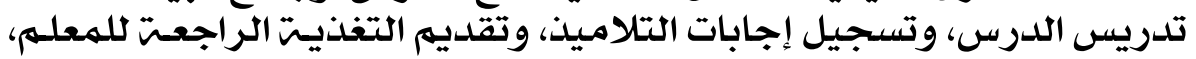

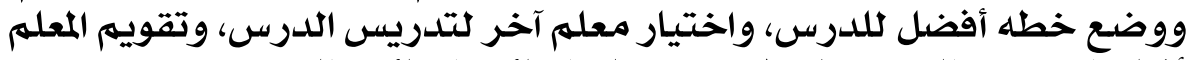

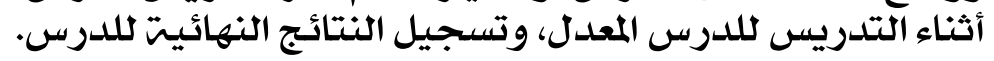

11. 
إن

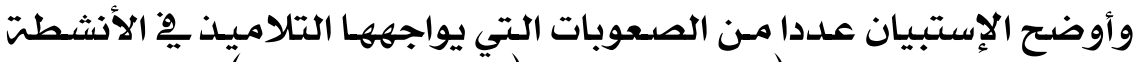

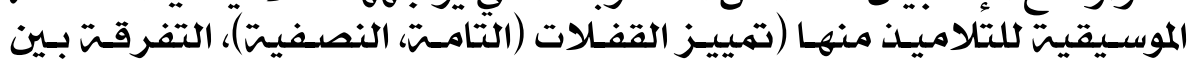

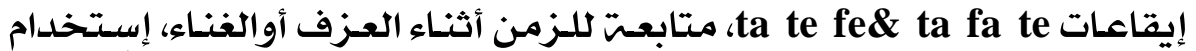

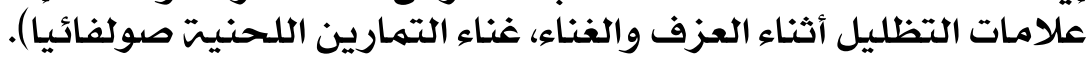

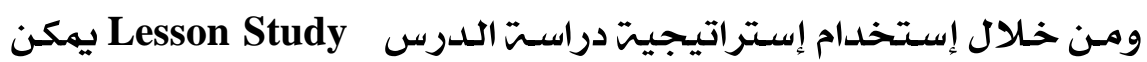

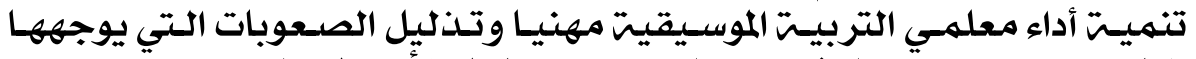

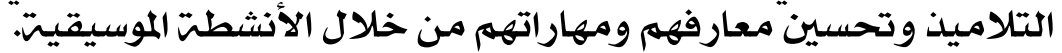

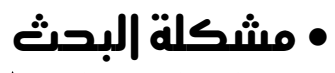

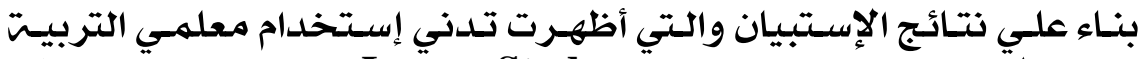

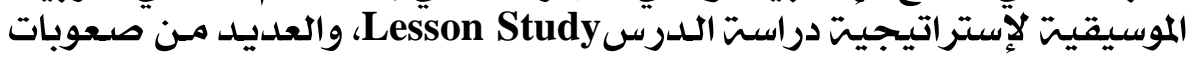

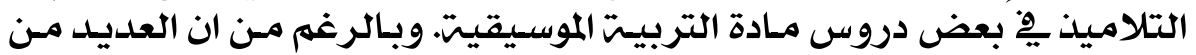

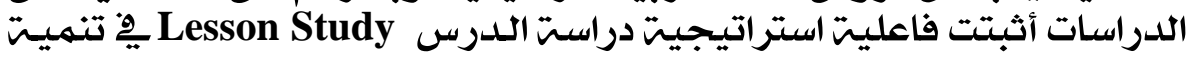

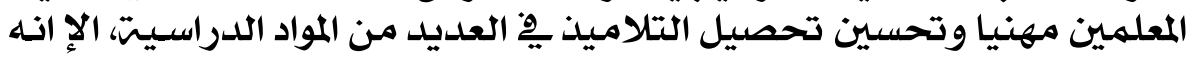

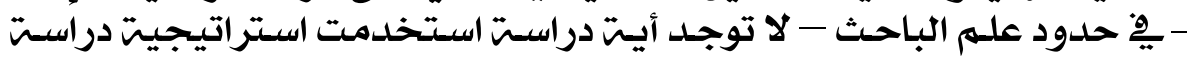

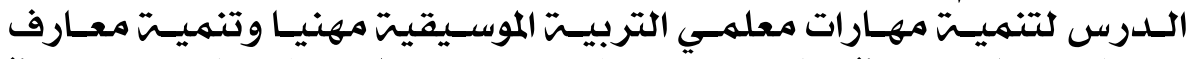

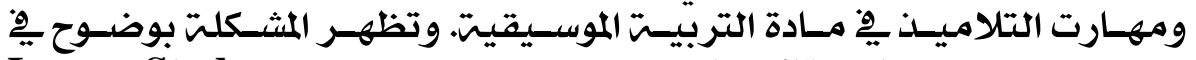

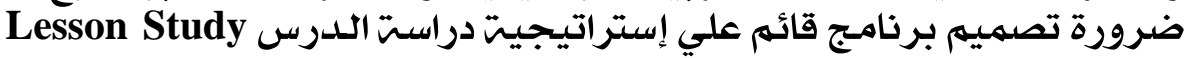

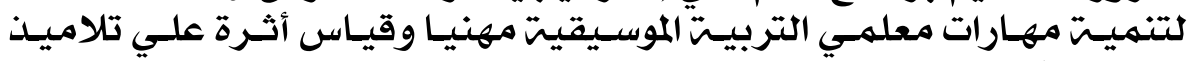
الخطوة الإعداديتة. • أسئلة البحثة الإنه

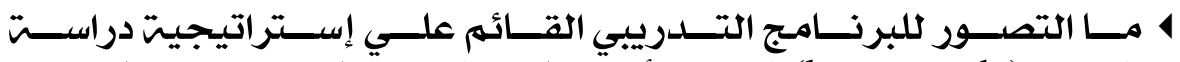

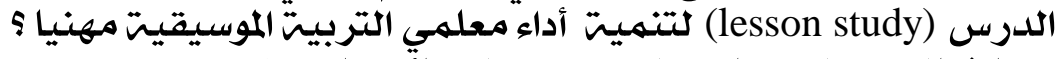

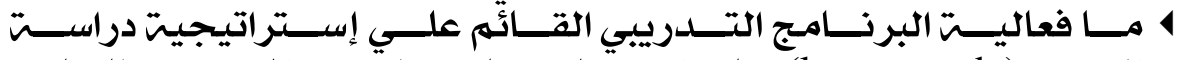

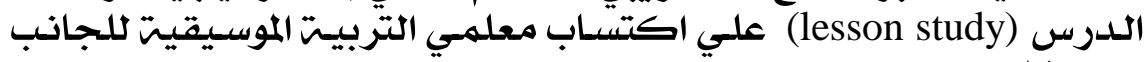

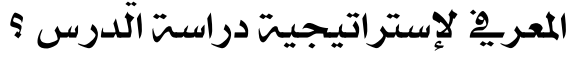

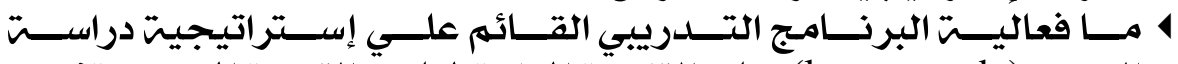

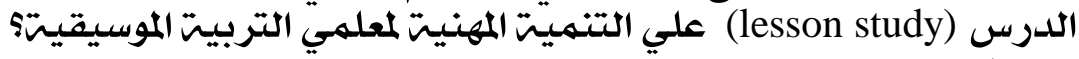

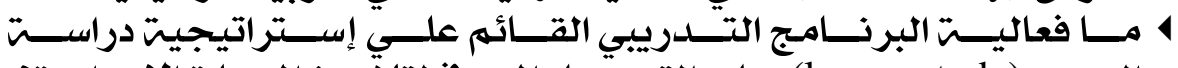

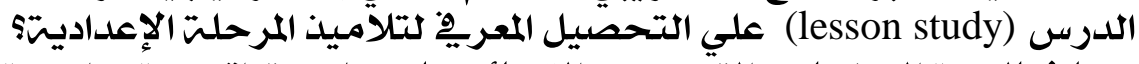

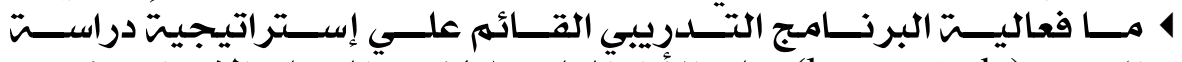

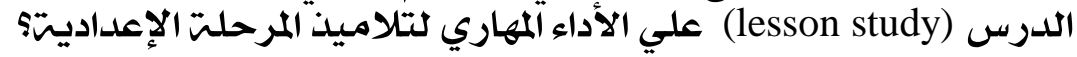
• أهد|ف البحث البحن

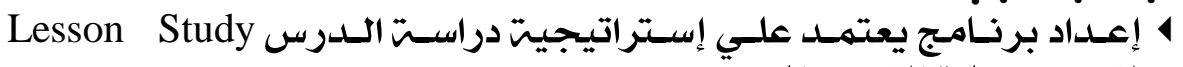

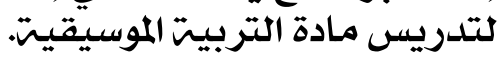

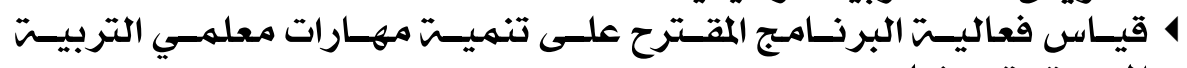




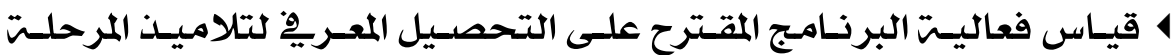

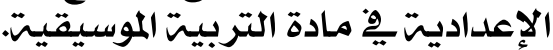

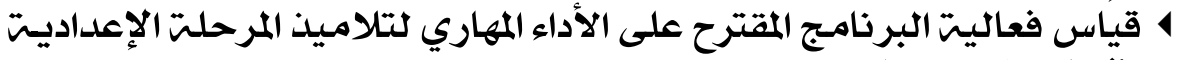
عِِّ مادة التربيت الموسيقيت.

$$
\begin{aligned}
& \text { • ألهمية البحث }
\end{aligned}
$$

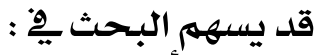

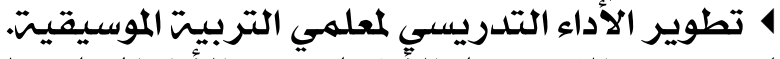

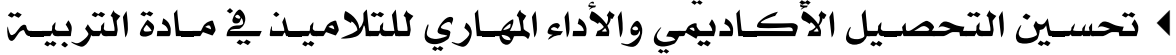
الموسيقيت.

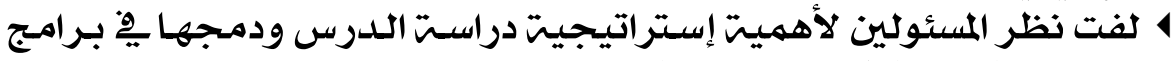

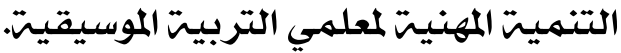
• إجراء|نه البحث :

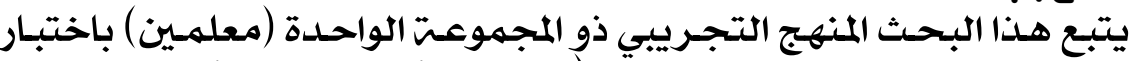

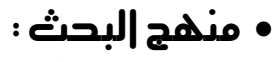

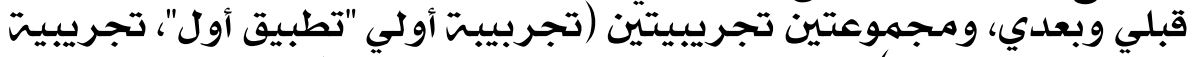

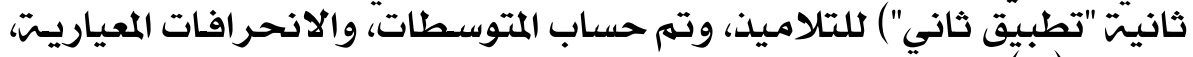

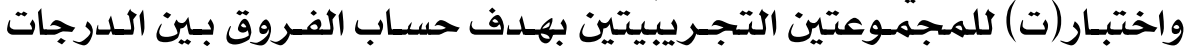
قبليا وبعديا.

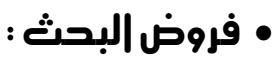

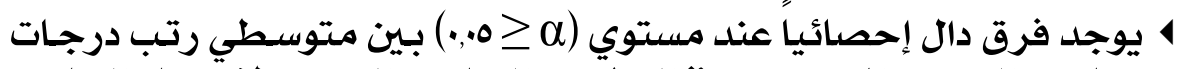

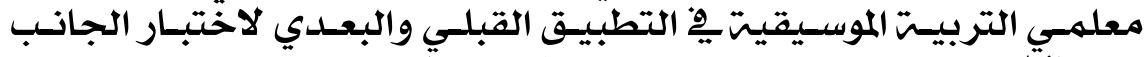

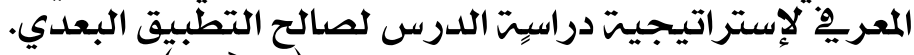

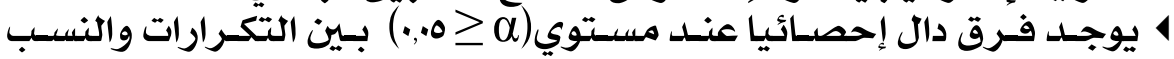

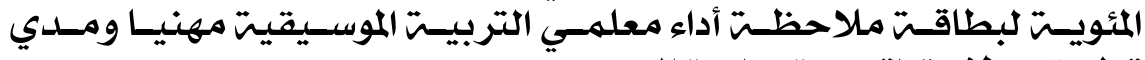

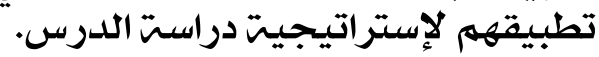

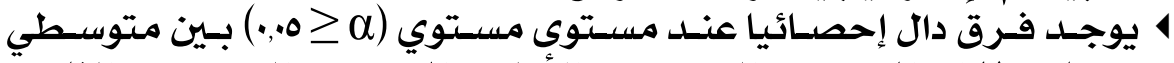

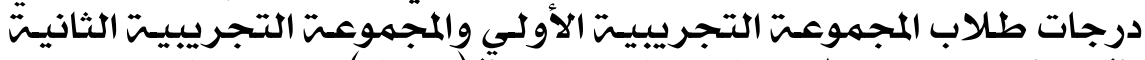

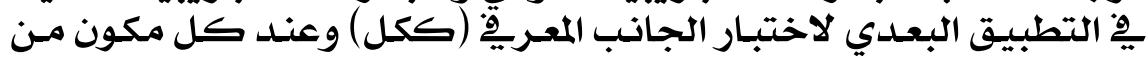

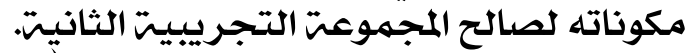

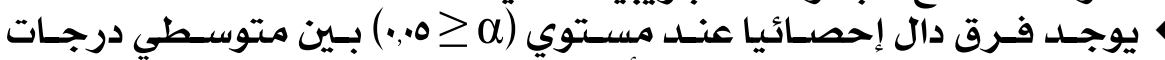

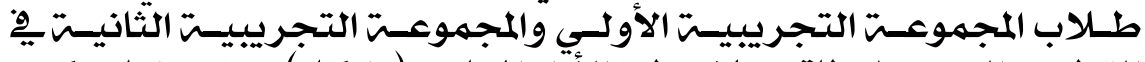

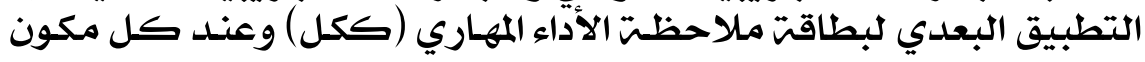

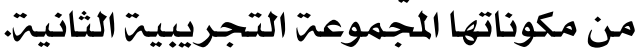

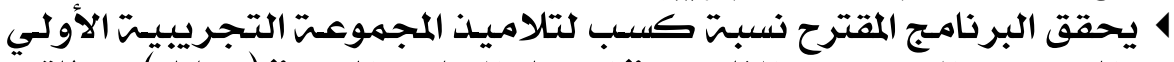

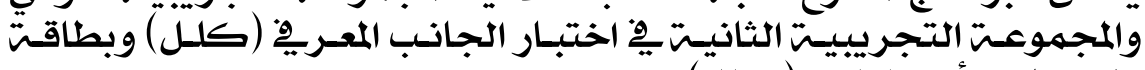

\section{$11 Y$} ماحظظت الأداء المهاري (كلتيلتئ. 


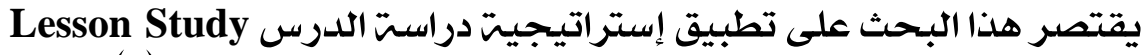

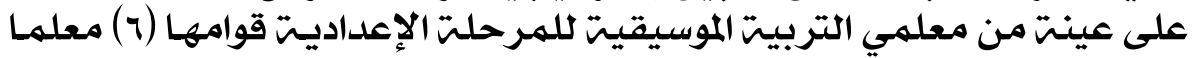

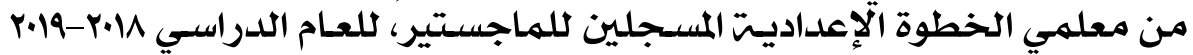

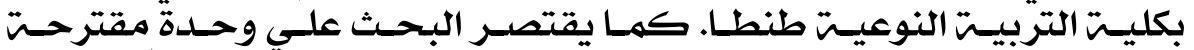

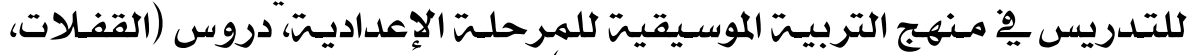

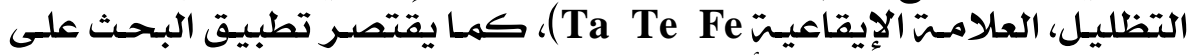

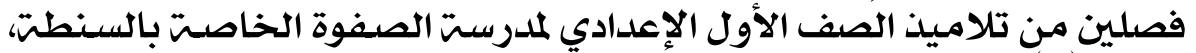

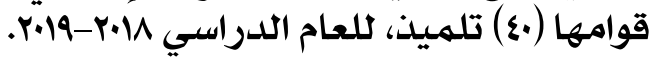

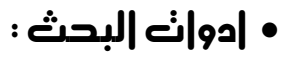

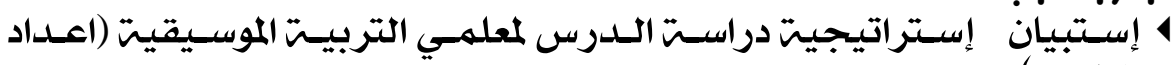
الباحثبانبان

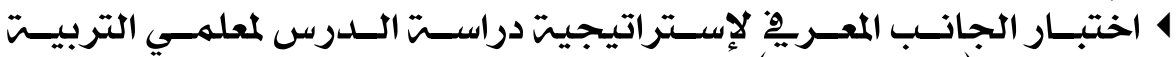

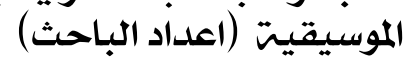

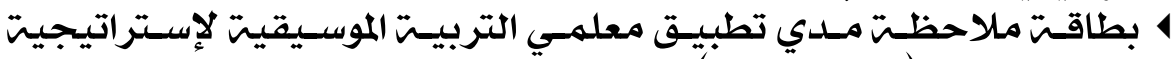
دراست الدرس (اعداد الداد البّاحث)

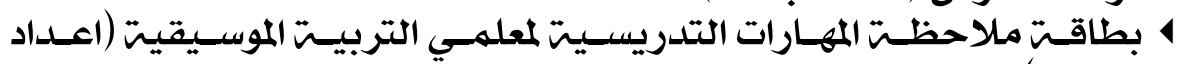

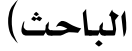

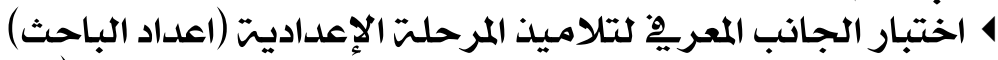

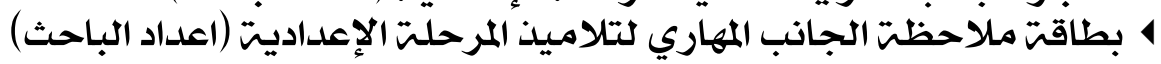

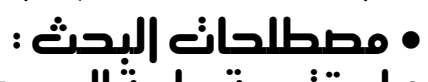

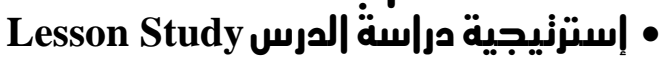

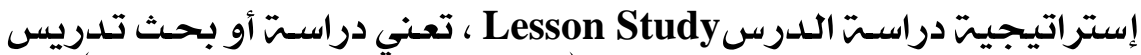

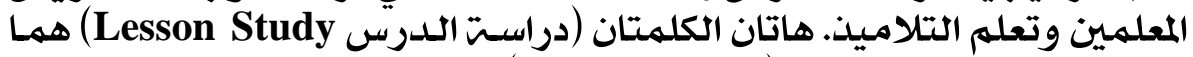

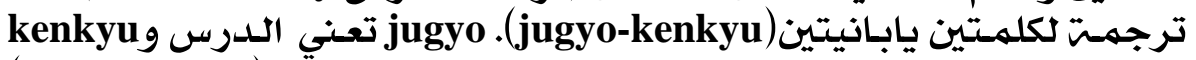

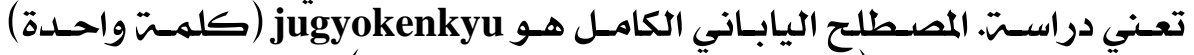

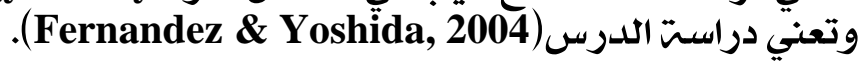

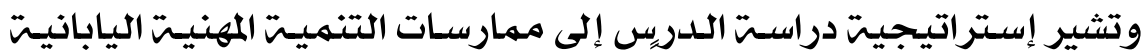

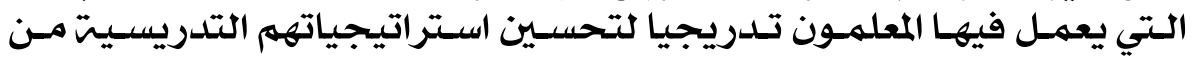

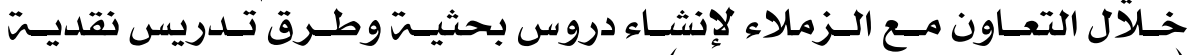
.(Takahashi \& Yoshida, 2004)

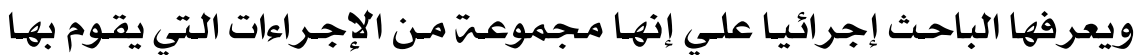

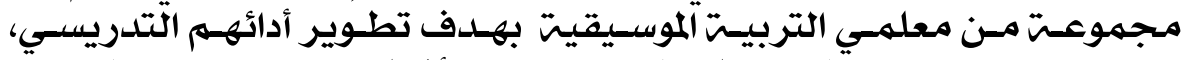

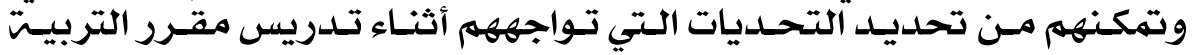

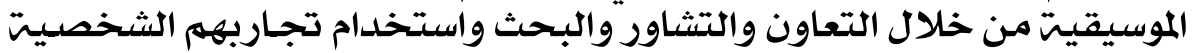

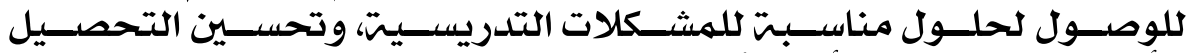

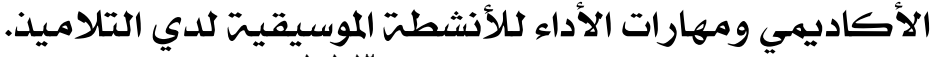
11 


\section{• الننمية الههنية}

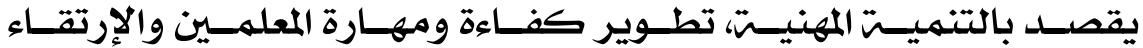

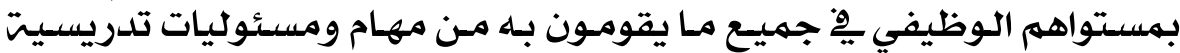

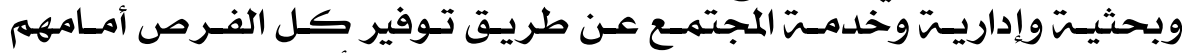

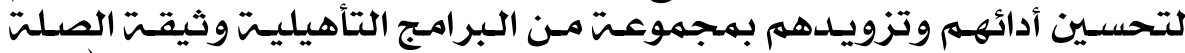

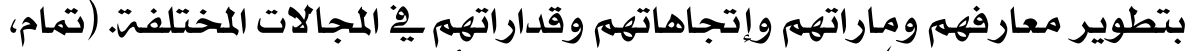

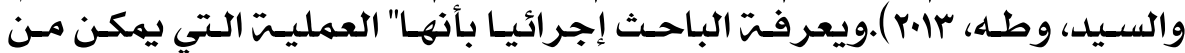

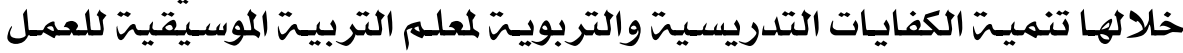

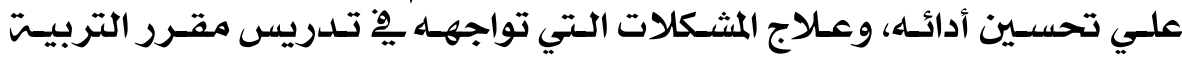

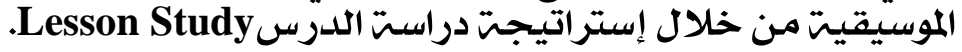

\section{• خصائص بر|مج الننمية المهنية الفمالة:}

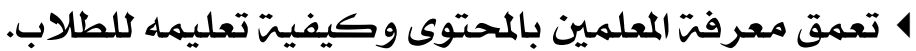

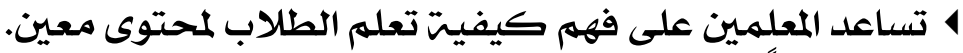

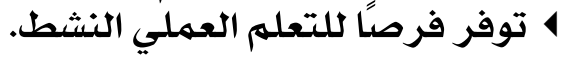

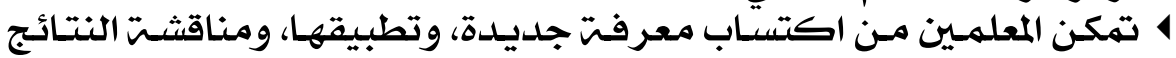
مـع الزملاءي.

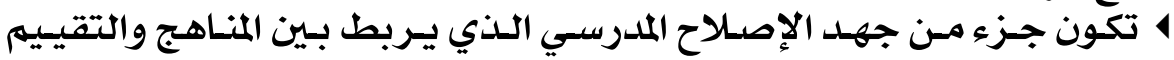
وكعايير التنهيت المهنيتئ.

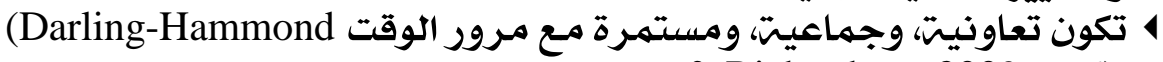
\& Richardson, 2009, p. 6)

• النحصيل الموسيقي إلجاتي

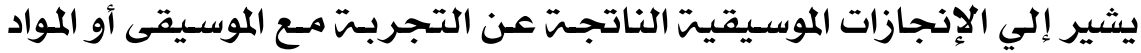

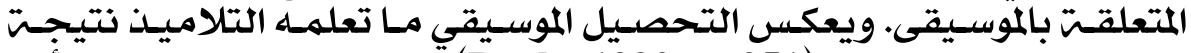

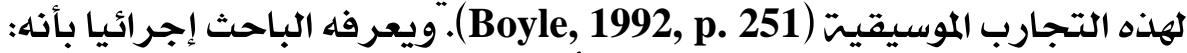

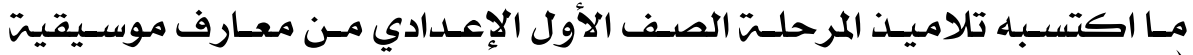

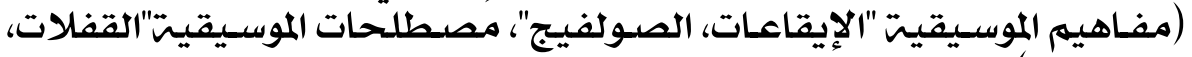

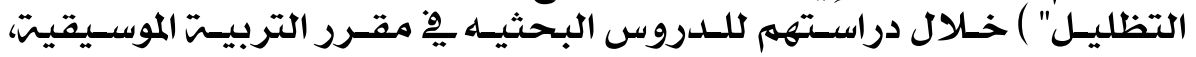

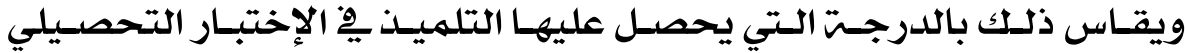

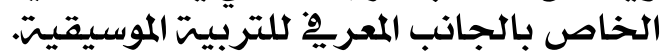

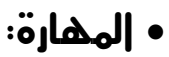

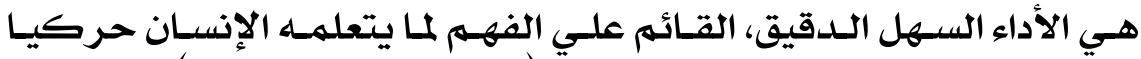

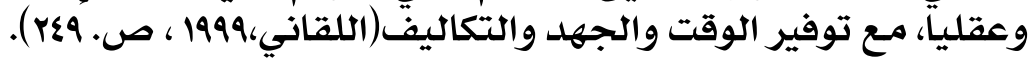

\section{• المهار|نه الموسيقية فوفير الهوفية}

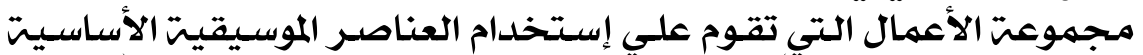

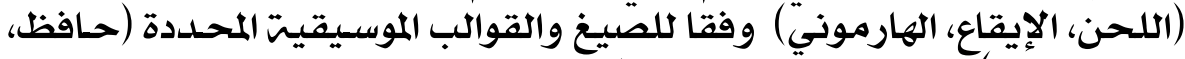

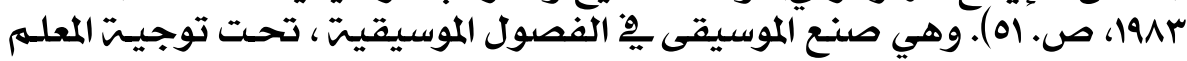




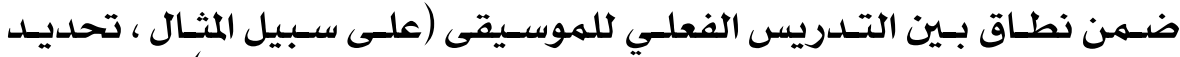

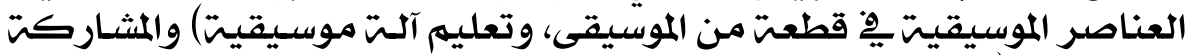

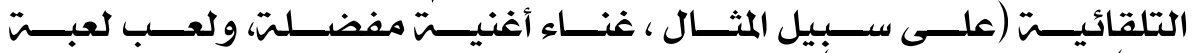

(Kujawski,1996)(أناءئ)

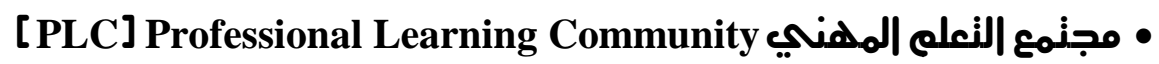
مجموعت من المعلمين والموجهين لديهم نفس المهائ الرؤيت يعملون بشكل تعاوني

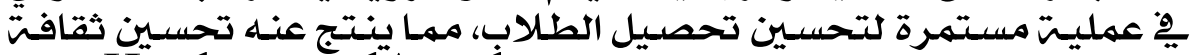
المدرستي

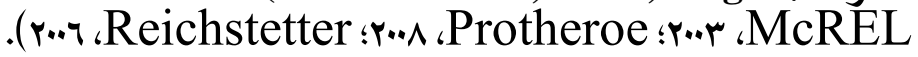

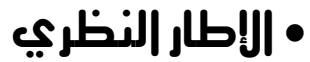

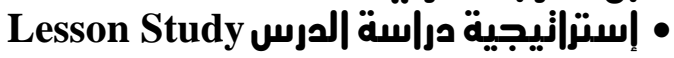

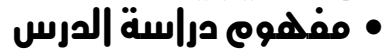

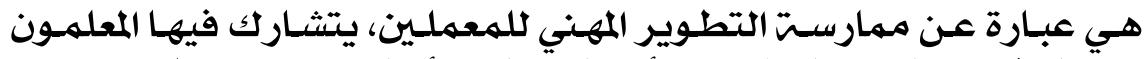

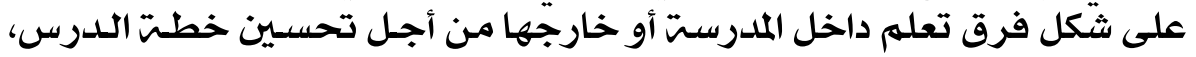

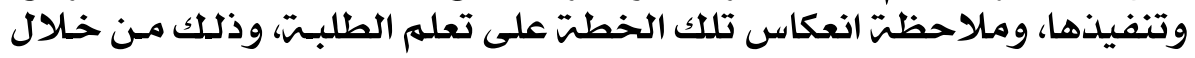

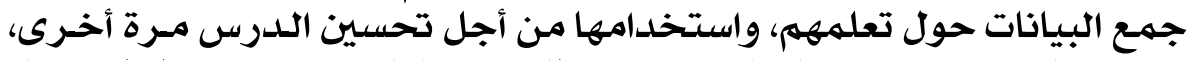

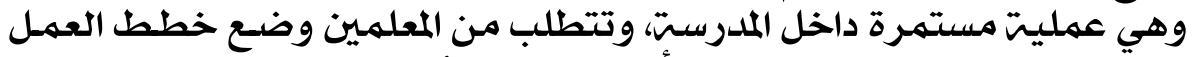

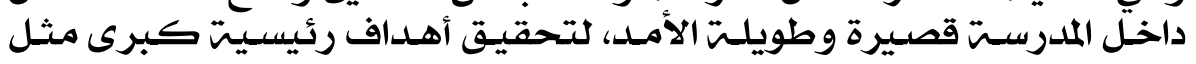

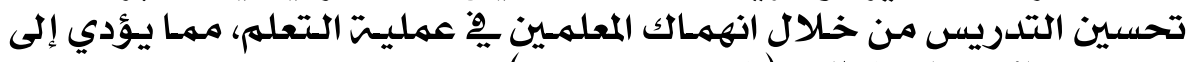

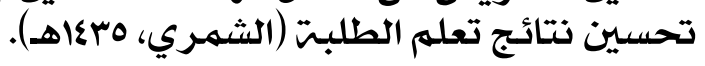

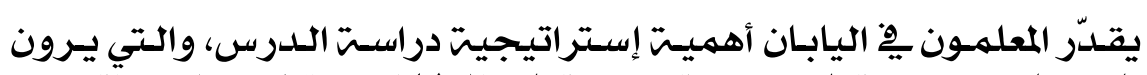

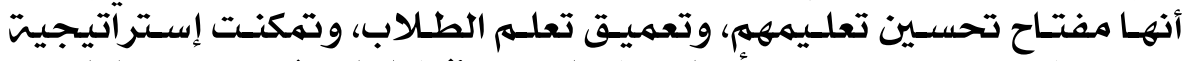

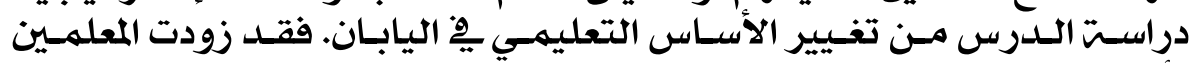

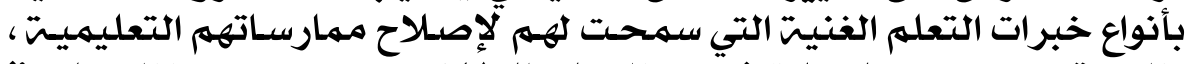

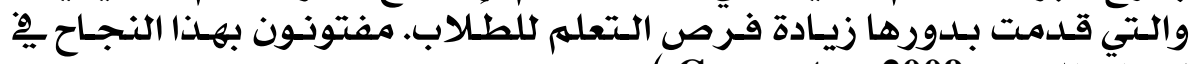

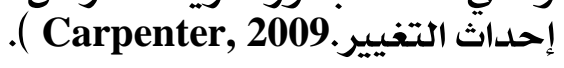

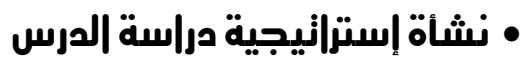

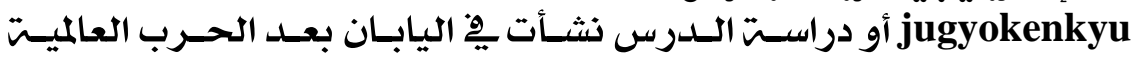

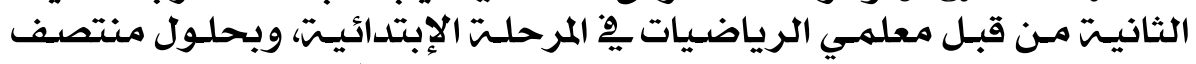

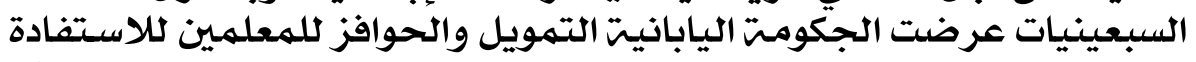

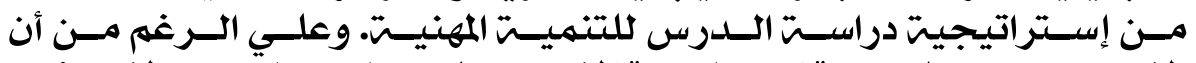

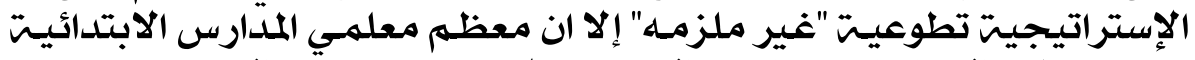

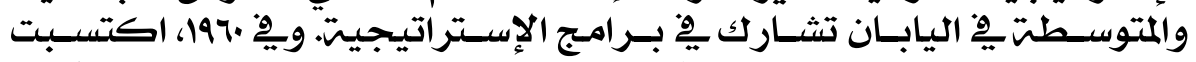

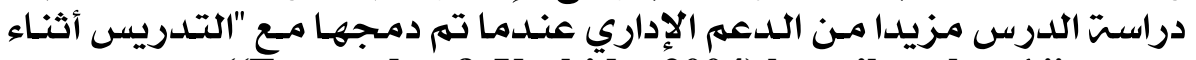

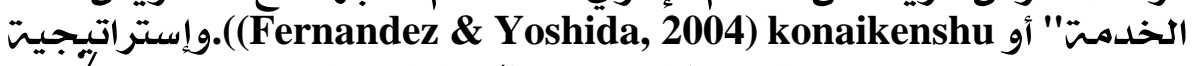

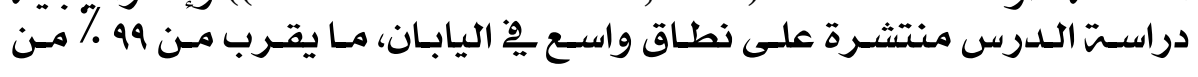




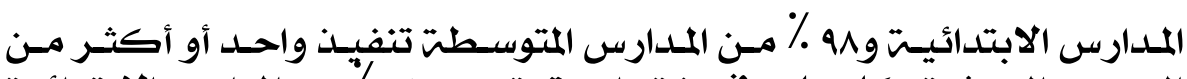

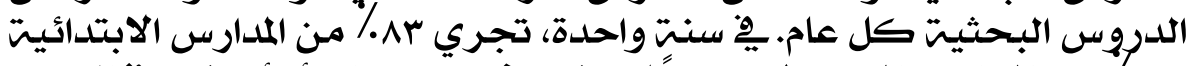

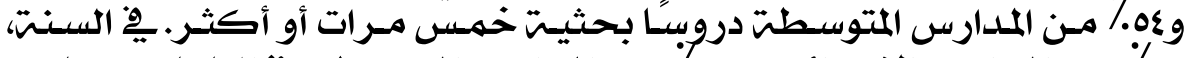

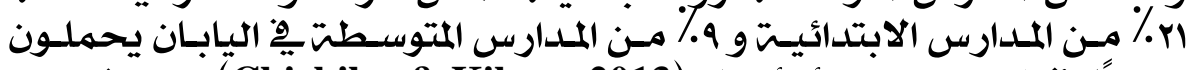

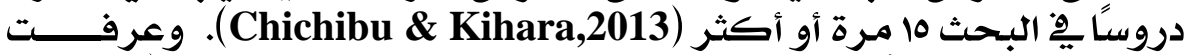

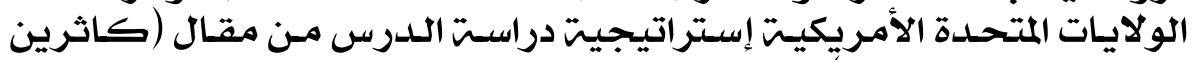

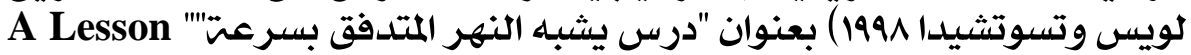

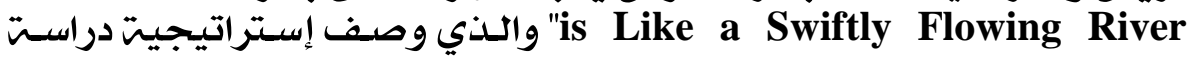

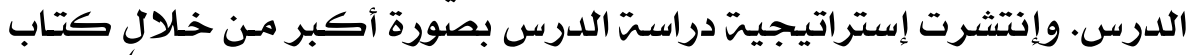

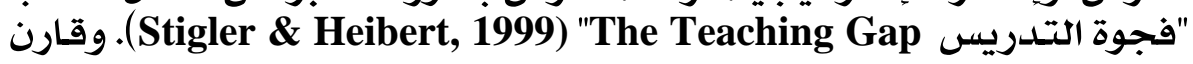

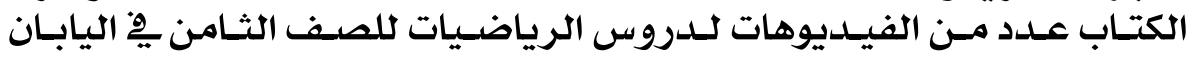

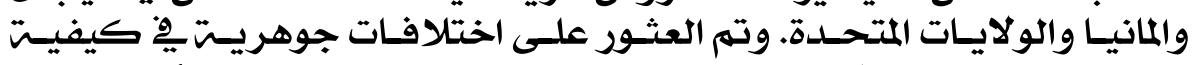

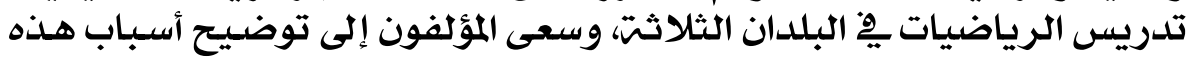

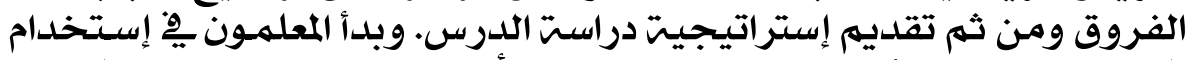

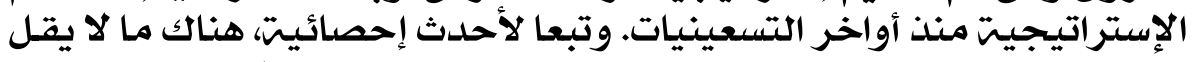

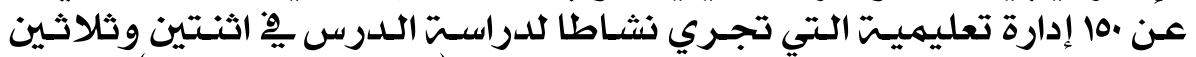

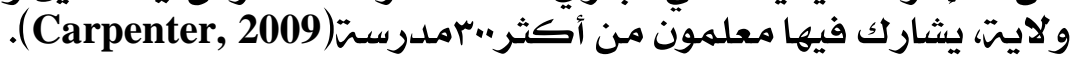

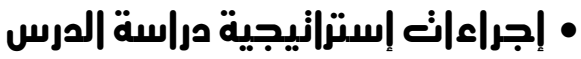

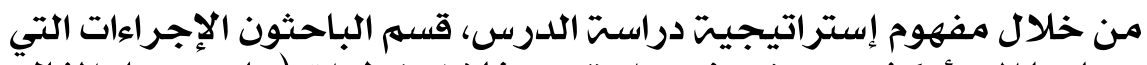

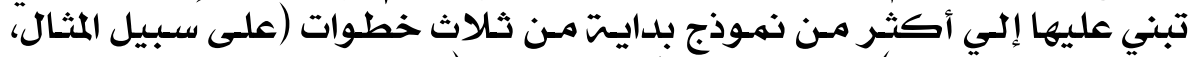
Hurd \& و Fernandez, 2002 Stigler \& Hiebert, 1999; Rock \&Wilson, ،Licciardo-Musso, 2005

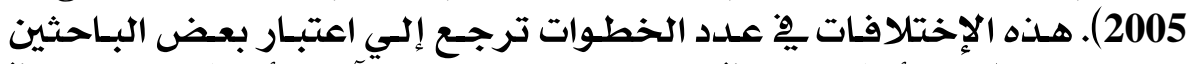

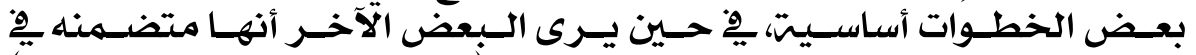

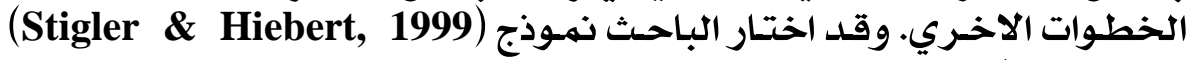

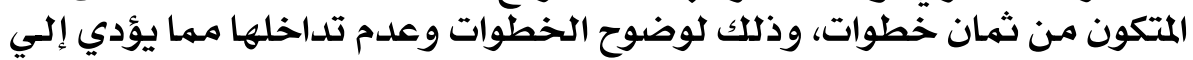

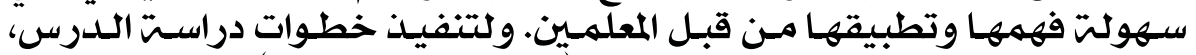

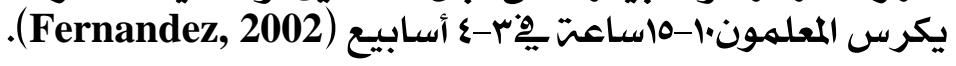
• خطو|نه إستر|نيجية در|سة الورسي:

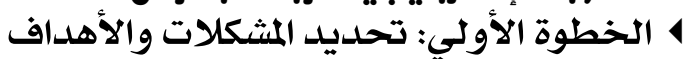

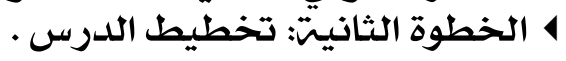

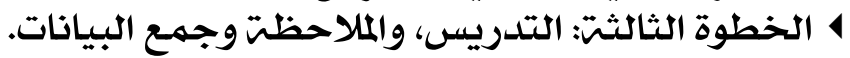

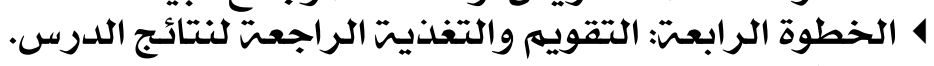

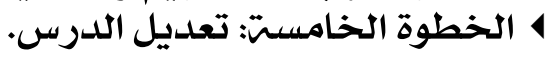

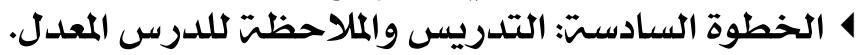

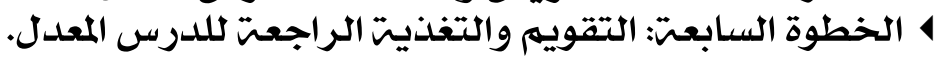
4 الخطوة الثامنتش: صياغتش وتبادل النتائج النهائيت للدروس. 


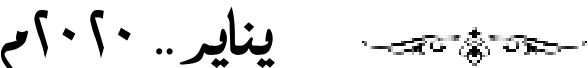

.(Rock \&Wilson,2005; Stigler \& Hiebert, 1999)

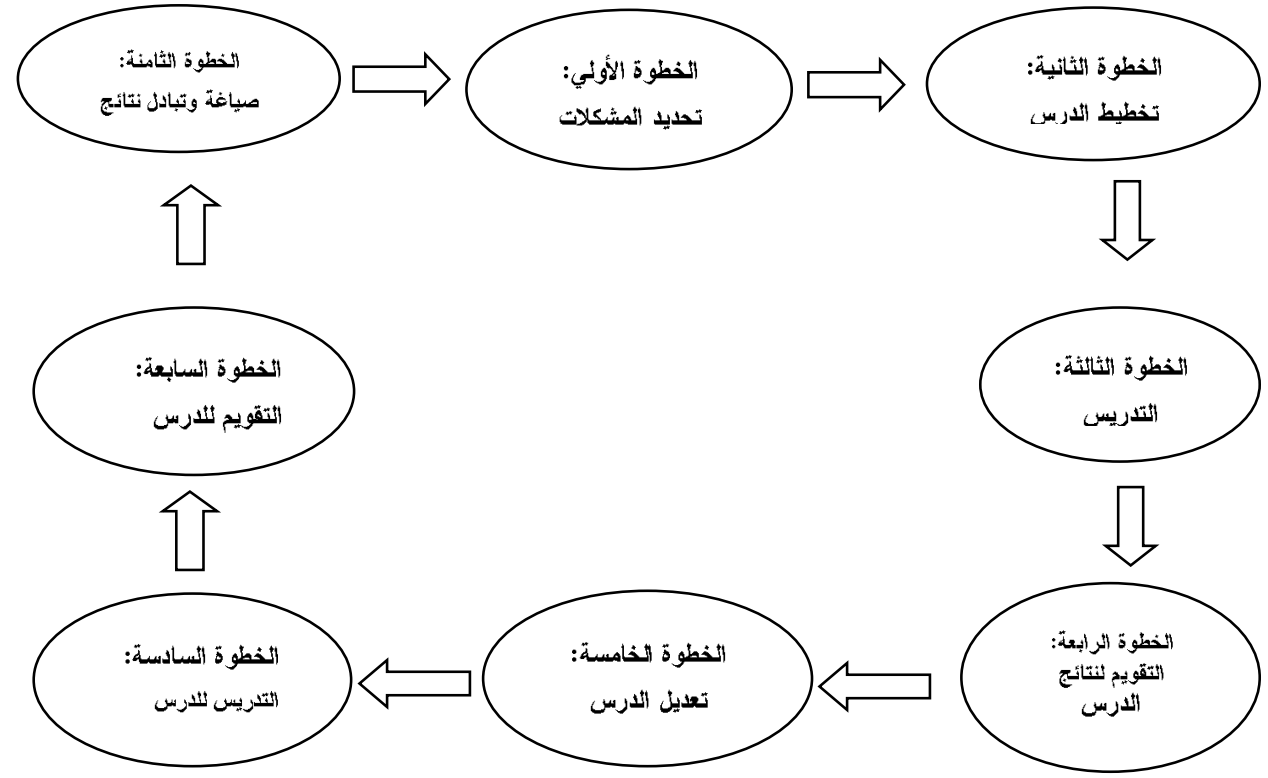

شكل (1): خطوات إسترتيجت دراست الدرس

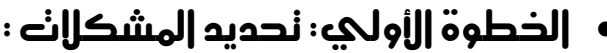

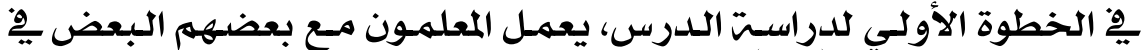

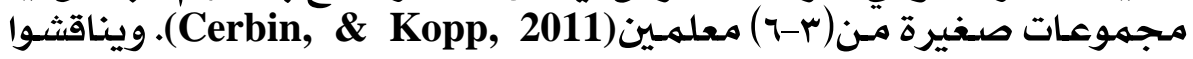

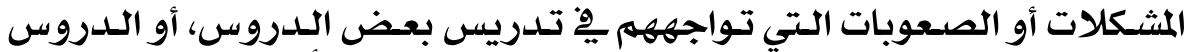

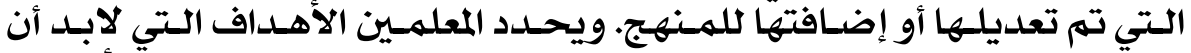

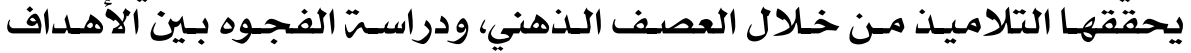

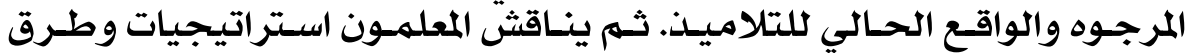

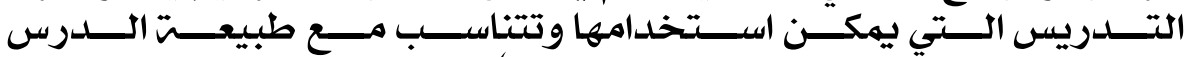

\section{.(Rekalidou,2012; Lewis, \& Hurd,2011)}

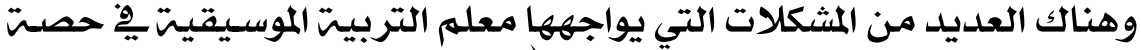

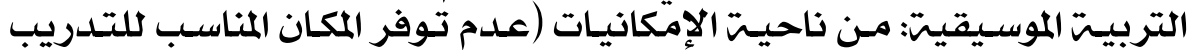

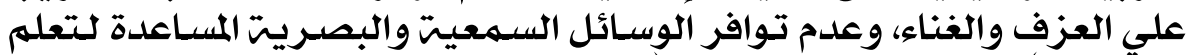

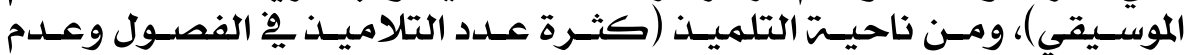

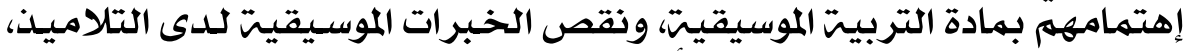

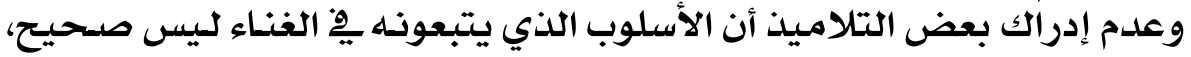

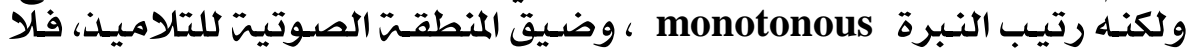

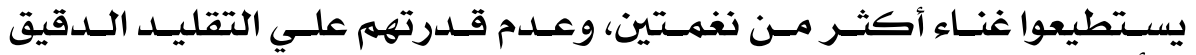

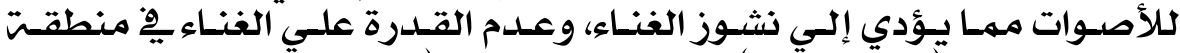

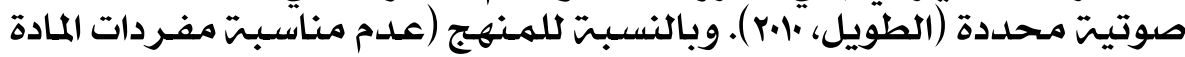




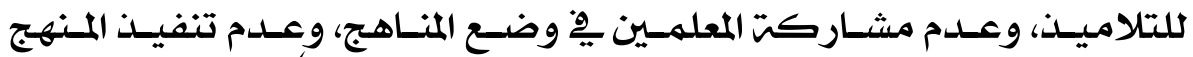

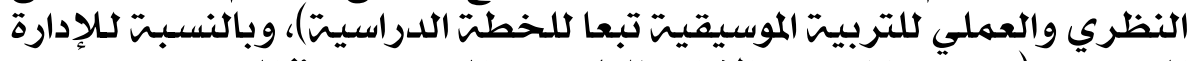

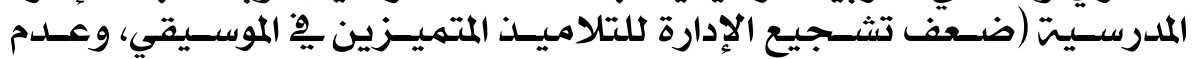

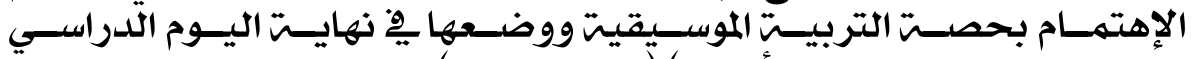

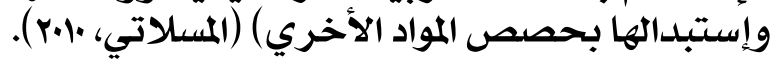

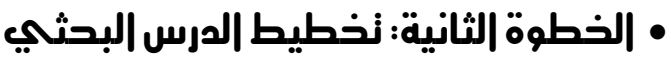

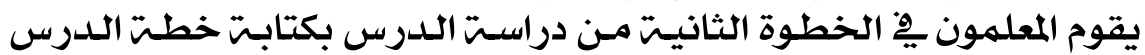

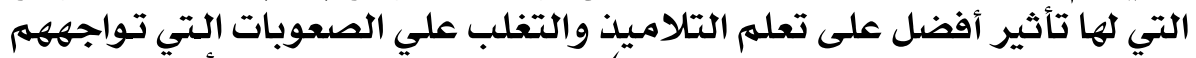

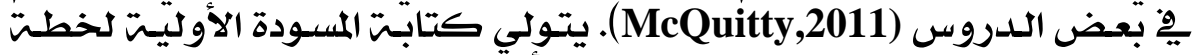

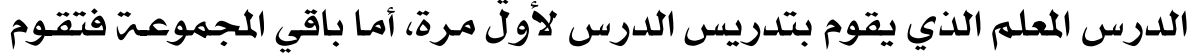

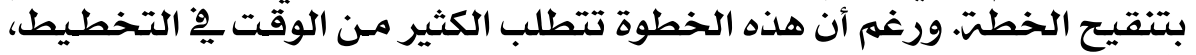

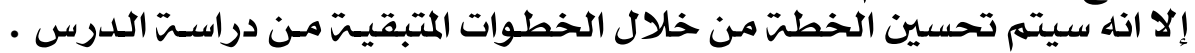

(Carpenter, 2009)

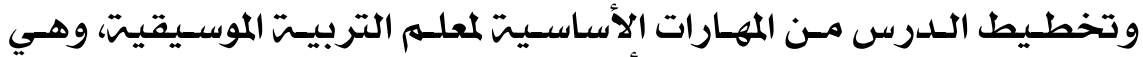

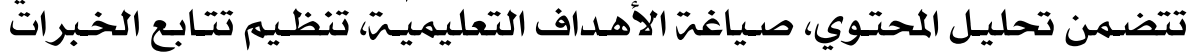

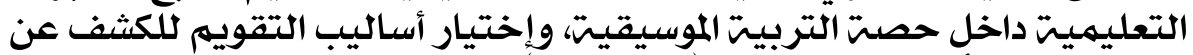

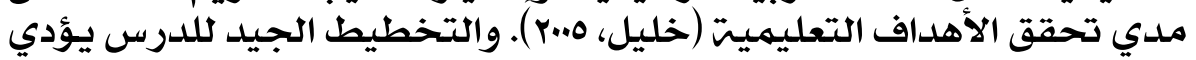

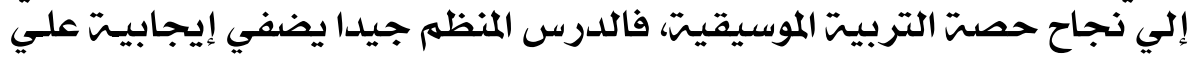

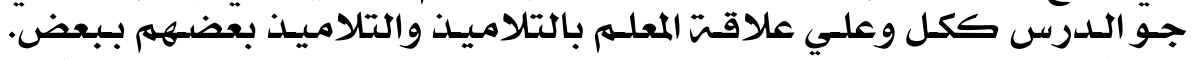

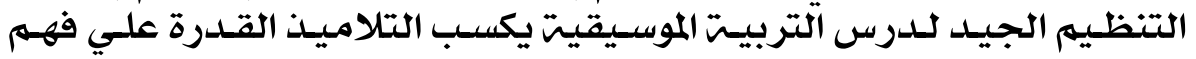

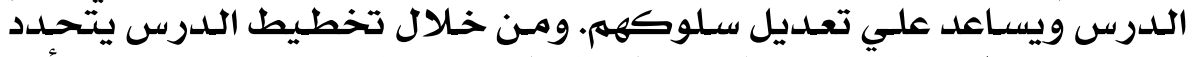

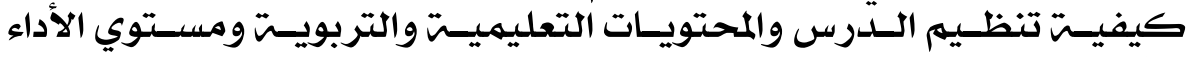

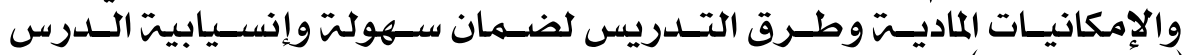

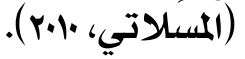

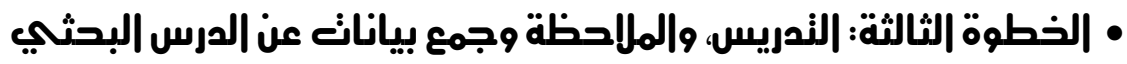

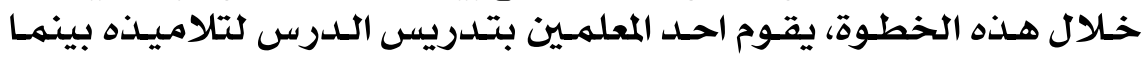

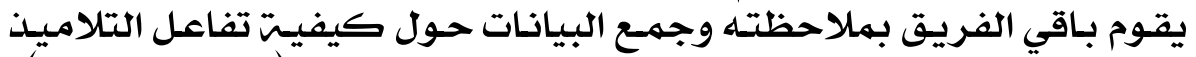

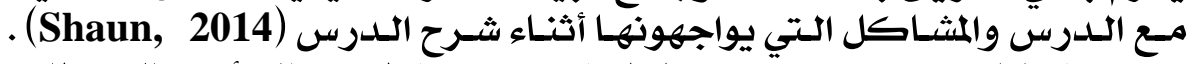

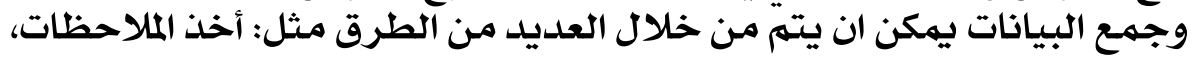

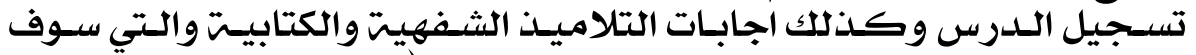

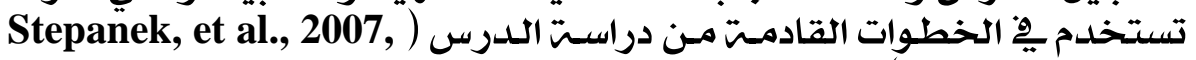

.(Rekalidou, 2012

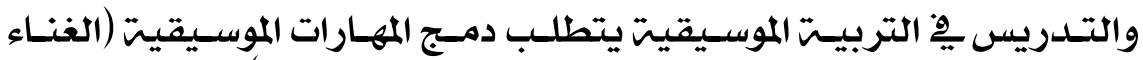

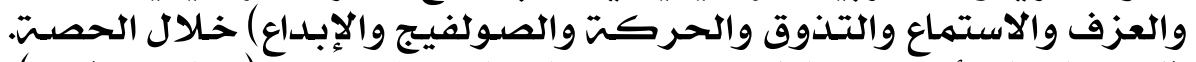

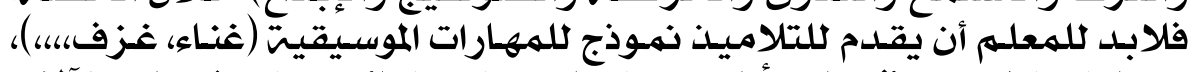

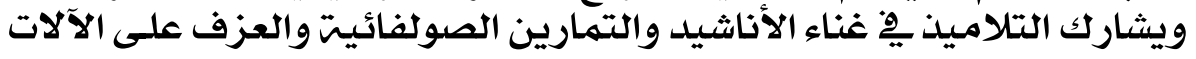




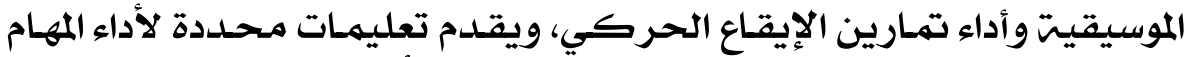

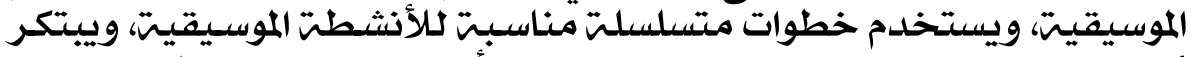

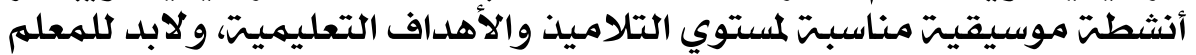

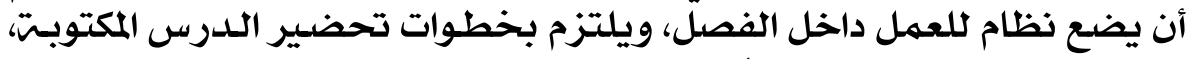

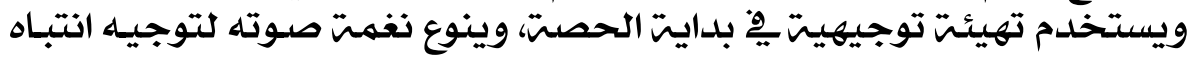

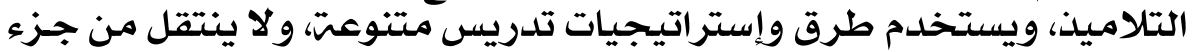

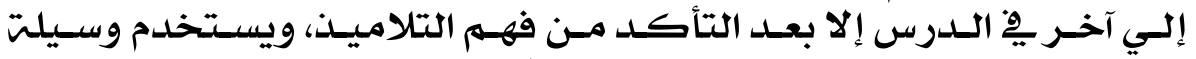

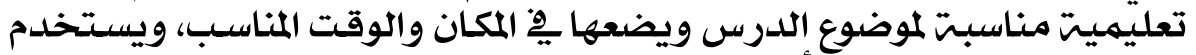

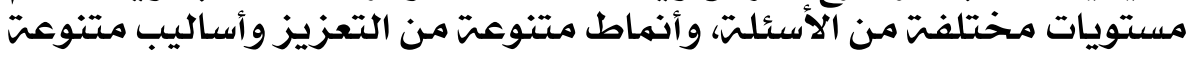

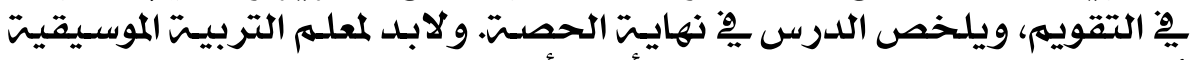

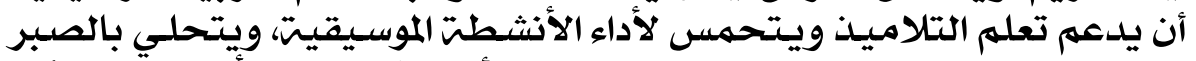

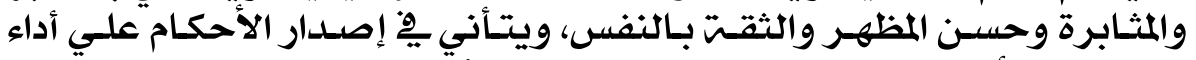

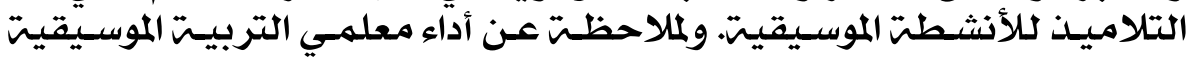

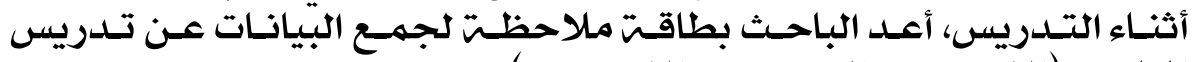

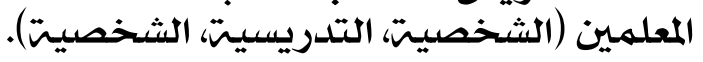

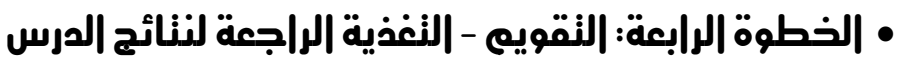

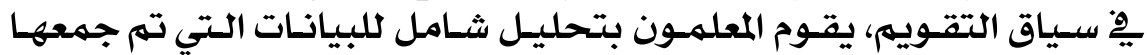

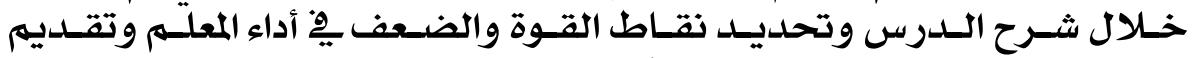

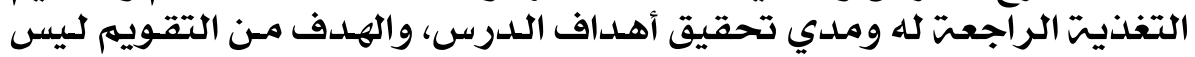

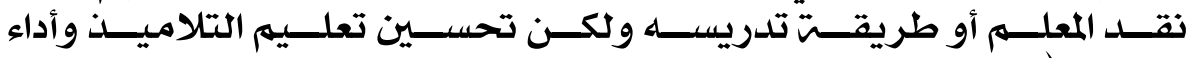

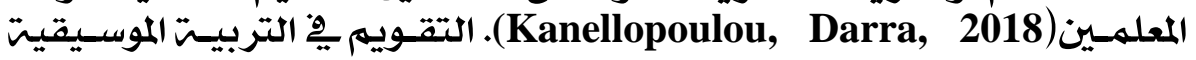

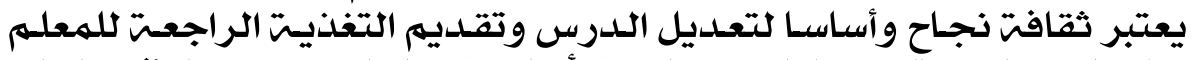

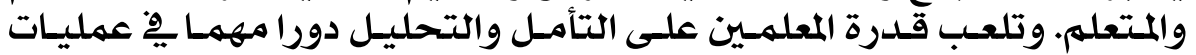

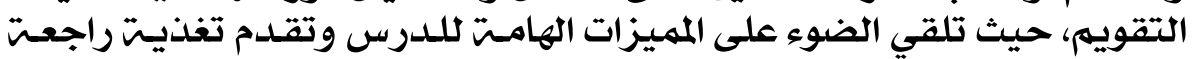

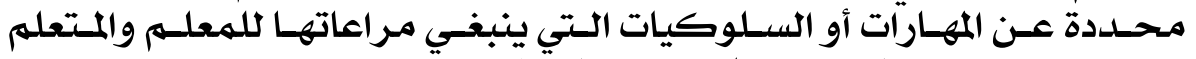

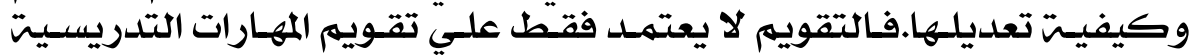

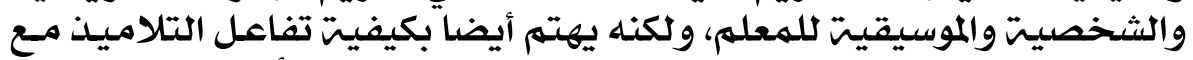

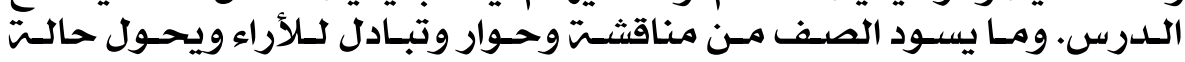

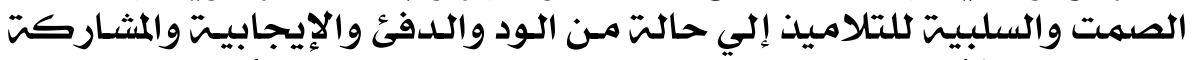

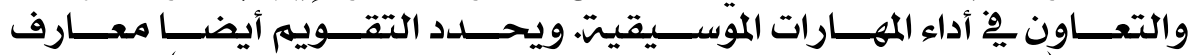

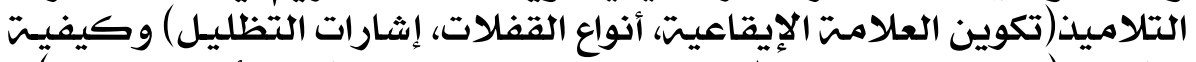

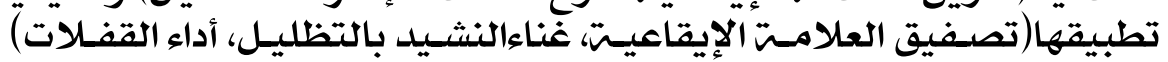
(Reid, 2005) • الخطوة الخامسة: نمديل الصرس إل

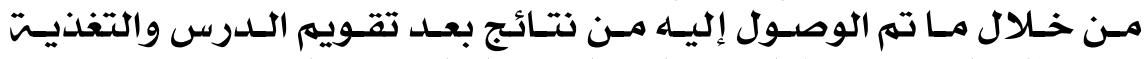

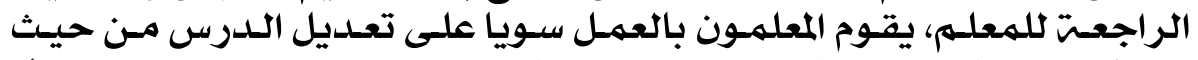

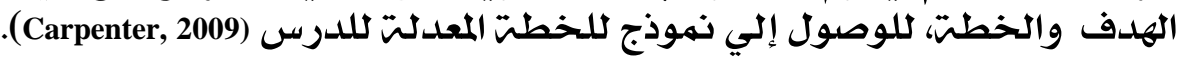


وِِِ مرحلت تعديل الدرس لابد أن يتم التخطيط لدرس التربيت الموسيقيت

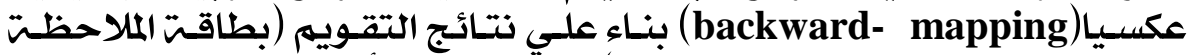

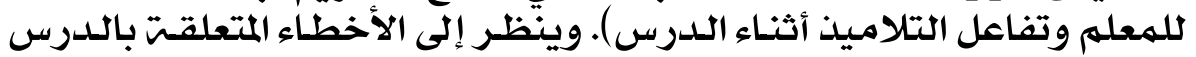

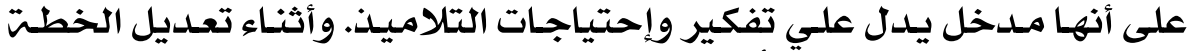

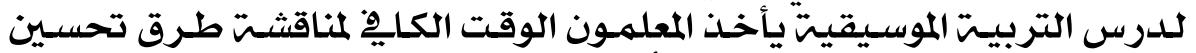

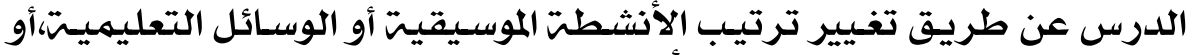

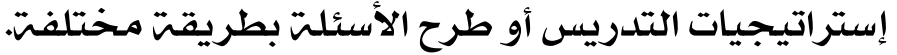

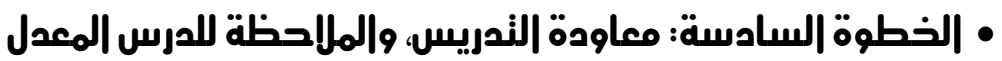

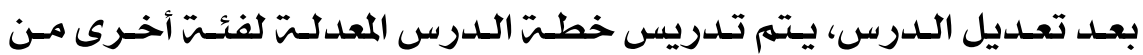

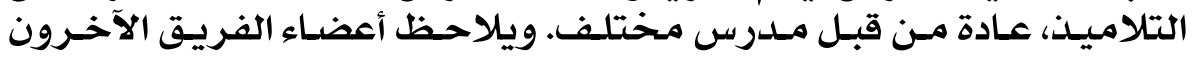

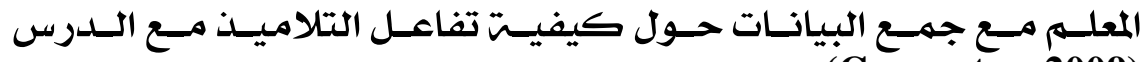
(Carpenter, 2009)

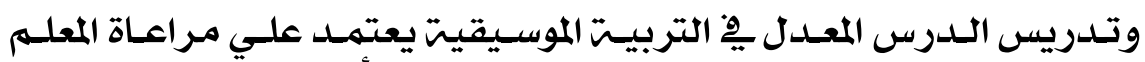

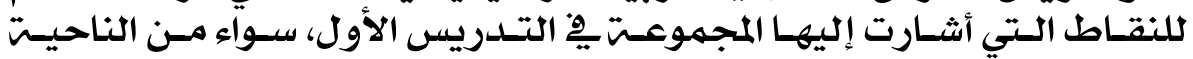

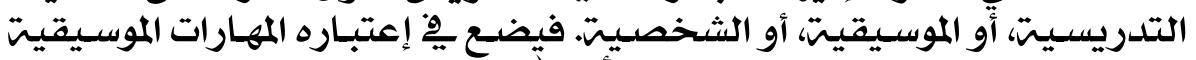

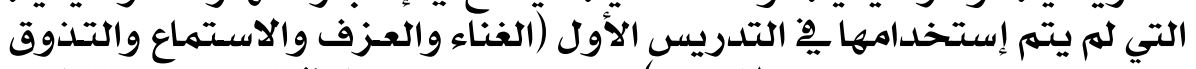

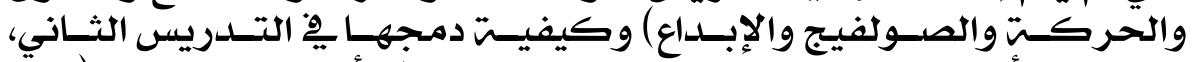

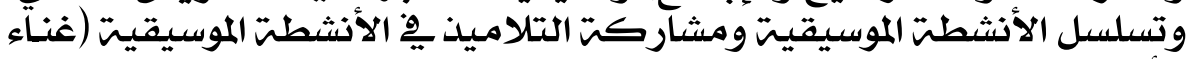

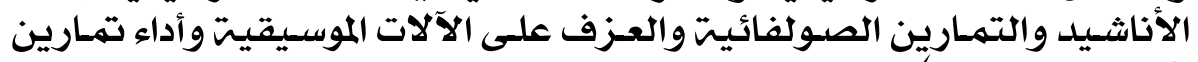

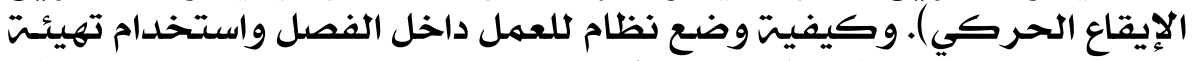

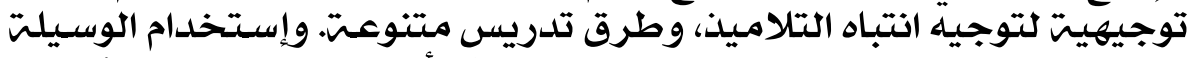

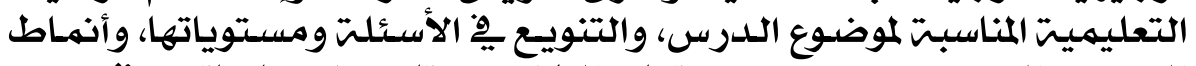

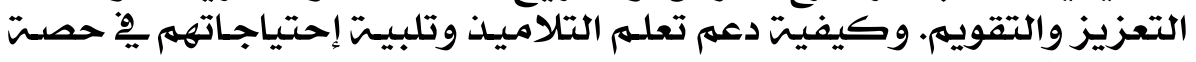
التربيت الموسيقيتة

\section{• الخطوة السابعة: النقويع والنفذية الر|جعة للمرس المعدل}

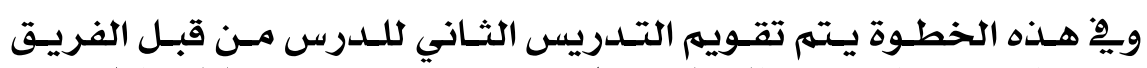

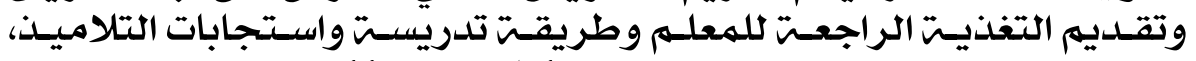

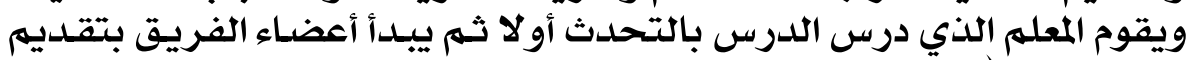

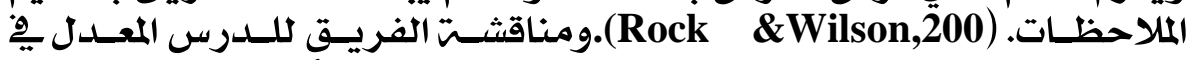

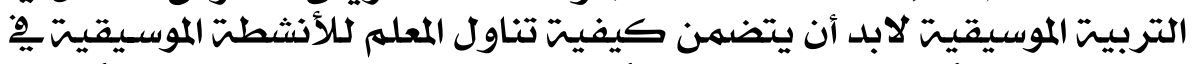

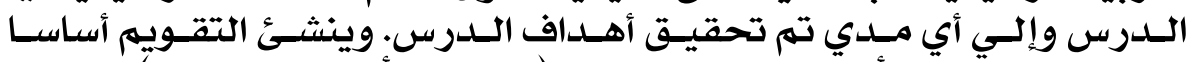

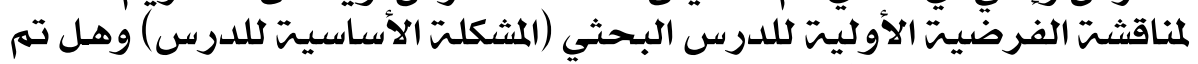

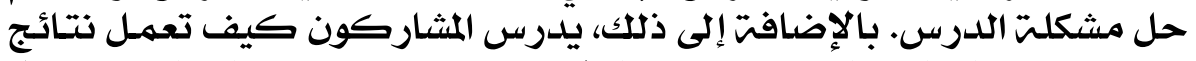

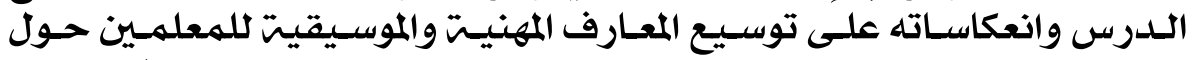

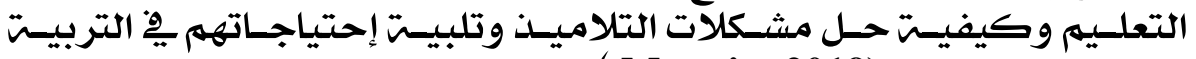

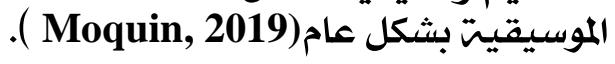

$1 \%$. 


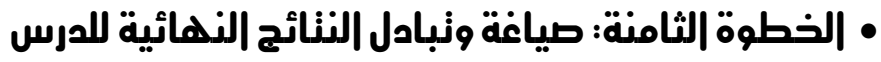

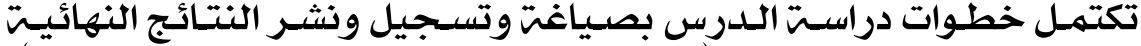
لخطوات تنفيذ الاستراتيجيت (Hiebert, Gallimore, \& Stigler, 2002)،

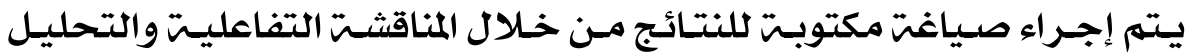

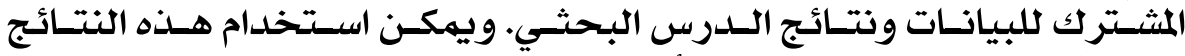

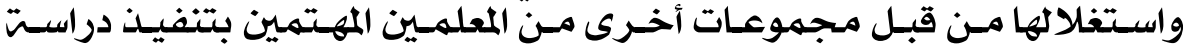

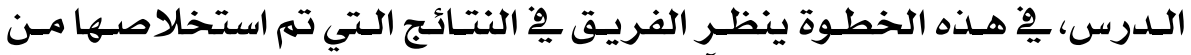

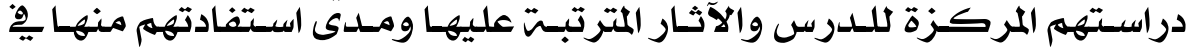

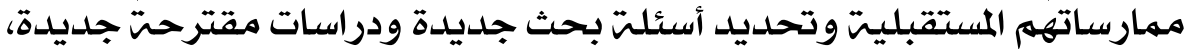
ويتهم تسجيل عمل المجموعت والنتائج هِّ تقرير موجز يتهم مشاركته مع إدارة المدرست (Carpenter, 2009).

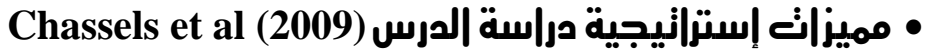

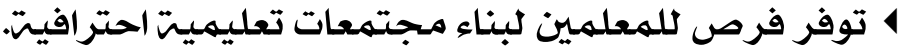
4 ك تعميق فهم المناهج الدراسيتة

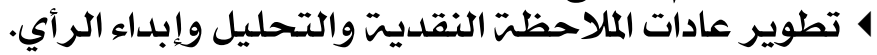

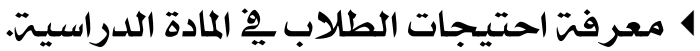
4 زيادة الوعي باستراتيجيات التدريس المختلفتلة.

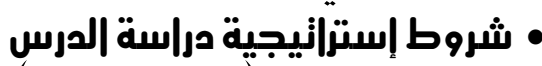

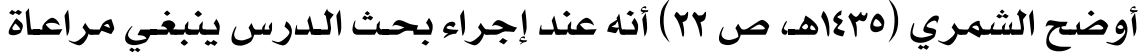

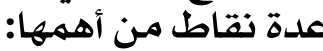
4 تحديد الحاجات والمبرورات والألماتهداف من تنفيذ الدرس.

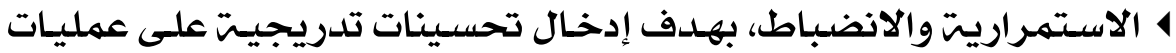
4 التركيز على العمليات والتأملات لبحث الدرس من أجل تحسين العمليات

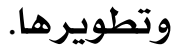
4 مناسبت طريقت تطبيق البحث مـع الوضع الحقيقي لظروف المدرستة.

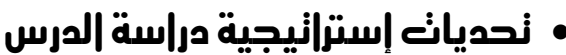

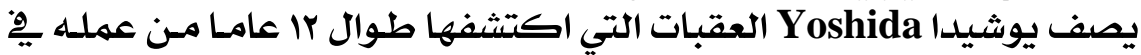

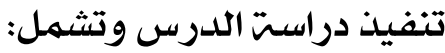

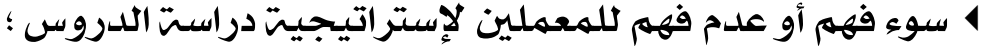

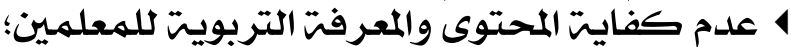

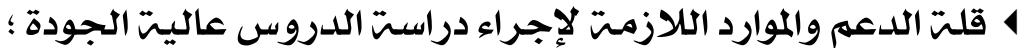

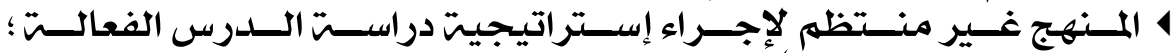
(Yoshida,2012,p.142)

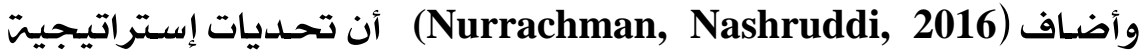
دراست الدرس تتركز بشكل أساسي على الهياكل الإداريت للوقت والمدرستية التي قد تعوق تعاون المعلمين. 


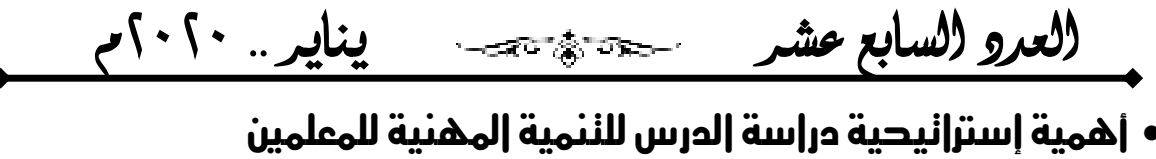

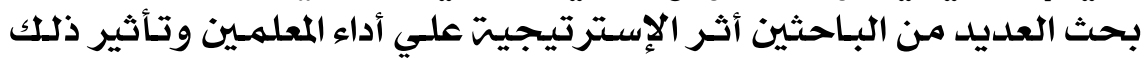

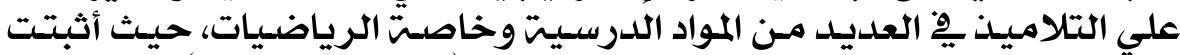

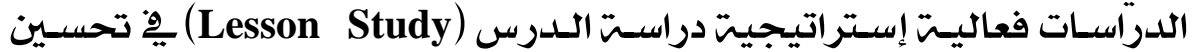

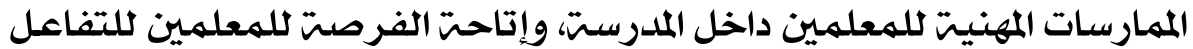

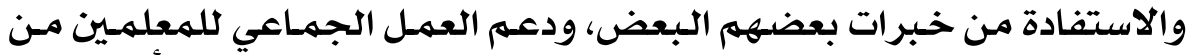

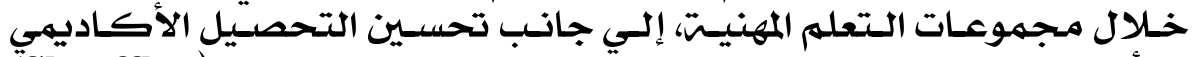

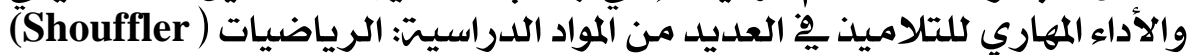
, 2018; Barbar,2016; Mon, Dali \& Sam, 2016 ; Rock\& Wilson, ؛2005; Jenne, 2005; Podhorsky, 2005; Puchner\& Taylor, 2006

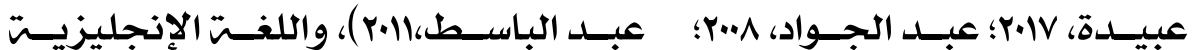
Carpenter, (Nashruddi,\& Nurrachman, 2016)

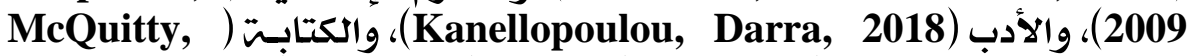
Espinosa, et al (2011; Sulastri, 2017

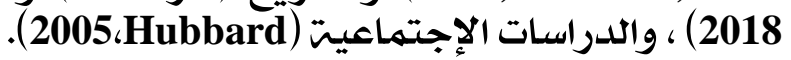
• النْنمية المهنية المهية

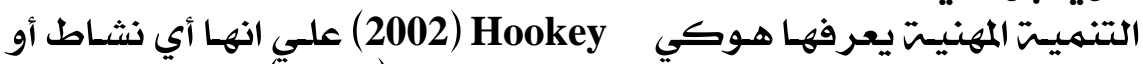

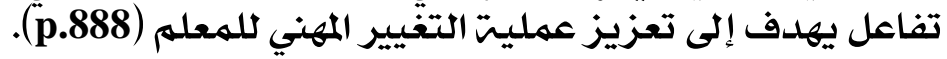

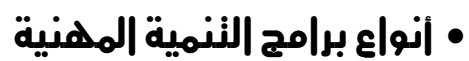

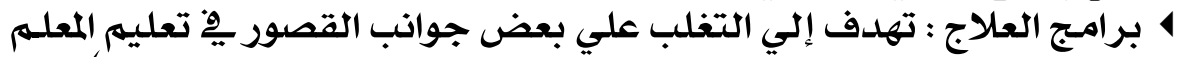

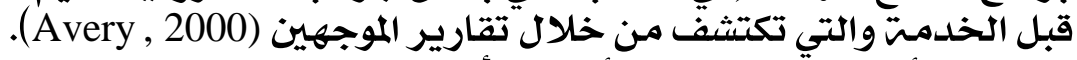

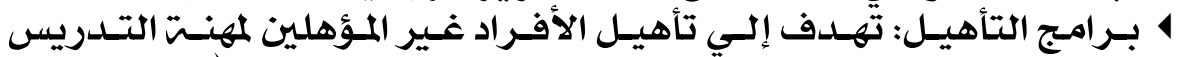

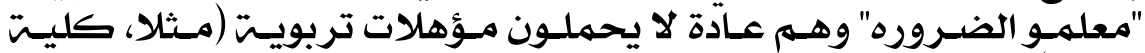

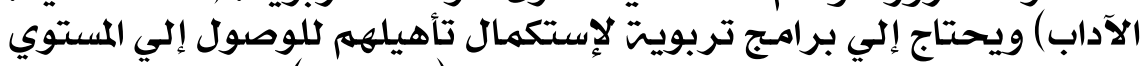

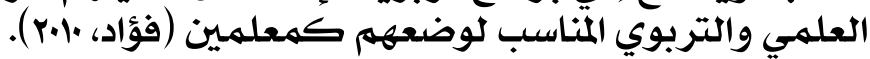

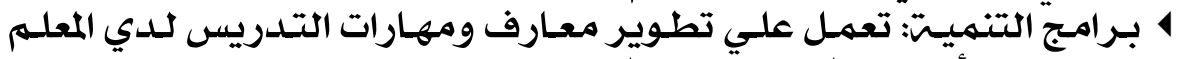

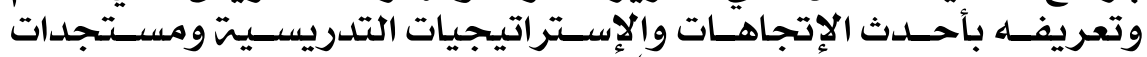

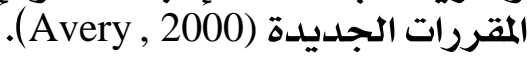

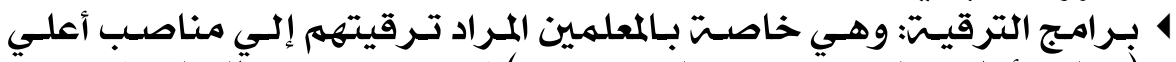

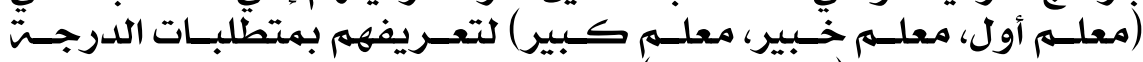

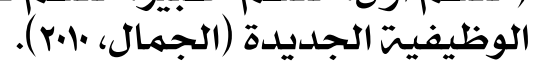

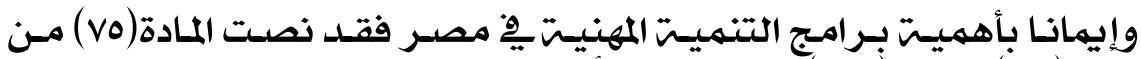

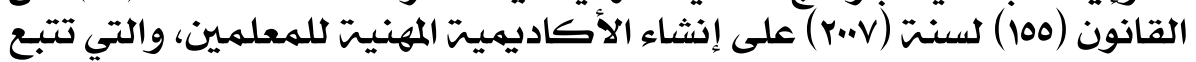

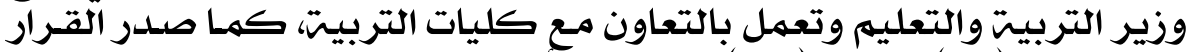

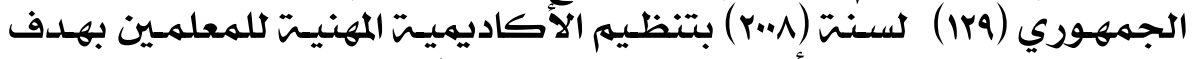

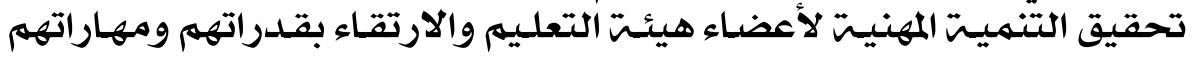

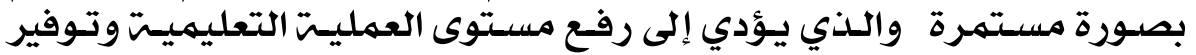




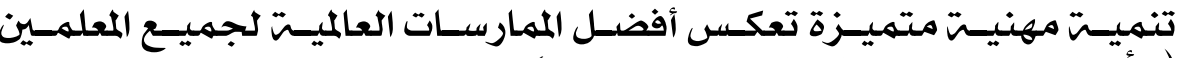

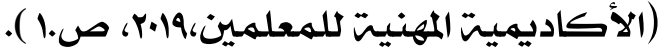

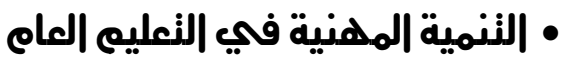

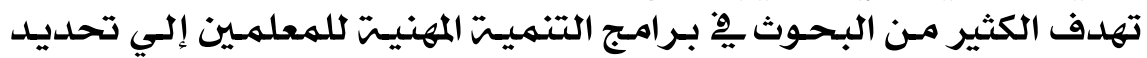

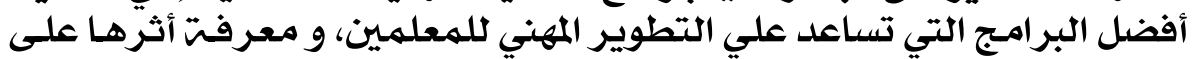

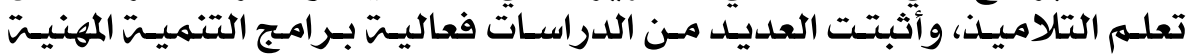

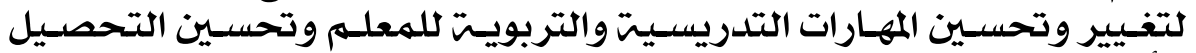

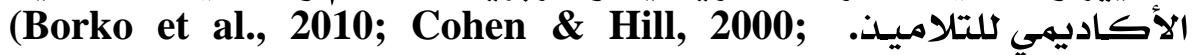
Conway \& Edgar, 2014; Desimone et al., 2002; Garet et al., 2001; Penuel et al., 2007; Gersten et al., 2010; Penuel, Gallagher, \& Desimone et al., 2002 Moorthy, 2011

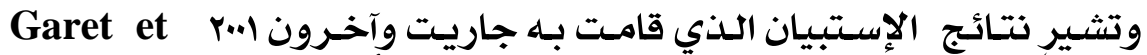

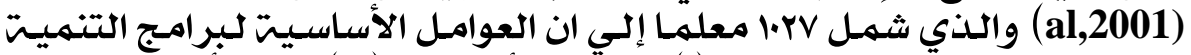

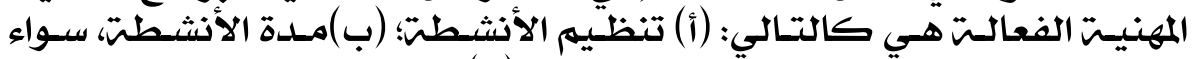

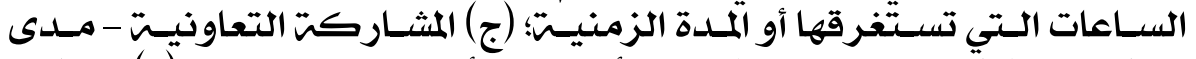

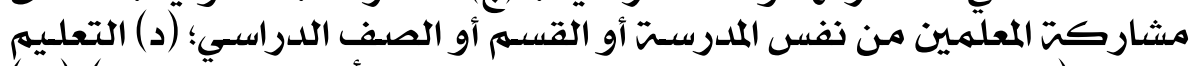

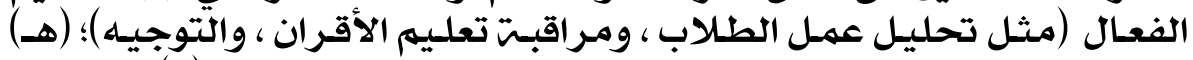

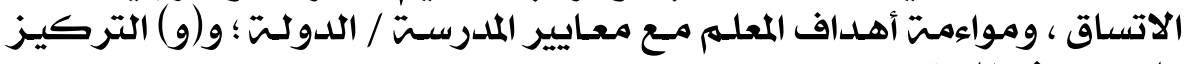

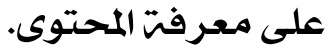

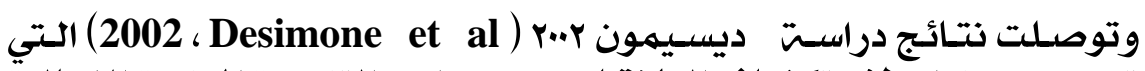

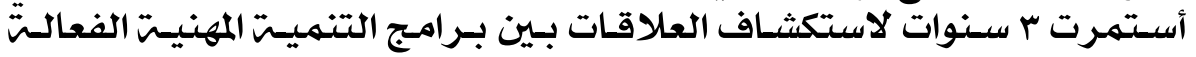

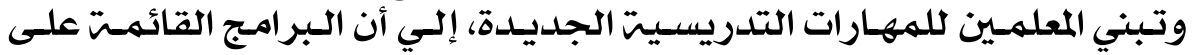

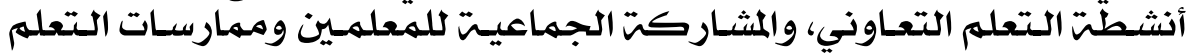

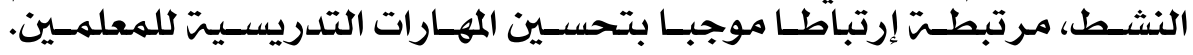

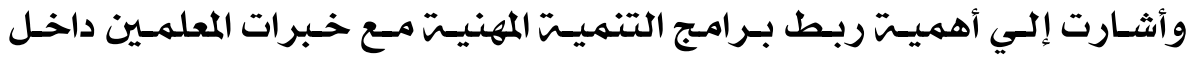

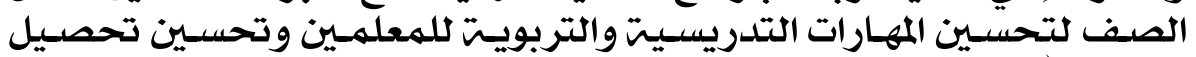

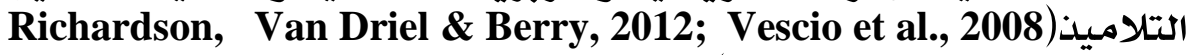

(Gersten et al., 2010; 2003;

\section{• الننمية المهنية لمعلماي التزبية الموسيقية}

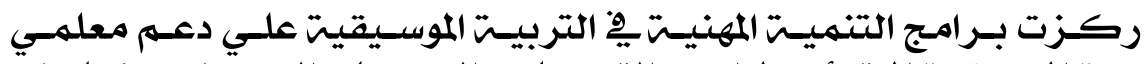

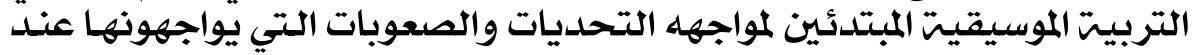

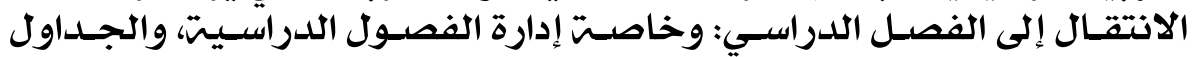

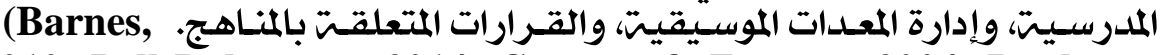
2010; Bell-Roberston, 2014; Conway \& Zerman, 2004; Roulston, . فقـد اهتهـت البحـوث التي أجررتها كنـواي (201te, \& Womak, 2005) (2001, 2003, 2012, 2015) Conway 
التربيت الموسيقيت المبتدئين وأشارت إلي أن غالبيت برامج التوجيه المدرسي غير

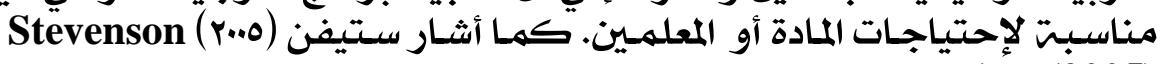

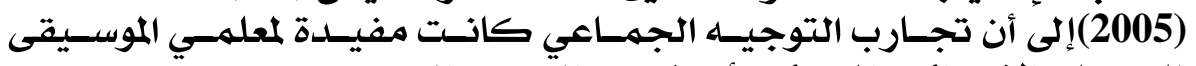

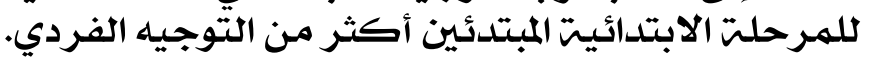

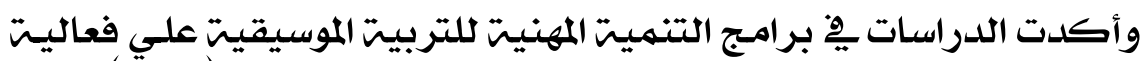

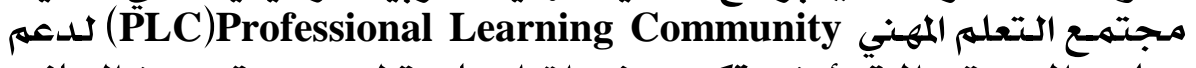

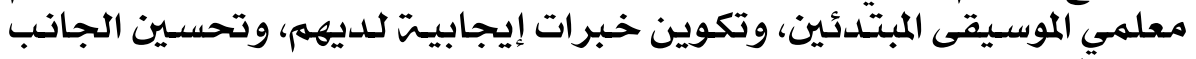

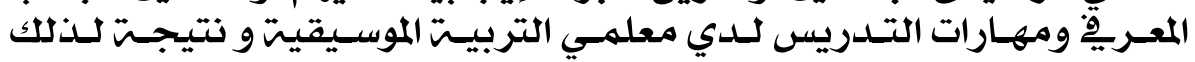

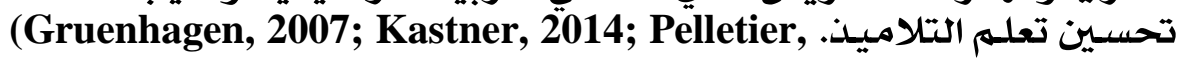
2012; Stanley et al., 2014). 2013; Sindberg, 2016; Stanley, • الننميـة المهنية لمعملي التربية الموسيقية وإسترانيجية دراسة الدرس ـاس Lesson Study

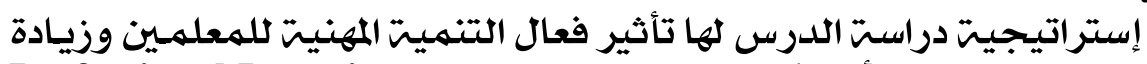

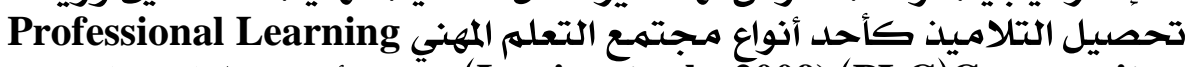

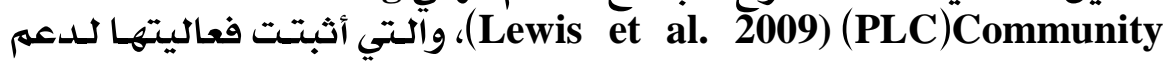

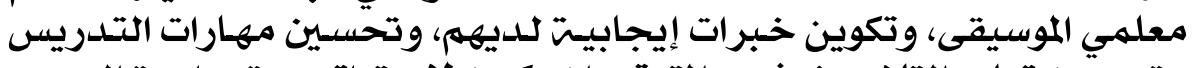

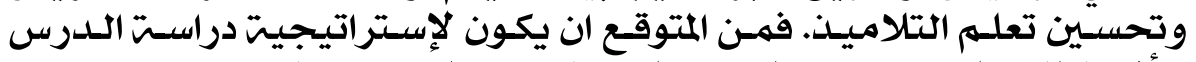

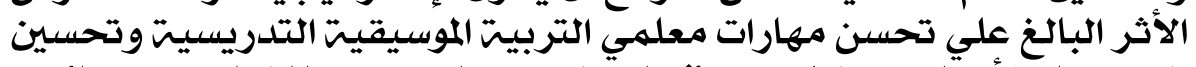

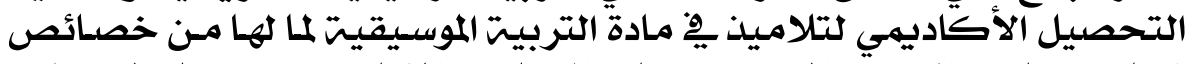

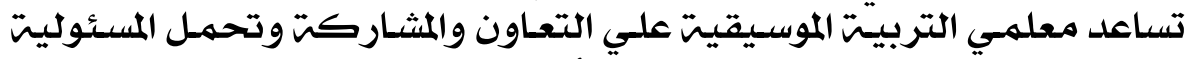

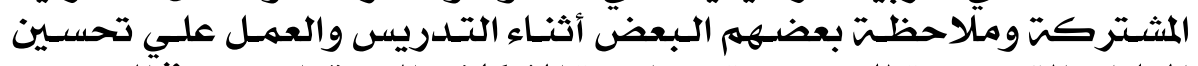

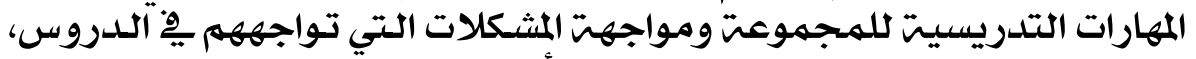

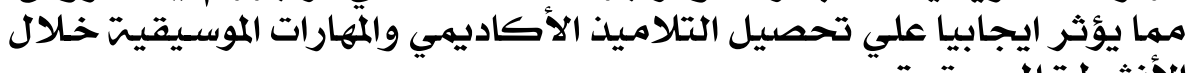
الأنثطن المؤسيقيت.

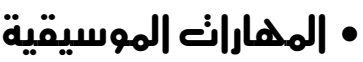

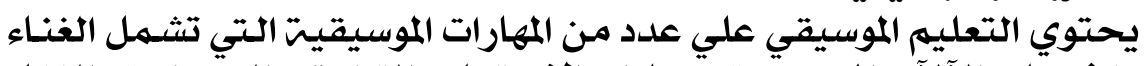

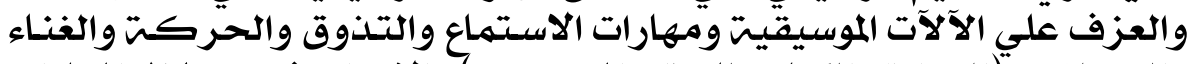

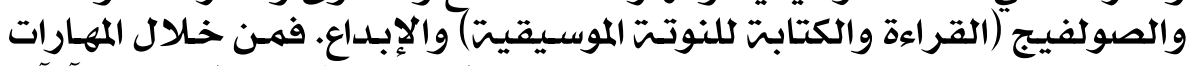

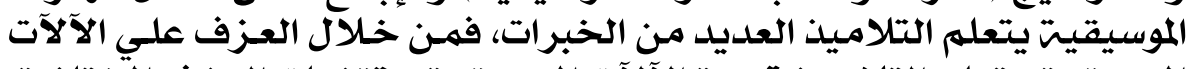

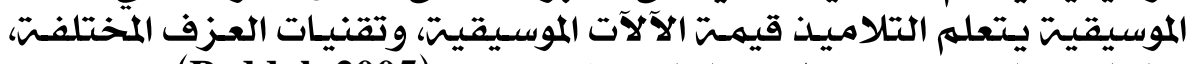

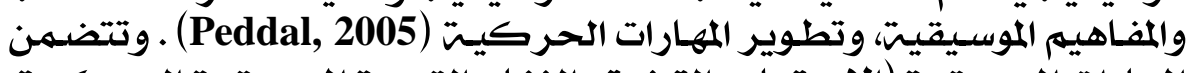

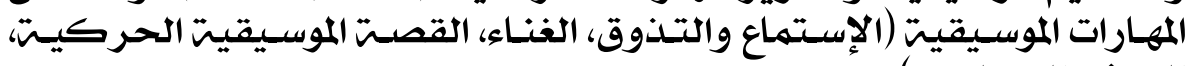
العزف، الصولفيج). (الموسية.

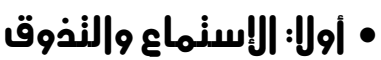

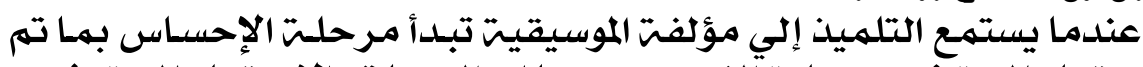

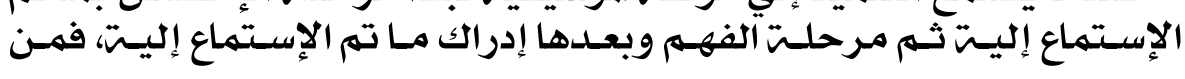




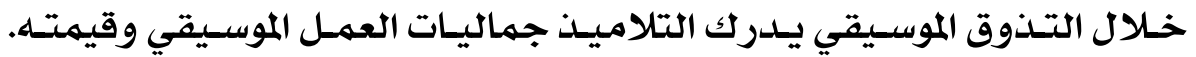

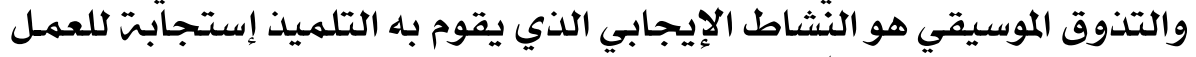

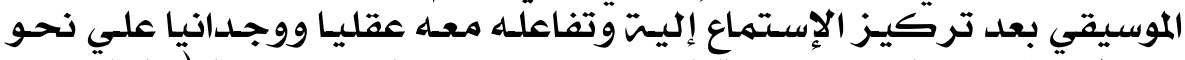

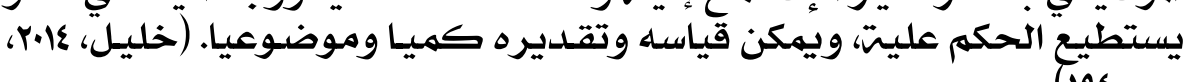

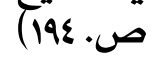

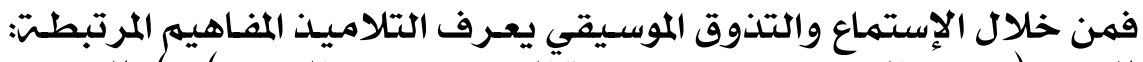

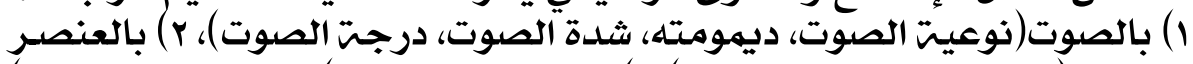

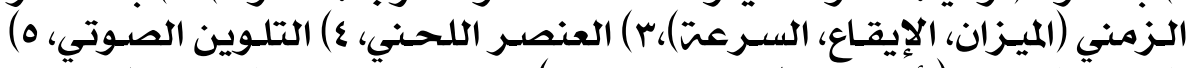

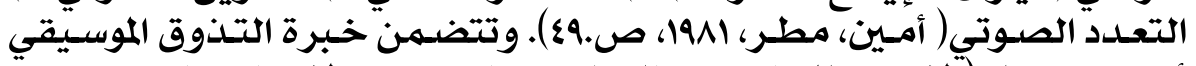

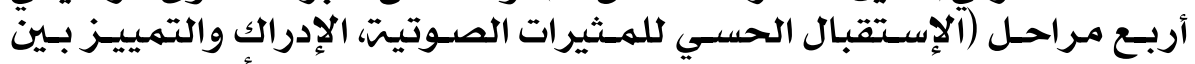

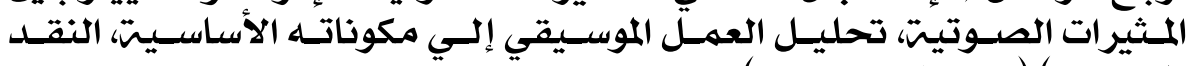

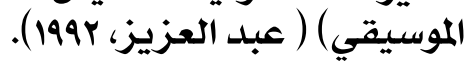
• ثانيا: الفناء

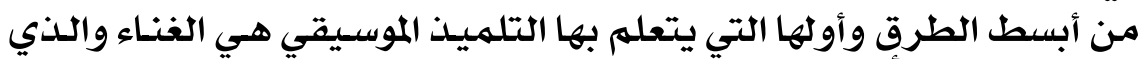

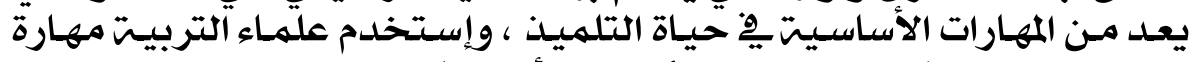

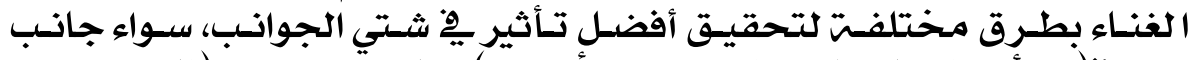

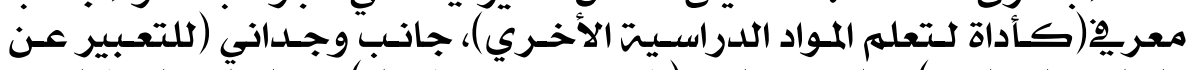

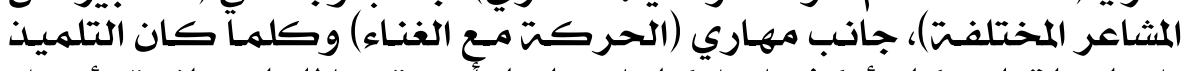

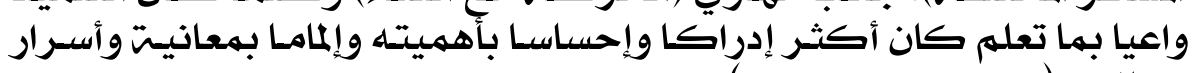

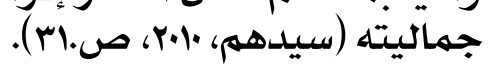

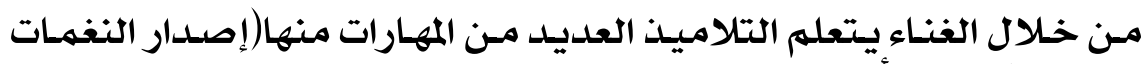

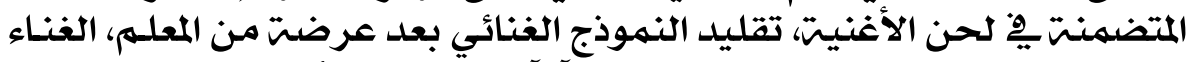

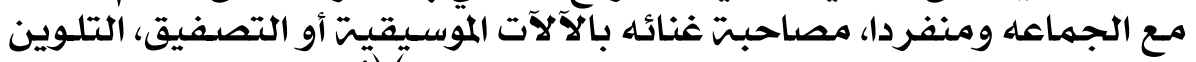

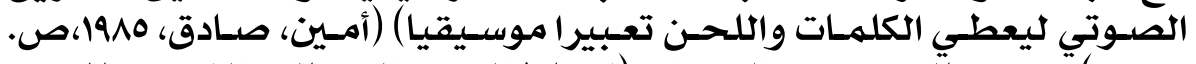

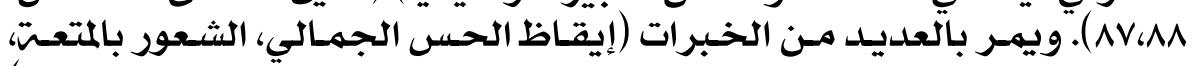

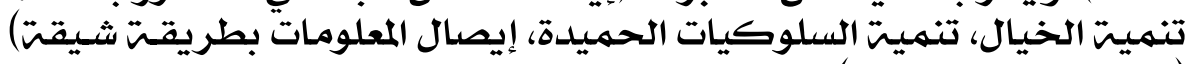

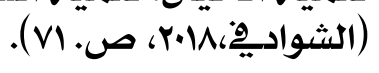

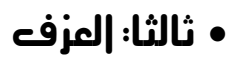

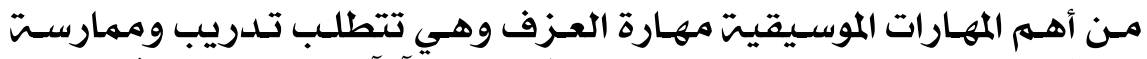

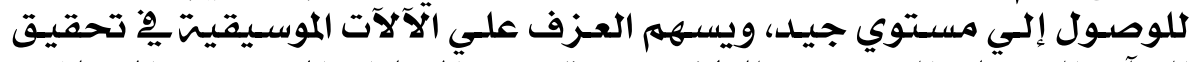

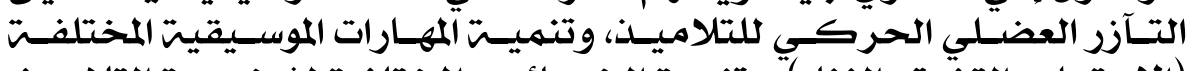

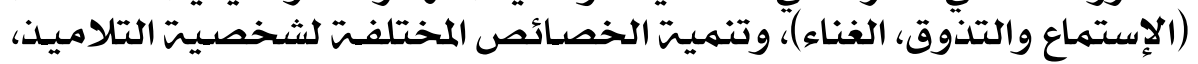

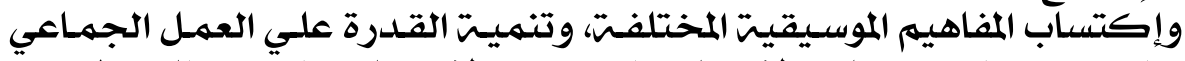

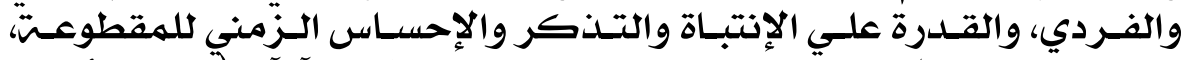

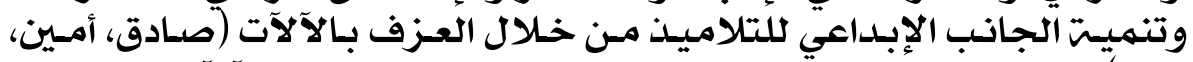

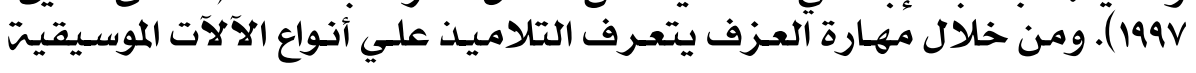




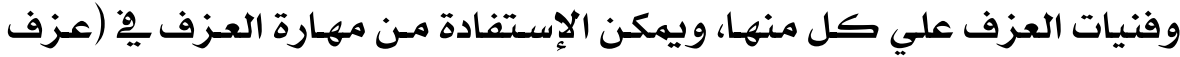

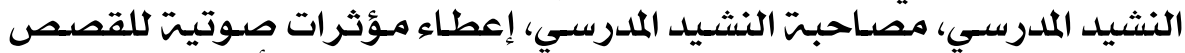

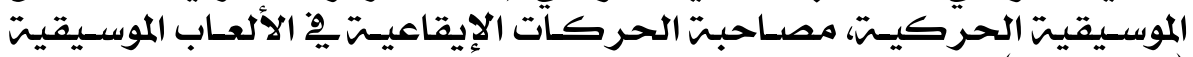

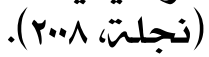

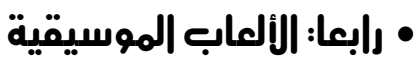

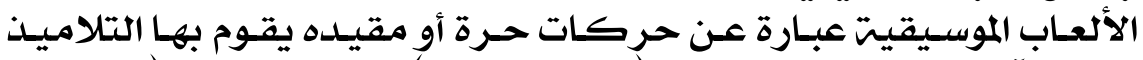

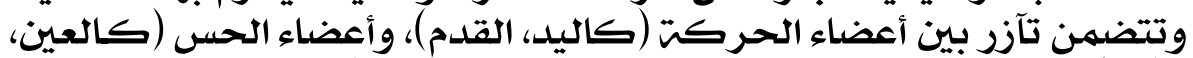

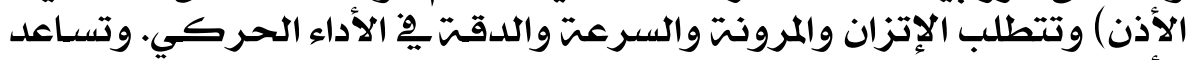

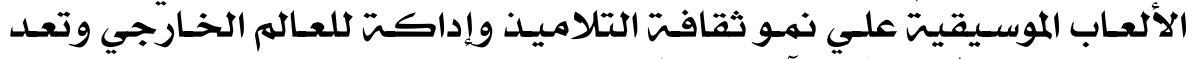

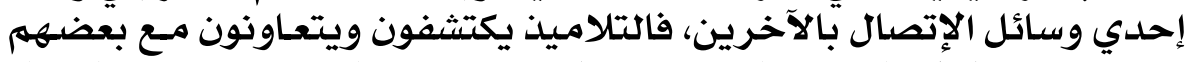

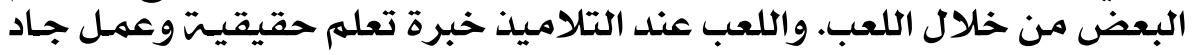

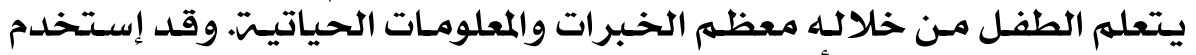

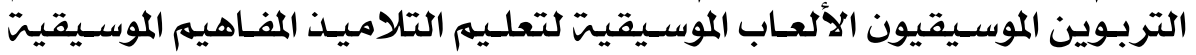

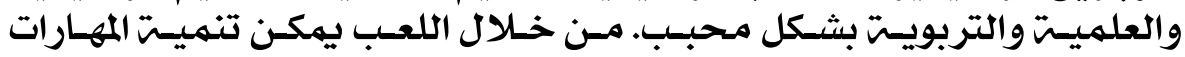

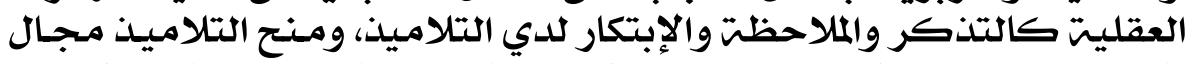

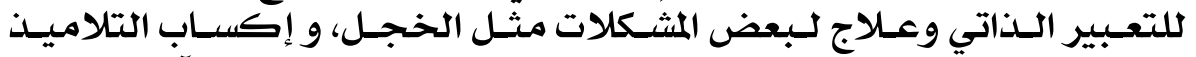

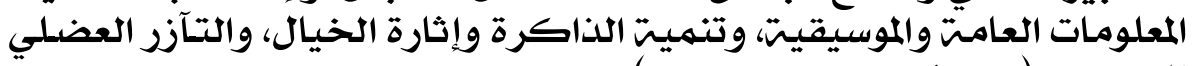

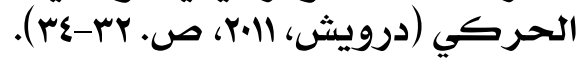

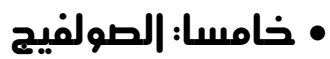

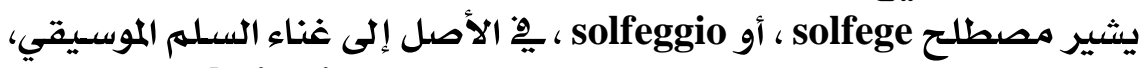

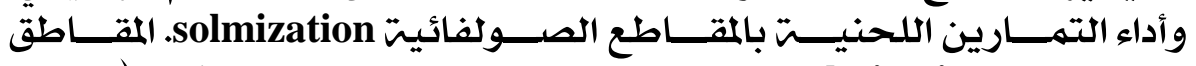

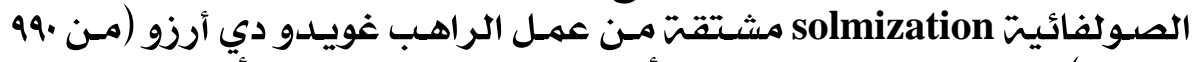

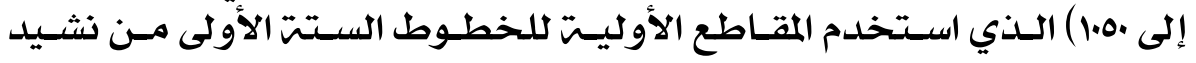

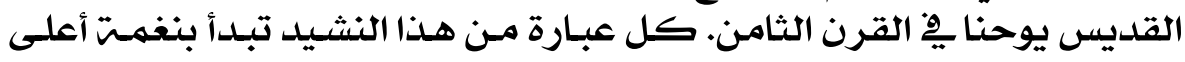

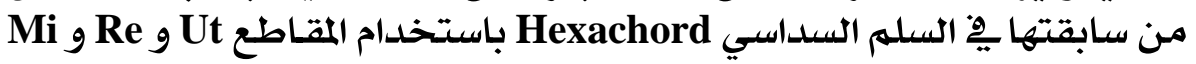

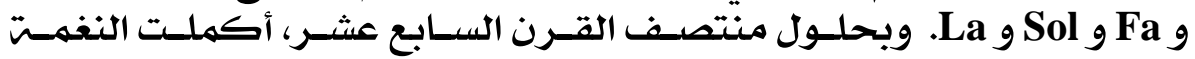

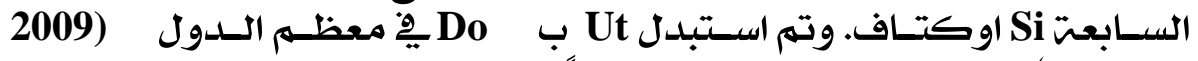

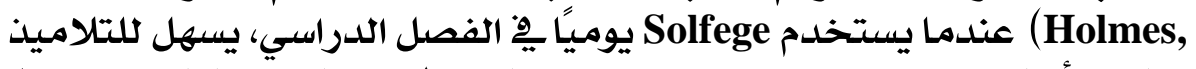

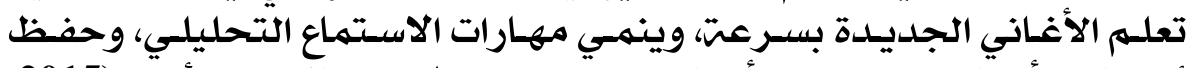

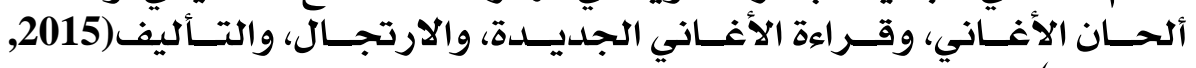
pitch accuracy (Bowyer sight بarbrough, and other, 1991) والكنابت (Reinfinger, 2007) singing

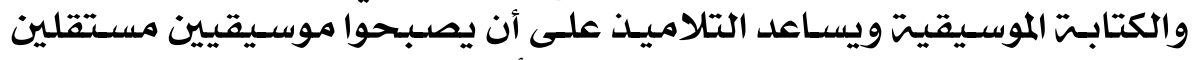

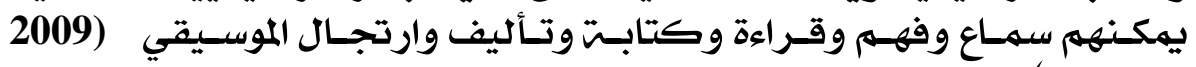

.(Holmes, 


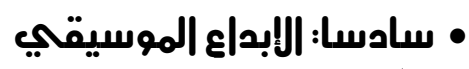

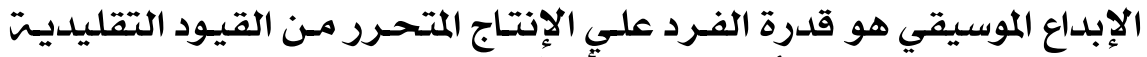

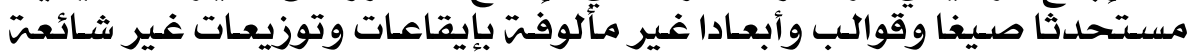

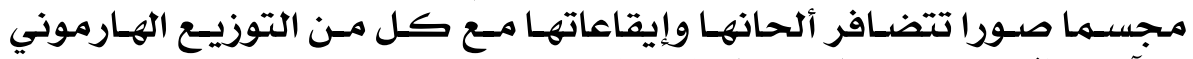

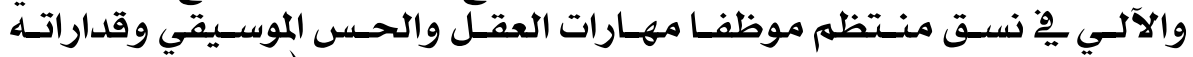

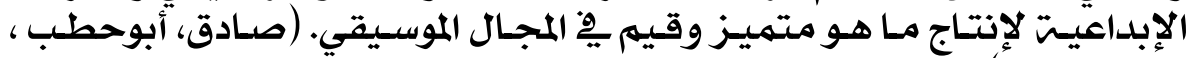

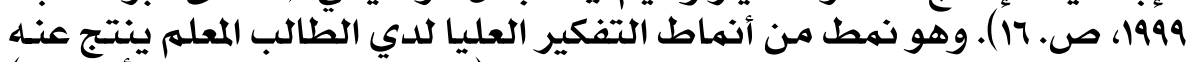

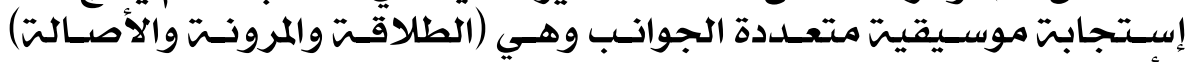

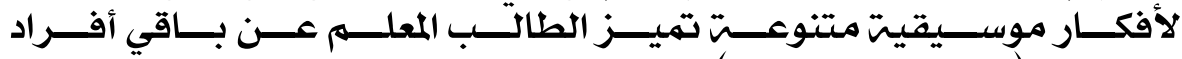

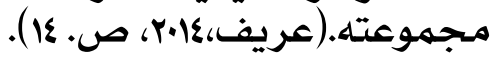

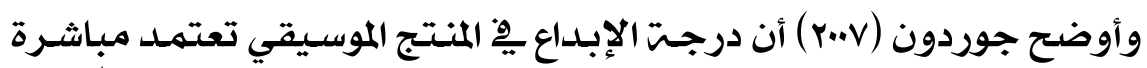

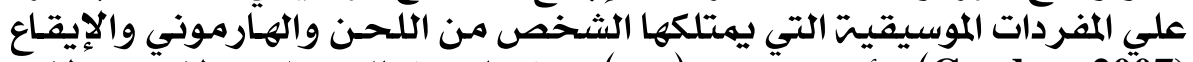

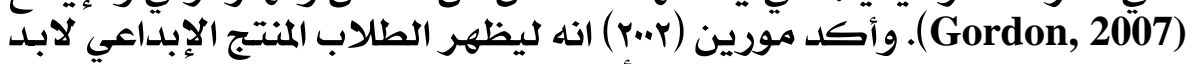

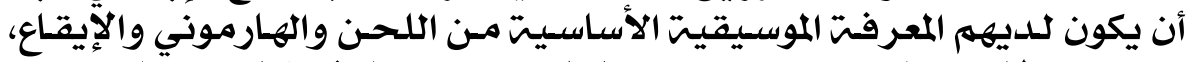

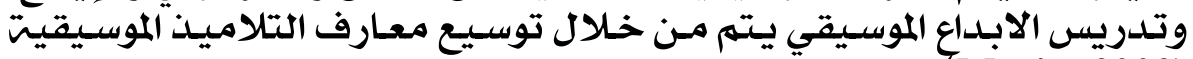
.(Morin, 2002)

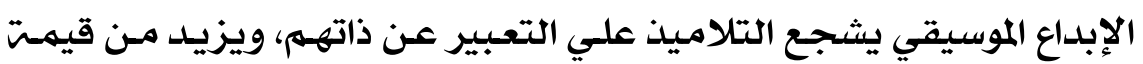

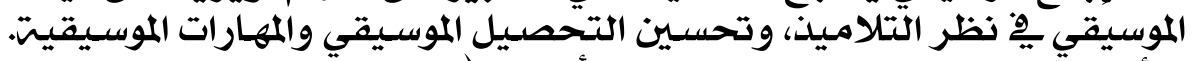

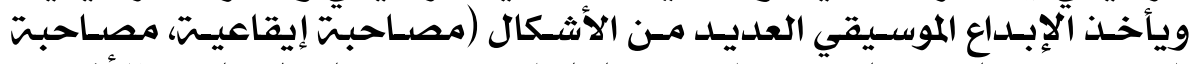

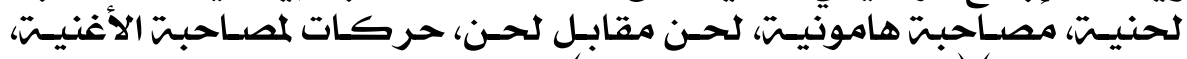

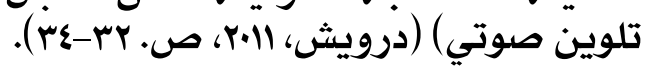

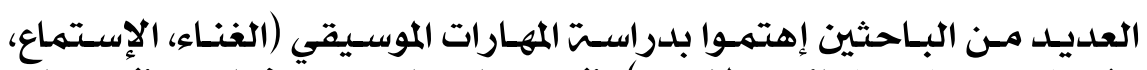

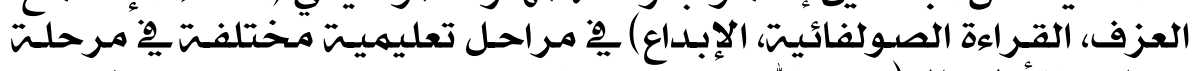

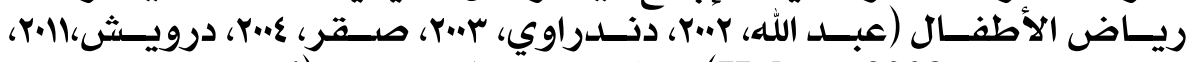

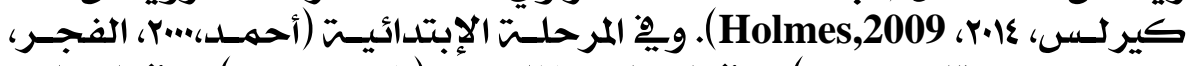

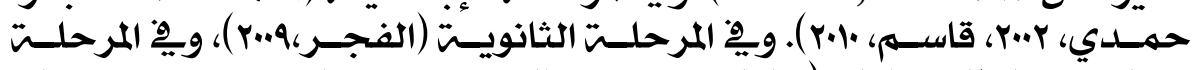

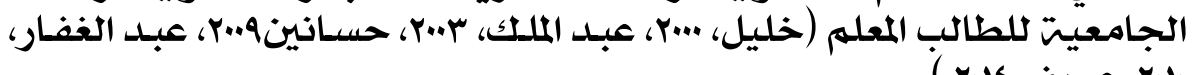

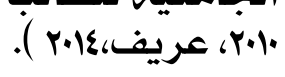

\section{• المر|سة الميد|نية}

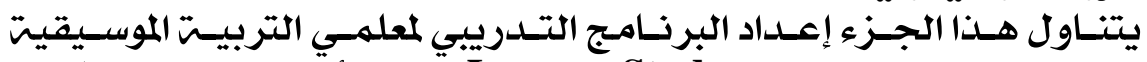

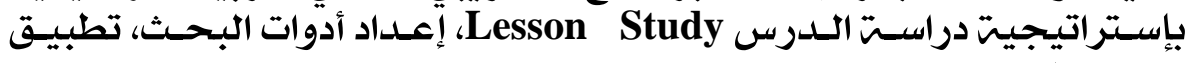
تجربت البحثث.

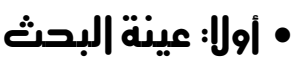

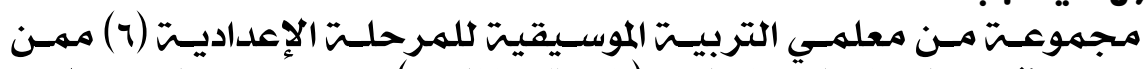

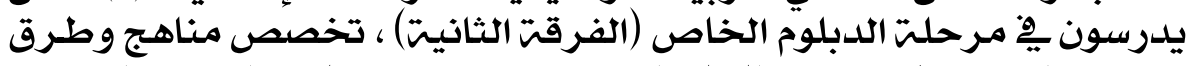

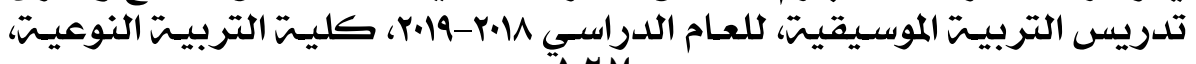




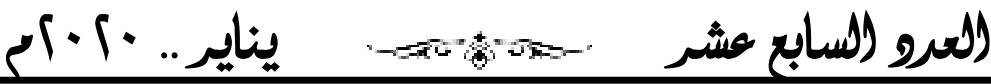

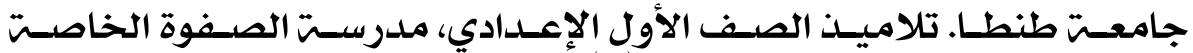

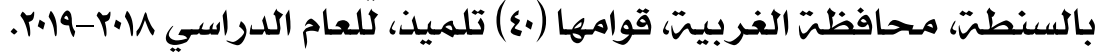

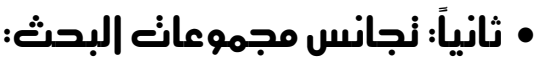

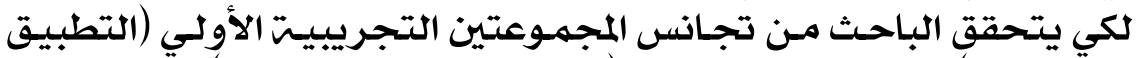

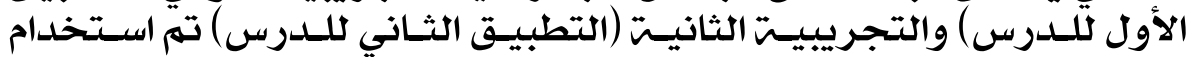

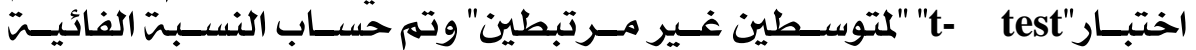

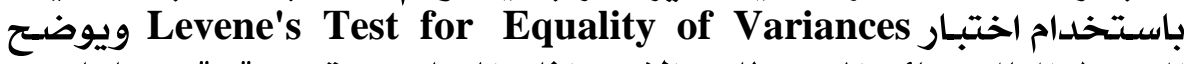
الجدول التالي نتائج المتوسطات والانحرافات المعياريت وقيمشت "ت" كما يلي:

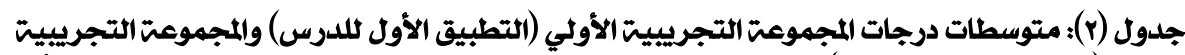

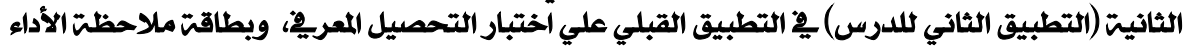

\begin{tabular}{|c|c|c|c|c|c|c|c|c|}
\hline مستوي & قيمت" "ت" & قيمت" & [الحريت & الالحراف & المتوسط & المجموعت & المكون & الاختبار \\
\hline \multirow[b]{2}{*}{ غير دالتً } & \multirow{2}{*}{1.520} & \multirow[t]{2}{*}{3.414} & \multirow{2}{*}{38} & 1.94 & 3.80 & التحريبيت (1) & \multirow[b]{2}{*}{ الدرس الأول } & \multirow{8}{*}{ التحصيل التحبار } \\
\hline & & & & 1.34 & 3.00 & التحريبيت (Y) & & \\
\hline \multirow[b]{2}{*}{ غير دالة } & \multirow{2}{*}{1.213} & \multirow[t]{2}{*}{. 124} & \multirow{2}{*}{38} & 1.31 & 3.60 & التجريبيت (1) & \multirow[b]{2}{*}{ الدرس الثاني } & \\
\hline & & & & 1.29 & 3.10 & التجريبيت (Y) & & \\
\hline \multirow[b]{2}{*}{ غير دالة } & \multirow[b]{2}{*}{.369} & \multirow[t]{2}{*}{.031} & \multirow{2}{*}{38} & 1.32 & 2.95 & التجريبية (1) & \multirow[b]{2}{*}{ الدرس الثالث } & \\
\hline & & & & 1.25 & 3.10 & التجريبيت (r) & & \\
\hline \multirow[b]{2}{*}{ غير دالة } & \multirow[b]{2}{*}{1.079} & \multirow[b]{2}{*}{4.014} & \multirow{2}{*}{38} & 4.09 & 10.35 & التجريبيت (1) & \multirow{2}{*}{ المعتبار التحصيل) (ككل) } & \\
\hline & & & & 2.44 & 9.20 & التجريبيت (Y) & & \\
\hline \multirow{2}{*}{ غير دالة } & \multirow[t]{2}{*}{1.633} & \multirow[t]{2}{*}{.024} & \multirow{2}{*}{38} & 0.76 & 5.50 & التجريبيت (1) & \multirow{2}{*}{ القفلات } & \multirow{8}{*}{ ملاحطظت } \\
\hline & & & & 0.79 & 5.90 & التجريبيت (r) & & \\
\hline \multirow{2}{*}{ غير دالة } & \multirow[t]{2}{*}{1.080} & \multirow[t]{2}{*}{.758} & \multirow{2}{*}{38} & 0.75 & 4.65 & التجريبيت (1) & \multirow{2}{*}{ الإلعالامية } & \\
\hline & & & & 0.72 & 4.90 & التجريبيت (r) & & \\
\hline \multirow[b]{2}{*}{ غير دالة } & \multirow[t]{2}{*}{.406} & \multirow[t]{2}{*}{.006} & \multirow{2}{*}{38} & 0.79 & 4.90 & التجريبيت (1) & & \\
\hline & & & & 0.77 & 4.80 & التجريبيت (r) & أتظليل & \\
\hline & 1.552 & .025 & 38 & 1.23 & 15.05 & التجريييت(1) & بطاقت الملاحطت & \\
\hline عير دالس & & & & 0.99 & 15.60 & التجريييت (v) & (كل) & \\
\hline
\end{tabular}

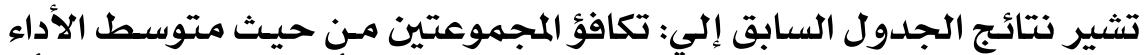

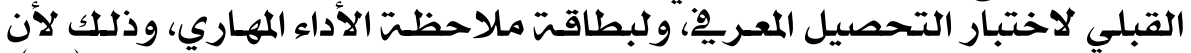

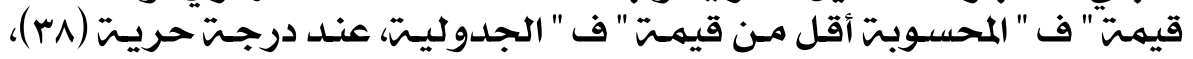

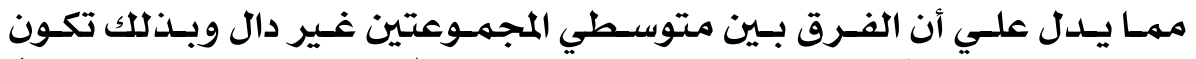

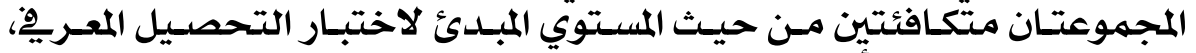

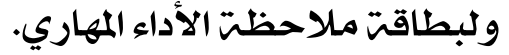

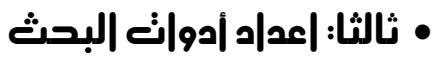

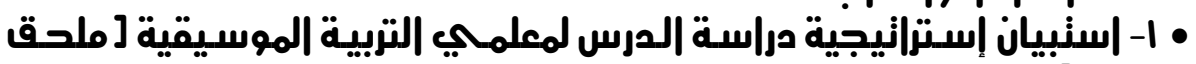

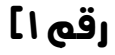

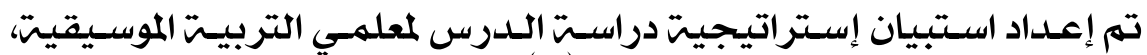

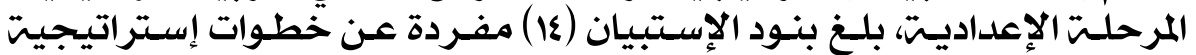

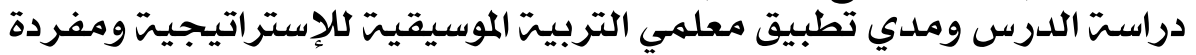

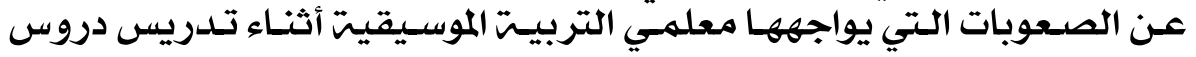




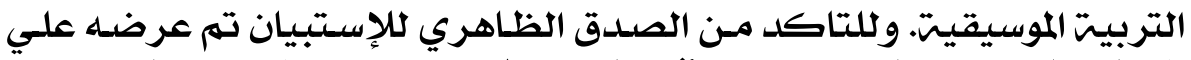

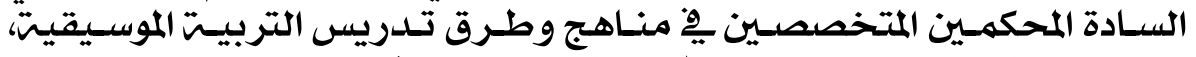

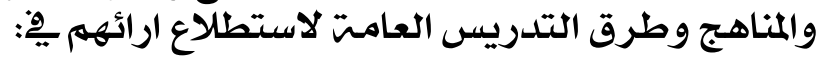

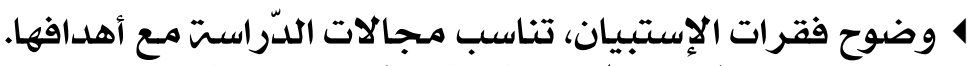

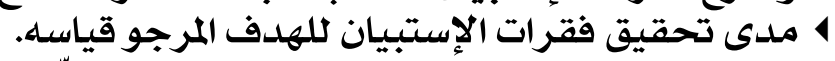

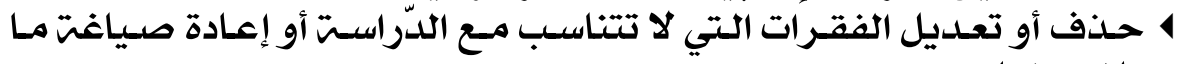
يلزم منها. 4 اقتتراح ما يلزم منها. إضافته من فقرات تُحقّق الهدف المرجو قياسـه.

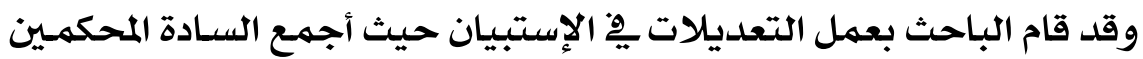

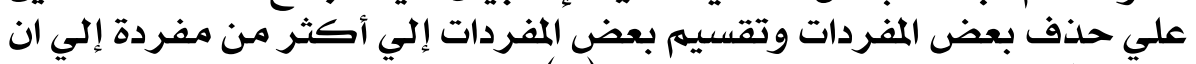

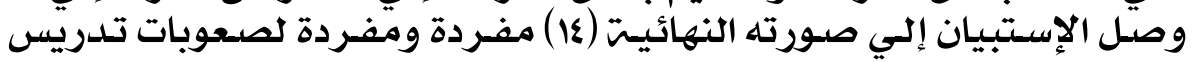
التربيت الموسيقيت.

جدول (r): تضمنت مجمومت المحكمين

\begin{tabular}{|c|c|}
\hline أستاذ مناهج وطرق تدريس التربيتًا الموسيقيته كليت التربيتً) جامعت حلوان. & أ.د/ محمد حيدر اليماني \\
\hline أستاذ مناهج وطرق تدريس التربيت الموسيقيت المتفرغ، كليت التربيتَ) جامعتَحلوان. & أ.د/ مانيرفا امين \\
\hline أستاذ مناهج وطرق تدريس التربيتا الموسيقيتش كليت التربيتا جامعتح حلوان. & أ.د أدسين عبد الرحمن \\
\hline أستاذ مناهج وطرق تدريس التربيت الموسيقيتش كليت التربيت النوعيش، جامعت عين شمس. & أ.د/ عنايات خليل \\
\hline أستاذ مناهج وطرق تدريس اللغتَا الفرنسيت، كليتة التربيتخ جامعت طنطا. & 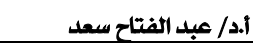 \\
\hline أستاذ مناهج وطرق تدريس المواد التجاريتئ كليت التربيتئ جامعت طنطا. & | ا. ا.د/ فاتن فودة \\
\hline أستاذ المناهج وطرق تدريس الرياضيات المساعد، كليتًالتربيتَ) جامعت طنطا & أ. أد/ ياسر عبد الرحيم \\
\hline 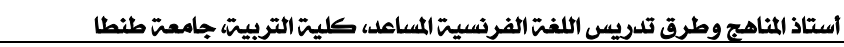 & إ. ا.م.د/ شعبان عبد الغني \\
\hline
\end{tabular}

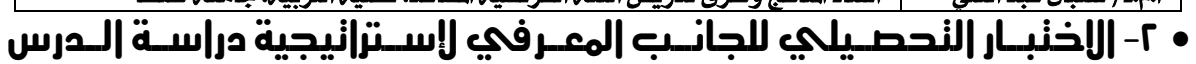

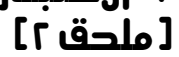

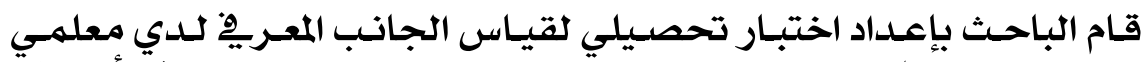

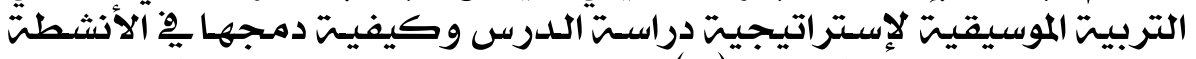

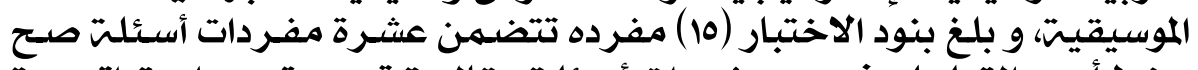

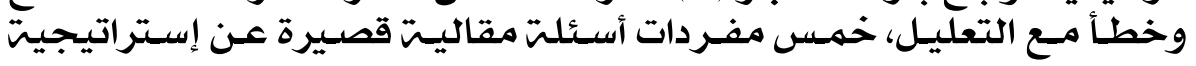
دراست الدرسم التعليـا

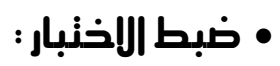

تم ضبط الاختبار من خلالال عمليتى قياس الصدق والثبات كما يلى :

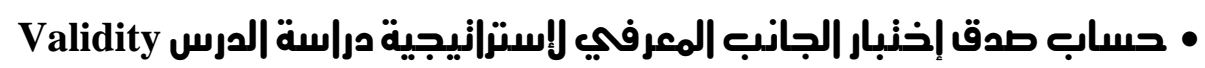

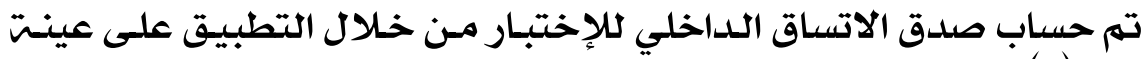

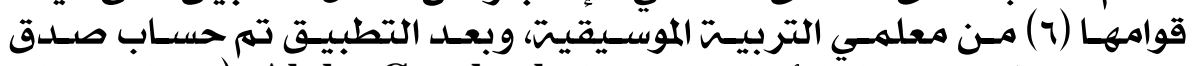

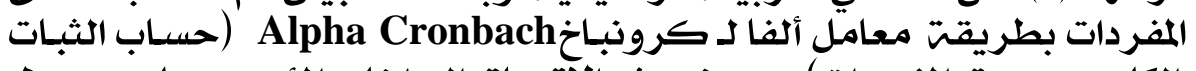

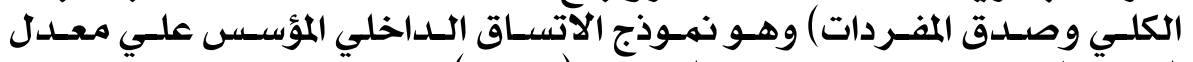

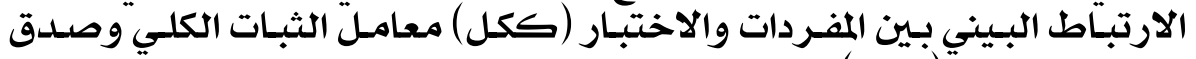

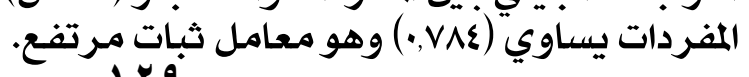

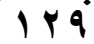




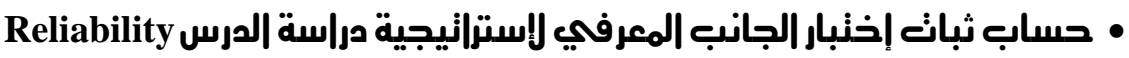

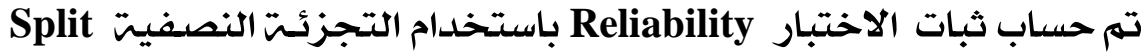
إلمي - Half

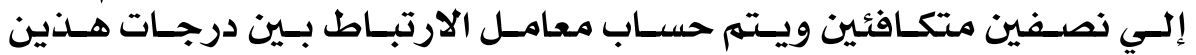

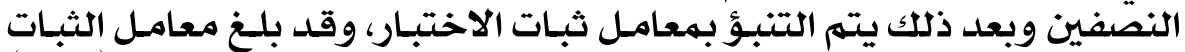

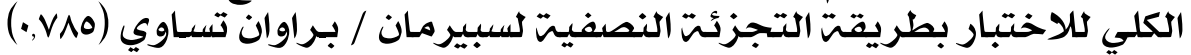

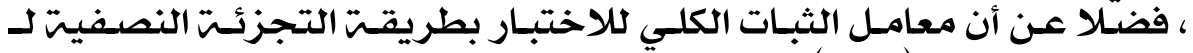

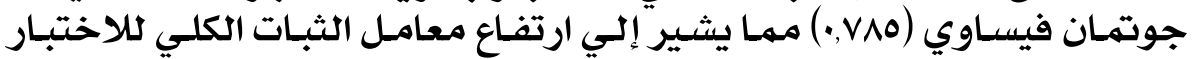
ككل.

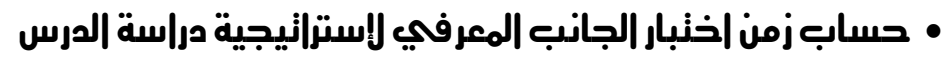

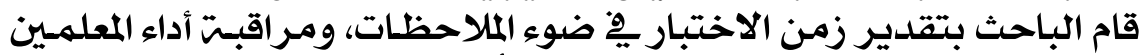

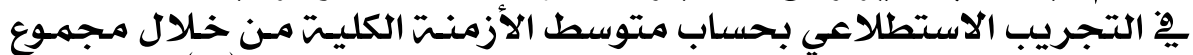

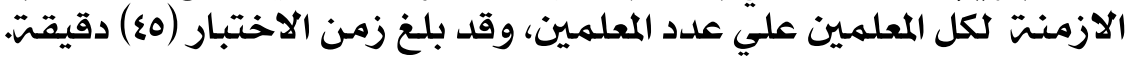

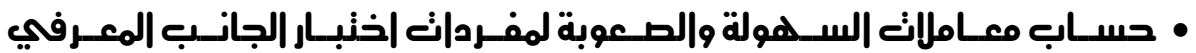

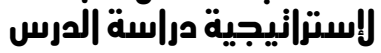

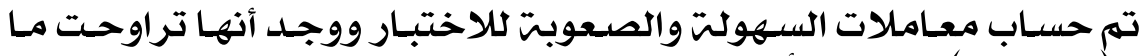

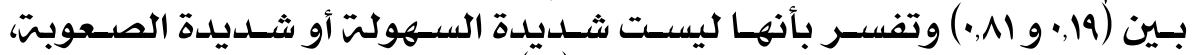

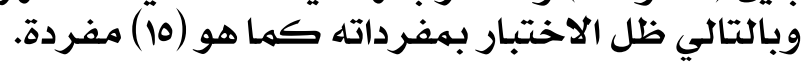

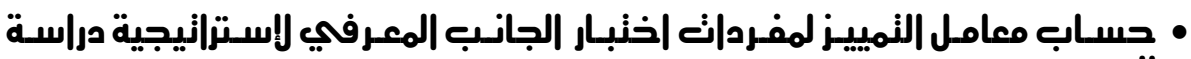

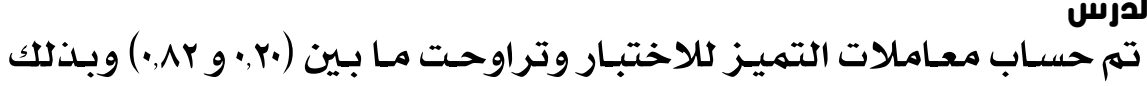
تعتبر مفردات الاختبار ذات قدرة مناسبت التهيت للتمييز.

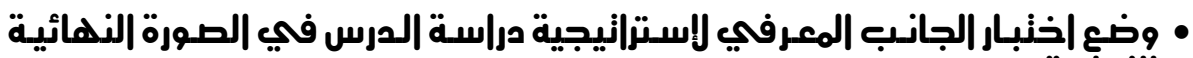
للنطبيق

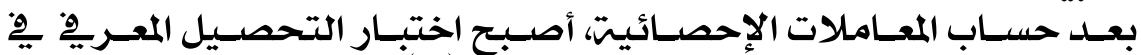

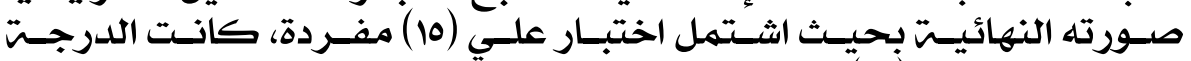

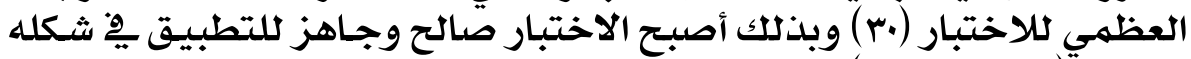

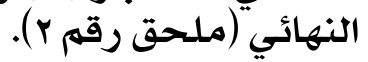

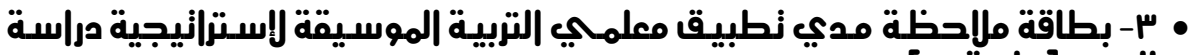
الصرس [ملحق مله

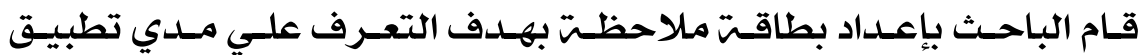

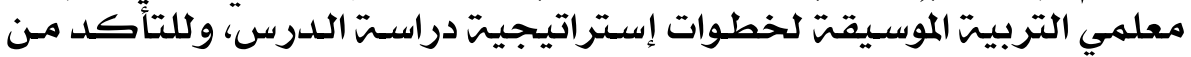

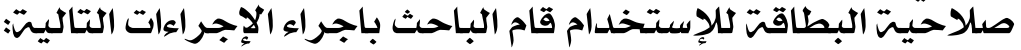

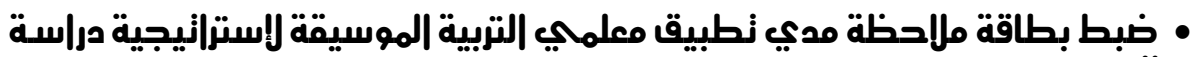
الصرس:

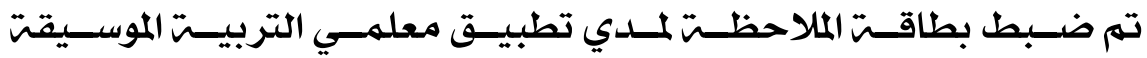

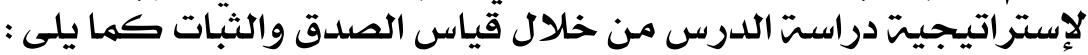




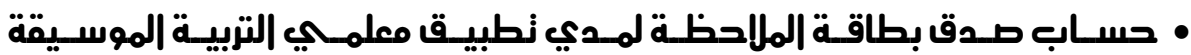
لإستر|نيجية در|سة الصرساب:

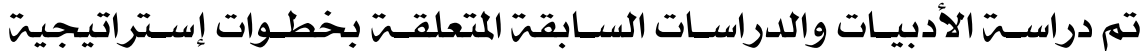

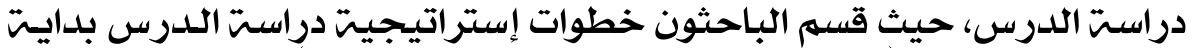

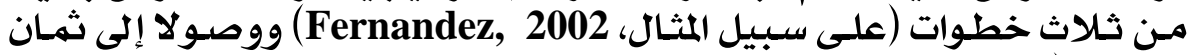
خطوات(على سبيل المثال،

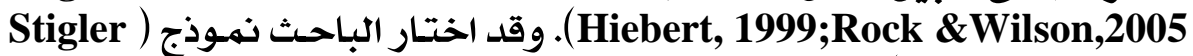

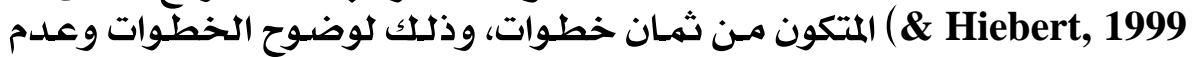

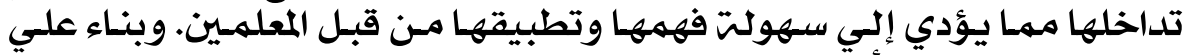

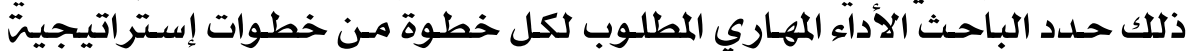

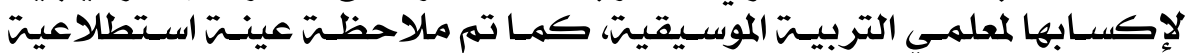

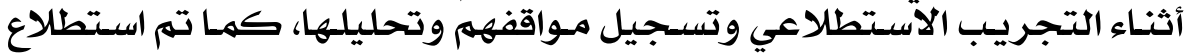

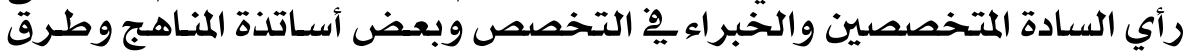

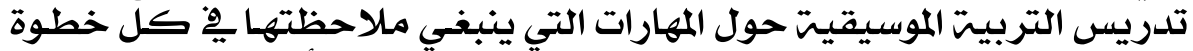

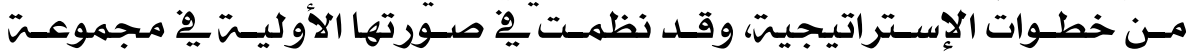

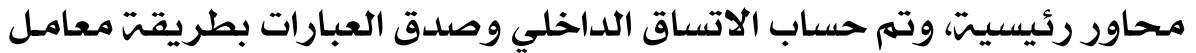

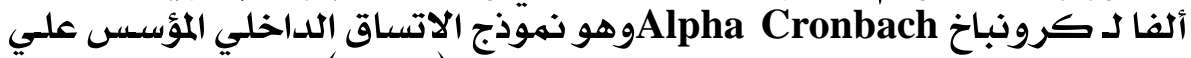

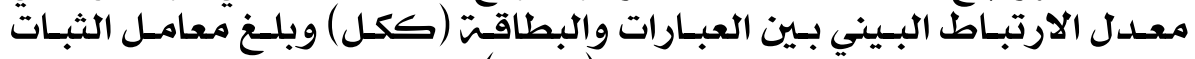

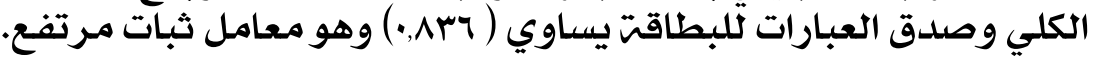

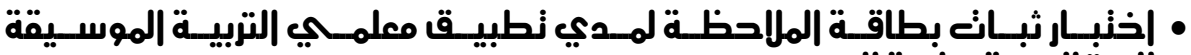

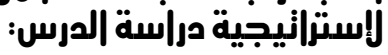

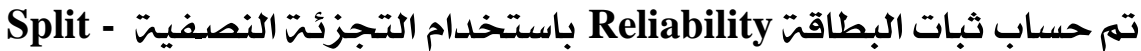

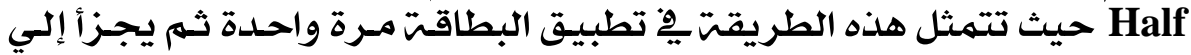

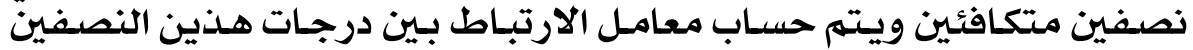

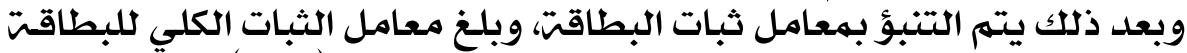

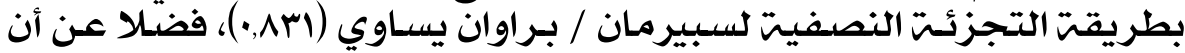

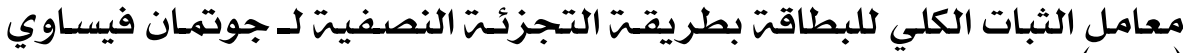

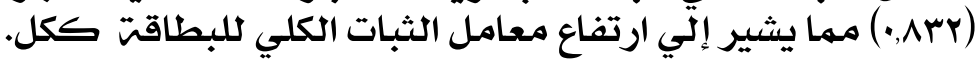

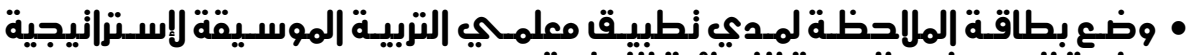

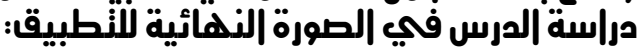

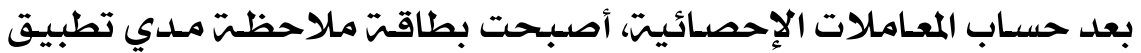

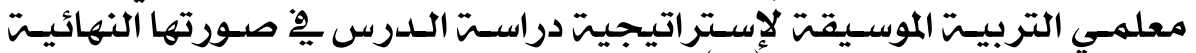

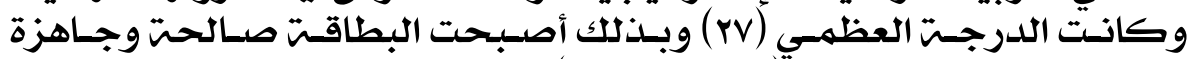

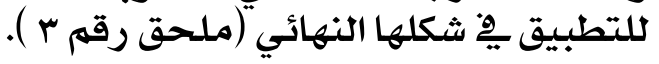

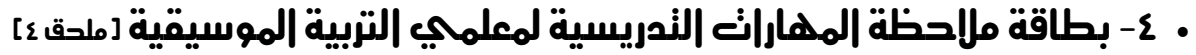

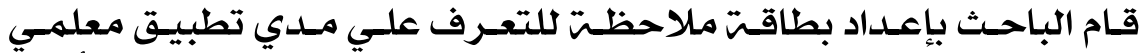

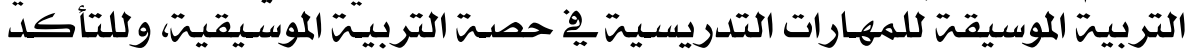

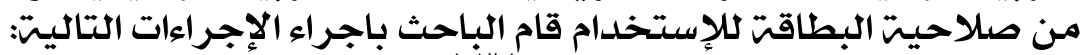

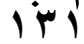


• ضبط بطاقة ملاحظة الهمار|نه الندريسية لمعلمي التزبية الموسيقية:

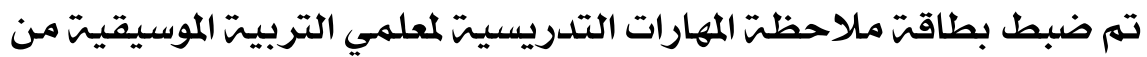

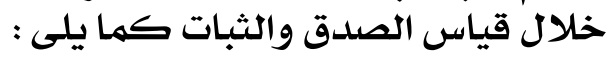

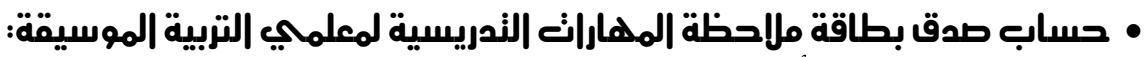

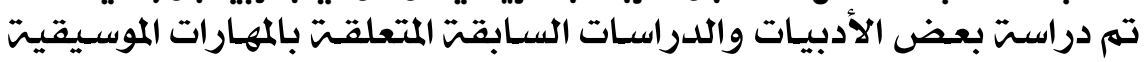

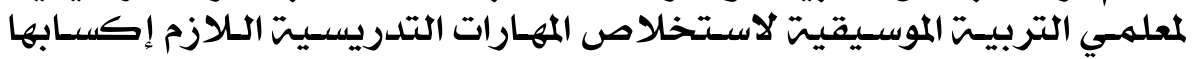

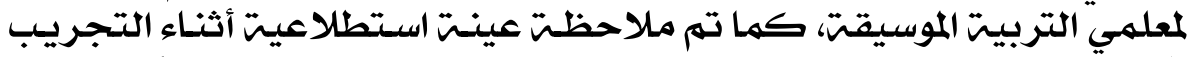

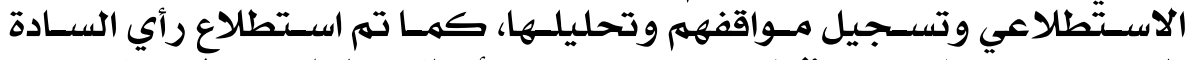

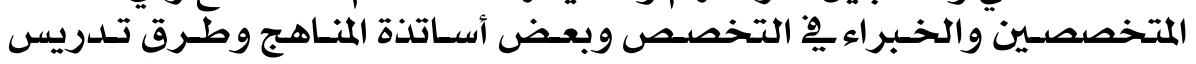

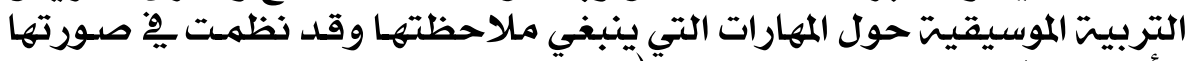

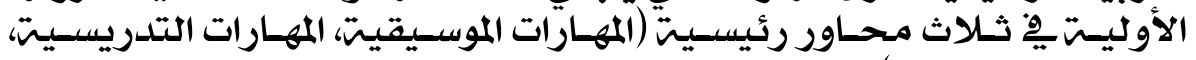

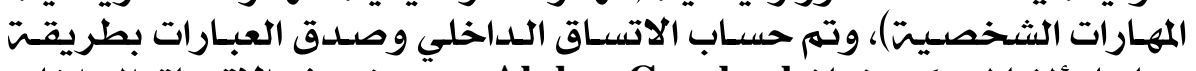

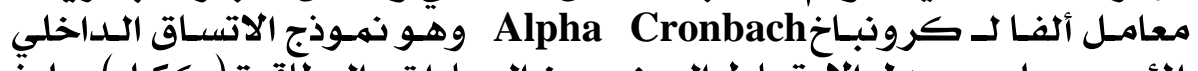

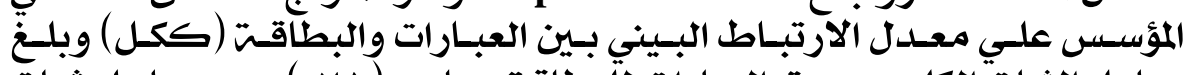

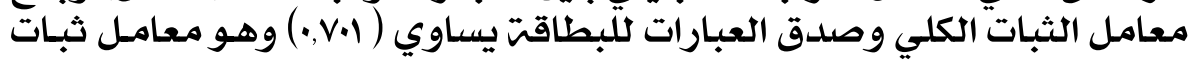
مرتفع.

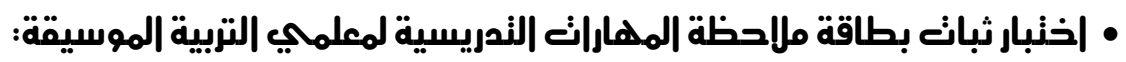

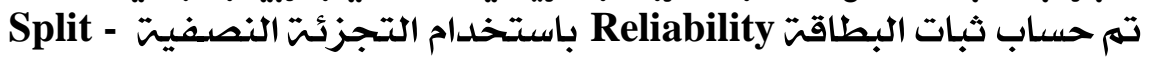

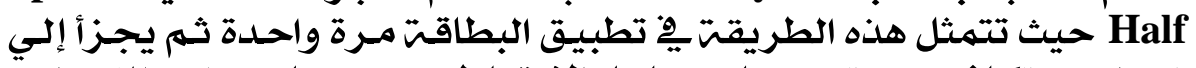

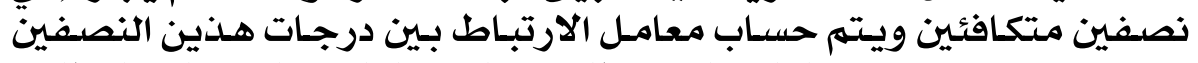

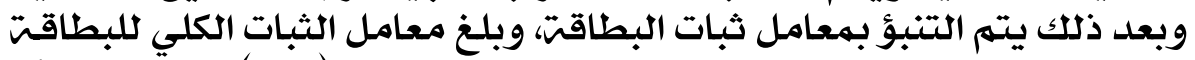

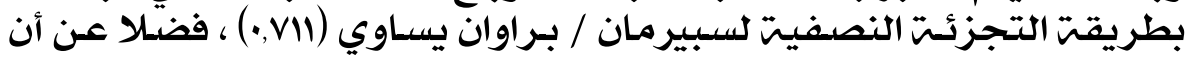

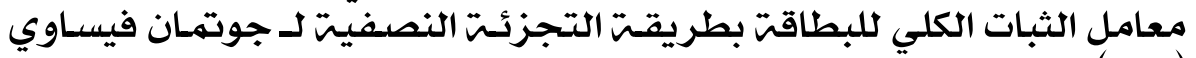

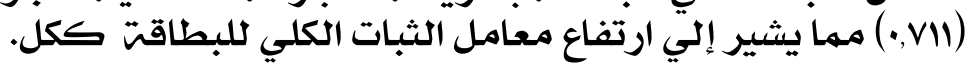

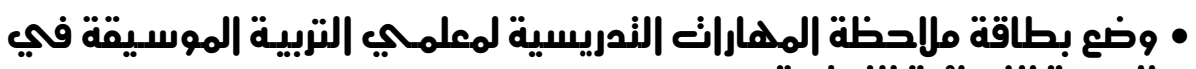

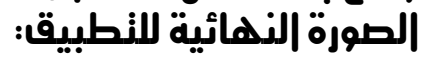

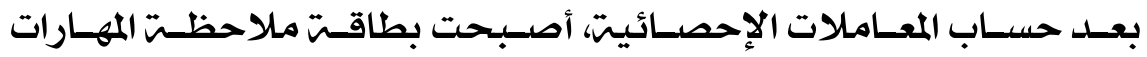

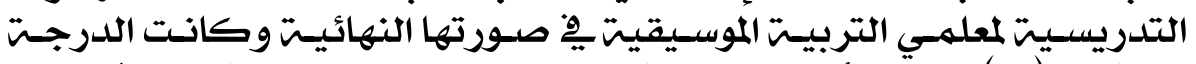

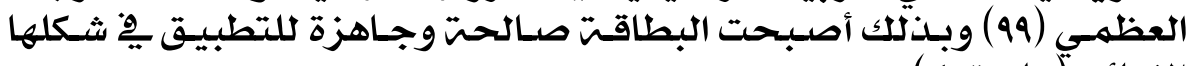

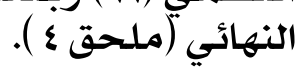

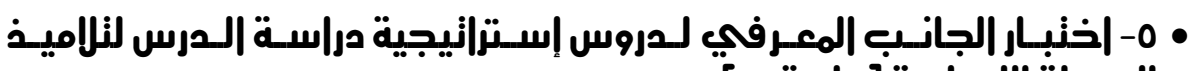

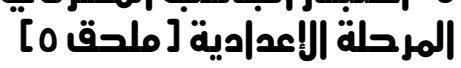

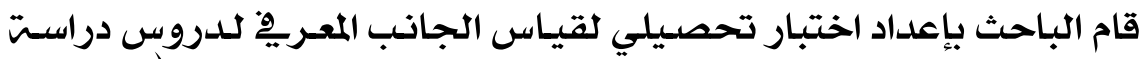

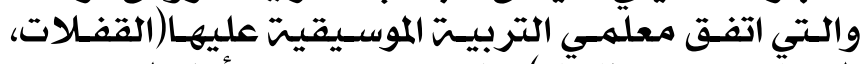

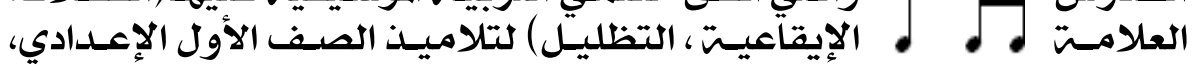

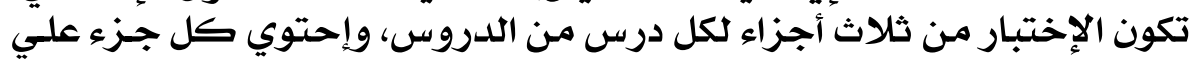




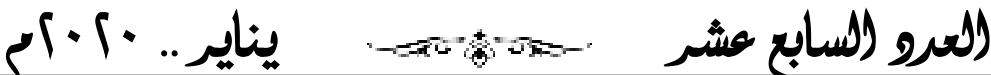

أسئلتة إختيار من متعدد، صح وخطأ، تمارين لحنيتة، تمارين إيقاعيت.

تم ضبط الاختبار من خلال عمليتى قياس الصدق والثبات كهما يلى :

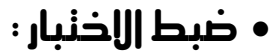

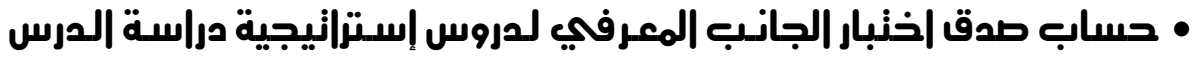

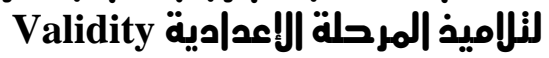

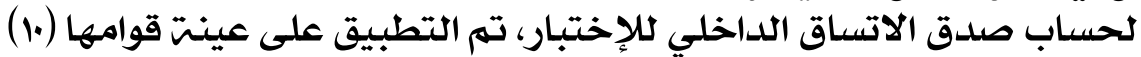

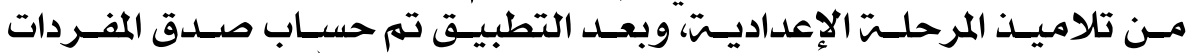

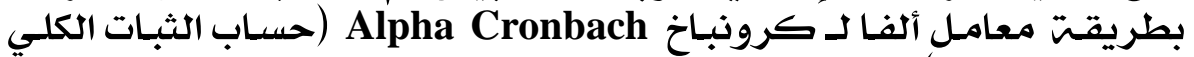

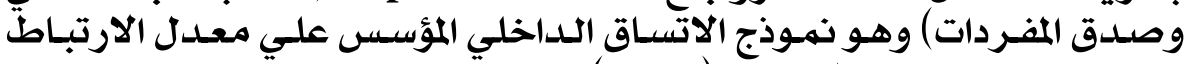

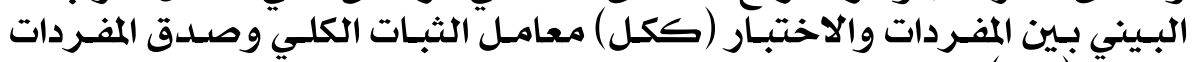

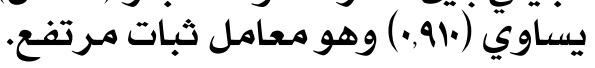
• حساب ثبانه |خنبار الجانب المعرفي لمرئ لمروس إستر|نيجية دراسة الدرس النلاميذابلمرحلة الإعد|دية Realality

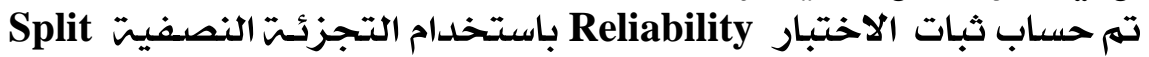

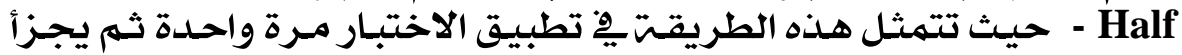

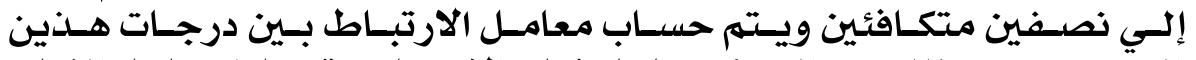

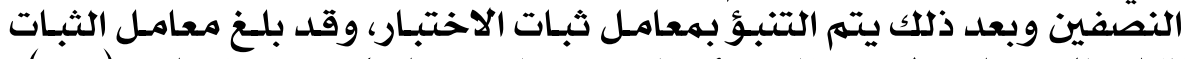

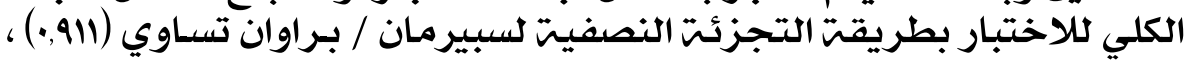

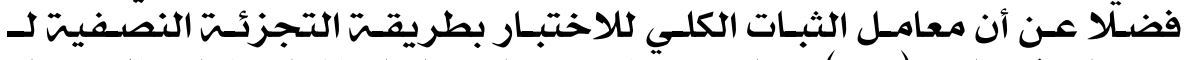

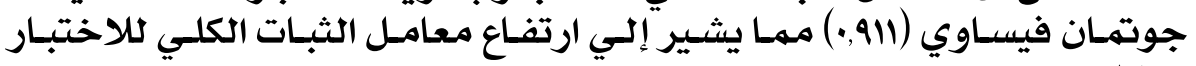

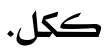
• حساب زمـناخنبار الجانب المعرفي لدروس إستر|نيجية دراسة الصرس لنالميف المرحلة الإنعد|دية

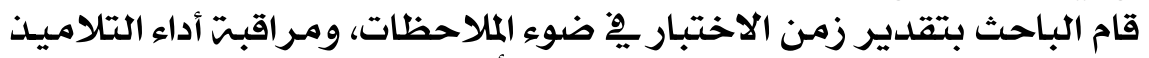

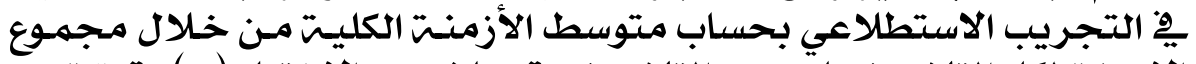

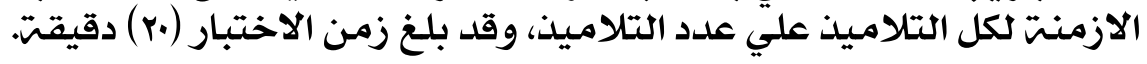

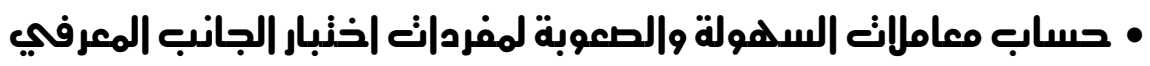

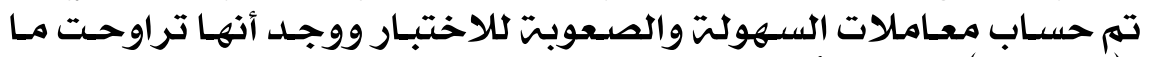

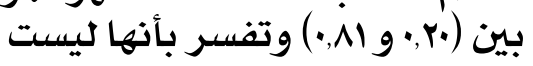

شديدة السهولتة أو شديدة الصعوبتة، وبالتالي ظل الاختبـار بمفرداته كهما هو (.7) مفردة.

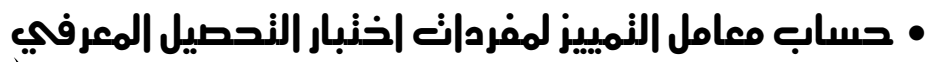

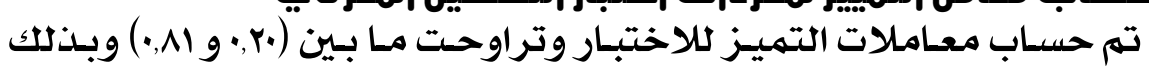
تعتبر مفردات الاختبار ذات قدرة مناسبت للمييز. 


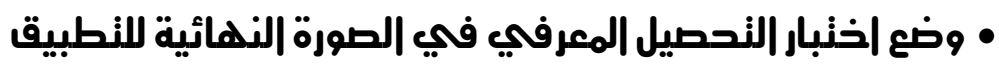

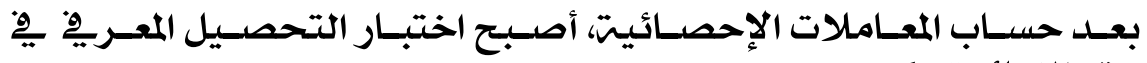

صورته النهائيت مكون من:

\begin{tabular}{|c|c|c|}
\hline \multicolumn{3}{|c|}{ النهاءيت لإختبار التحصيل } \\
\hline الدرجت العظمي & علدد المفردات & 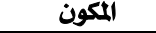 \\
\hline$r$ & $r \cdot$ & الدرس الأول \\
\hline r. & r. & الدرس الثاني \\
\hline$\mu_{*}$ & $p_{*}$ & اللدرس الثالثة \\
\hline
\end{tabular}

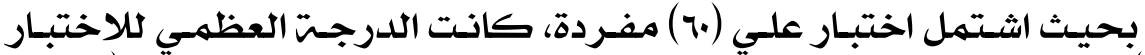

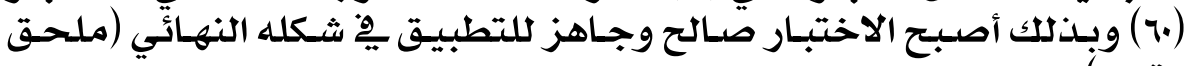
رقمى 0).

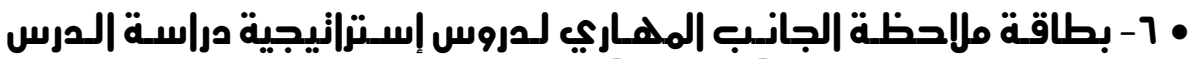

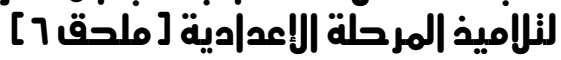

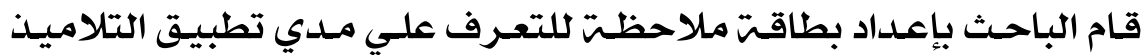

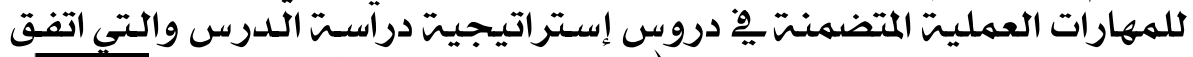

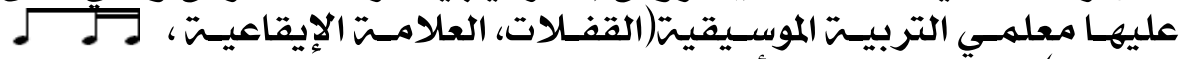

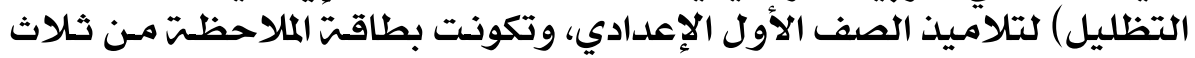

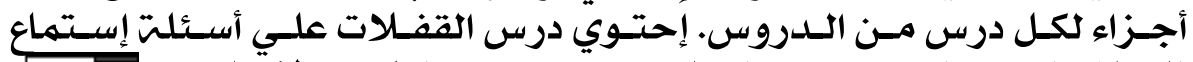

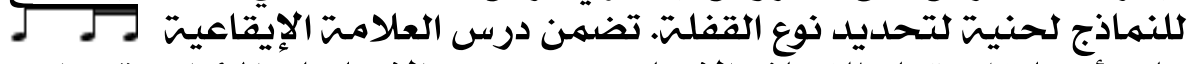

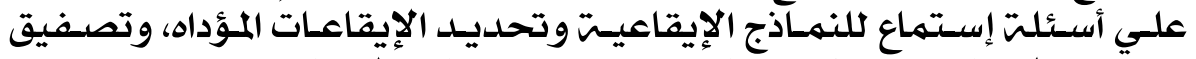

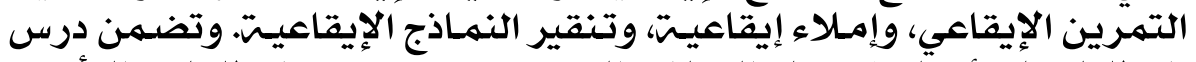

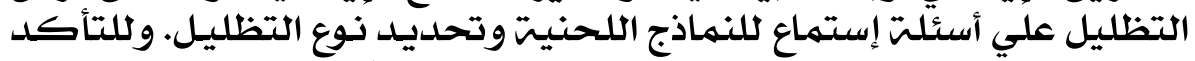

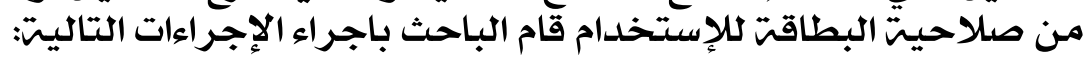

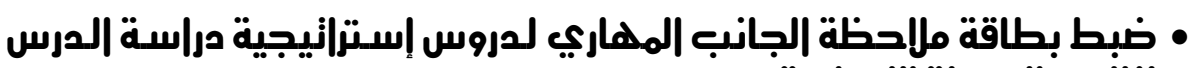

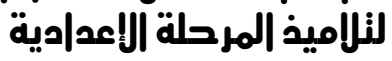

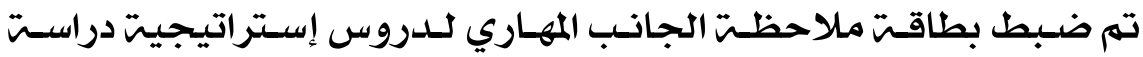

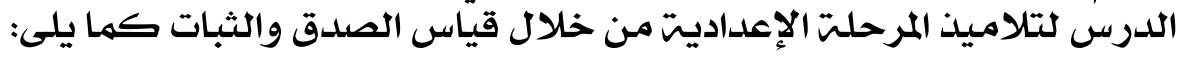
• حسابع صدق بطاقة ملاحظة الجانب المهاريب لدروس إستر|نيجية دراسة الإنة

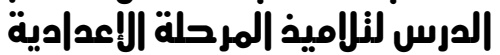

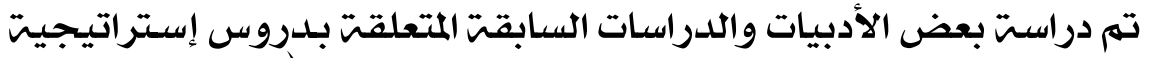

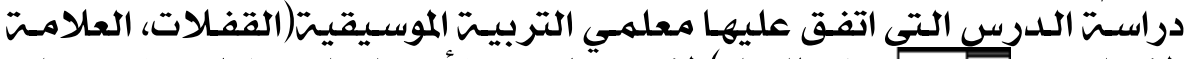

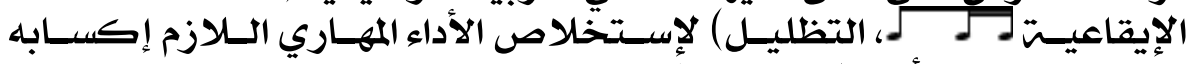

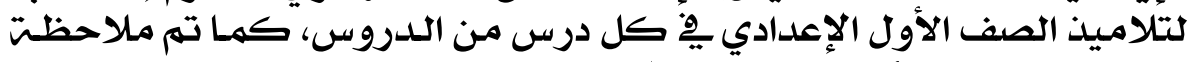

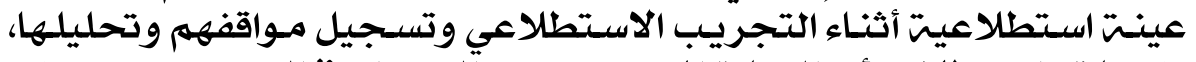

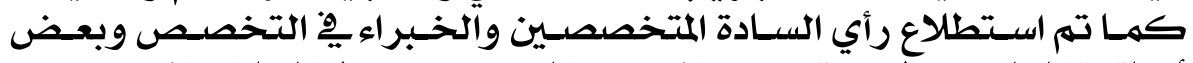

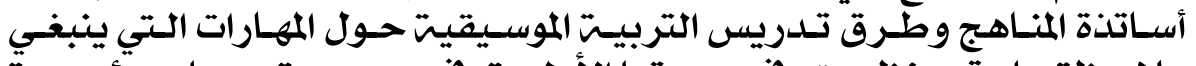

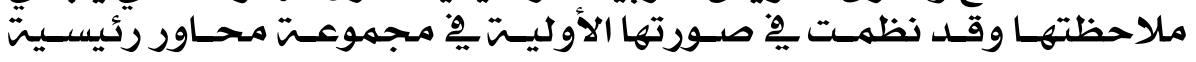




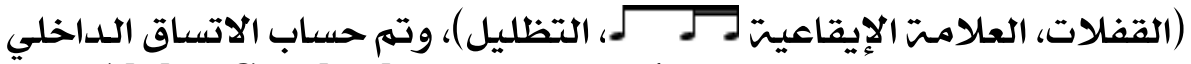

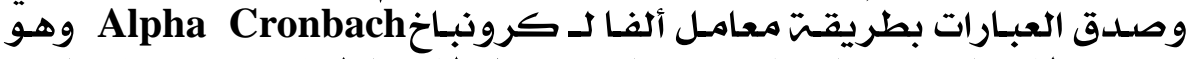

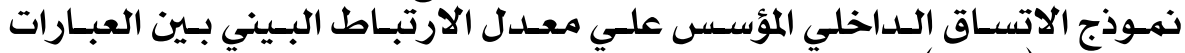

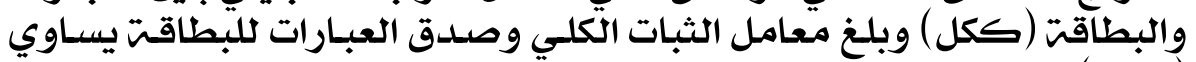

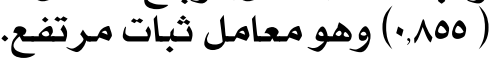

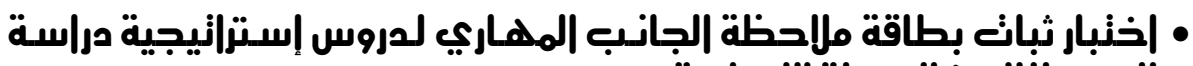
المرس لنزإميذ المرحلة الإعد|دية.

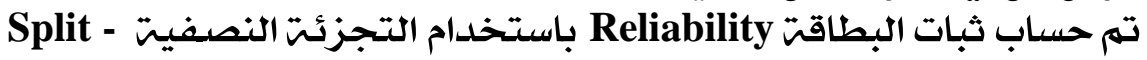

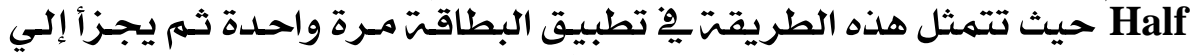

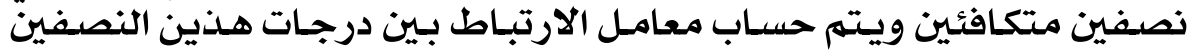

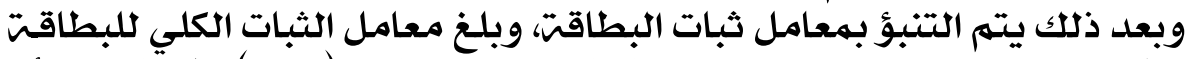

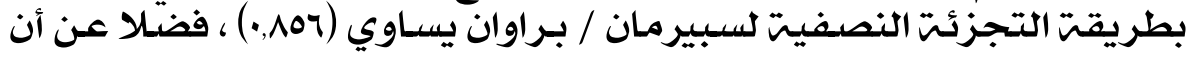

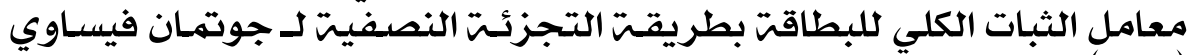

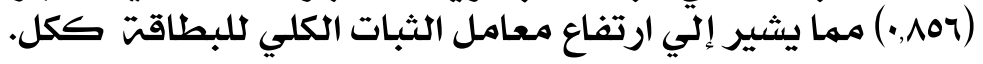

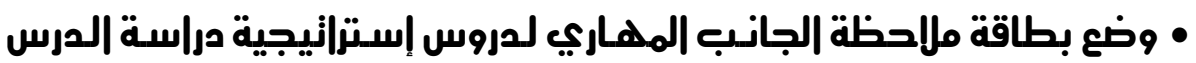

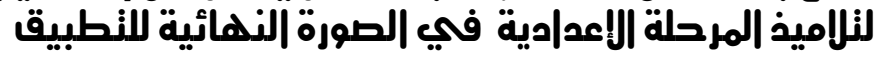

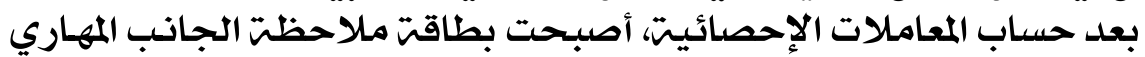

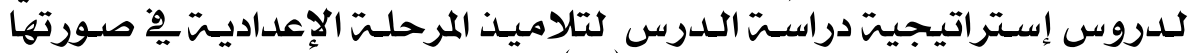

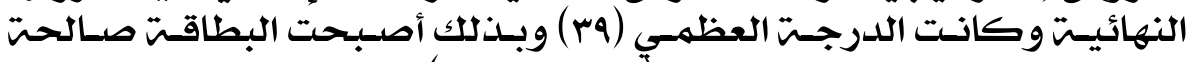

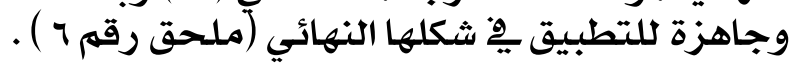

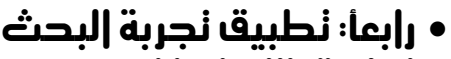 • ن ن نطبيق الإسنبيان:}

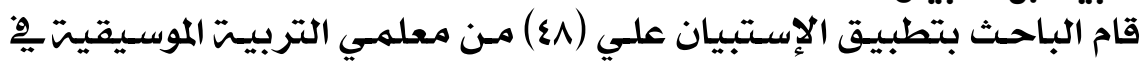

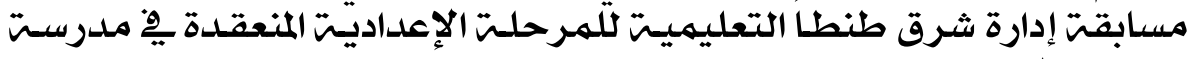

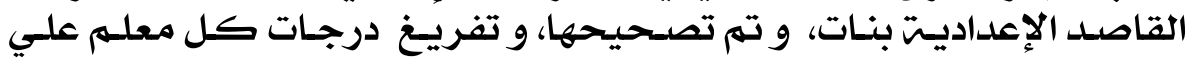
حلده. • نطبيق أدوانه البحث قبليا:

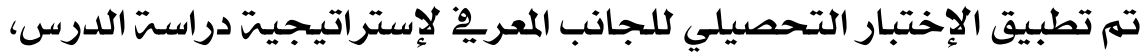

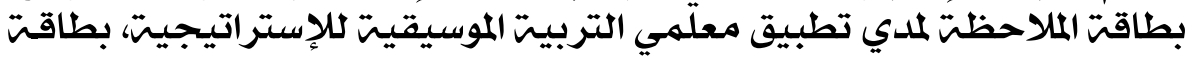

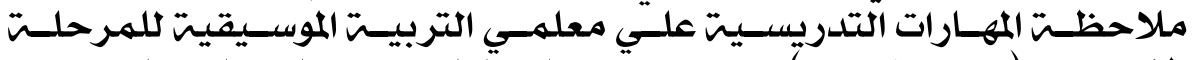

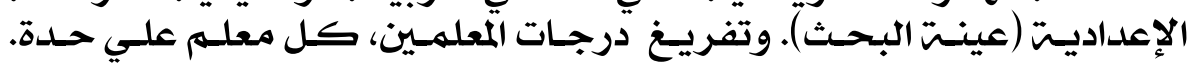

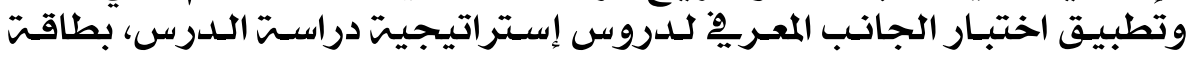

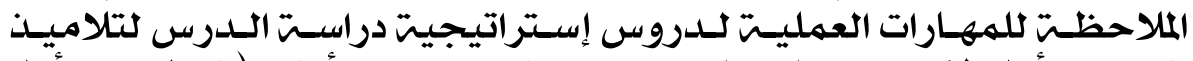

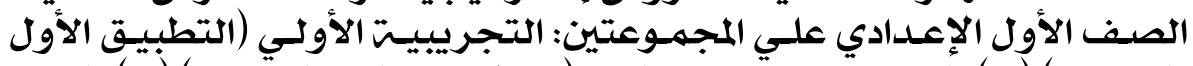

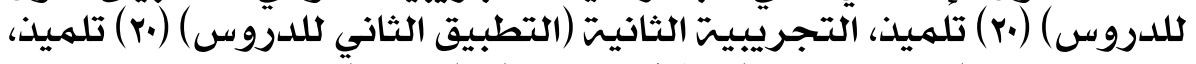

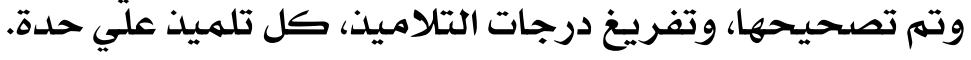




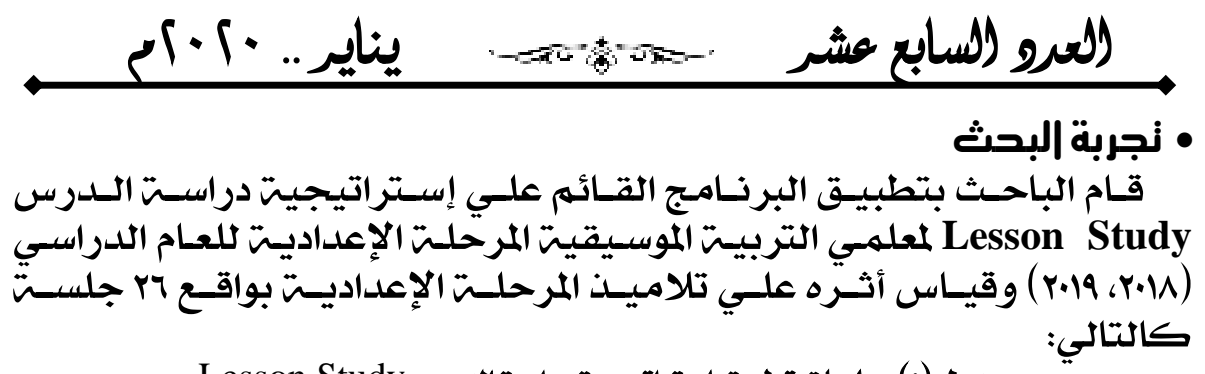

\begin{tabular}{|c|c|}
\hline \multicolumn{2}{|l|}{ 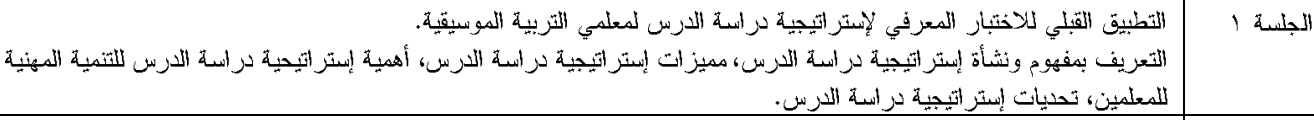 } \\
\hline مثاقثة خطو ات إستر اثيجية دراسـة اللزس: & | الجلسة r \\
\hline الخطوة الأولى: تحديد المشكلات والأهداف. & \\
\hline 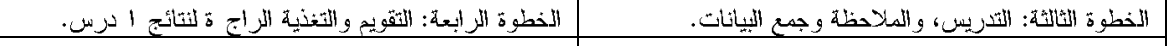 & \\
\hline الخطوة السادسة: التثريس و المدلاحظة للذرس المعدل. & \\
\hline الخطوة المسابعة: الاثقويم والثيذية اللر اجعة للارس المعدل. & \\
\hline 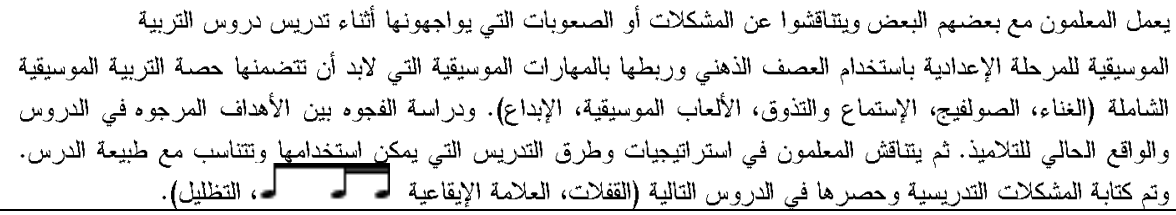 & الجلسة با \\
\hline 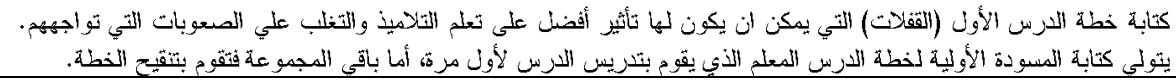 & الكجسة ؛ \\
\hline 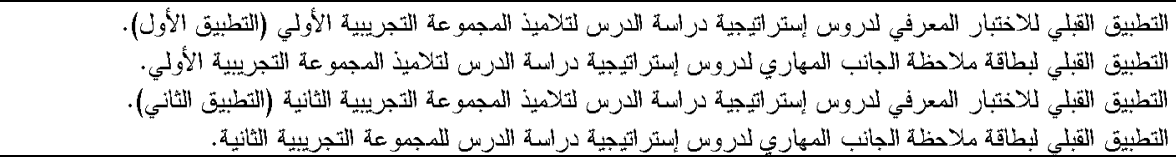 & الاجلسة ه \\
\hline 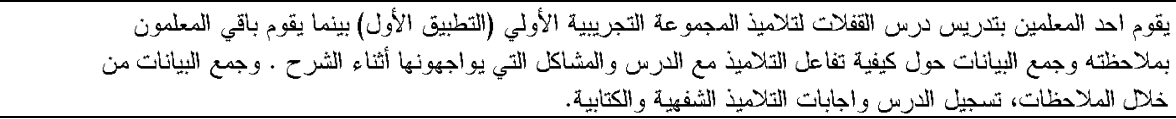 & الجلسة ؟ \\
\hline 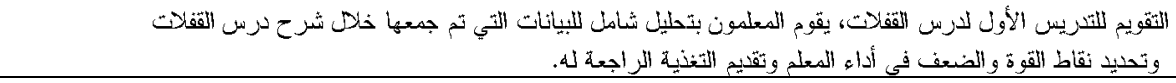 & V الاجسة V V \\
\hline 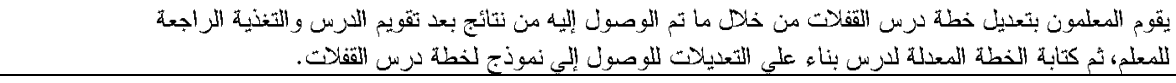 & الجلسـ \\
\hline 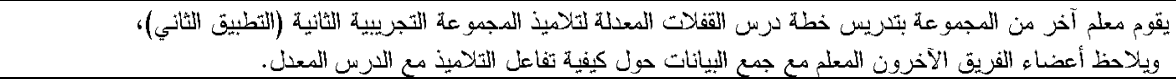 & الاجلسة 9 \\
\hline 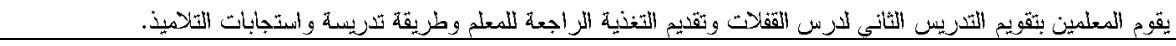 & الجلسة 1. 1. \\
\hline 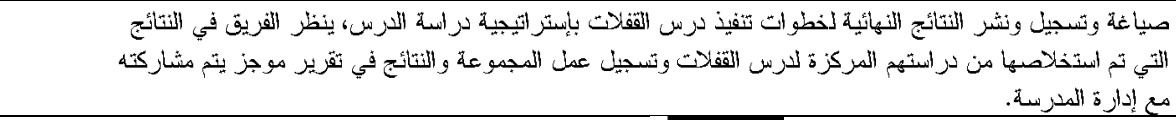 & 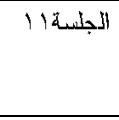 \\
\hline 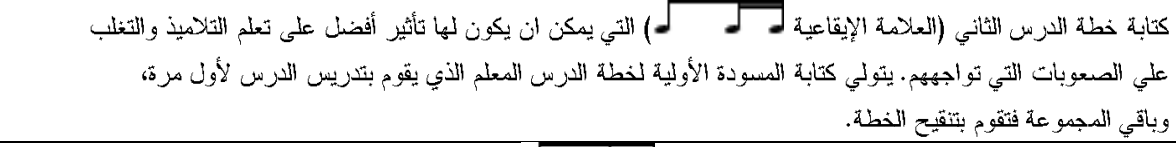 & | الجلسـة | \\
\hline 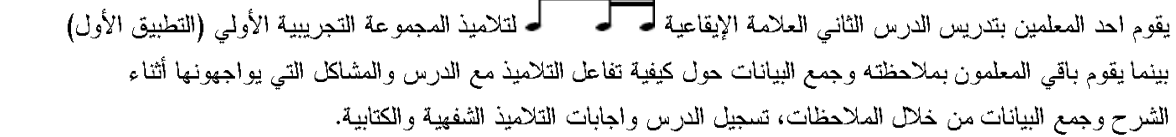 & الجلسـا سا \\
\hline
\end{tabular}

\section{I}

C. 2 


\begin{tabular}{|c|c|}
\hline 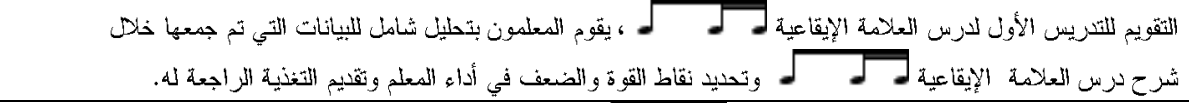 & 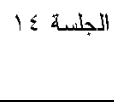 \\
\hline 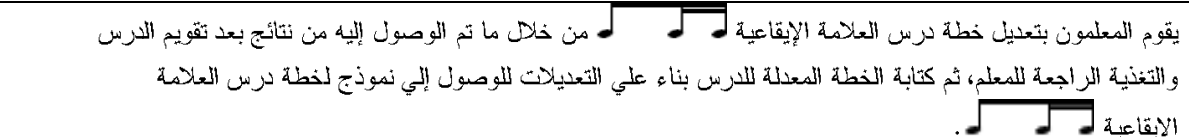 & الجلسة 10 \\
\hline 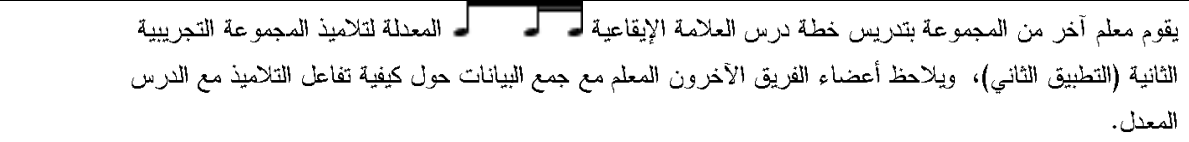 & الجلسة 17 \\
\hline 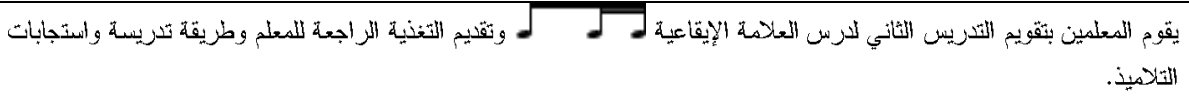 & | الجلسة| | \\
\hline 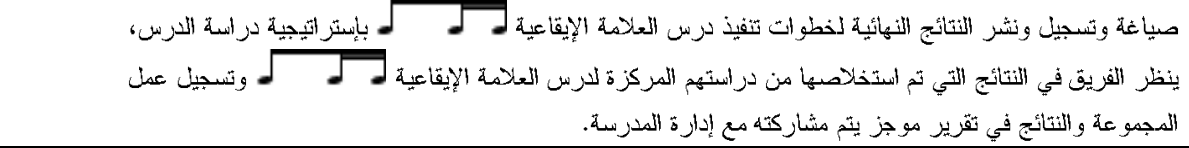 & 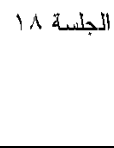 \\
\hline 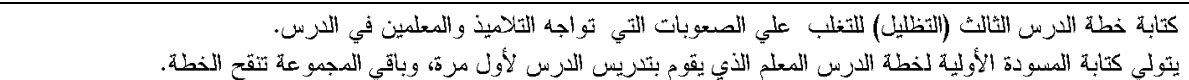 & الجلسة 19 الجية \\
\hline 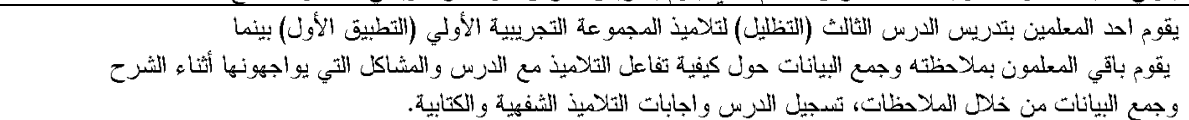 & 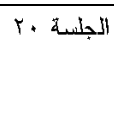 \\
\hline 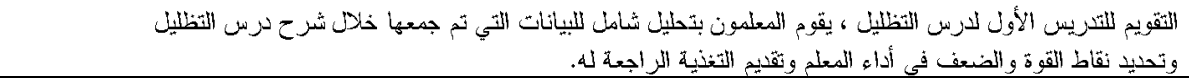 & الجلسمة \\
\hline 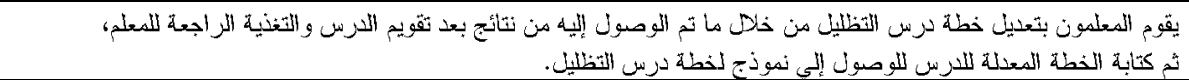 & الذجلسةrr \\
\hline 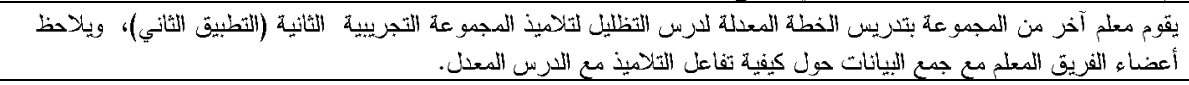 & الجلسة "ri \\
\hline 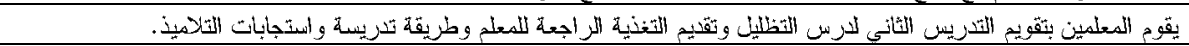 & الجلسية \\
\hline 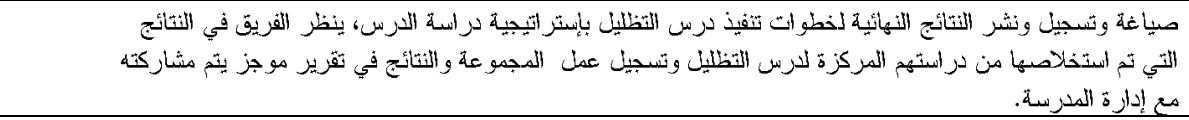 & 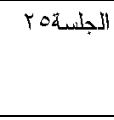 \\
\hline 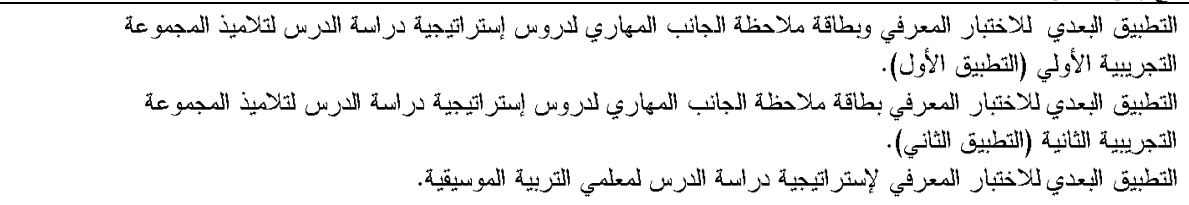 & الجلسة بri \\
\hline
\end{tabular}

\section{• نطبيق أووانه البحث بعديا}

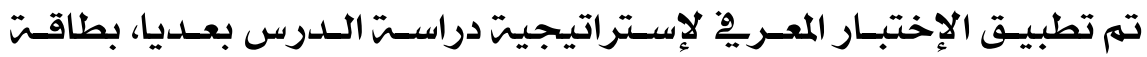

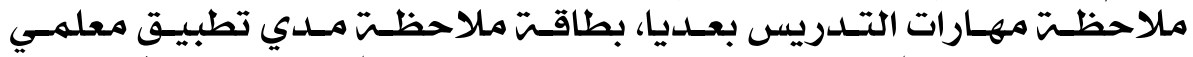

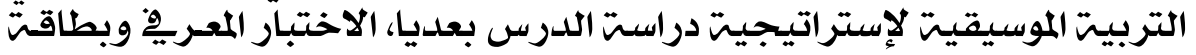

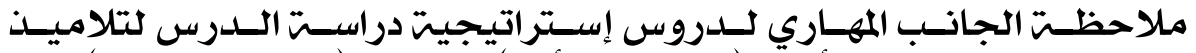

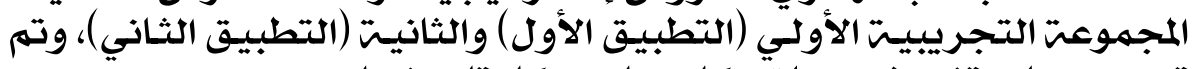

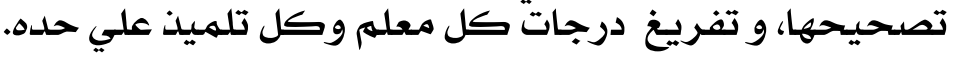




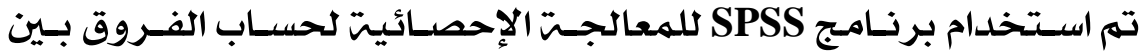

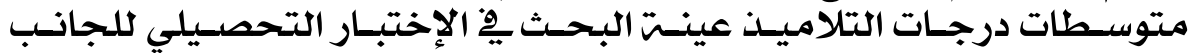

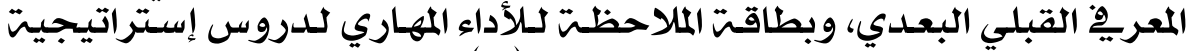

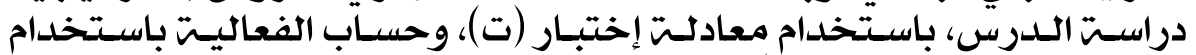

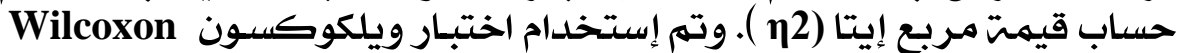
Signed Rank Test

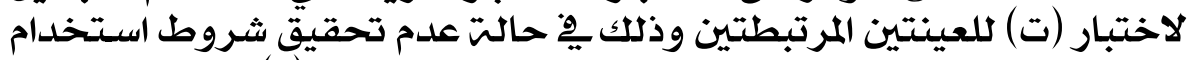

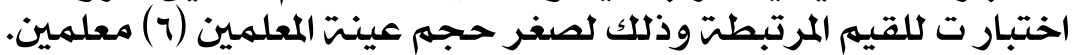

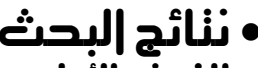

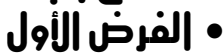

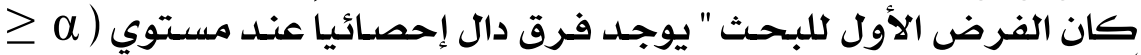

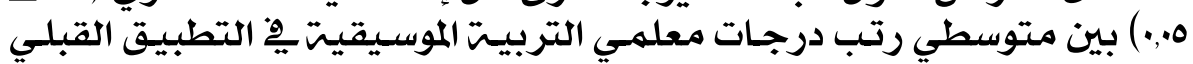

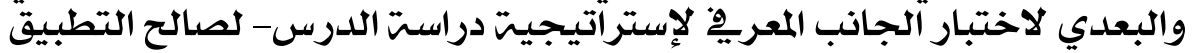

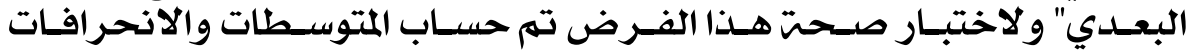

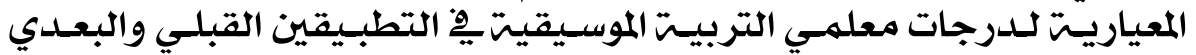

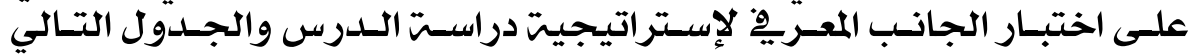
يلخص هذه النتائج.

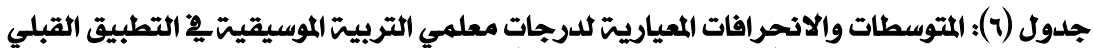

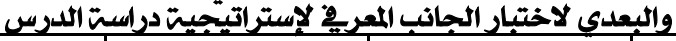

\begin{tabular}{|c|c|c|c|}
\hline الانحراف المعيلري & المتوبط & الكلدد الكد & نوع الأداء \\
\hline 2.58 & 8.33 & 6 & القبلى \\
\hline 2.32 & 25.83 & 6 & البعدي \\
\hline
\end{tabular}

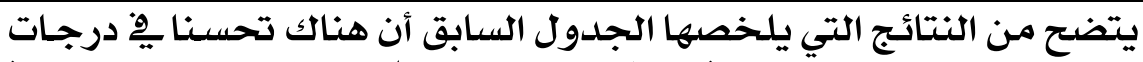

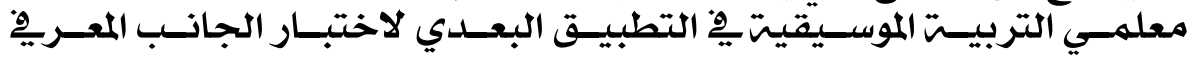

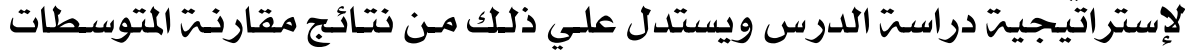
والانحر افات المعياريت دراسيت

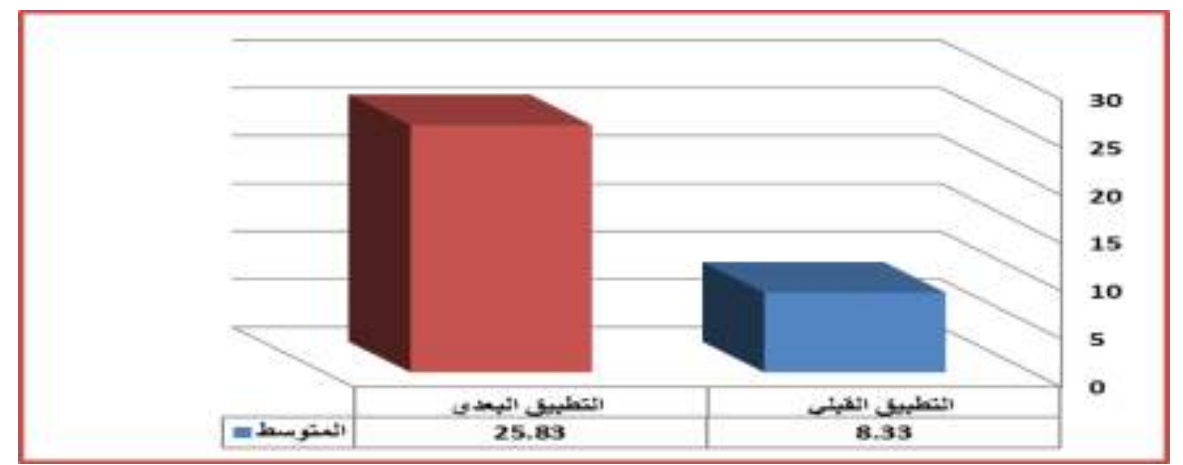

شكل (Y): المتوسطات لدرجات معلمي التربيت الموسيقيتيخ التطبيق القبلي والبعدي لاختبار الجانب المعري2

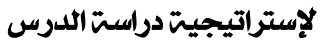
$1 \mathrm{r}$ 


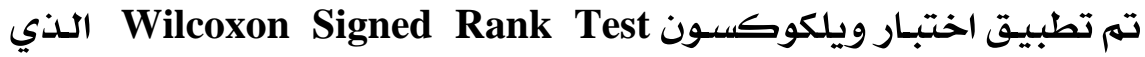

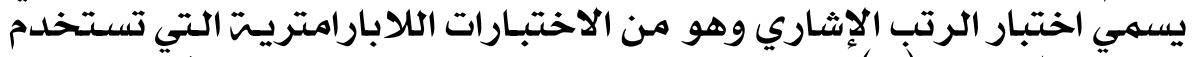

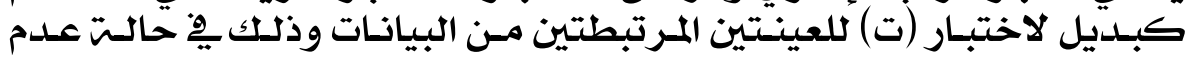

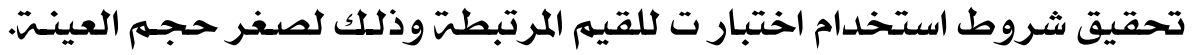

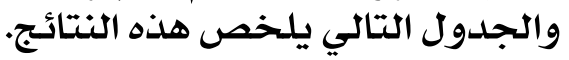

جدول (v) : قيمت " Z " ودلالتها الإحصائيت للفرق بين متوسطي رتب درجات معلمي التربيت الموسيقيتية

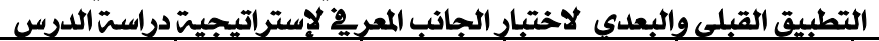

\begin{tabular}{|c|c|c|c|c|c|}
\hline 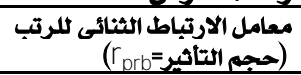 & مستوي الدلالتة & " إحصائى & مجموع الرتب & متوسط الرتب & رتب الأثارات \\
\hline \multirow{2}{*}{ تاثير قوي جداً } & \multirow{2}{*}{ دالت عند 0,י } & \multirow[t]{2}{*}{2.226} & .00 & .00 & الساليتة \\
\hline & & & 21.00 & 3.50 & الموجبت \\
\hline
\end{tabular}

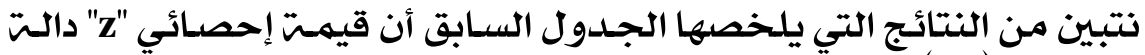

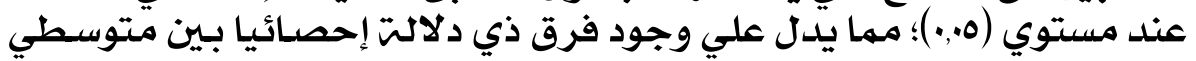

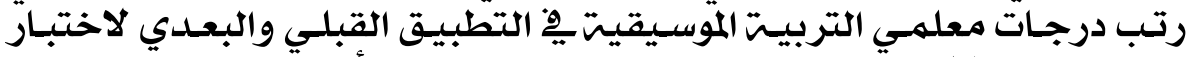

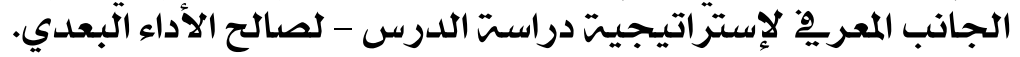

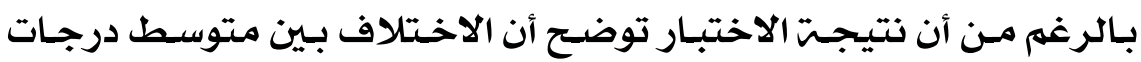

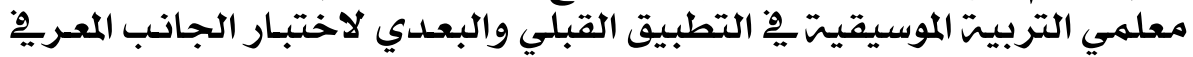

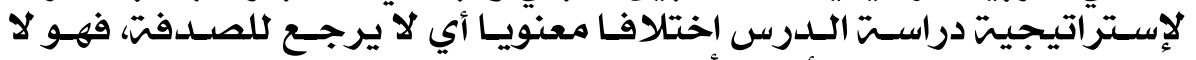

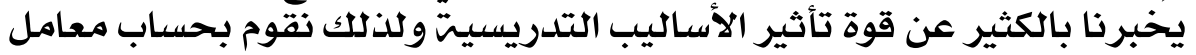

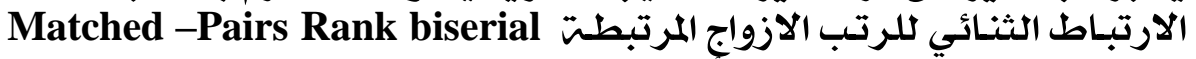

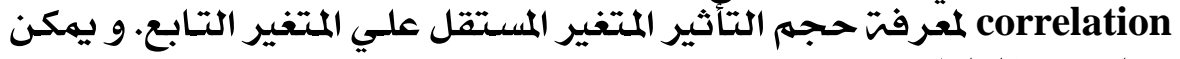
حسابه من المعادلتة

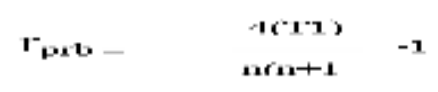

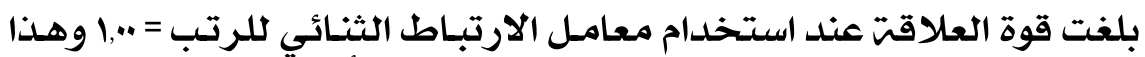

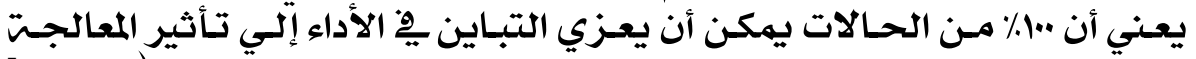

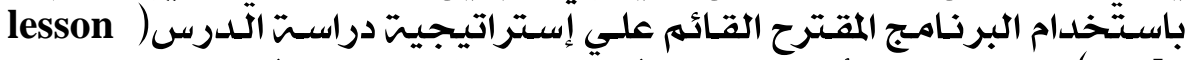

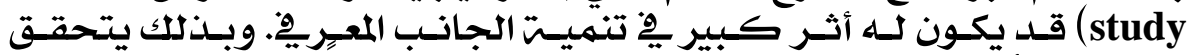

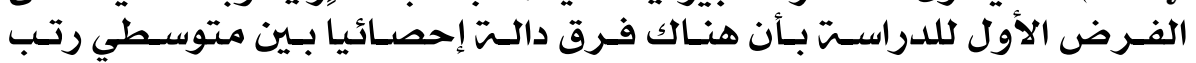

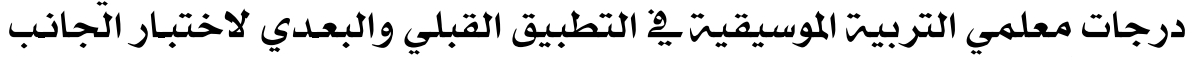

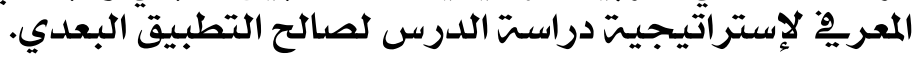

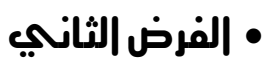

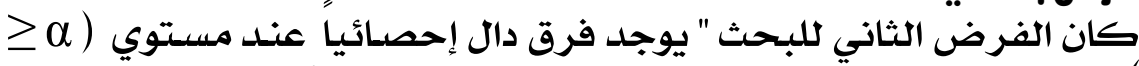

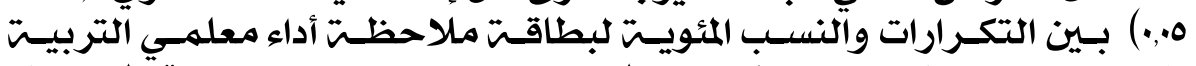

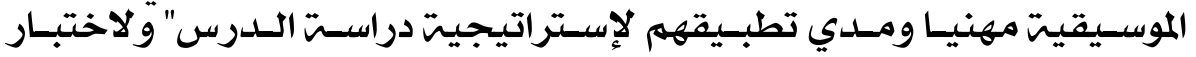

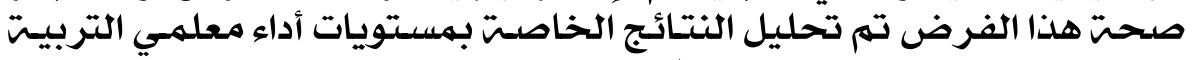

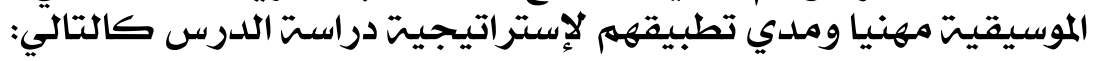


جلدول (^): التكرارات والنسب المئويت لاستجابات معلمي التربيت الموسيقيت علي بطاقت

ملاحظت مدي تطبيقهم لإستراتيجيت دراست الدرسي (lesson study)

\begin{tabular}{|c|c|c|c|c|c|c|c|c|}
\hline \multirow{2}{*}{ | إلنسبيي } & \multirow{2}{*}{ المستوسطي } & \multicolumn{2}{|c|}{ مقبول } & \multicolumn{2}{|c|}{ جيــ } & \multicolumn{2}{|l|}{ ممتاز } & \multirow{2}{*}{ مؤشرات الأداء } \\
\hline & & $\%$ & كप & $\%$ & 도 & $\%$ & ك듬 & \\
\hline 100.00 & 3.00 & 0.00 & 0 & 0.00 & 0 & 100.00 & 6 & 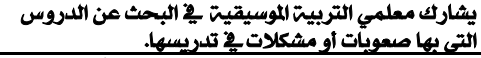 \\
\hline 88.89 & 2.67 & 0.00 & 0 & 33.33 & 2 & 66.67 & 4 & 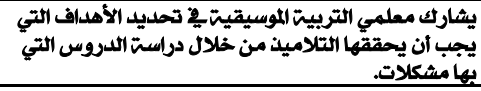 \\
\hline 94.44 & 2.83 & 0.00 & 0 & 16.67 & 1 & 83.33 & 5 & 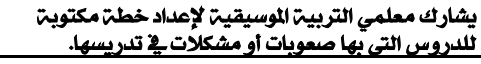 \\
\hline 77.78 & 2.33 & 16.67 & 1 & 33.33 & 2 & 50.00 & 3 & 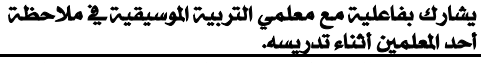 \\
\hline 83.33 & 2.50 & 16.67 & 1 & 16.67 & 1 & 66.67 & 4 & 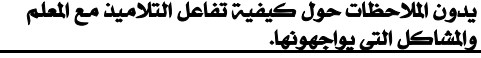 \\
\hline 77.78 & 2.33 & 16.67 & 1 & 33.33 & 2 & 50.00 & 3 & 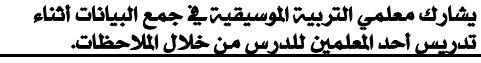 \\
\hline 100.00 & 3.00 & 0.00 & 0 & 0.00 & 0 & 100.00 & 6 & 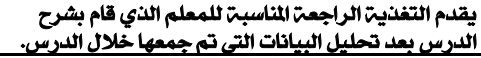 \\
\hline 83.33 & 2.50 & 16.67 & 1 & 16.67 & 1 & 66.67 & 4 & 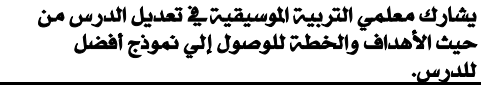 \\
\hline 94.44 & 2.83 & 0.00 & 0 & 16.67 & 1 & 83.33 & 5 & 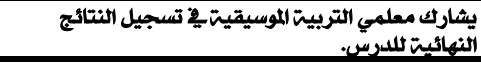 \\
\hline
\end{tabular}

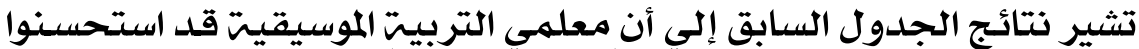

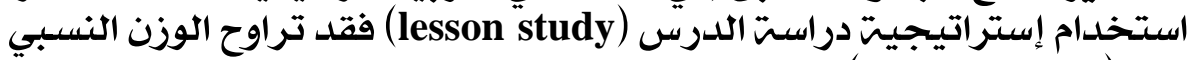

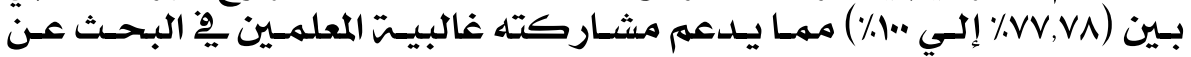

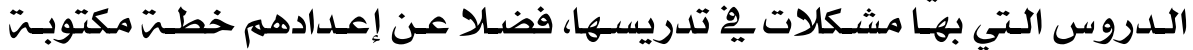

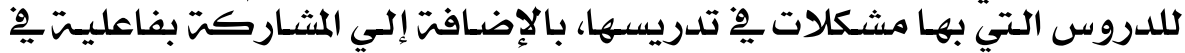

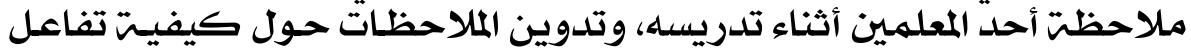

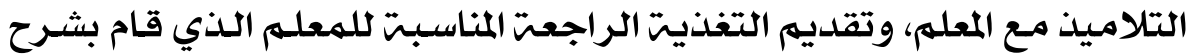

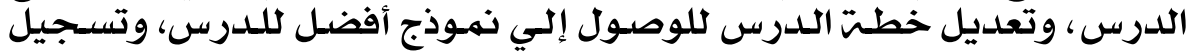

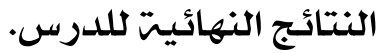

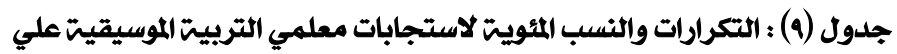

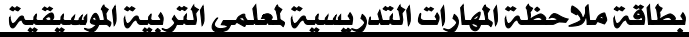

\begin{tabular}{|c|c|c|c|c|c|c|c|c|c|}
\hline \multirow{3}{*}{ النسبيئي } & \multirow{3}{*}{ المستوبي } & \multicolumn{6}{|c|}{ مستوى الآداء } & \multirow{2}{*}{ مؤشرات الأداء } & \multirow{2}{*}{ 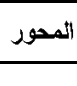 } \\
\hline & & \multicolumn{2}{|c|}{ متلاني } & \multicolumn{2}{|c|}{ جزئُى } & \multicolumn{2}{|l|}{ تام } & & \\
\hline & & 0.00 & $\mathbf{0}$ & 33.33 & 2 & 66.67 & 4 & 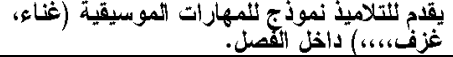 & \\
\hline 77.78 & 2.33 & 16.67 & $\mathbf{1}$ & 33.33 & 2 & 50.00 & 3 & 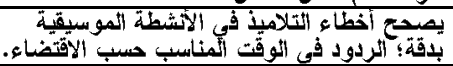 & \\
\hline 88.89 & 2.67 & 0.00 & $\mathbf{0}$ & 33.33 & 2 & 66.67 & 4 & 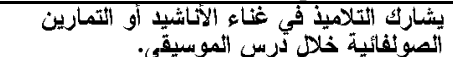 & $\overline{1}$ \\
\hline 83.33 & 2.50 & 16.67 & 1 & 16.67 & $\mathbf{1}$ & 66.67 & 4 & يخلار درس الثلاميذ فيقي المزف على الالات الموسيقية & $\frac{S}{5}$ \\
\hline 77.78 & 2.33 & 16.67 & 1 & 33.33 & 2 & 50.00 & 3 & 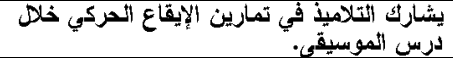 & ד. \\
\hline 77.78 & 2.33 & 16.67 & 1 & 33.33 & 2 & 50.00 & 3 & 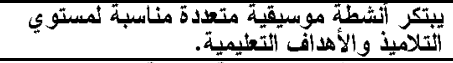 & 拏: \\
\hline 88.89 & 2.67 & 0.00 & $\mathbf{0}$ & 33.33 & 2 & 66.67 & 4 & 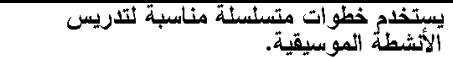 & \\
\hline 66.67 & 2.00 & 16.67 & 1 & 16.67 & 1 & 50.00 & 3 & يقدم تعليمات محذدة لاذلاء المهام المو سيقية. & \\
\hline $\begin{array}{l}88.89 \\
83.33\end{array}$ & 2.67 & 0.00 & $\mathbf{0}$ & 33.33 & 2 & 66.67 & 4 & يثوع بين أستاليب الإتصال المختلفة. & \\
\hline 83.33 & 2.50 & 16.67 & 1 & 16.67 & $\mathbf{1}$ & 66.67 & 4 & يضع نظام للعمل داخل الفصل. & \\
\hline
\end{tabular}




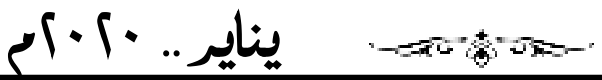

(العرو (لسابع عشر

\begin{tabular}{|c|c|c|c|c|c|c|c|c|c|}
\hline 77.78 & 2.33 & 16.67 & 1 & 33.33 & 2 & 50.00 & 3 & آلألتزم بخطو ات تحضير اللارس المكتوبة في خطة & \\
\hline 94.44 & 2.83 & 0.00 & $\mathbf{0}$ & 16.67 & 1 & 83.33 & 5 & 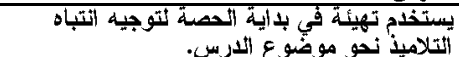 & \\
\hline 100.00 & 3.00 & 0.00 & $\mathbf{0}$ & 0.00 & $\mathbf{0}$ & 100.00 & 6 & يتفاعز مـ الثتلاميذ داخل الفصن.. & \\
\hline 83.33 & 2.50 & 16.67 & 1 & 16.67 & 1 & 66.67 & 4 & 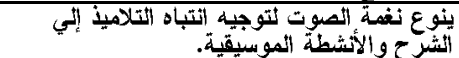 & \\
\hline 77.78 & 2.33 & 16.67 & 1 & 33.33 & 2 & 50.00 & 3 & 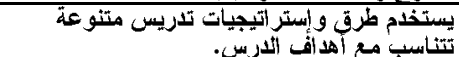 & \\
\hline 83.33 & 2.50 & 16.67 & 1 & 16.67 & 1 & 66.67 & 4 & 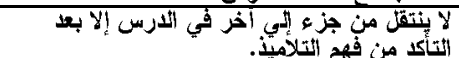 & \\
\hline 94.44 & 2.83 & 0.00 & $\mathbf{0}$ & 16.67 & $\mathbf{1}$ & 83.33 & 5 & يستخذم وسيئة تعليمية مناسبة لموضو ع اللارس. & \\
\hline 94.44 & 2.83 & 0.00 & 0 & 16.67 & 1 & 83.33 & 5 & 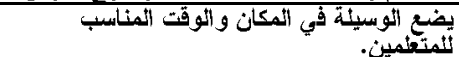 & \\
\hline $\begin{array}{l}77.78 \\
77.78\end{array}$ & $\frac{2.33}{2.33}$ & $\begin{array}{l}16.67 \\
16.67\end{array}$ & $\frac{1}{1}$ & $\begin{array}{l}33.33 \\
33.33\end{array}$ & $\frac{2}{2}$ & $\begin{array}{l}50.00 \\
50.00\end{array}$ & $\frac{3}{3}$ & 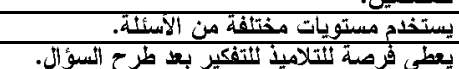 & \\
\hline 77.78 & 2.33 & 16.67 & 1 & 33.33 & 2 & 50.00 & 3 & يستخذاج أنماط متنوعة من الثتعزيز تبعا لإستجابات & \\
\hline $\mathbf{7 7 . 7 8}$ & 2.33 & 16.67 & $\mathbf{1}$ & 33.33 & 2 & 50.00 & 3 & 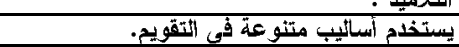 & \\
\hline 88.89 & 2.67 & 0.00 & $\mathbf{0}$ & 33.33 & 2 & 66.67 & 4 & يلخص ألارس في نهاية الحصية. & \\
\hline 77.78 & 2.33 & 16.67 & 1 & 33.33 & 2 & 50.00 & 3 & 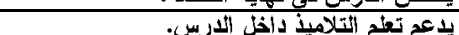 & \\
\hline 94.44 & 2.83 & 0.00 & $\mathbf{0}$ & 16.67 & 1 & 83.33 & 5 & يتحمس لآداء الأتشطة الموسيقية داخل الأرس. & \\
\hline 83.33 & 2.50 & 16.67 & 1 & 16.67 & 1 & 66.67 & 4 & 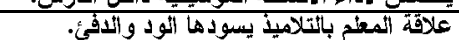 & $\overline{7}$ \\
\hline 88.89 & 2.67 & 0.00 & $\mathbf{0}$ & 33.33 & 2 & 66.67 & 4 & 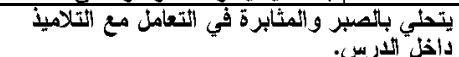 & \\
\hline 100.00 & 3.00 & 0.00 & $\mathbf{0}$ & 0.00 & $\mathbf{0}$ & 100.00 & 6 & يتمتع بحسن المظهر. & A \\
\hline 83.33 & 2.50 & 16.67 & 1 & 16.67 & 1 & 66.67 & 4 & 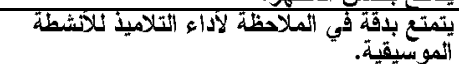 & \\
\hline 77.78 & 2.33 & 16.67 & 1 & 33.33 & 2 & 50.00 & 3 & 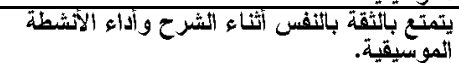 & \\
\hline 88.89 & 2.67 & 0.00 & $\mathbf{0}$ & 33.33 & 2 & 66.67 & 4 & 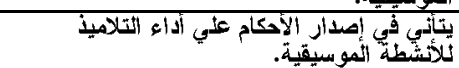 & \\
\hline
\end{tabular}

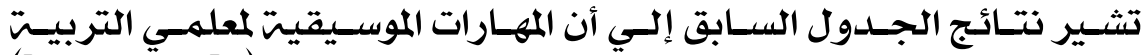

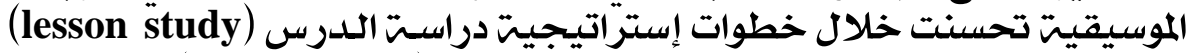

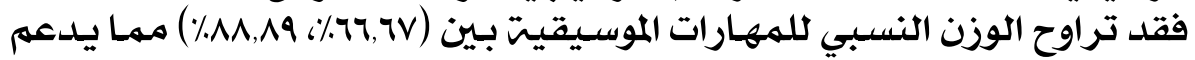

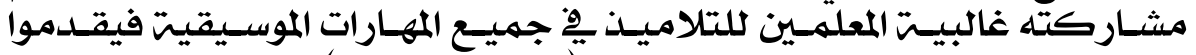

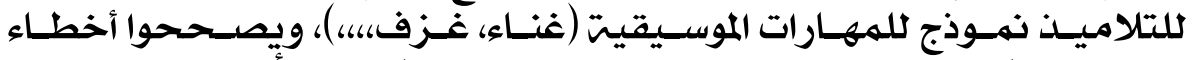

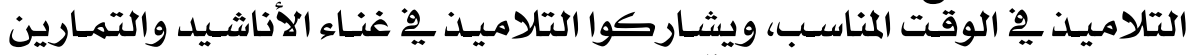

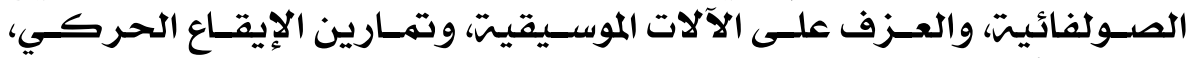

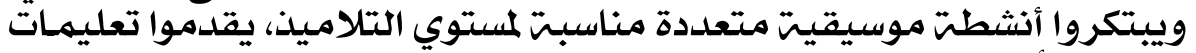

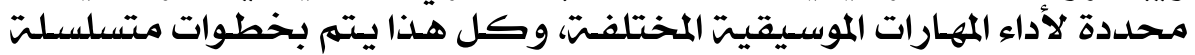
مناسبت للدرس.

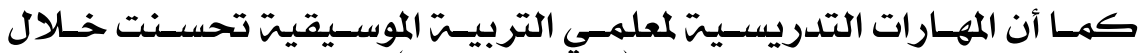

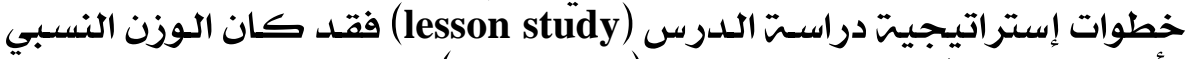

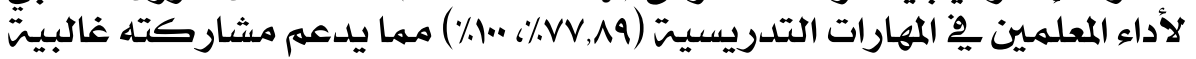

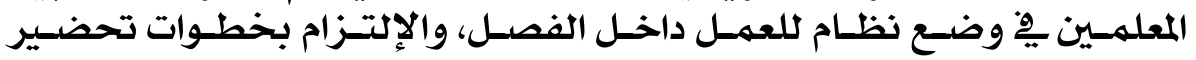

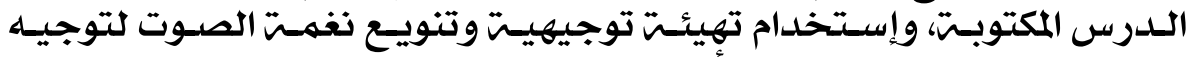

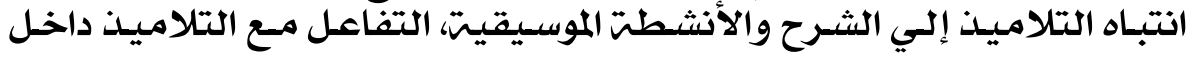

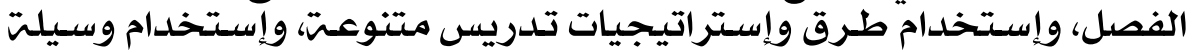

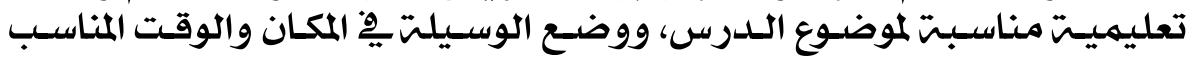




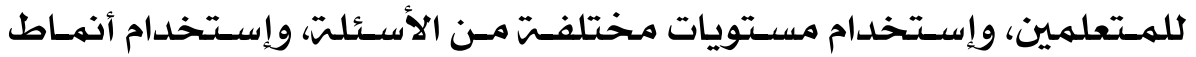

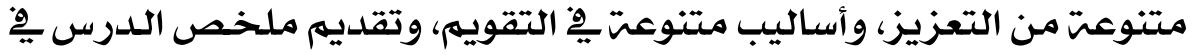

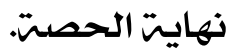

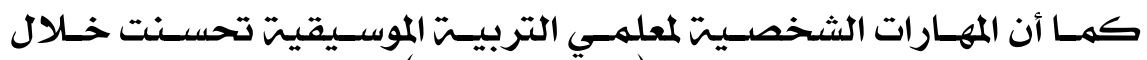

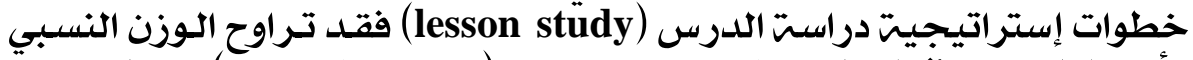

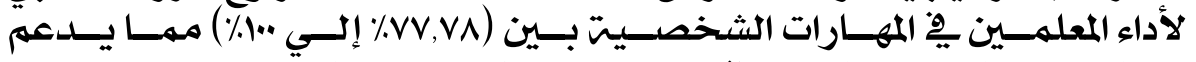

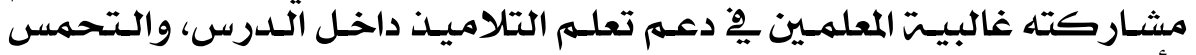

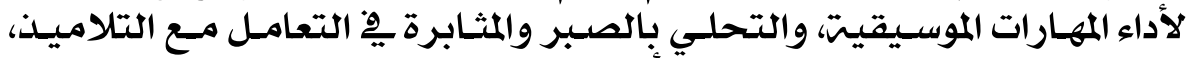

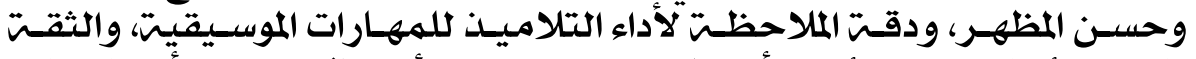

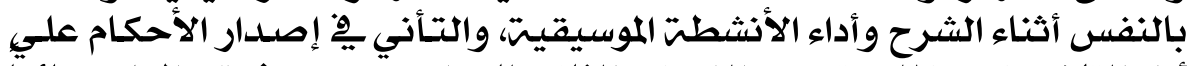

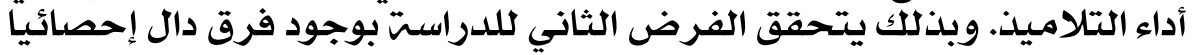

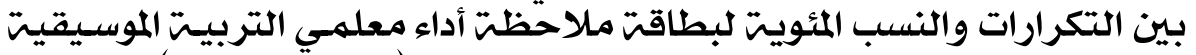
مهنيا ومدي تطبيقهم لإستراتيجيت دراست الدرس (Lesson Sudy).

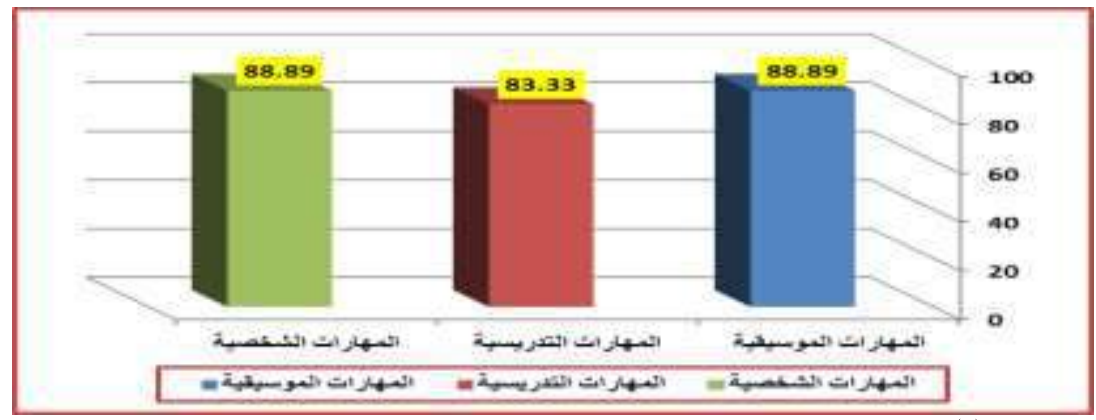

ثكل (r): الوزن النسبي لاستجابات معلمي التربيت الموسيقيت علي بطاقت ملاحظت المهارات التدريسيت لمعلمى التربيت الموسيتيتيت الموسية

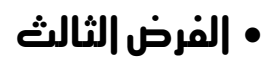

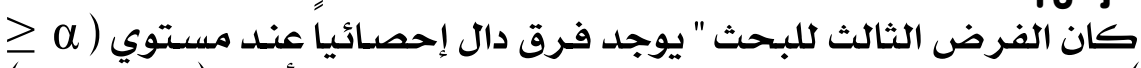

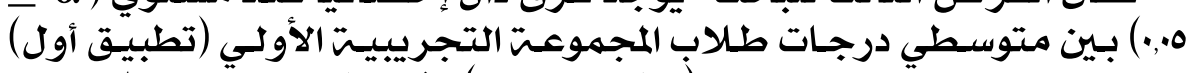

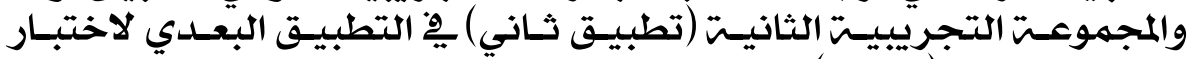

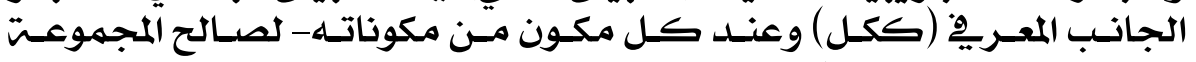

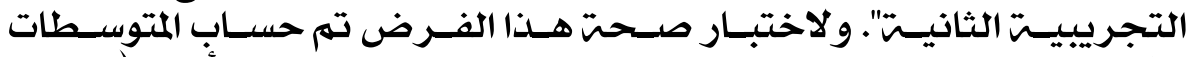

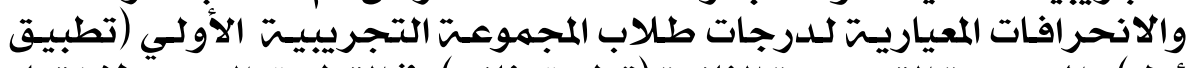

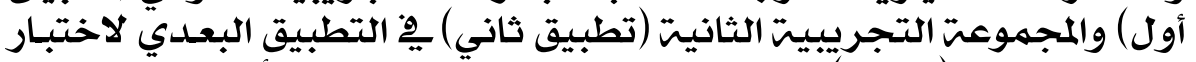

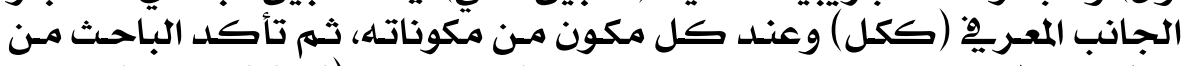

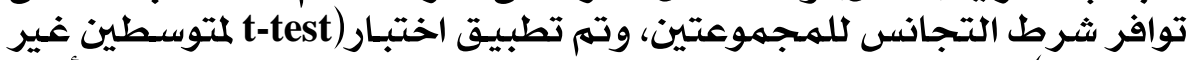

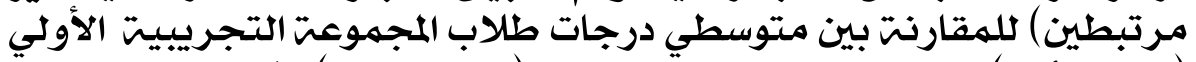

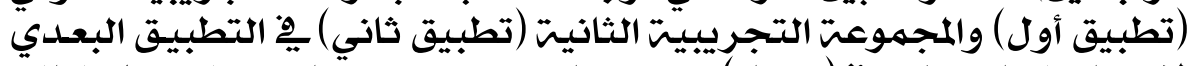

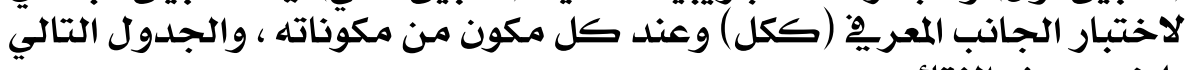

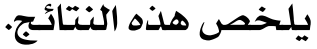




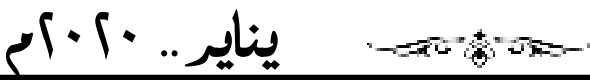

(العرو (لسابع عشر

جدول (.1): قيمت " ت " ودلالتها الإحصائيت للفرق بين متوسطي درجات طلاب المجموعت التجريبيت الأولي (تطبيق

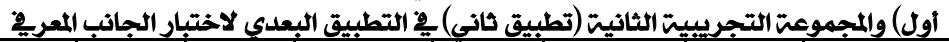

\begin{tabular}{|c|c|c|c|c|c|c|c|c|c|}
\hline قابتاثير دلاك & حجم التأثير & 2مريع & مستوي & قيمت"ت" & لدالحرجيت & الانحراف & المتوسط & المجموعت & المكون \\
\hline \multirow[b]{2}{*}{ 口كبير } & \multirow{2}{*}{1.280} & \multirow{2}{*}{0.390} & \multirow[b]{2}{*}{ دالة } & \multirow{2}{*}{4.932} & \multirow{2}{*}{38} & 1.85 & 14.45 & التجريبيت (1) & \multirow{2}{*}{ الدرس الأول } \\
\hline & & & & & & 1.67 & 17.20 & التجريبيت (Y) & \\
\hline \multirow{2}{*}{ كبير } & \multirow{2}{*}{2.100} & \multirow{2}{*}{0.512} & \multirow{2}{*}{ دالت } & \multirow{2}{*}{6.317} & \multirow{2}{*}{38} & 1.53 & 13.85 & التجريييت(1) & \multirow{2}{*}{ اللدرس الثاني } \\
\hline & & & & & & 1.57 & 16.95 & التجريبيت (r) & \\
\hline \multirow{2}{*}{ كبير } & \multirow{2}{*}{2.240} & \multirow{2}{*}{0.528} & \multirow{2}{*}{ دالت } & \multirow{2}{*}{6.524} & \multirow{2}{*}{38} & 1.49 & 14.00 & التجريييت (1) & \multirow{2}{*}{ الدرس الثالث } \\
\hline & & & & & & 1.52 & 17.10 & التجريبيت (r) & \\
\hline \multirow{2}{*}{ 口كبير } & \multirow{2}{*}{3.966} & \multirow{2}{*}{0.665} & \multirow{2}{*}{ دالة } & \multirow{2}{*}{8.681} & \multirow{2}{*}{38} & 2.62 & 42.30 & التجريبيت (1) & \multirow{2}{*}{ المعريجا (ككل) الجاثب } \\
\hline & & & & & & 3.80 & 51.25 & التجريبيت (r) & \\
\hline
\end{tabular}

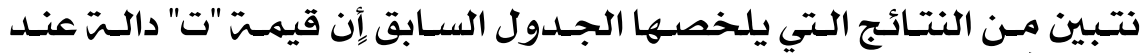

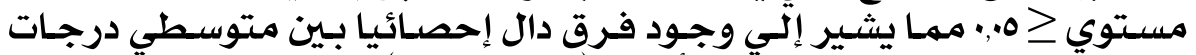

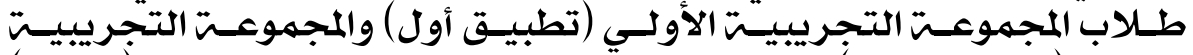

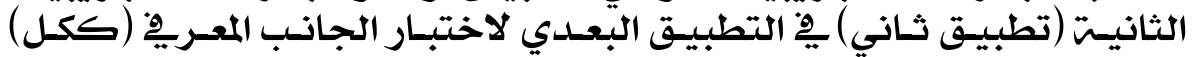
وعند كل مكون من مـكوناته.

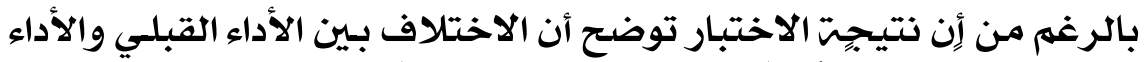

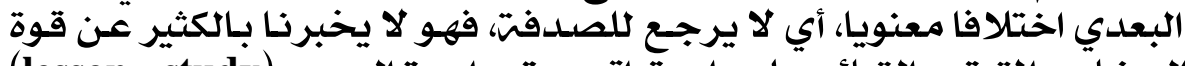

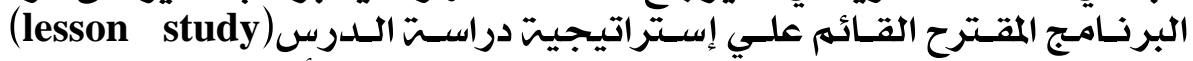

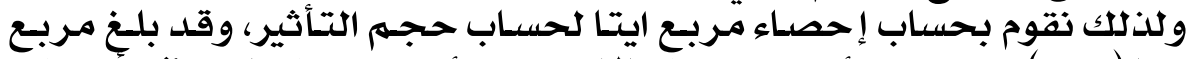

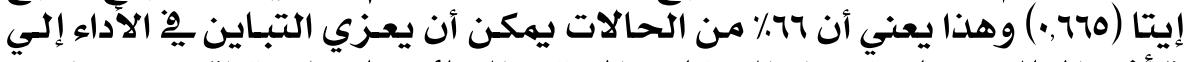

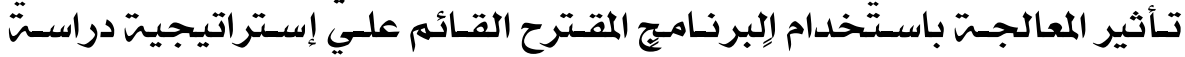

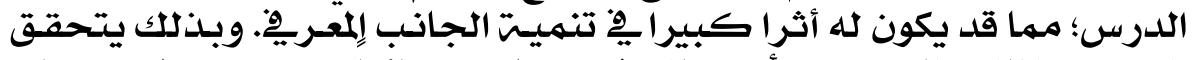

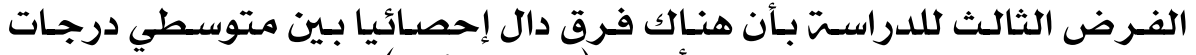

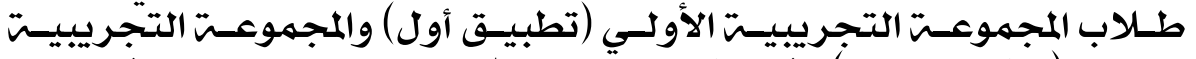

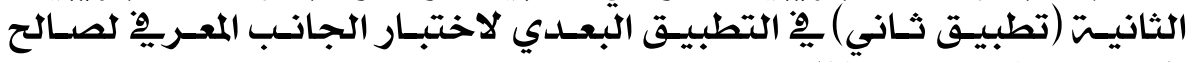
المجموعت التجريبينت ألثانيتئ.

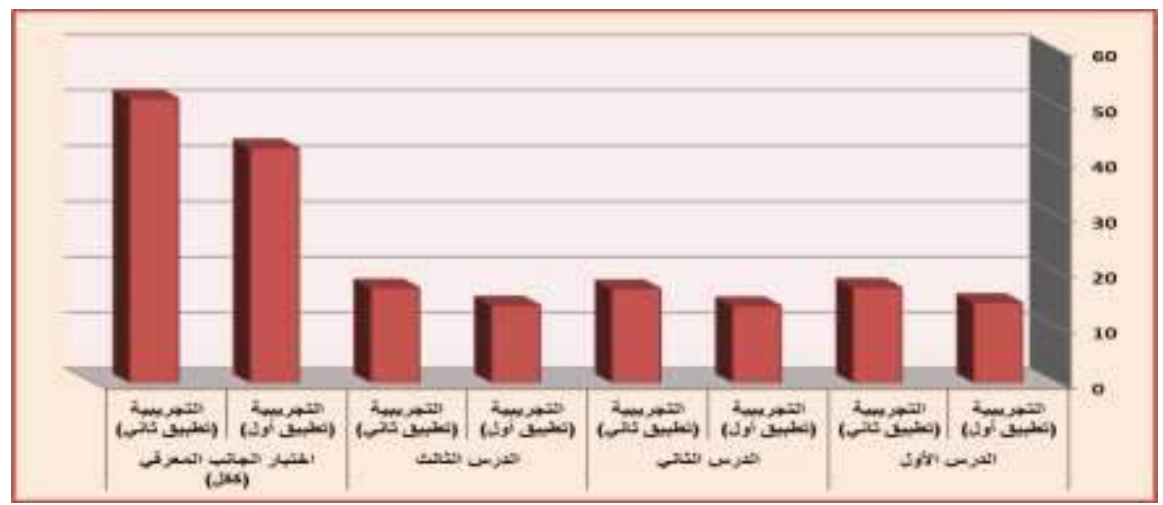

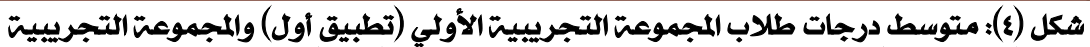

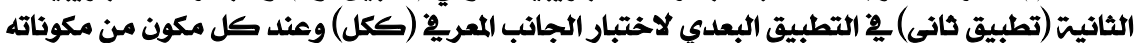




\section{• الفرض الر|بع}

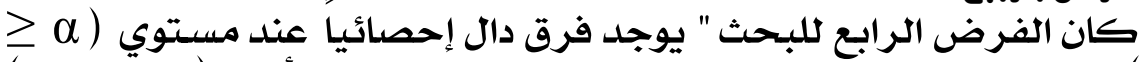

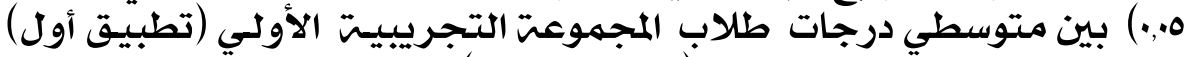

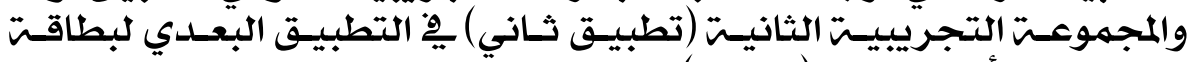

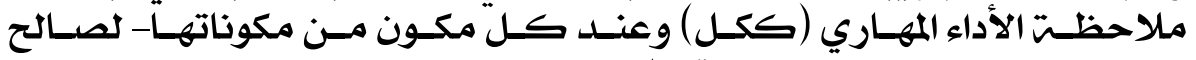

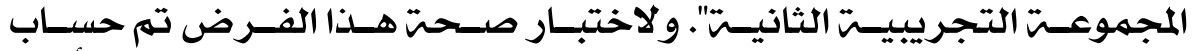

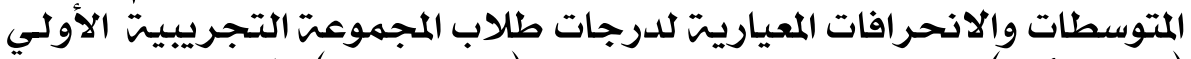

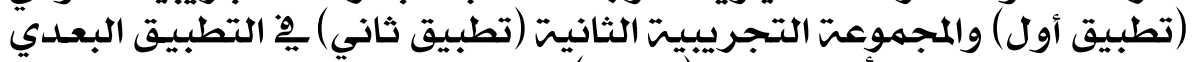

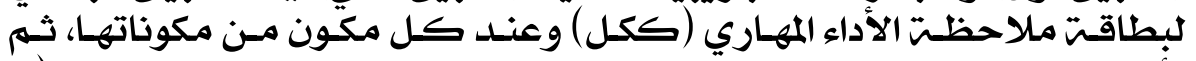

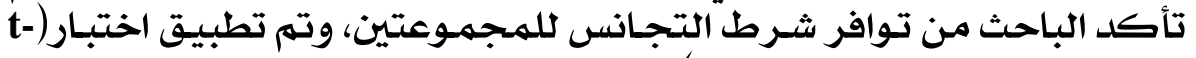

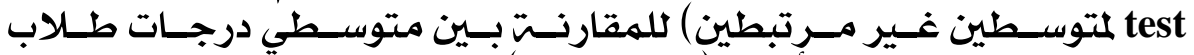

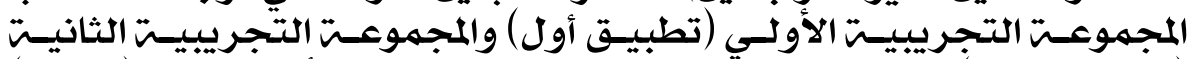

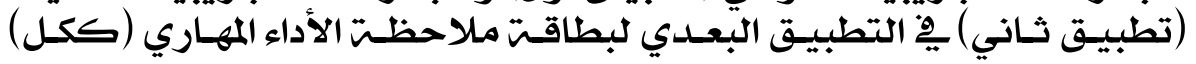

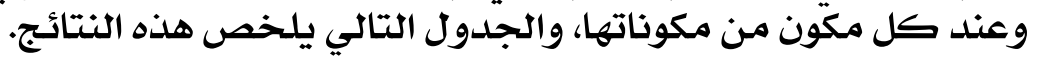

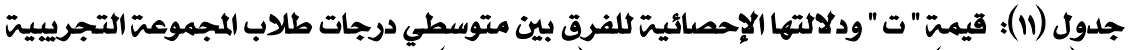

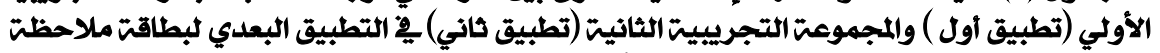
الأداء المهاري (تطبيق

\begin{tabular}{|c|c|c|c|c|c|c|c|c|c|}
\hline قوة دألثالة & حجم الثأثير & 2مربي & مستولة الاليّة & قيمة "ت" & لدرجة & الالانحراف & المتتوسط & المجمو عة & المكون \\
\hline \multirow[b]{2}{*}{ كبير } & \multirow{2}{*}{5.08} & 0.7 & \multirow{2}{*}{ دالة } & \multirow{2}{*}{9.826} & \multirow{2}{*}{38} & 0.93 & 8.85 & التحريسة (1) & \multirow{2}{*}{ القفلات } \\
\hline & & 18 & & & & 1.43 & 12.60 & التحريسة: (r) & \\
\hline \multirow[b]{2}{*}{ كبير } & \multirow{2}{*}{2.44} & 0.5 & \multirow{2}{*}{ دالة } & \multirow{2}{*}{6.821} & \multirow{2}{*}{38} & 0.99 & 8.15 & التقريسة (1) & \multirow{2}{*}{ الإلعقاعية } \\
\hline & & 50 & & & & 1.10 & 10.40 & التصريسة: (r) & \\
\hline \multirow[b]{2}{*}{ كبير } & \multirow{2}{*}{2.51} & 0.5 & \multirow{2}{*}{ دالة } & \multirow{2}{*}{6.914} & \multirow{2}{*}{38} & 0.88 & 8.15 & الثجريبية (1) & \multirow[b]{2}{*}{ التظليل } \\
\hline & & 57 & & & & 1.08 & 10.30 & التهريسة (r) & \\
\hline \multirow[b]{2}{*}{ كبير } & \multirow{2}{*}{11.37} & 0.8 & \multirow{2}{*}{ دالة } & \multirow{2}{*}{$\begin{array}{r}14.70 \\
4\end{array}$} & \multirow{2}{*}{38} & 1.35 & 25.15 & التجريبية (1) & \multirow{2}{*}{ الألاء (ككل) المهاري } \\
\hline & & 51 & & & & 2.08 & 33.30 & التجريبية (r) & \\
\hline
\end{tabular}

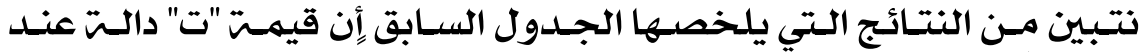

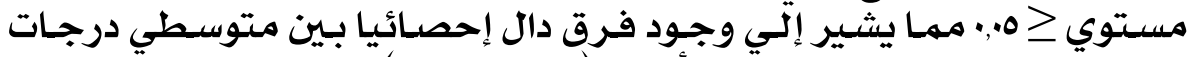

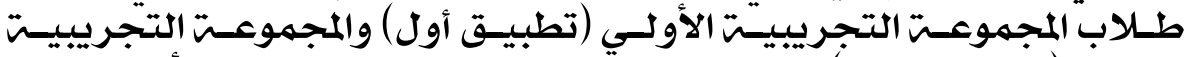

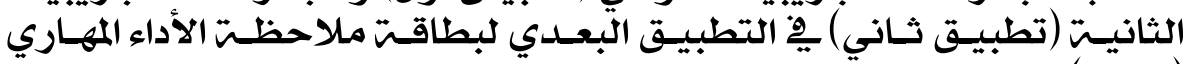

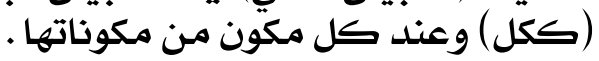

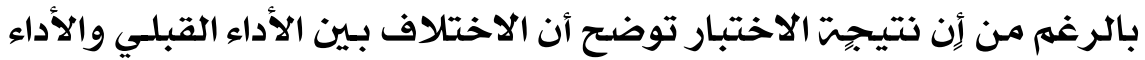

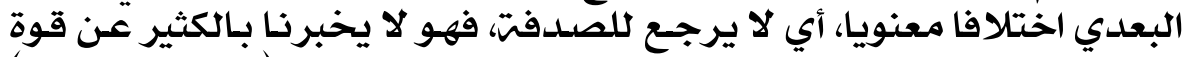

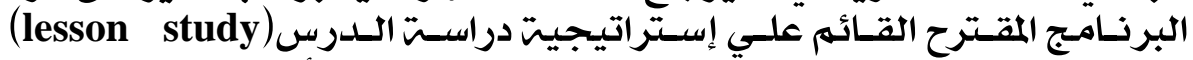

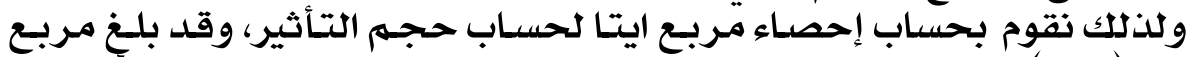

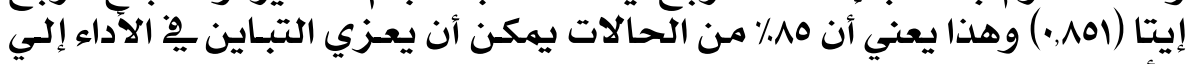

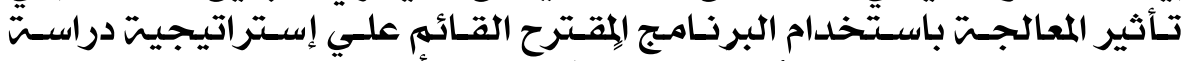

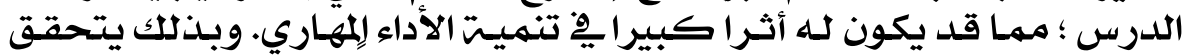

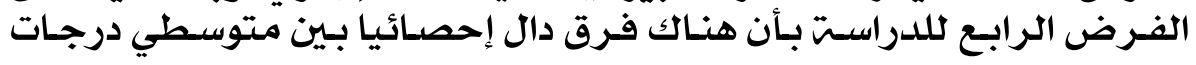




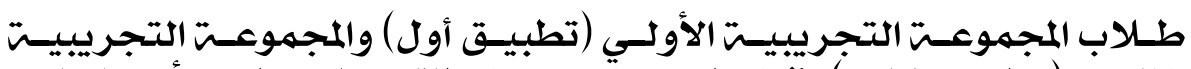

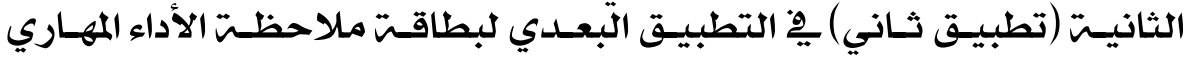

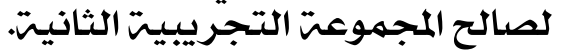

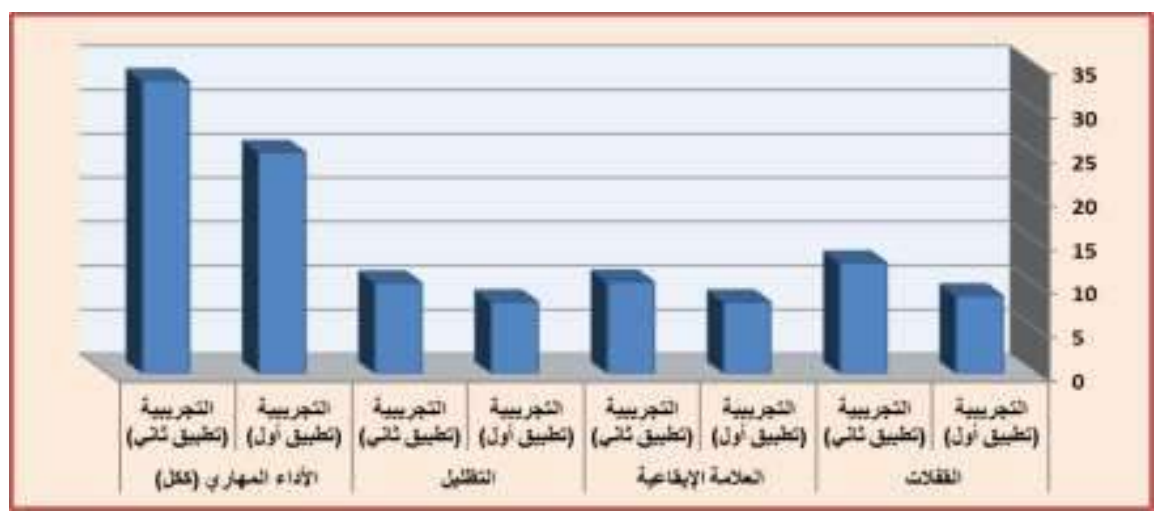

ثكل (ه): متوسط درجات طلاب المجموعت التجريبيت الأولي (تطبيق أول)

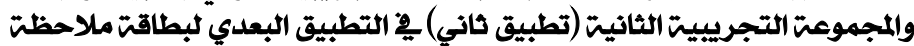
الأداء المهاري وعند كل مكون من مكوناتها

• الفرض الخامس انف

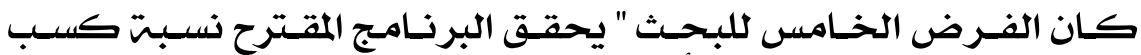

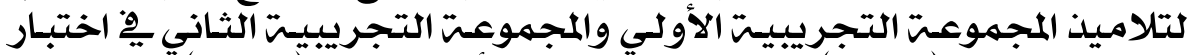

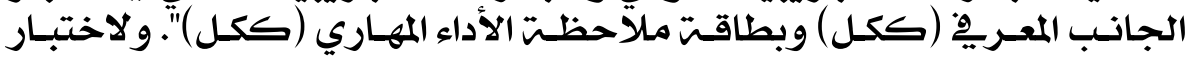

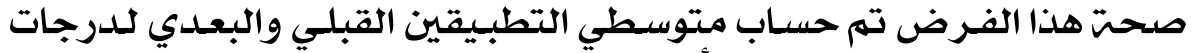

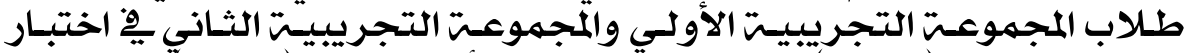

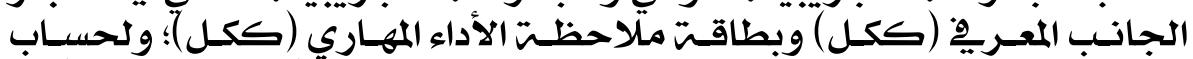

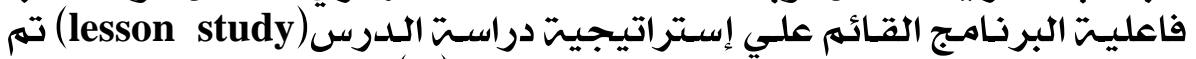

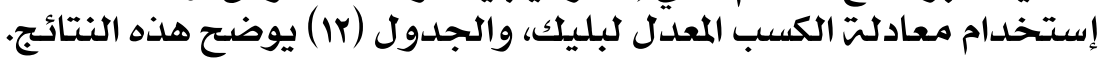

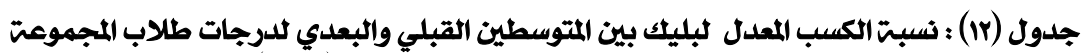

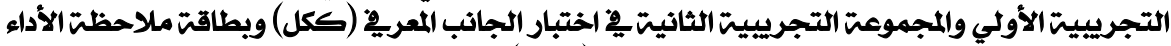
المهاري (كلين).

\begin{tabular}{|c|c|c|c|c|c|c|}
\hline اللالاية & معدل الكبيك & الألطفية & المتو سط & التطبيق & الاختبار & المجمو عة \\
\hline \multirow{2}{*}{ مقبو الثو احزيل } & \multirow[b]{2}{*}{1.176} & \multirow[b]{2}{*}{60} & 10.35 & ألقبّلى & \multirow[b]{2}{*}{ الجانب المعرفي } & \multirow{3}{*}{ التجريبية ألأولي (تطبيق } \\
\hline & & & 42.30 & البعدي & & \\
\hline ثير مقبولة & 0.681 & 39 & $\frac{15.05}{25.15}$ & 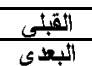 & الأداء المهاري & \\
\hline \multirow{2}{*}{ مقنو المولة تزيلد } & \multirow[b]{2}{*}{1.529} & \multirow[b]{2}{*}{60} & 9.20 & ألقبطى & \multirow[b]{2}{*}{ الجاتب المعرفي } & \multirow{4}{*}{ التجريبية ثانثانية (تطبيق } \\
\hline & & & 51.25 & البعدي & & \\
\hline \multirow{2}{*}{ 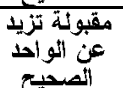 } & \multirow{2}{*}{1.210} & \multirow{2}{*}{39} & 15.60 & الثقبلي & \multirow{2}{*}{ الأداء المهاري } & \\
\hline & & & 33.30 & الثبدي & & \\
\hline
\end{tabular}

يوضـح نتائج الجدول السـابق أن: 


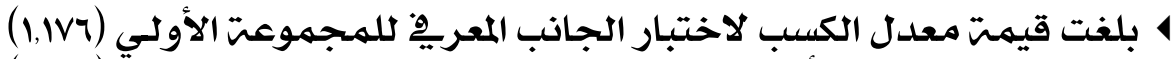

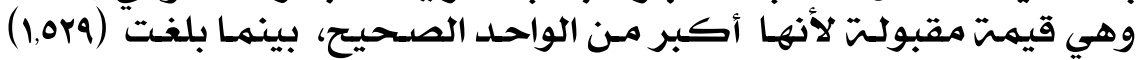

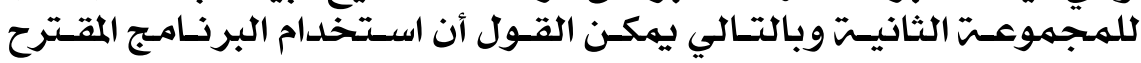

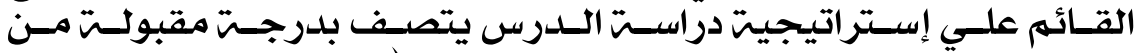

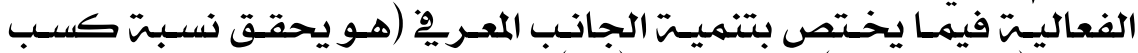

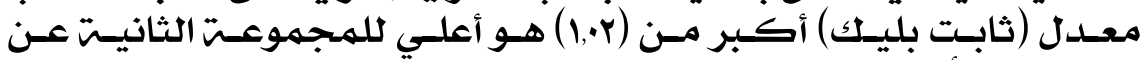

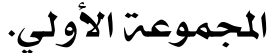

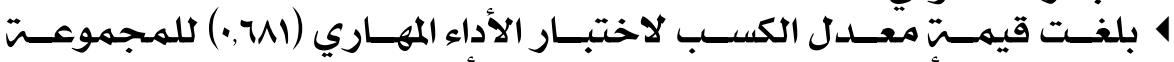

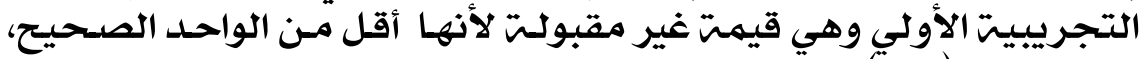

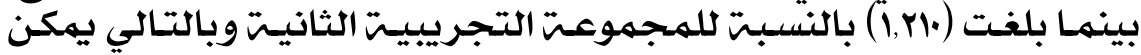

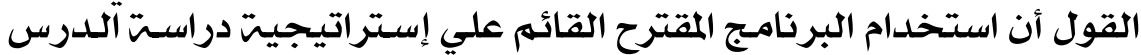

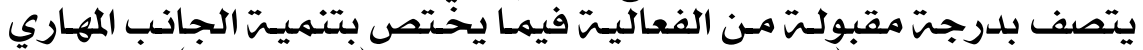

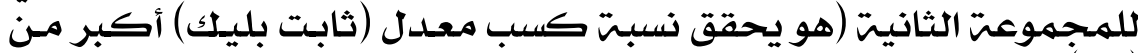
$(1, r)$

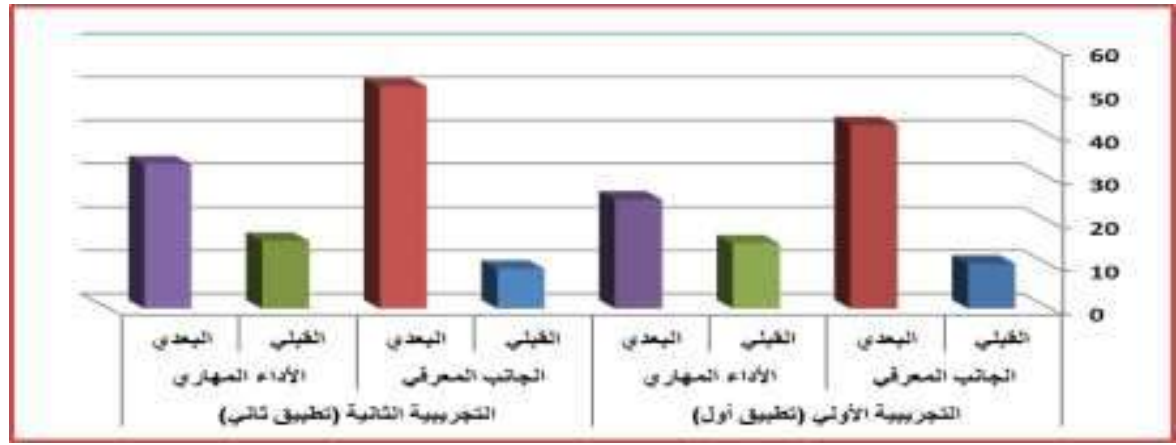

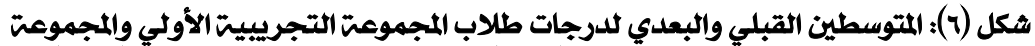

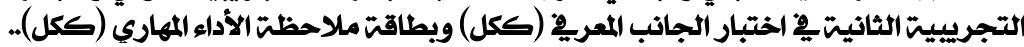

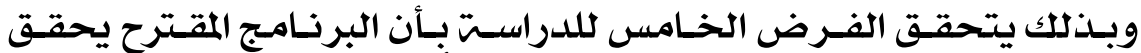

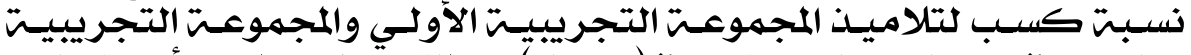

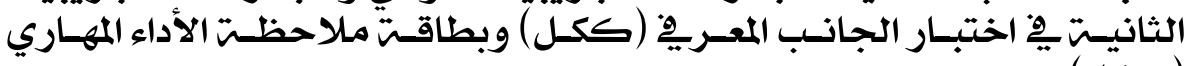
(كل) (كن)

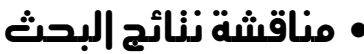

تم مناقشت نتائج البحث بِّ ضوء تساؤلات البحث وأهدافه كما يلي:

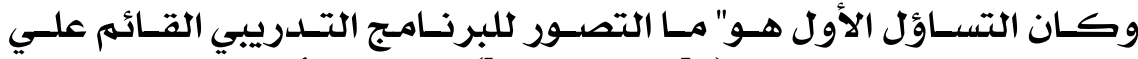

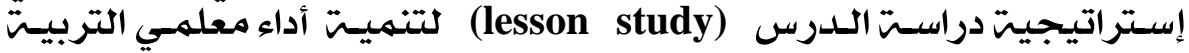
الموسيقيت مهنيا ؟

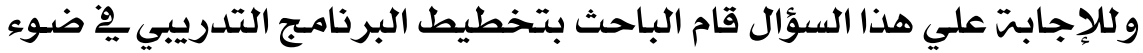

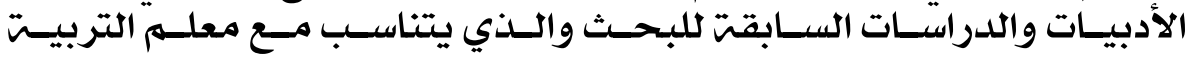




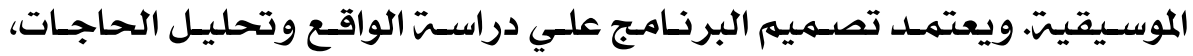

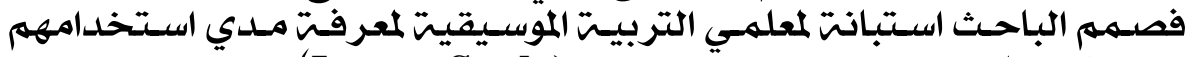

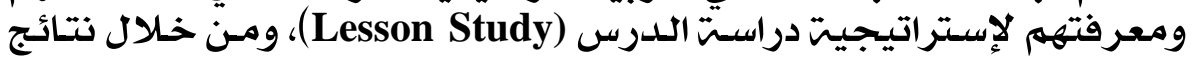

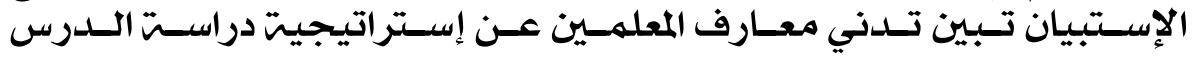

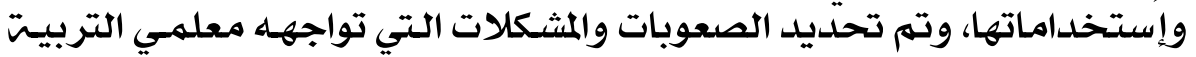

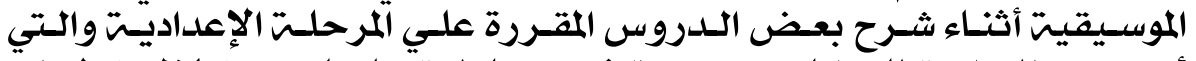

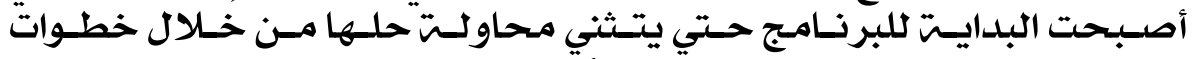

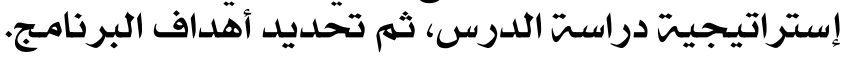

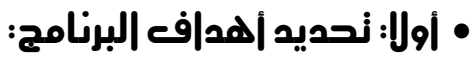

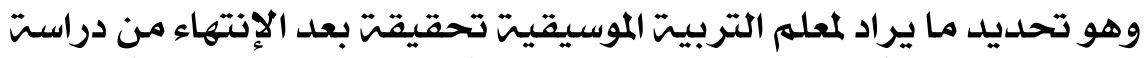

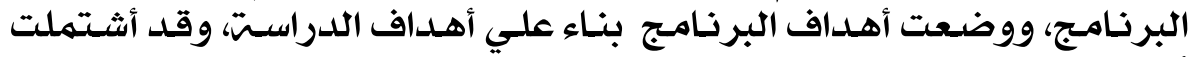

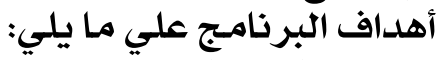

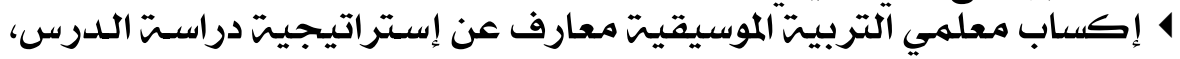

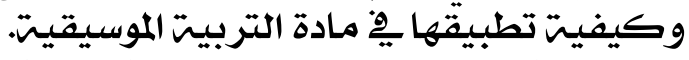

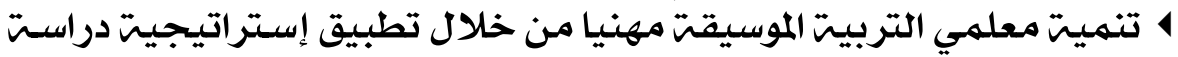

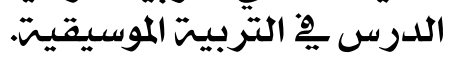

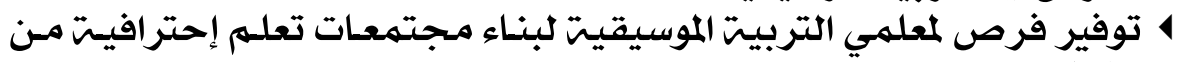

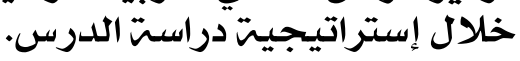

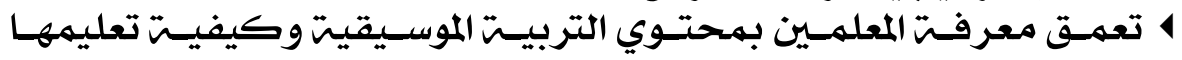

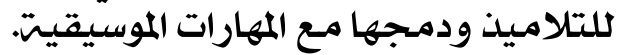

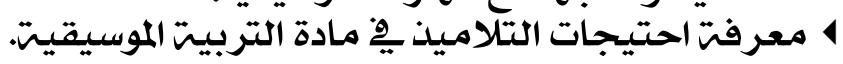

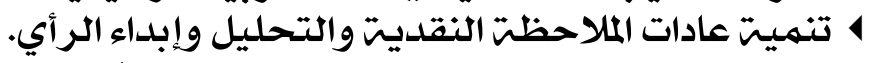

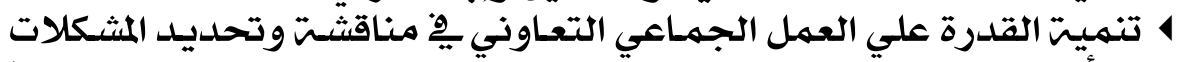

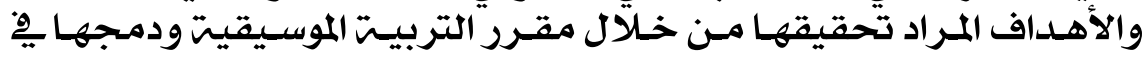
المهارات الموسيقيت أثناء التهيقدريس.

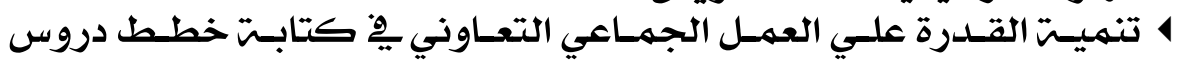

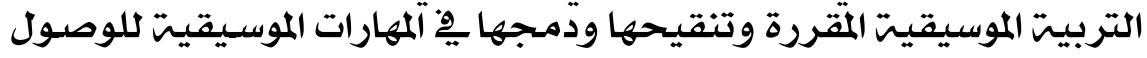

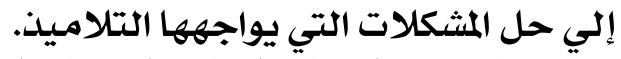

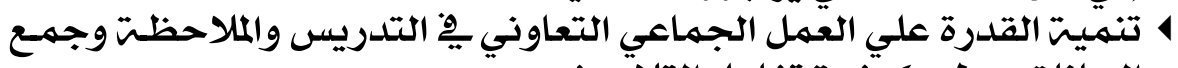

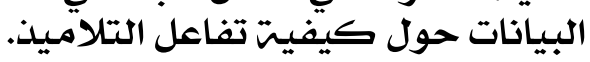

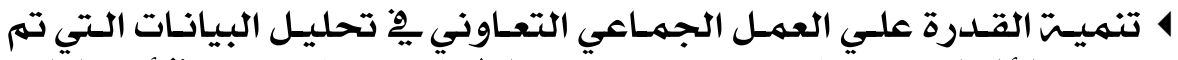

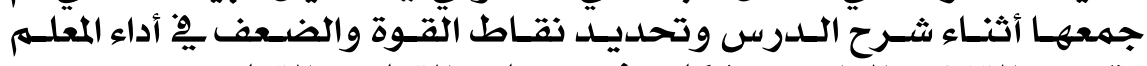

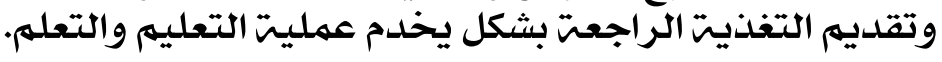

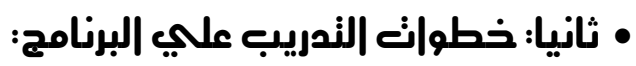

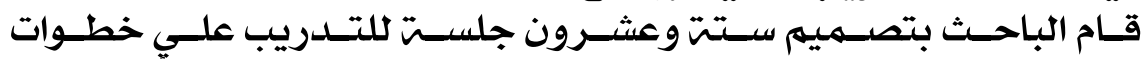

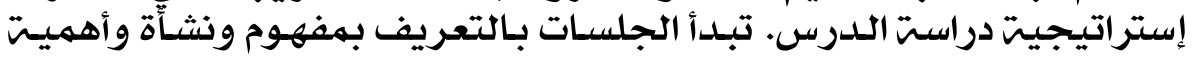

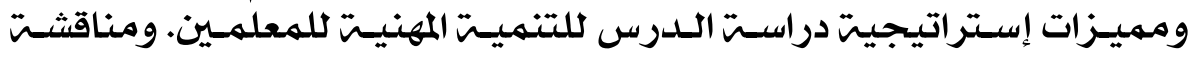




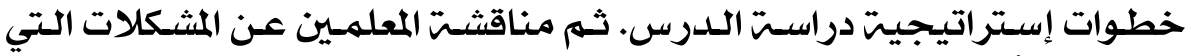

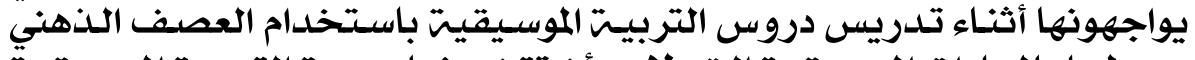

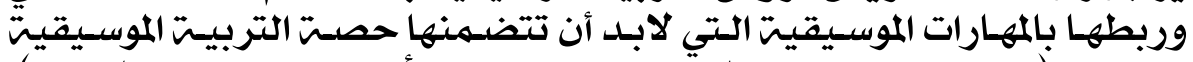

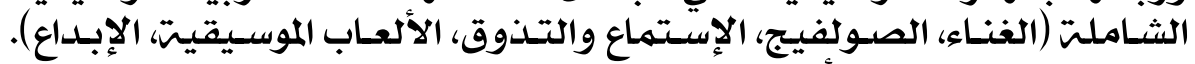

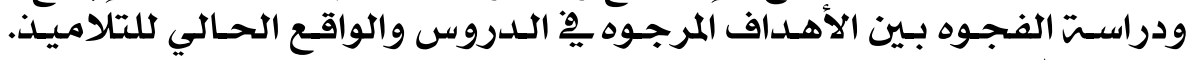

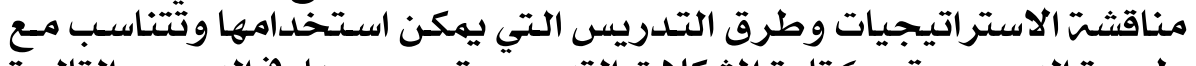

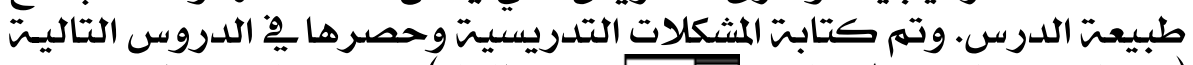

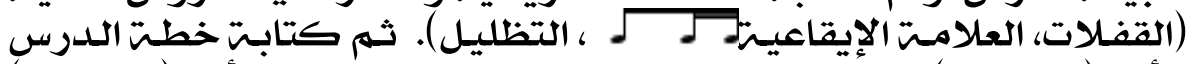

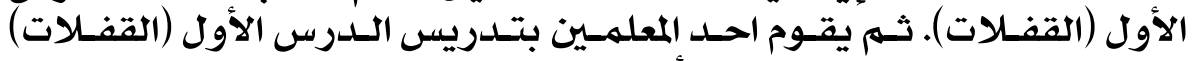

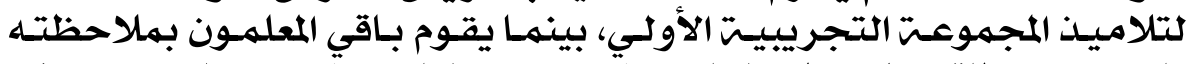

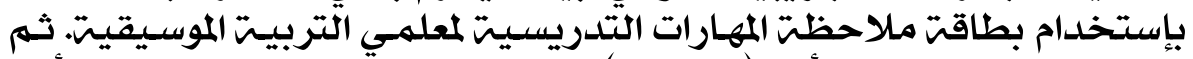

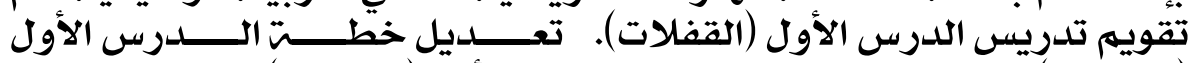

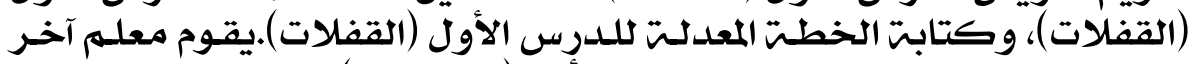

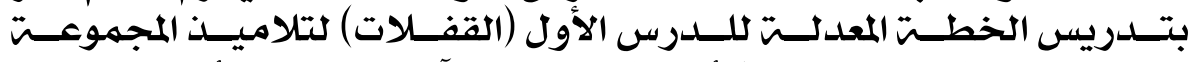

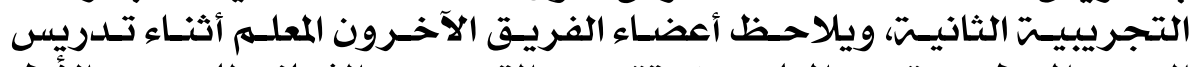

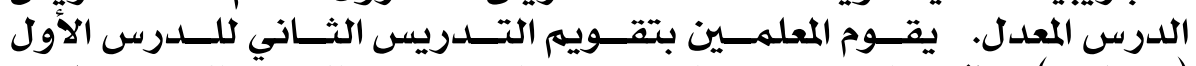

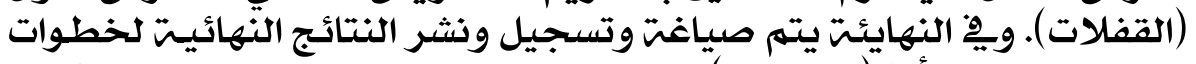

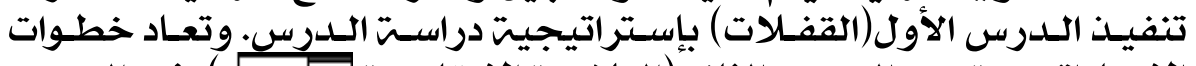

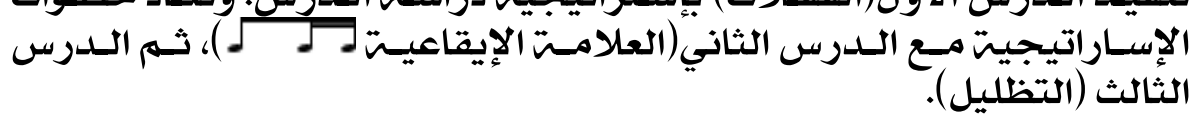

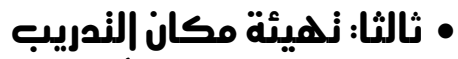

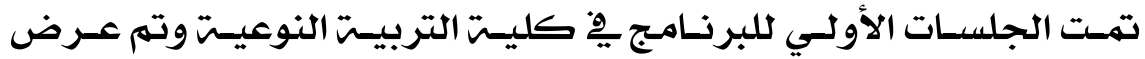

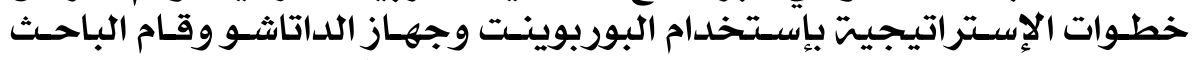

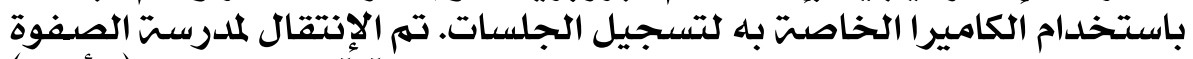

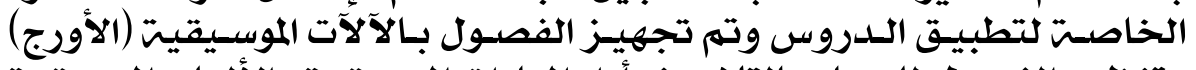

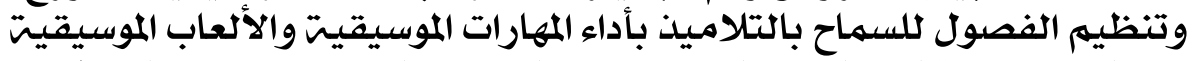

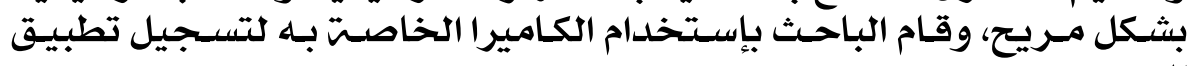
الدروس.

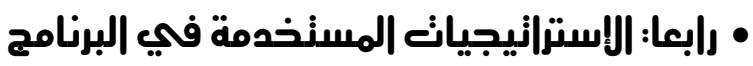

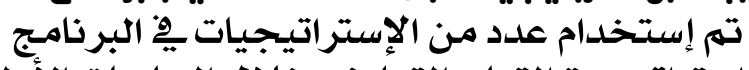

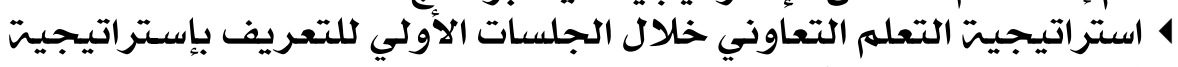

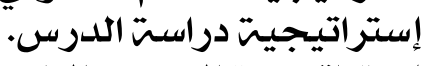

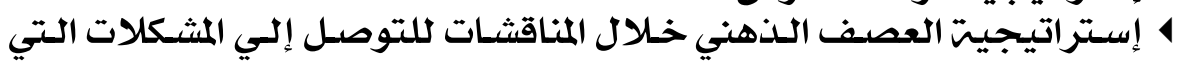

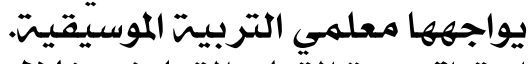

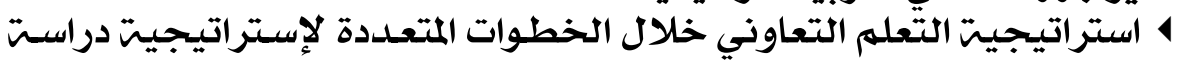
4 استراتيجيت دراستّ الدرس خلال التدريس للدروس. $1 \leqslant 1$ 


\section{• خامسا: نقويم ننائج البرنامج}

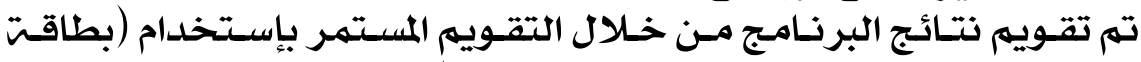

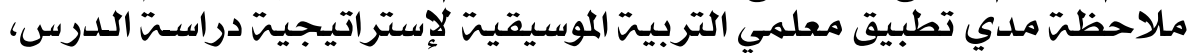

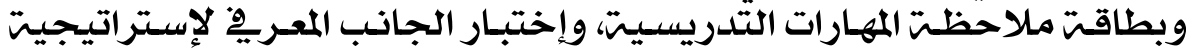

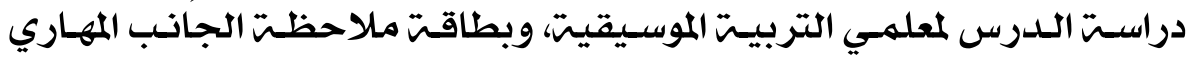

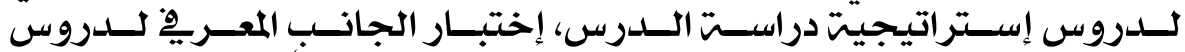

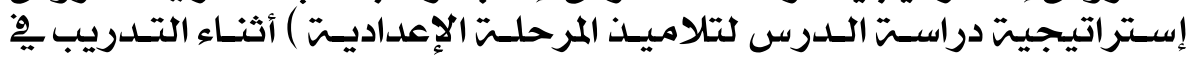

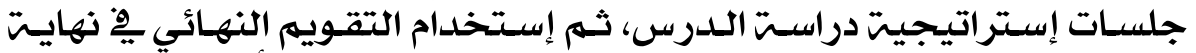

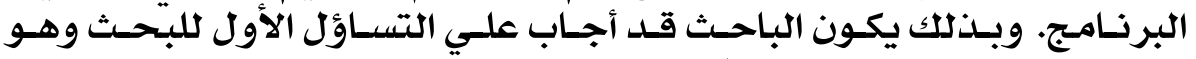

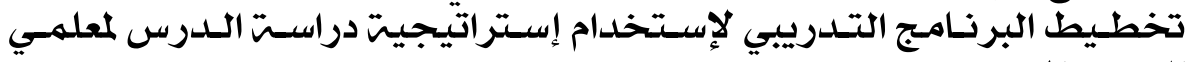
التربيت الموسيقيت.

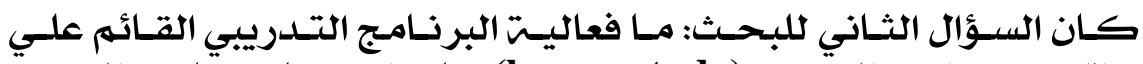

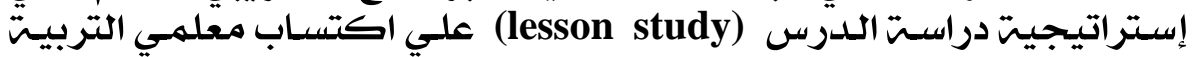

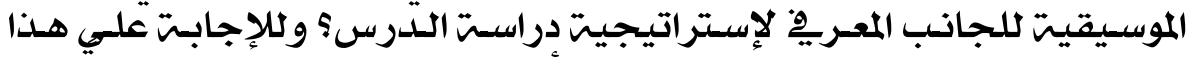

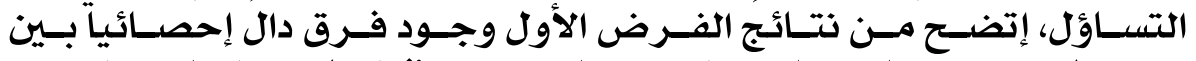

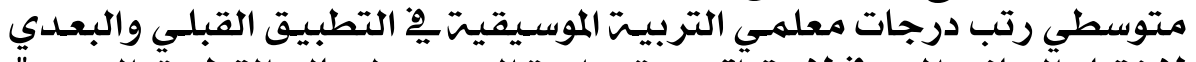

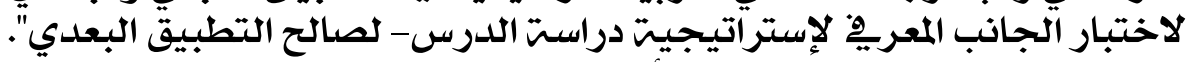

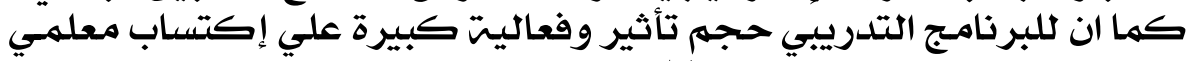

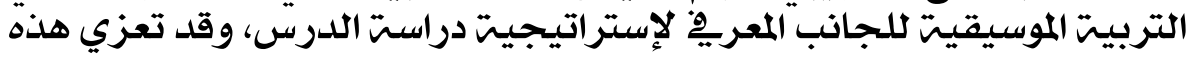
النتيجتش إلي: الموسي:

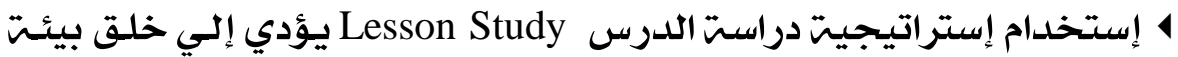

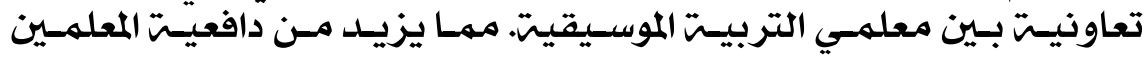

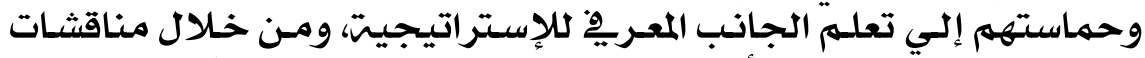

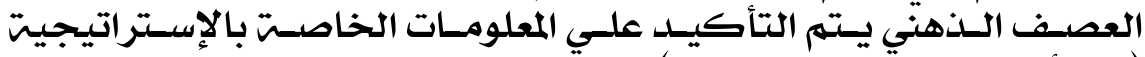

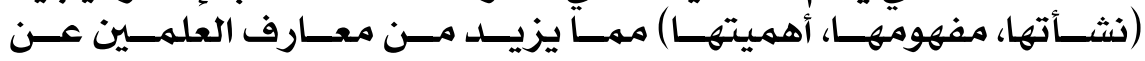

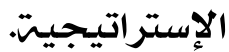

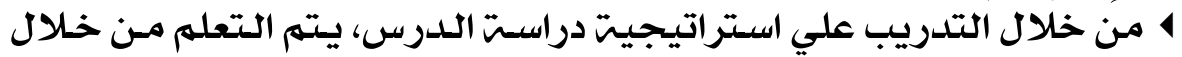

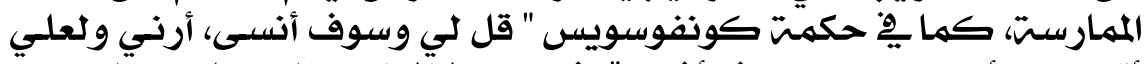

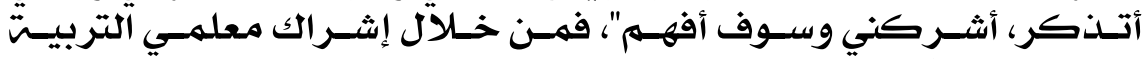

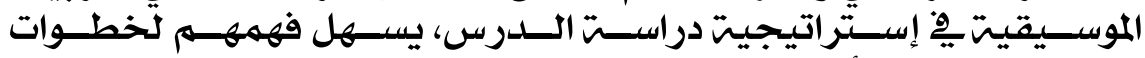

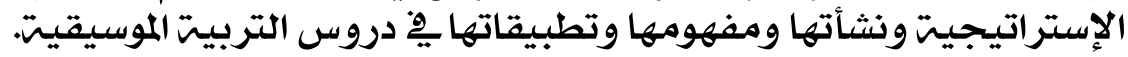

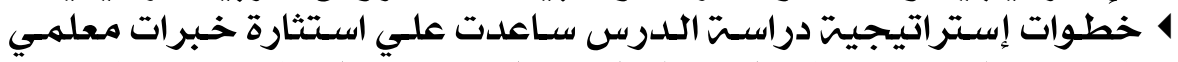

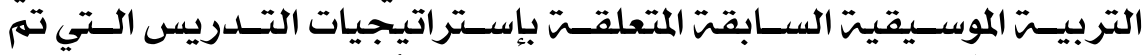

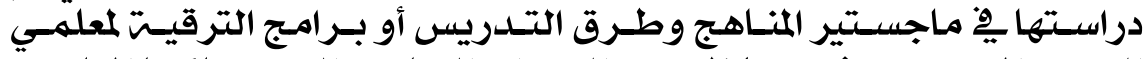

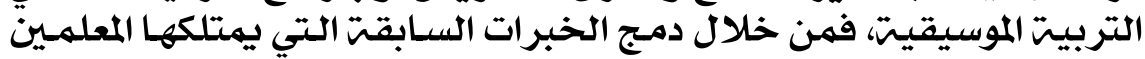

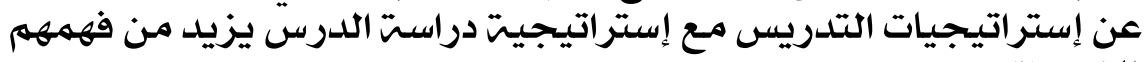
كلإستراتيجيتي. 


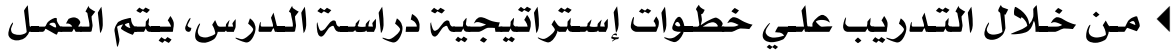

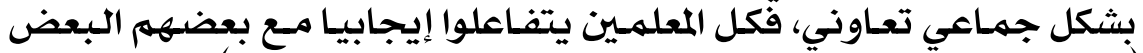

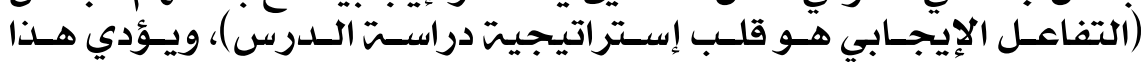

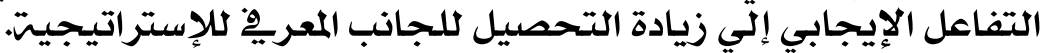

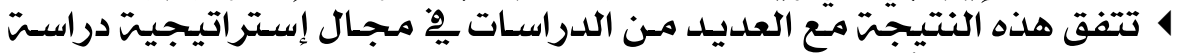

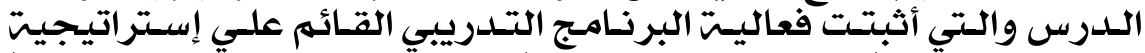

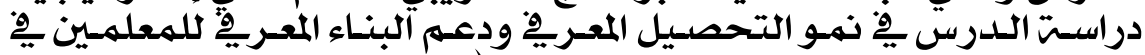

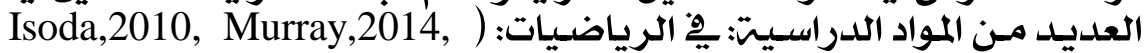
Lewis, Perry, ،Rock\&Wilson,2005, Sotirhos, 2005, Vessela, 2011 ، عبـد Shouffler,2018،Cheng, \& Yee, 2012 \& Hurd, 2009

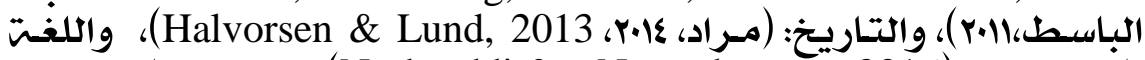
الأنجليزيـت(Nashruddi,\& Nurrachman, 2016)، والعلـوم الإنسـانية

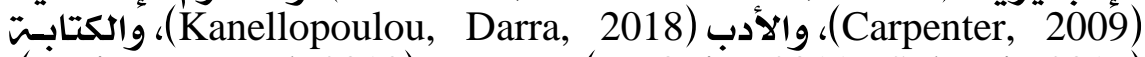

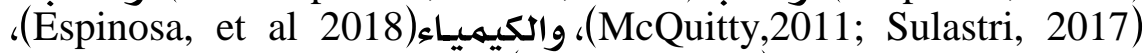

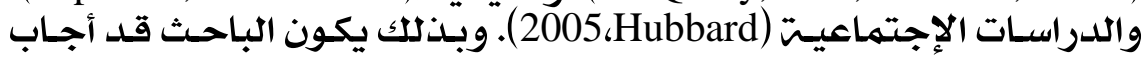

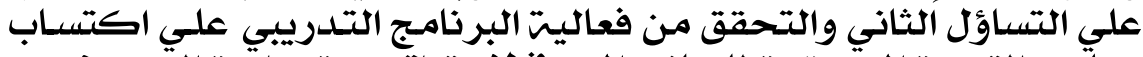

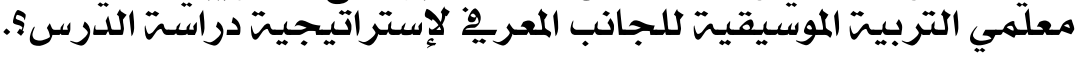

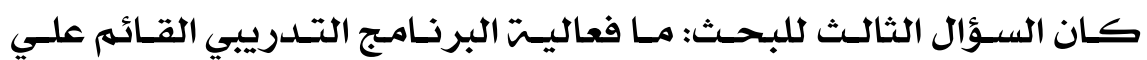

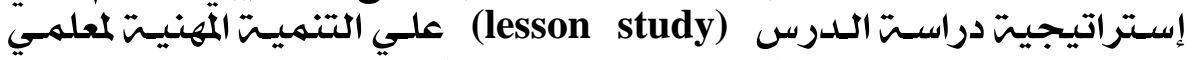

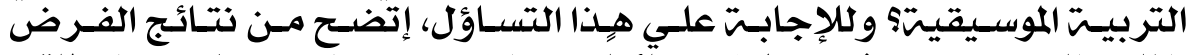

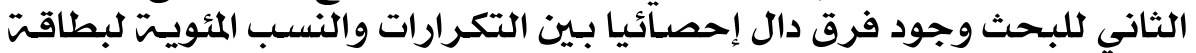

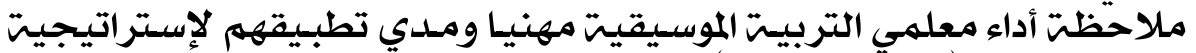

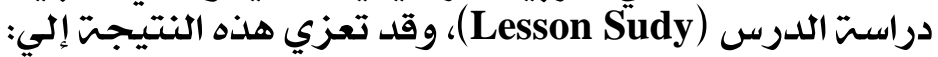

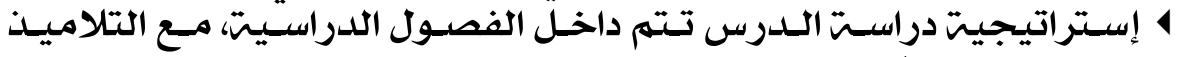

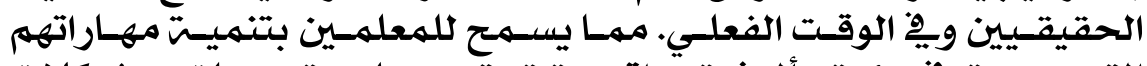

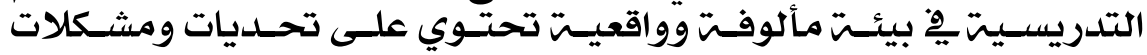

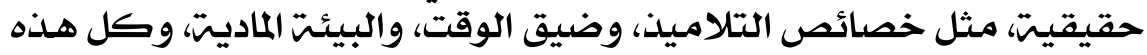

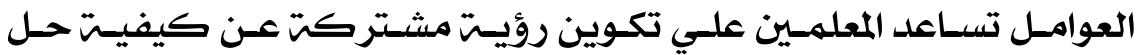
المشكلات من خلال خطوات العات الإستراتيجيتش.

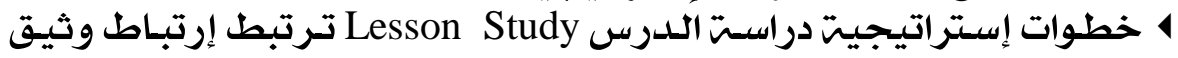

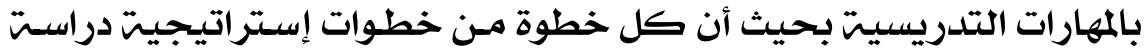

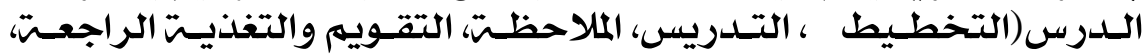

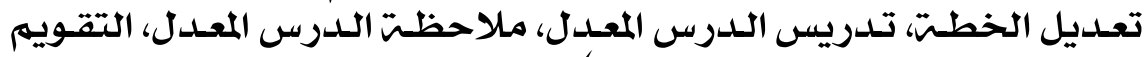

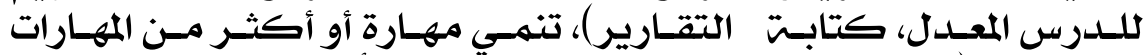

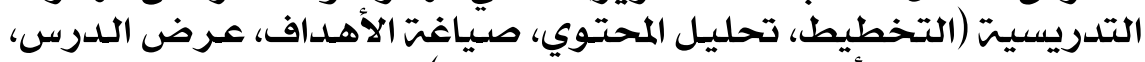

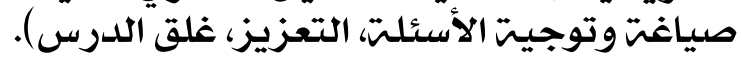

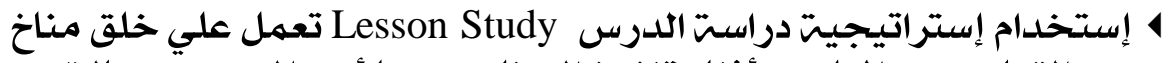

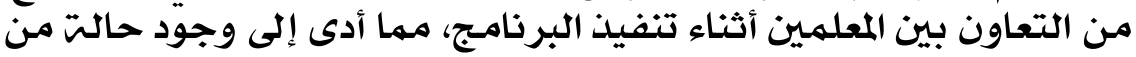




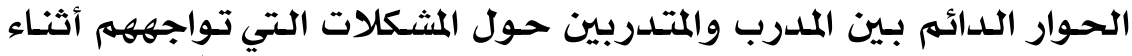

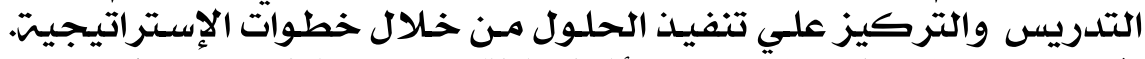

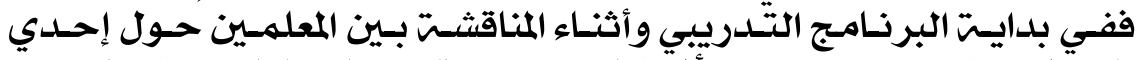

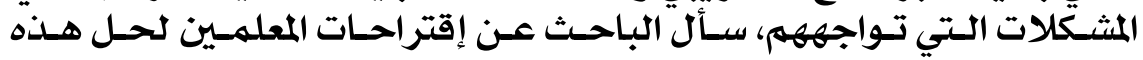

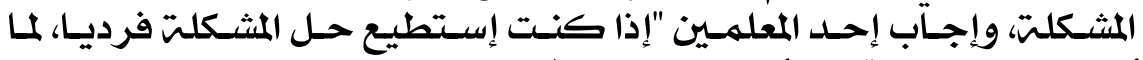

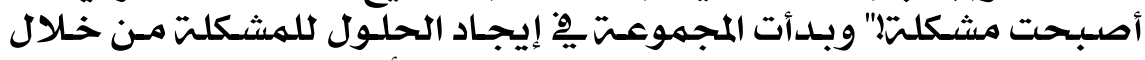

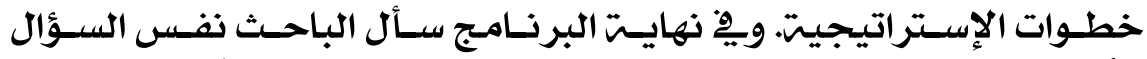

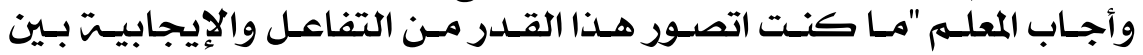

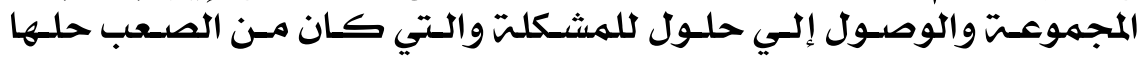

منفردا".

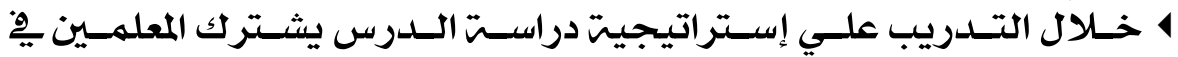

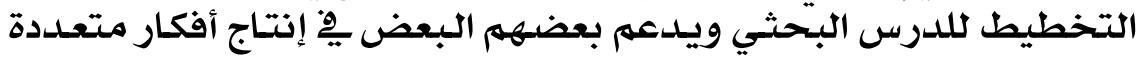

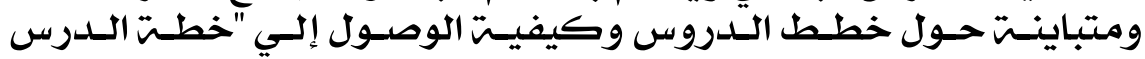

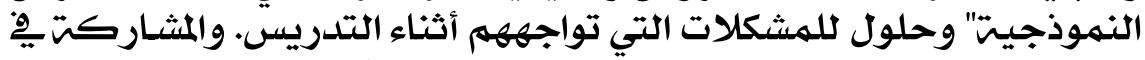

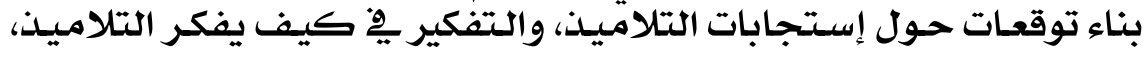

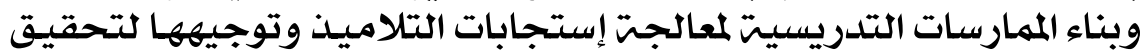

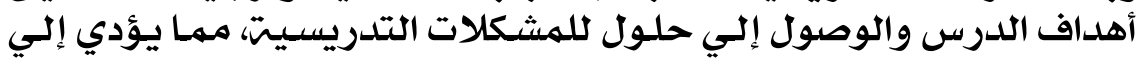

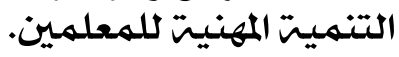

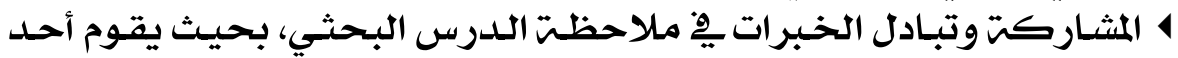

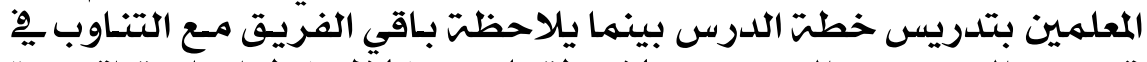

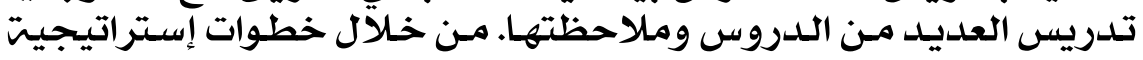

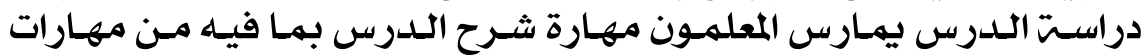

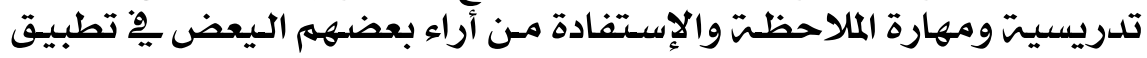

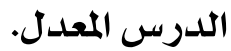

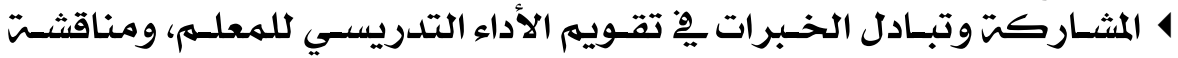

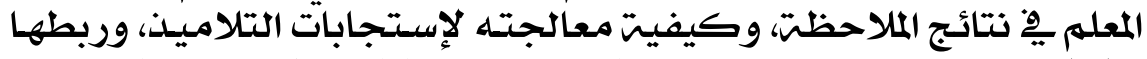

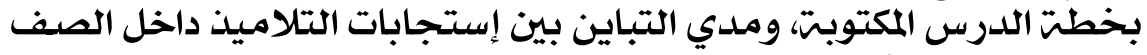

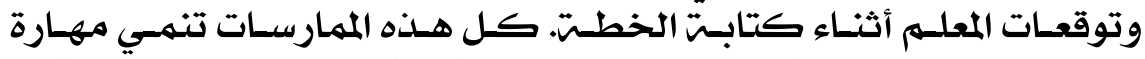

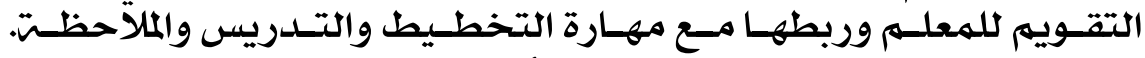

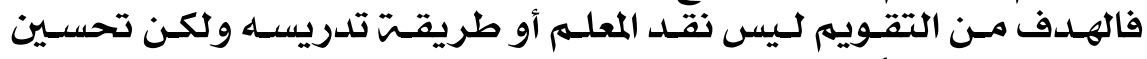

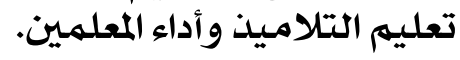

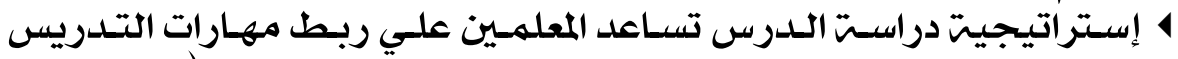

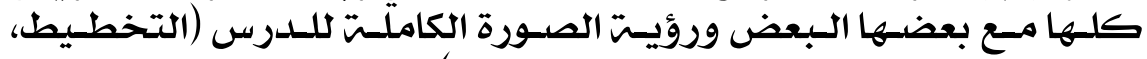

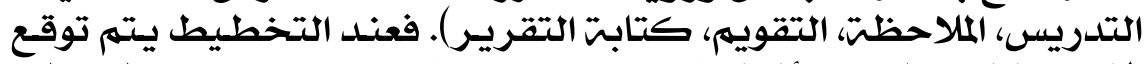

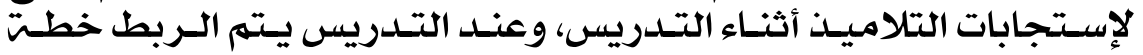

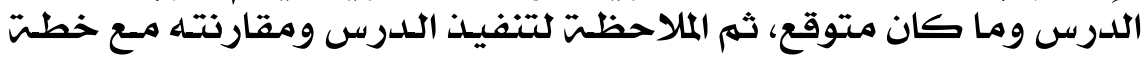

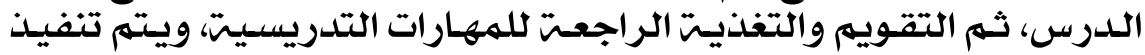

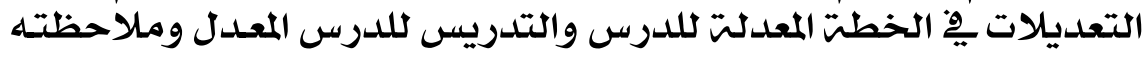




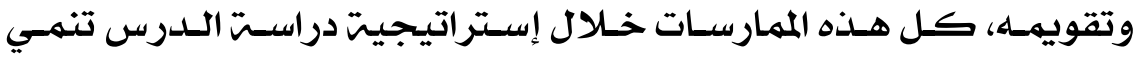

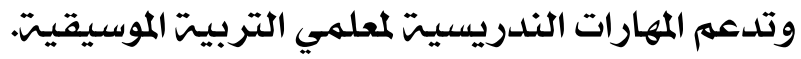

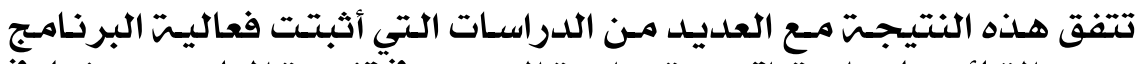

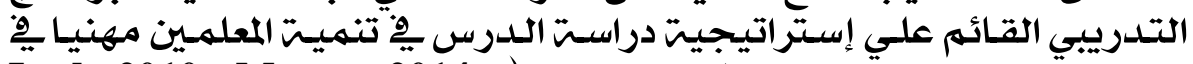

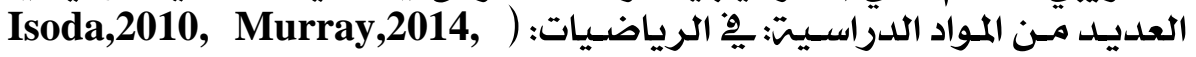
Lewis, Perry, \& ،Rock\&Wilson, 2005, Sotirhos, 2005, Vessela, 2011 الت Shouffler,2018،Cheng, \& Yee, 2012 ،Hurd, 2009

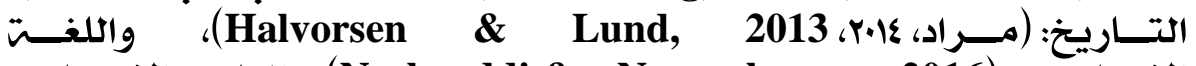
الإنجليزيـتم(Nashruddi,\& Nurrachman, 2016)، والعلــوم الإنسـانيت

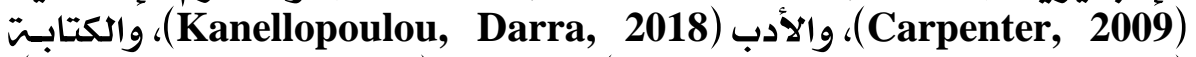

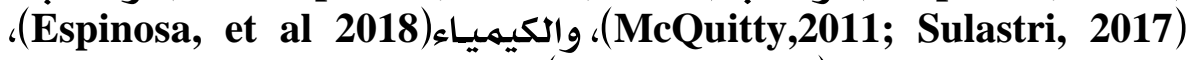
والدراسات الإجتماعيت (2005،Hubbard). وبذلكك يكون الباحث قد أجاب علي

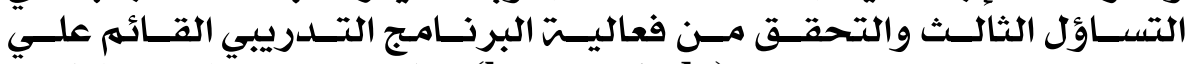

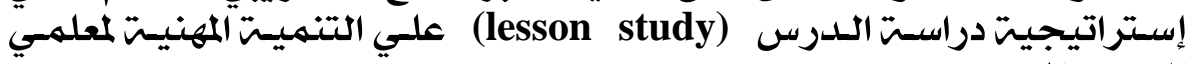

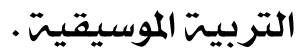

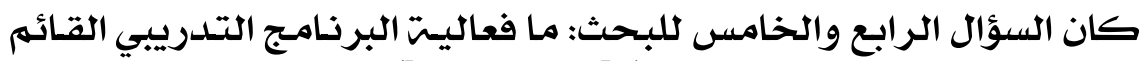

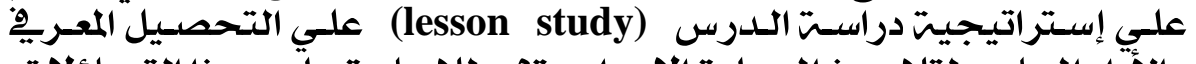

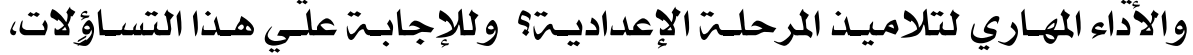

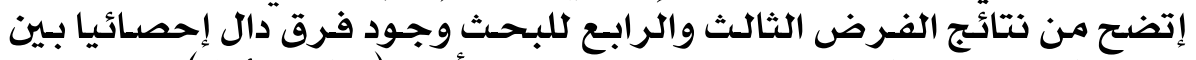

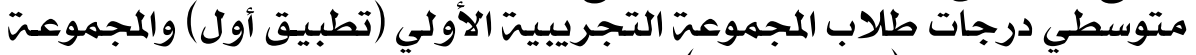

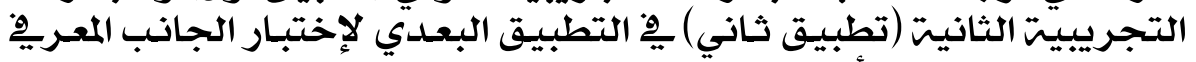

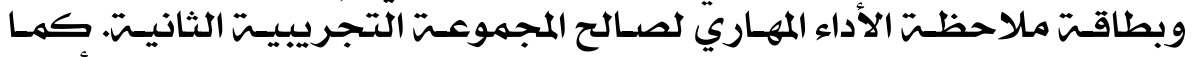

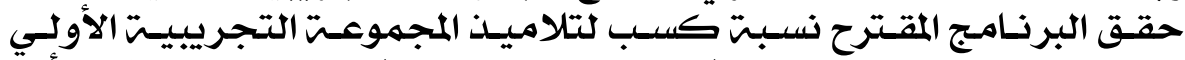

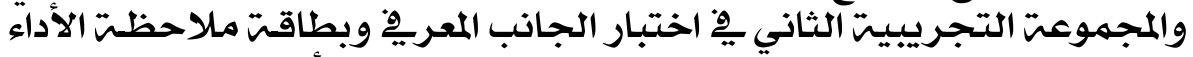

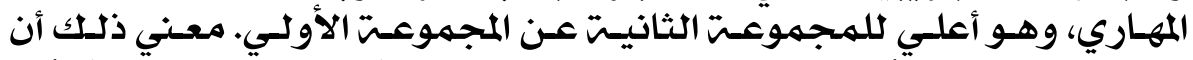

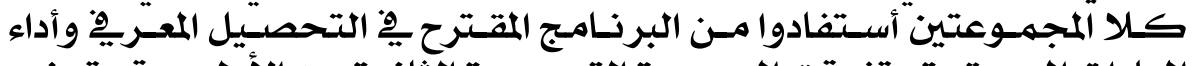

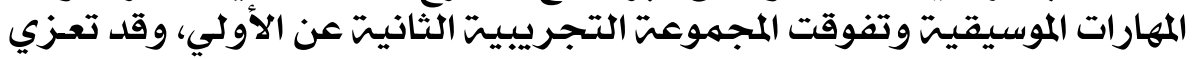
هذه النتيججت إلىي:

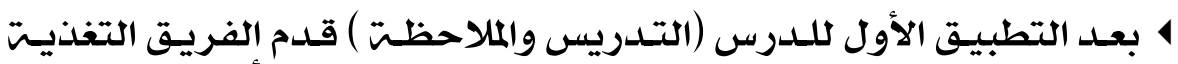

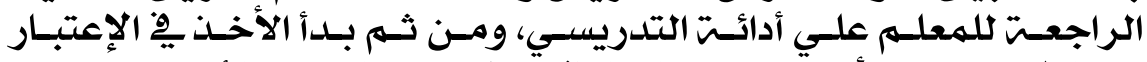

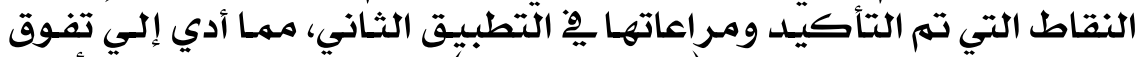

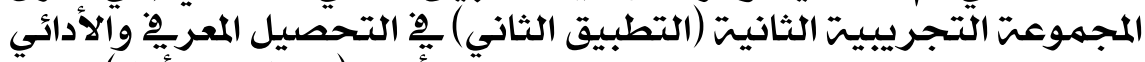

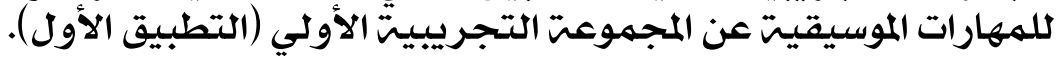

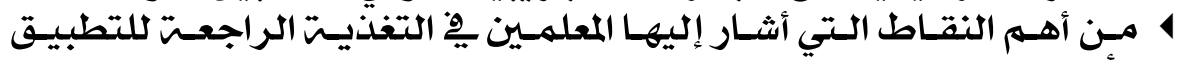

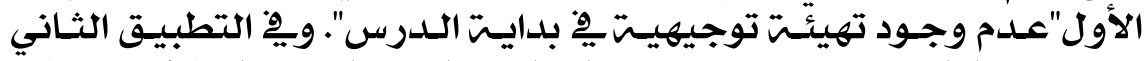

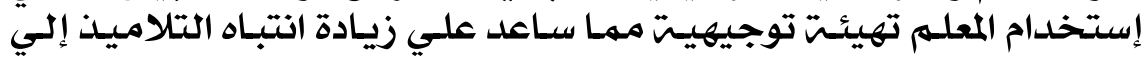




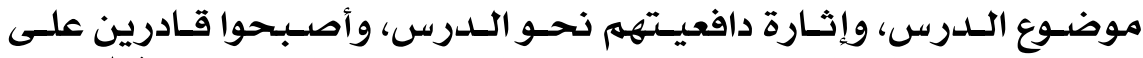

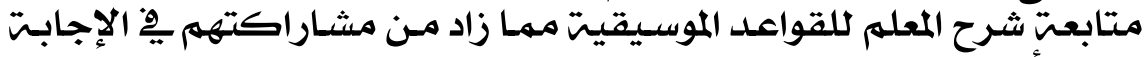
علي الأسئلتّ.

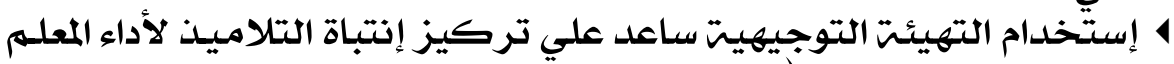

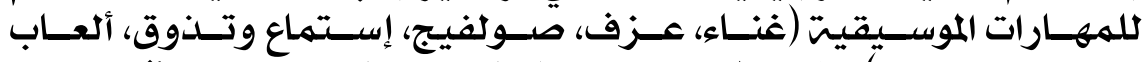

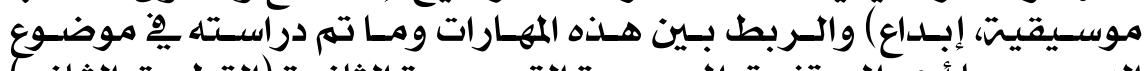

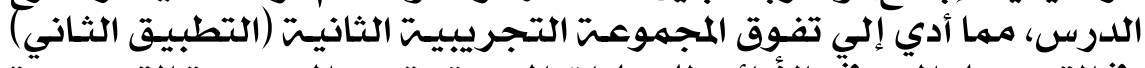

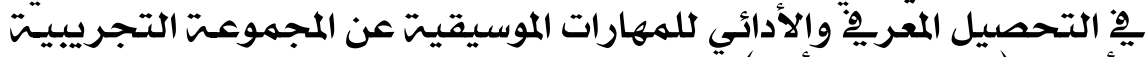

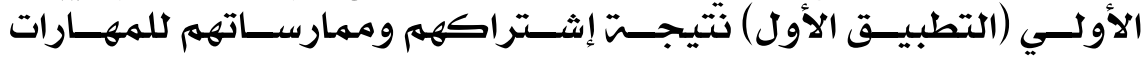
الموسيقيتي.

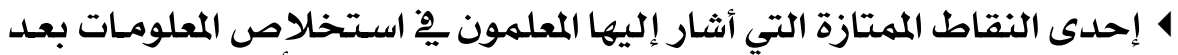

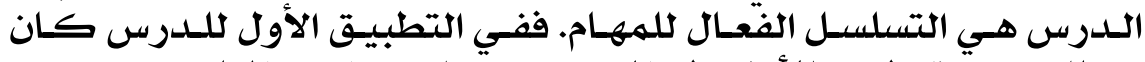

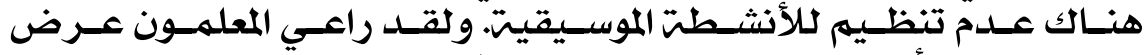

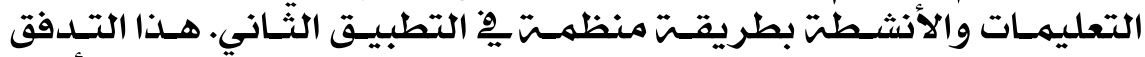

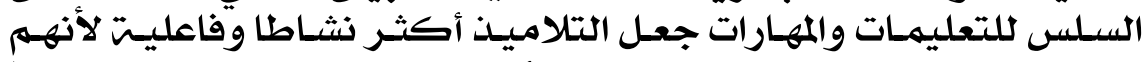

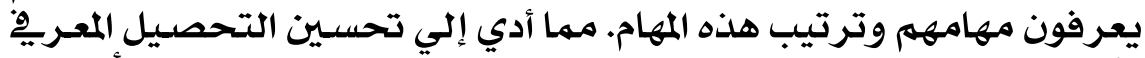

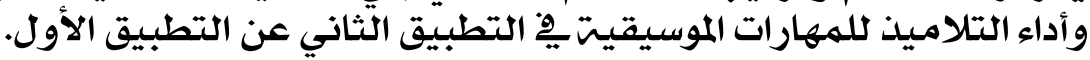

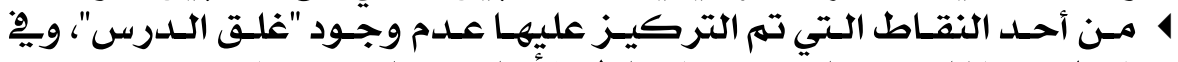

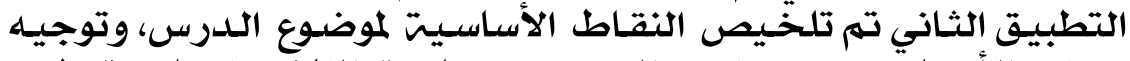

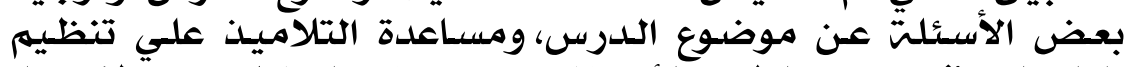

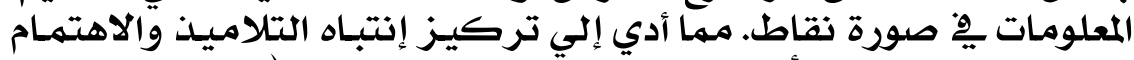

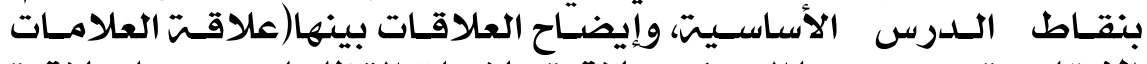

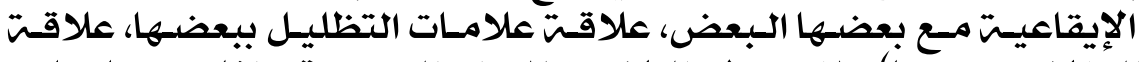

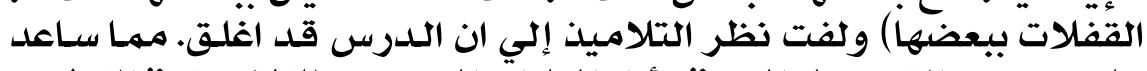

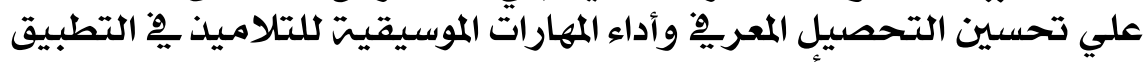

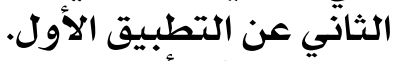

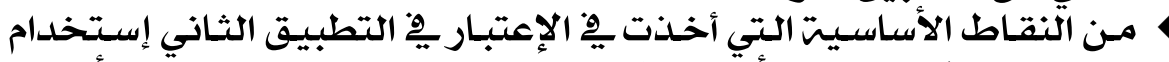

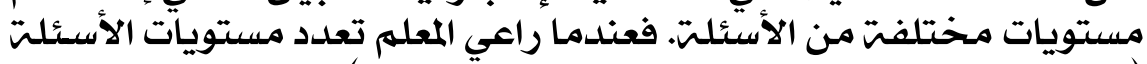

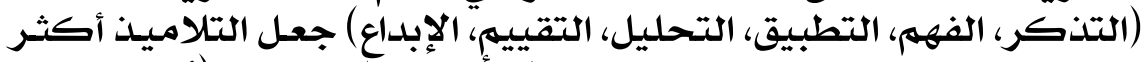

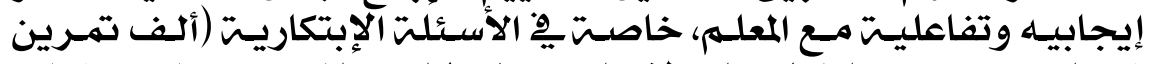

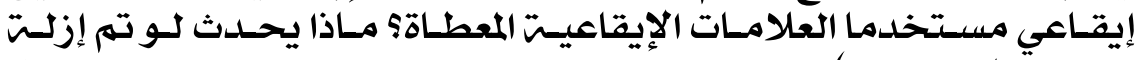

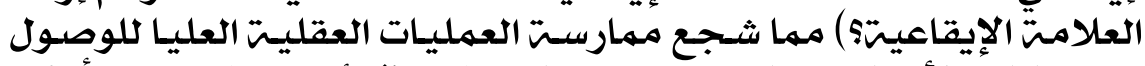

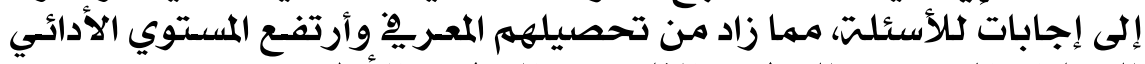

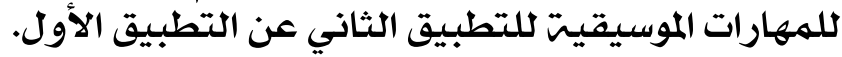

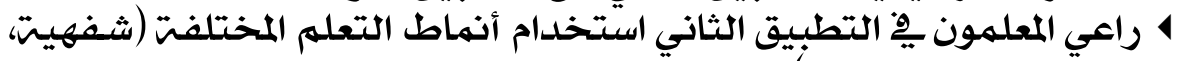

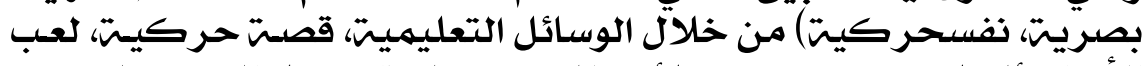

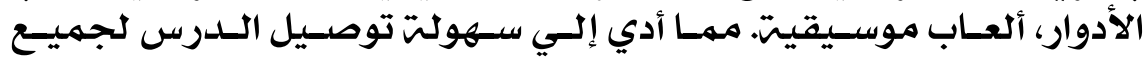




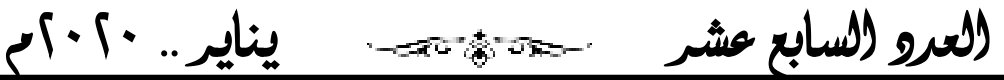

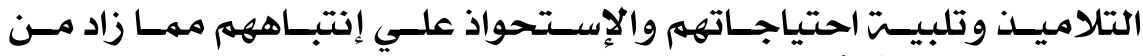

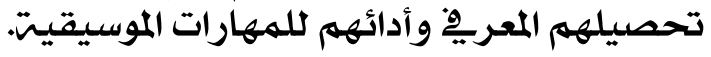

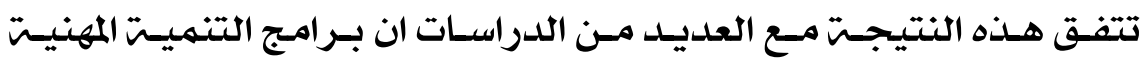

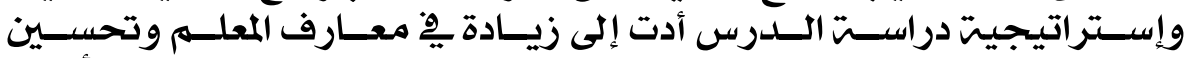

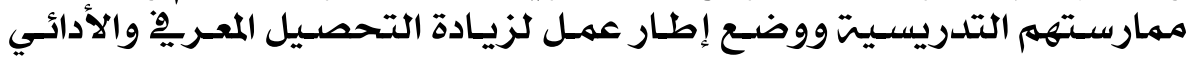
(Desimone et al., 2002; Desimone, 2010; Fulgencio, et al., للتلاميل 2017; Garet et al., 2001; Hochberg \& Porter et al., 2003; Penuel et (al., 2007; Roher, 2009)

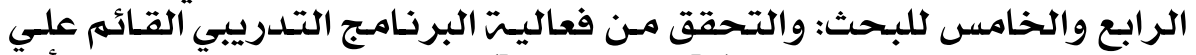

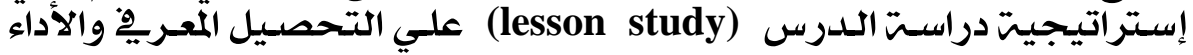
المهاري لتتلاميذ المرحلت الإعداديتية.

\section{• نوصيانه المر|سنة}

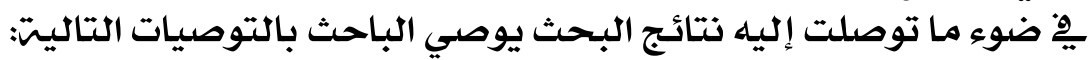

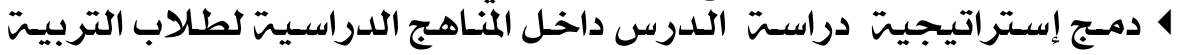

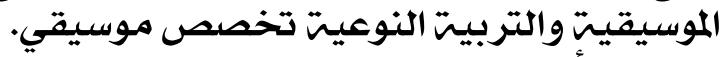

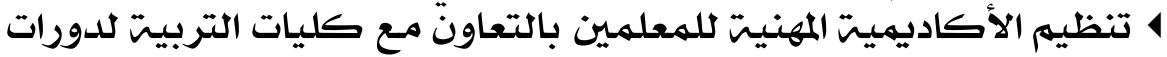

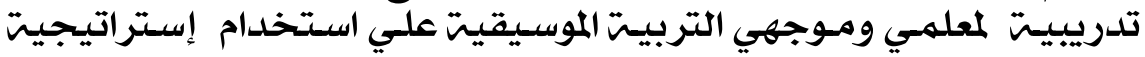
دراستة الدرس.

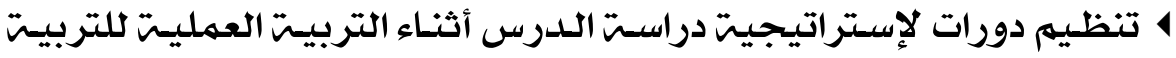

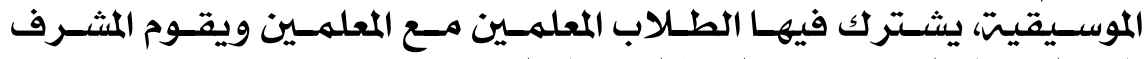

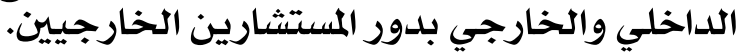

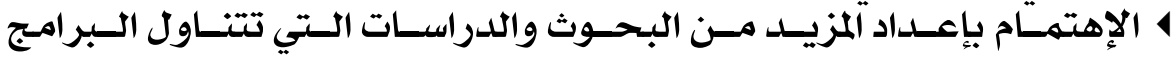

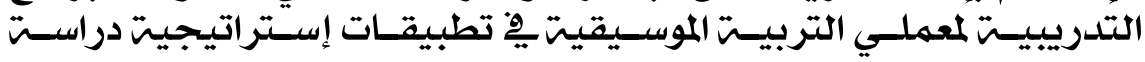
الدرس.

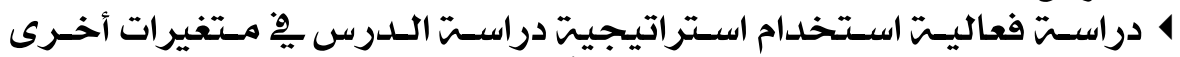

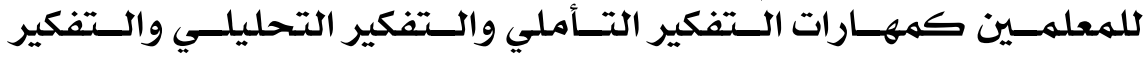
التباعدي.

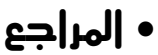

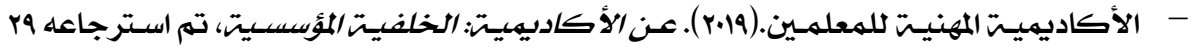

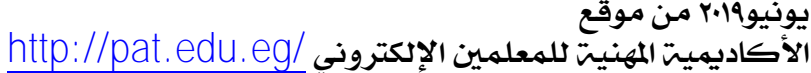

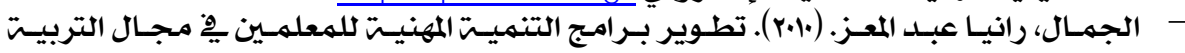

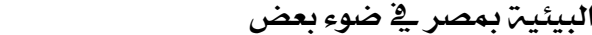

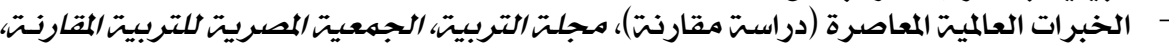

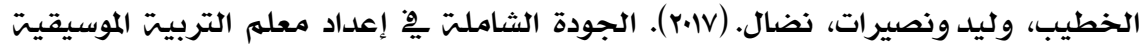
وتنميته مهنيا، دراسات

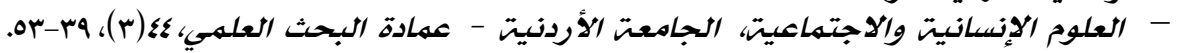




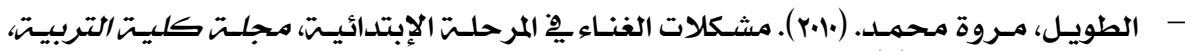

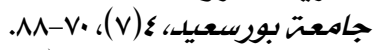

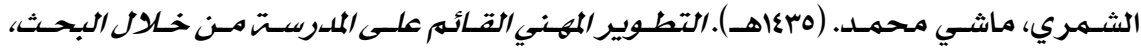

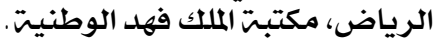

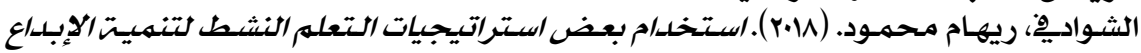

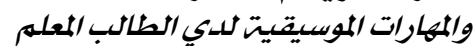

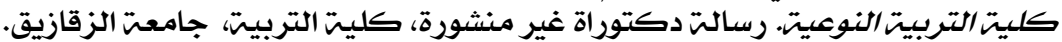

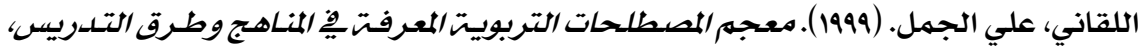

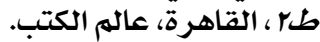

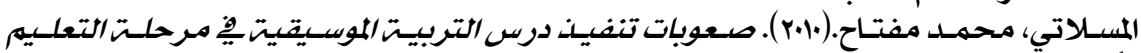

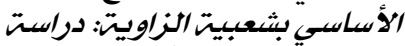

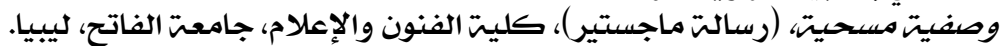

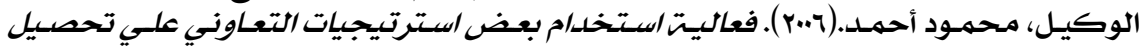

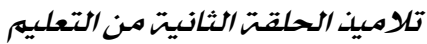

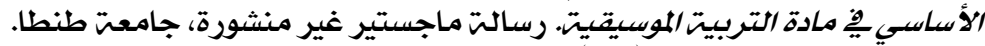

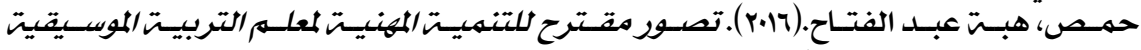

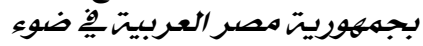

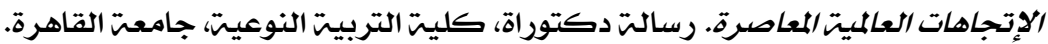

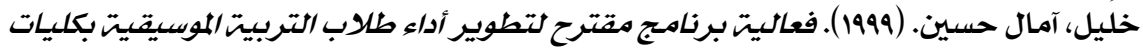

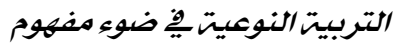

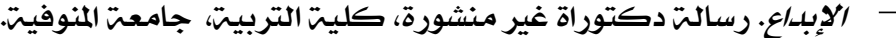

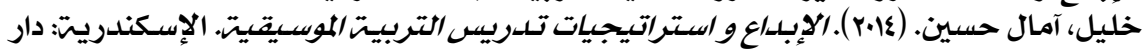
الثقافت العلميتئ.

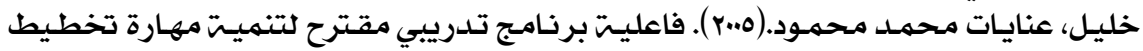

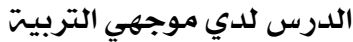

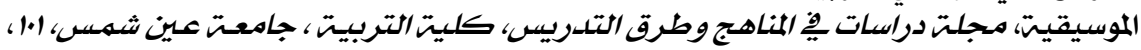
T

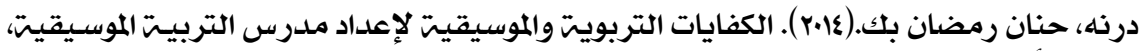

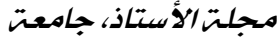

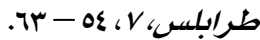

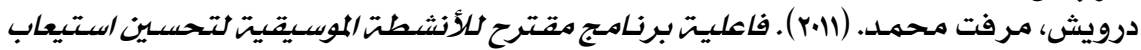

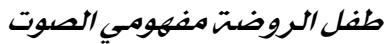

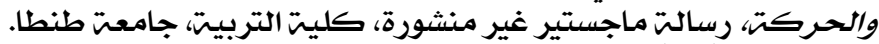

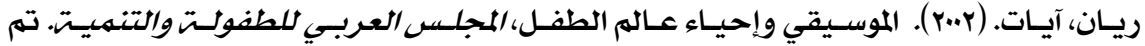

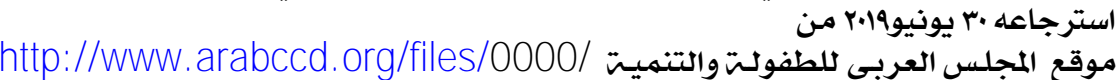
270/Part\%204.pdf

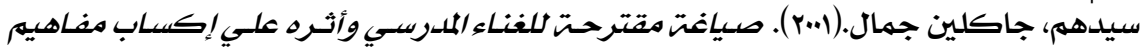

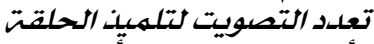

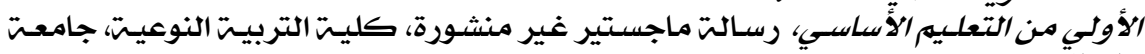
طنطا.

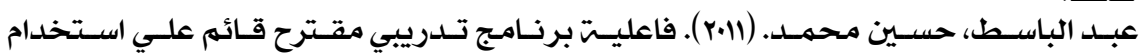

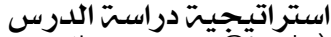

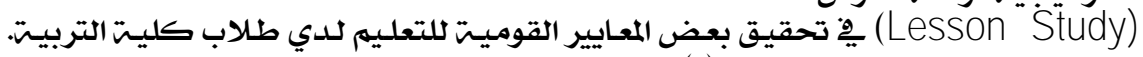

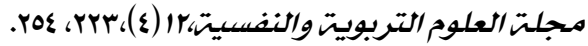
100 


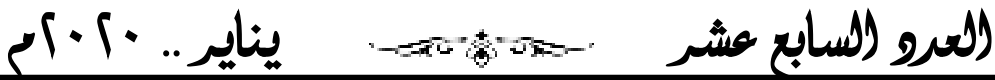

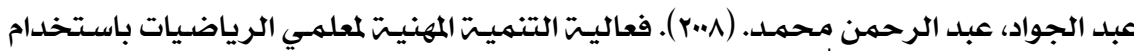

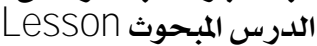

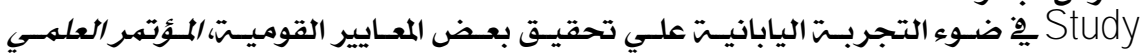

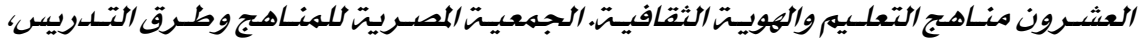

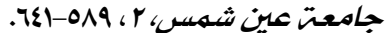

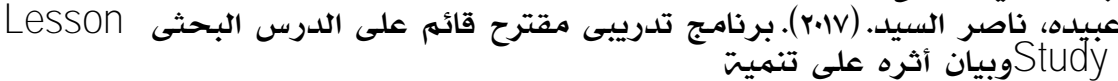

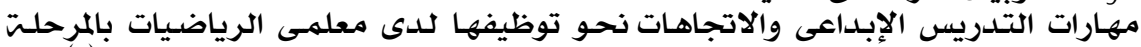

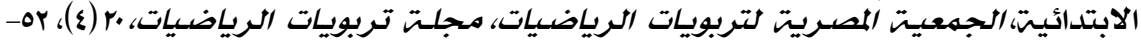

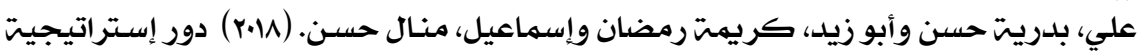

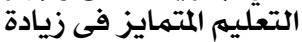

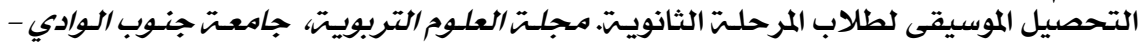

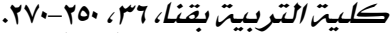

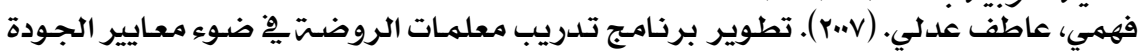

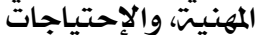

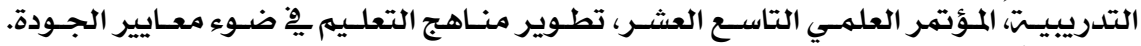

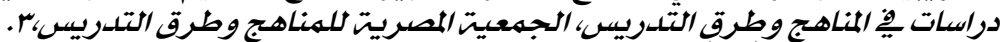

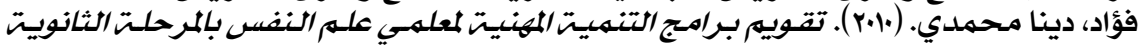

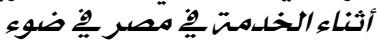

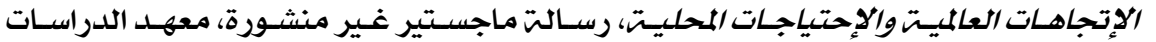

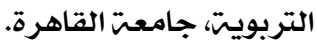

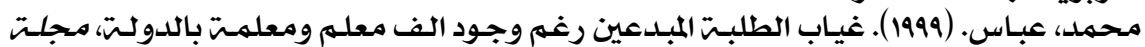

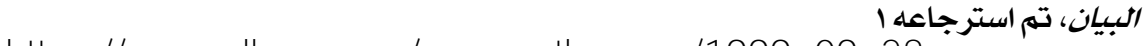
https://mww. albayan.ae/across- the uae/1999- 09- 281.1230995

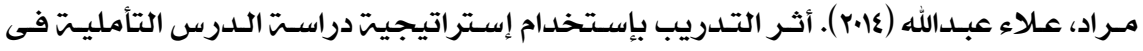

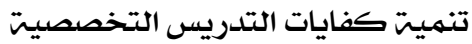

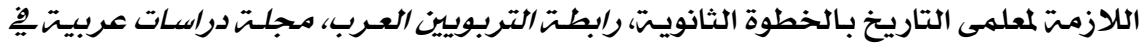

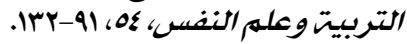

- Arani, M. R. S., Keisuke, F., \& Lassegard, J.P. (2010). "Lesson Study" as professional culture in Japanese schools: an historical perspective on elementary classroom practices. Japan Review, 22, $171-200$

- Avery, S. (2001). Vision 20/20 and in-service education for music teachers.(Doctoral dissertation). Rochester University, New York.

- Barber, K. (2016). Developing mathematical-task knowledge through lesson study. (Doctoral dissertation). Syracuse University

- Barnes, G. V. (2010). Teaching music: The first year. Bulletin of the Council for Research in Music Education, 185, 63-76.

- Barrett, J. R. (2006). Recasting professional development for music teachers in an era of reform. Arts Education Policy Review, 107, 1928.

- Birman, B. F., Desimone, L. M., Porter, A. C., \& Garet, M. (2000). Designing professional development that works. Educational Leadership, 57(8), 28-33. 

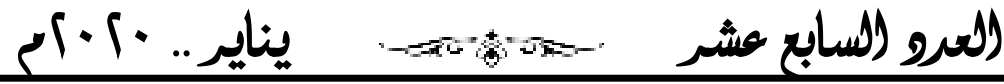

- Borko, H., Jacobs, J., \& Koellner, K. (2010). Contemporary approaches to teacher professional development. International Encyclopedia of Education, 7, 548-556.

- Boyle, J. D. (1992). Evaluation of music ability. In R. Cowell (Ed.), Handbook of research on music teaching and learning (pp. 247265). New York: Schirmer.

- Bowyer, J. (2015). More than solfège and hand signs: philosophy, tools, and lesson planning in the authentic Kodaly classroom, Music Educators Journal, 102 (2), 69-76.

- Bush, J. E. (2000). The effects of a hypermedia program, cognitive style, and gender on middle school students' music achievement, Contributions to Music Education, Ohio Music Education Association, 27 (1), 9-26.

- Bush, J. E. (2007). Importance of various professional development opportunities and workshop topics as determined by in-service music teachers. Journal of Music

- Teacher Education, 16(2), 10-18.

- Byo, J. L. (2017). "Modern Band" as school music: A case study. International Journal of Music Education, 36(2), 259-269.

- Carpenter, J. (2009). Lesson study by secondary humanities teachers. (Doctoral dissertation). Curry School of Education. Virginia University.

- Cerbin, B., \& Kopp, B. (2006). Lesson study as a model for building pedagogical knowledge and improving teaching. International Journal of Teaching and Learning in Higher Education, 18(3), 250257.

- Cerbin, B., \& Kopp, B. (2011). Lesson study project overview. Retrieved from http://www.uwlax.edu/sotl/lsp/overview.htm

- Chassels, C., \& Melville, W. (2009). Collaborative, reflective, and iterative Japanese lesson study in an initial teacher education program: Benefits and challenges. Canadian Journal of Education 32 (4), 734-763

- Cheng, L., \& Yee, L. (2012). A singapore case of lesson study. Mathematics Educator, 21(2),34-57.

- Chichibu, T., \& Kihara, T. (2013). How Japanese schools build a professional learning community by lesson study. International Journal for Lesson and Learning Studies, 2(1), 12-25.

- Cohen, D. \& Hill, H. (2000). Instructional policy and classroom performance: The mathematics reform in California. Teachers College Record, 102, 294-343.

- Conway, C. M. (2007). Setting an agenda for professional development policy,practice, and research in music education. Journal of Music Teacher Education 17(1), 56-61.

- Conway, C. M., \& Edgar, S. N. (2014). Inservice music teacher professional development. In C. M. Conway (Ed.), The Oxford handbook of qualitative research in American music education (pp. 479-500). New York: Oxford University Press. 
- Conway, C. M., \& Zerman, T. (2004). Perceptions of an instrumental music teacher regarding mentoring, induction, and the first year of teaching. Research studies in music education, 22, 72-83

- Darling-Hammond, L. (1996). The quiet revolution: Rethinking teacher development. Educational Leadership, 53(6), 4-10.

- Darling-Hammond, L. (1998). Teachers and teaching: Testing policy hypotheses

- from a National Commission. Educational Researcher, 27(1), 5-15.

- Darling-Hammond, L., \& Richardson, N. (2009). Teacher learning: What matters? How Teachers Learn, 66(5), 46-53.

- Darling-Hammond, L., Wei R. C., Andree, A., Richardson, N., \& Orphanos, S. (2009). Professional learning in the learning profession: A status report on teacher development in the United States and abroad. Oxford, OH: National Staff Development Council. Retrieved from https://learningforward.org/docs/pdf/nsdc study 2009.pdf

- Bauer, W. I. (2007). Research on professional development for experienced music teachers. Journal of Music Teacher Education, 17(1), 12-21.

- Desimone, L. M., Porter, A. C., Garet, M. S., Yoon, K. S., \& Birman, B. F. (2002). Effects of professional development on teachers' instruction: Results from a three-year longitudinal study. Education Evaluation and Policy Analysis, 24(2), 81-112.

- DuFour, R., DuFour, R., \& Eaker, R. (2008). Revisiting professional learning communities at work: New insights for improving schools. Bloomington, IN: Solution Tree Press.

- Espinosa, A., Datukan, J., Butron , B., \&, Tameta, A. (2018). International Journal for the Scholarship of Teaching and Learning, 12 (1), 1-7.

- Fernandez, C. (2002). Learning from Japanese approaches to professional development: the case of lesson study. Journal of Teachers Education, 53(5), 393-405.

- Freeman, C. (2011). Effects of teaching intensity on high school band students' music achievements and attitudes. (Doctoral dissertation), Wake Forest, North Carolina University.

- Fulgencio M. G., Laristan, S., \& San Andres, P. B. (2017).Aapplying lesson study to develop

- manipulatives based lesson and improve student academic achievement. Proceedings of the 2017 International Conference of Joint Societies for Mathematics Education: KSME, KSESM, Singapore NIE, Seoul, Korea.

- Garet, M., Porter, A., Desimone, L., Birman, B., \& Yoon, K. S. (2001). What makes professional development effective? Results from a national sample of teachers. American Educational Research Journal, 38 (4), 915-945.

- Gersten, R., Dimino, J., Jayanthi, M., Kim, J. S., \& Santoro, L. E. (2010). Teacher study group: Impact of the professional development model on reading instruction and student outcomes in 
first grade classrooms. American Educational Research Journal, 47, 694-739.

- Giannakidou, E., Yoftsali, K., \& Tziora, E. (2013). The Reflective Action of Candidate Teachers in Applying an Adapted Version of the Lesson Study Model. Research in Education Hellenic Journal of Research in Education, 1, 30-58. Alexandroupolis.

- Green, L. (2002). How popular musicians learn: A way ahead for music education. Aldershot: Ashgate.

- Green, L. (2004). What can music educators learn from popular musicians? In C.X. Rodriguez (Ed.), Bridging the gap: Popular music and music education (pp. 224- 240). Reston, VA: MENC: The National Association for Music Education.

- Green, L. (2008). Music, informal learning and the school: A new classroom pedagogy. Aldershot: Ashgate.

- Green, L., \& Walmsley, A. (2006). Classroom resources for informal learning .London: Paul Hamlyn Foundation.

- Gruenhagen, L. M. (2007). Investigating professional development: Early childhood music teacher learning in a community of practice (Doctoral dissertation). Retrieved from ProQuest Digital Dissertations (UMI No. 3295323).

- Halvorsen, A. \&, Lund, A. (2013). Lesson study and history education. Journal of Social Studies, 104 (3), 123-129.

- Hammond, Linda D.; Wei, Ruth C.; Andree, Alethea, \& Richardson, Nikole (2009). Professional learning the learning profession, a status report on teacher development in the united states and abroad, National Staff Development Council NSDC, Stanford University, USA.

- Hiebert, J., Gallimore, R., \& Stigler, J. (2002). A Knowledge base for the teaching profession: What would it look like and how can we get one? Educational Researcher, 31(5), 3-15.

- Hochberg, E., \& Desimone, L. (2010). Professional development in the accountability context: Building capacity to achieve standards. Educational Psychologist, 45(2), 89-106.

- Holmes, A. (2009). Effect of fixed-do and movable-do solfege instruction on the development of sight-singing skills in 7- and 8year-old children. (Doctoral dissertation). Florida University .

- Hookey, M. (2002). Professional development. In R. Colwell \& C. P. Richardson (Eds.), The new handbook of research on music teaching and learning (pp. 887-902). New York: Oxford University Press.

- Hubbard. D. (2005). The implications of using lesson study as a professional development model for second grade social studies teachers. (Doctoral dissertation). Alabama University.

- Hurdj J., \& Licciardo-Musso, L. (2005). Lesson study: Teacher-led professional development in literacy instruction. Language Arts, 82(5), 388-395.

- Isoda, M. (2010). Lesson Study: Problem Solving approaches in Mathematics Education as a Japanese Experience. Procedia Social and Behavioral Sciences, 8, 17-27. 

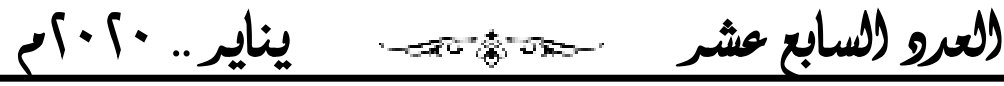

- Jenne, K. (2005). Lesson study as a form of professional development for teaching and learning mathematics. (Doctoral dissertation). New Mexico University.

- Johnson, E. A. (2011). The effect of peer-based instruction on rhythm reading achievement, Contributions to Music Education, Ohio Music Education Association, 38 (2), 43-60.

- Kanellopoulou, M. \& Darra, M. (2018). The planning of teaching in the context of lesson study: Research findings. International Education Studies, 11, (2), 67-82.

- Kastner, J. D. (2014). Exploring informal music learning in a professional development community of music teachers. Bulletin of the Council for Research in Music Education, 202, 71-89.

- Kujawski, L.S. (1996). Engagement in musical activities by elementary classroom teachers in specialist and non-specialist settings. (Doctoral dissertation). Arizona State University.

- Levy, D. W. (2016). Examining the impacts of varied curriculum approaches on music achievement: A quasi-experimental action research study informing cognitive theory. (Doctoral Dissertation). North-central University, Prescott Valley, Arizona.

- Lewis, C. \& Tsuchida, I. (1998). A lesson is like a swiftly flowing river: Research lessons and the improvement of Japanese education. American Educator, 14-17 \& 50-52

- Lewis, C., Perry, R. \& Murata, A. (2006). How should research contribute to instructional improvement? The case of lesson study. Educational Researcher, 35(3), 3-14.

- Lewis, C., Perry, R., Hurd, J. \& O’Connell, M. P. (2006). Lesson study comes of age in North America. The PhiDelta Kappan, 88(4), 273-281.

- Lewis, C., \&Perry, R. (2008). What is successful adaptation of lesson in the U.S.? Journal of Educational Change, 10(4), 365-391.

- Lewis, C. C., Perry, R. R., \& Hurd, J. (2009). Improving mathematics instruction through lesson study: A theoretical model and North American case. Journal of Mathematics Teacher Education, 12(4), 285- 304.

- Lewis, C., \& Hurd, J. (2011). Lesson Study step by step. How Teacher Learning Communities Improve Instruction. Portsmouth, $\mathrm{NH}$, USA.

- Loucks-Horsley, S., Stiles, K., \& Hewson, P. (1996). Principles of effective professional development for mathematics and science education: A synthesis of standards. National Institute for Science Education Brief, 1(1). Madison: University of Wisconsin-Madison.

- Maehr, M. L., Pintrich, P. R., \& Linnenbrink, E. A. (2002). Motivation and achievement.In R. Colwell, \& C. Richardson (Eds.). The new handbook of research on music teaching and learning: A project of the Music Educators National Conference (pp. 348-372). New York: Oxford University Press. 
- McCombs, B., \& Whisler, J. S. (1997). The learner-centered classroom and school: Strategies for increasing student motivation and achievement. San Francisco: Jossey-Bass.

- McQuitty, V. (2011). Lesson study: Developing a knowledge base for elementary writing instruction (Doctoral dissertation). Syracuse University.

- MENC. (2008). Music Educators National Conference. Retrieved June 30, 2019.

- Mon, C. Dali, M., \& Sam, L. (2016). Implementation of lesson study as an innovative professional development model among Malaysian school teachers. Malaysian Journal of Learning and Instruction, 13, 83-111.

- Moquin, F. K. (2019). How do teachers experience lesson study? (Doctoral Dissertation). Syracuse University.

- Murry, J. (2014). Designing and implementing effective professional learning. Crown Press, Thousand Oaks.

- National Research Council. (2001). Educating teachers of science, mathematics, and technology. Washington, D.C.: National Academy Press.

- Nashruddin, W., \& Nurrachman, D. (2016). The implementation of lesson study in english language learning: a case study. Dinamika Ilmu, 16 (2).

- Noor, A. R. (2014). The effectiveness of electronic learning (elearning) on music theory and music appreciation achievement of form 1 (grade 7) Malaysian secondary school students. (Doctoral Dissertation), Miami University.

- Peddell, K.A. (2005). Activities in elementary general music classrooms current practices in Pennsylvania, (Doctoral dissertation), Minnesota University.

- Pelletier, C. L. (2013). The learning communities of exemplary midcareer elementary general music teachers (Doctoral dissertation). Retrieved from ProQuest Digital Dissertations (UMI No. 3673450)

- Penteri, E., Karadimitriou, K., \& Rekalidou, G. (2013). Involvement of future and active teachers in an advanced model of teacher education. Conference of the Network of Practice Exercises in the Department of Early Childhood Education, on "Improving the Education of Future Teachers in Crisis of Institutions: Proposals, Applications". Alexandroupolis, 26-28 September.

- Penuel, W. R., Fishman, B., Yamaguchi, R., \& Gallagher, L. P. (2007). What makes professional development effective? Strategies that foster curriculum implementation. American Educational Research Journal, 44(4), 921-958.

- Penuel, W. R., Gallagher, L. P., \& Moorthy, S. (2011). Preparing teachers to design sequences of instruction in earth systems science: 
A comparison of three professional development programs. American Educational Research Journal, 48, 996-1025.

- Podhorsky, C. P. (2005). Reshaping teacher professional development:Perceptions of lesson study as a model for change. (Doctoral dissertation). California University.

- Polemi-Todoulou, M. (2010). The systemic approach-key to a new educational planning. metologist, Systemic Society of Northern Greece, 18, 1-27.

- Porter, A., Garet, M., Desimone, L., \& Birman, B. (2003). Providing effective professional development: Lessons from the Eisenhower program. ScienceEducator, 12(1), 23-40.

- Puchner, L. D. \& Taylor, A. R. (2006). Lesson study, collaboration and teacher efficacy: Stories from two school-based math lesson study groups. Teaching and Teacher Education, 22(7), 922-934.

- Rauscher, Francis H. (2003). Can music instruction affect children's cognitive development? ERIC Digest, 3.

- Reid, M. (2005). Music assessment collaboration model for secondary music teachers,(Doctoral Dissertation), California University, Los Angeles.

- Reifinger, J. L. Jr. (2007). The effect of instruction with song-related tonal patterns on second graders' pitch reading accuracy (Doctoral dissertation), Indiana University.

- Rekalidou, G. (2012). Improving teaching. The case of Lesson Study. Pedagogy -Theory and Practice, 5, 98-109.

- Rekalidou, G., Karadimitriou, K., \& Moumoulidou ,M. (2013). Basic components of the implementation of the Lesson Study model in the practical training of four-year students of TEEP-DTU: collaboration, reflection, feedback, observation. Conference of the Network of Practice Exercises in the Department of Early Childhood Education, on "Improving the Education of Future Teachers in Crisis of Institutions: Proposals, Applications". Alexandroupolis, 2628 September.

- Richardson, V. (2003). The dilemmas of professional development. Phi Delta Kappan, 84, 401-407.

- Rock, T., \& Wilson, C. (2005). Improving teaching through lesson study.Teacher Education Quarterly, 32 (1), 77-92.

- Roher, L. (2009). The relationship between the degree of participation in online embedded professional development communities for high school mathematics teachers and student achievement gains in college algebra. (Doctoral dissertation). Kentucky University.

- Roulston, K., Legette, R., \& Womak, S. T. (2005). Beginning music teachers' perceptions of the transition from university to teaching in schools. Music Education Research, 7(1), 59-82. 


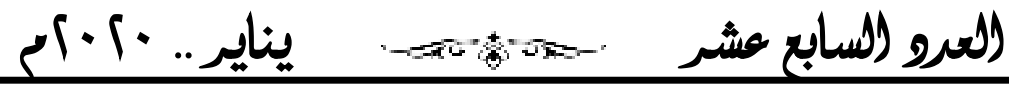

- Shaun, A. (2014). Perfect CPD Teacher-Led. U.K., Independent Thinking Press.

- Shouffler , J.(2018).Teacher learning within united states lesson study: a study of a middle school mathematics lesson study team (Doctoral dissertation). Pennsylvania University.

- Sindberg, L. K. (2016). Elements of a successful professional learning community for music teachers using comprehensive musicianship through performance. Journal of Research in Music Education, 64, 202-219.

- Smith, R. (2008). Lesson study: Professional development for empowering teachers and improving classroom practice. (Doctoral dissertation). College of Education, Florida State University.

- Sofos, A., \& Darra, M. (2015). Models of learning planning: comparative and interpretative assessment. Education Sciences, 1, 66-83. University of Crete, Rethymnon.

- Sotirhos, S. K. (2005). Lesson study in the U.S. context: as case of professional community building (Doctoral dissertation). New York University.

- Sparks, D., \& Hirsh, S., (1997). A new vision for staff development. Alexandria, VA: Association for Supervision and Curriculum Development.

- Stanley, A. M. (2011). Professional development with collaborative teacher study groups: Pitfalls and promises. Arts Education Policy Review, 112(2), 71-78.

- Stanley, A. M. (2012). The experience of elementary music teachers in a collaborative teacher study group. Bulletin of the Council for Research in Music Education,192, p. 53-74.

- Stanley, A. M., Snell, A., \& Edgar, S. (2014). Collaboration as effective music professional development: Success stories from the field. Journal of Music Teacher Education, 24(1), 76-88.

- Stepanek, J., Appel, G., Leong, M., Turner Mangan, M., \& Mitchell, M. (2007). Leading Lesson Study. A practical guide for teachers and facilitators. California, USA.

- Stevenson, B. A. (2005). A study of a pilot support program for first year elementary music teachers (Doctoral dissertation). Retrieved from ProQuest Digital Dissertations (UMI No. 3172115).

- Stigler, J., \& Hiebert, J., (1999). The teaching gap. New York: The Free Press.

- Stigler, James W.\& James Hiebert. (2009). The teaching gap: Best ideas from the world's teachers for improving education in the classroom. Reissue edition, New York, Library of Congress cataloguing in Publication Data.

- Sulastri, D. (2017). The practice of lesson study model in teaching writing report text. Journal of Education and Learning. 11 (1), 103110 . 

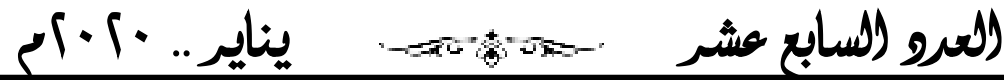

- Suppovitz, J. A., \& Turner, H. M. (2000). The effects of professional - development on science teaching practices and classroom culture. Journal of Research in Science Teaching, 37(9), 963-980.

- Takahashi, A., \& Yoshida, M. (2004). Ideas for establishing LessonStudy communities. Teaching Children Mathematics, 10 (9), 436442.

- Van Driel, J. H., \& Berry, A. (2012). Teacher professional development focusing on pedagogical content knowledge. Education Researcher, 41(1), 26-28.

- Verhoef, N., \& Tall, D. (2011). Lesson Study: The effect on teachers' professional development. Proceedings of the 35th Conference of the International Group for the Psychology of Mathematics Education, 1, Ankara, Turkey: PME 35. Retrieved from http://doc.utwente.nl/80245/1/RR_verhoef.pdf

- Vescio, V., Ross, D., Adams, A. (2008). A review of research on the impact of professional learning communities on teaching practice and student learning.Teaching and Teacher Education, 24, 80-91.

- Vessela, I. (2011). Actively seeking change: Mathematics lesson study for the diverse U.S. schools. Teacher Education and Practice, 24 (1), 74-95.

- Wilson, Suzanne M. (2013). Professional development for science teachers, Science Magazine, 340(613), 310-313.

- Wenglinsky, H. (2000). How teaching matters: Bringing the classroom back into discussions of teacher quality. Princeton, NJ: Educational Testing Service.

- Yarbrough, C., Green, G., Benson, W., \& Bowers, J. (1991). Inaccurate singers: an exploratory study of variables affecting pitchmatching. Bulletin of the Council for Research in Music Education, 32, 107.

- Yoder-White, M. (1993). Effects of teaching intensity on sixth-grade students' general music achievements and attitudes. (Doctoral dissertation), North Carolina University, Greensboro.

- Yoshida, M. (2012). Current status and ideas for conducting effective Lesson Study.

- Wayne, NJ: Center for Lesson Study, William Paterson University.

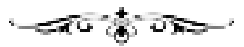


